




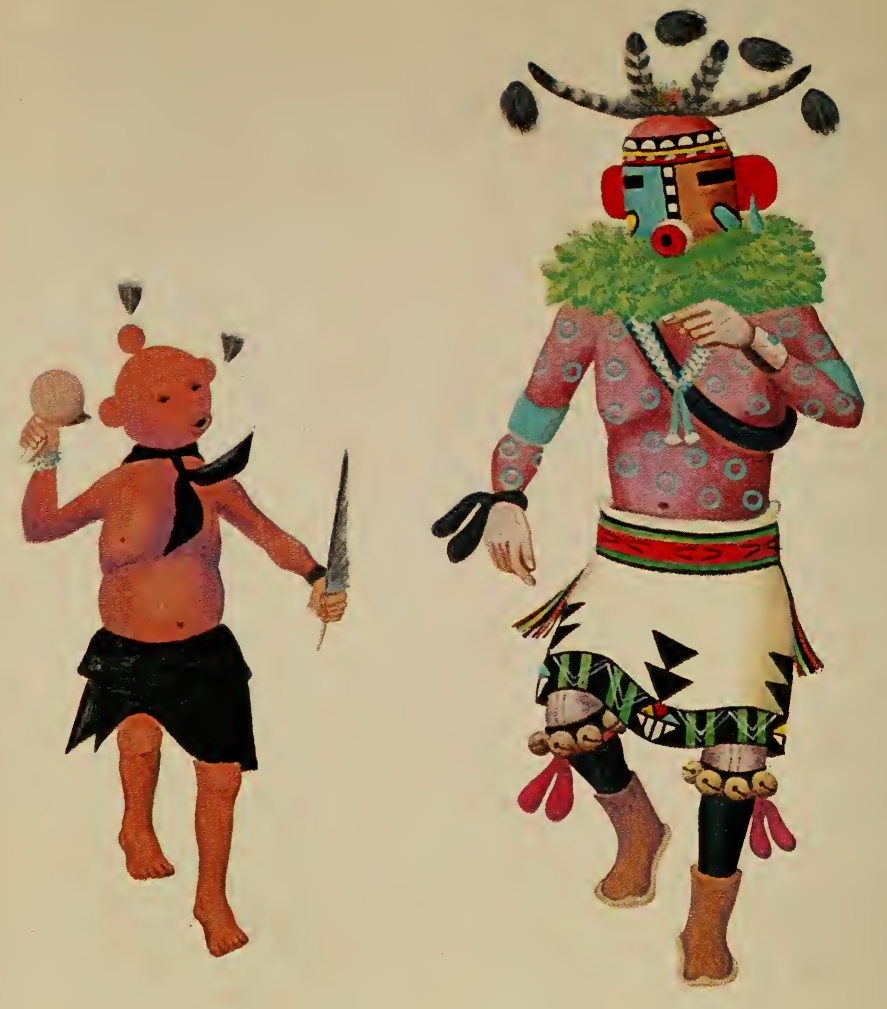

Corn Kachina and Mudhead Kachina 
CONTRIBUTIONS FROM THE

MUSEUM OF THE AMERICAN INDIAN

HEYE FOUNDATION

VOL. XXIV

\title{
RITUAL IN PUEBLO ART
}

Hopi Life in Hopi Painting

\author{
By \\ BYRON HARVEY III
}

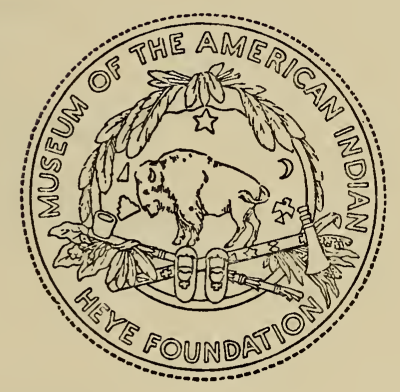

NEW YORK

MUSEUM OF THE AMERICAN INDIAN

HEYE FOUNDATION

1970 


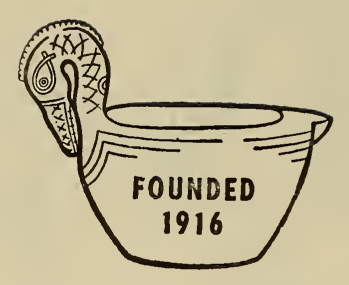

Library of Congress catalog card number 67-30973

Printed in Germany at J.J.Augustin, Glückstadt

Price \$IO 


\section{CONTENTS}

$\begin{array}{llllllllllllllllllll}\text { Preface } & \ldots & \ldots & \ldots & \ldots & \ldots & \ldots & \ldots & \ldots & \ldots & \ldots & \ldots & \ldots & \ldots & \ldots & \ldots & & \mathrm{v}\end{array}$

$\begin{array}{llllllllllllllllll}\text { FOREWORD } & \ldots & \ldots & \ldots & \ldots & \ldots & \ldots & \ldots & \ldots & \ldots & \ldots & \ldots & \ldots & \ldots & \ldots & \ldots & \text { vii }\end{array}$

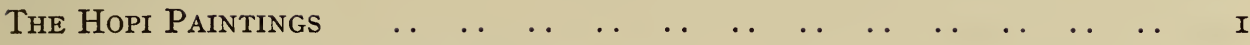

Historical Review of the Project $\ldots \begin{array}{llllllllll} & \ldots & \ldots & \ldots & \ldots & \ldots & \ldots & \ldots & \ldots & \text { I }\end{array}$

Analysis of the Paintings .

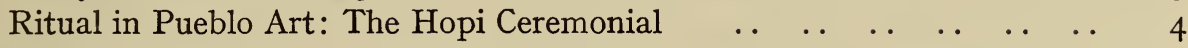

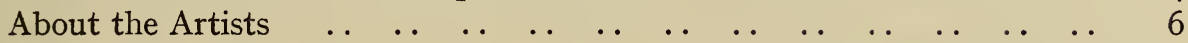

Description of the PAintings

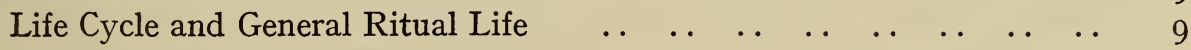

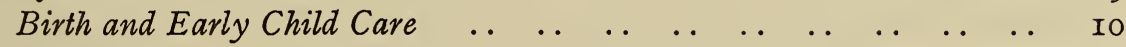

$\begin{array}{llllllllllllllll}\text { Childhood } & . & \ldots & \ldots & \ldots & \ldots & \ldots & \ldots & \ldots & \ldots & \ldots & \ldots & \ldots & \ldots & \text { II }\end{array}$

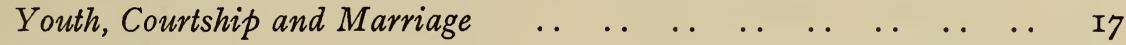

$\begin{array}{llllllllllllll}\text { Daily Life . . } & \ldots & \ldots & \ldots & \ldots & \ldots & \ldots & \ldots & \ldots & \ldots & . & . & \ldots & 20\end{array}$

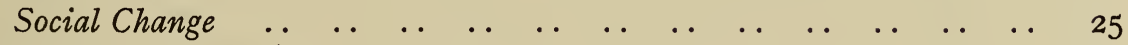

$\begin{array}{lllllllllllllll}\text { Ritual Life . . } & . & \ldots & \ldots & \ldots & \ldots & \ldots & \ldots & \ldots & \ldots & . & \ldots & . & . & 26\end{array}$

$\begin{array}{lllllllllllll}\text { Ceremonial Activities .. } & \ldots & \ldots & \ldots & \ldots & \ldots & \ldots & \ldots & \ldots & \ldots & \ldots & 26\end{array}$

$\begin{array}{llllllllllllll}\text { The Eagle Cult } & \ldots & \ldots & \ldots & \ldots & \ldots & \ldots & \ldots & \ldots & \ldots & \ldots & \ldots & \ldots & 32\end{array}$

$\begin{array}{llllllllllllll}\text { The Salt Journey } & \ldots & \ldots & \ldots & \ldots & \ldots & \ldots & \ldots & \ldots & \ldots & \ldots & \ldots & 35\end{array}$

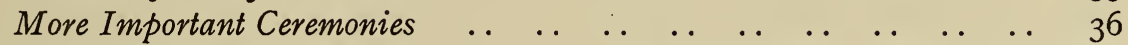

$\begin{array}{llllllllllllll}\text { The Kachina Cult } & \ldots & \ldots & \ldots & \ldots & \ldots & \ldots & \ldots & \ldots & \ldots & . & \ldots & 38\end{array}$

Unmasked (Social) Dances $\quad \ldots \quad$.

A Hopi Legend . .

$\begin{array}{llllllllllllllll}\text { Clowning } & \ldots & \ldots & \ldots & \ldots & \ldots & \ldots & \ldots & \ldots & . & \ldots & \ldots & . & \ldots & . & 46\end{array}$

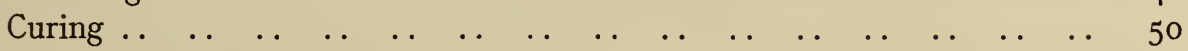

Home Cure . .

Causes of Serious Illness

$\begin{array}{lllllllllllll}\text { The Medicine Man } & \ldots & \ldots & \ldots & . & \ldots & \ldots & \ldots & . & \ldots & \ldots & \ldots & 52\end{array}$

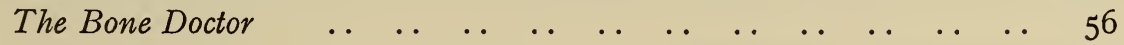

Payment of Fees $\quad \ldots \quad$.

Economic Life $\begin{array}{llllllllllllllll} & \ldots & \ldots & \ldots & \ldots & \ldots & \ldots & \ldots & \ldots & \ldots & \ldots & \ldots & \ldots & 59\end{array}$

$\begin{array}{lllllllllllllllll}\text { Crops } & . & \ldots & \ldots & \ldots & \ldots & \ldots & \ldots & \ldots & \ldots & \ldots & \ldots & \ldots & . & \ldots & 59\end{array}$

Making a Piki Stone $\quad \ldots \quad$.

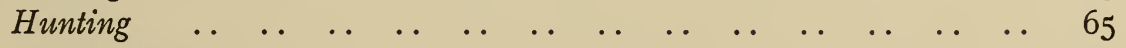

$\begin{array}{llllllllllllll}\text { Basket Making } & \ldots & \ldots & \ldots & \ldots & \ldots & \ldots & \ldots & \ldots & \ldots & \ldots & \ldots & \ldots & 67\end{array}$

Other Economic Activities . .

LIST OF ILLUSTRATIONS

$\begin{array}{llllllllllllllllll}\text { BIBLIOGRAPHY } & \ldots & \ldots & \ldots & \ldots & \ldots & \ldots & \ldots & \ldots & \ldots & \ldots & \ldots & \ldots & \ldots & \ldots & 79\end{array}$ 



\section{PREFACE}

While the literature devoted to the American Indian written by non-Indians is tremendous, accounts by native writers are rare, and most of these are in prose form; pictorial views of Indian life by Indians are even scarcer. Therefore, when the possibility of securing such a visual record presented itself, the Museum reacted with enthusiasm. Funds were secured and entrusted to the supervision of Byron Harvey III, a Research Associate of the Museum, who had originally developed the project.

Over the two-year period, as new selections of paintings arrived, it became increasingly evident that this collection offered an unparalleled opportunity to examine Hopi life as viewed through the eyes of four young Hopi men, all of whom had lived both on and off the Reservation, and that it reflected a variety of interpretations and interests. It was obvious that this would form an invaluable corpus requiring publication for permanent reference; this book is the result.

It must be emphasized that this is not an "ancient record," although it does portray a way of life which has developed over many centuries in Arizona. This is the contemporary United States, in which the Hopi people have been able to maintain an astonishing degree of cultural integrity despite tremendous pressures from the outside. Indeed, one lesson which emerges from this entrancing document is the fact that such differences are valuable, giving strength to all who share it. We must treasure these differences, else we shall inhabit a gray, monochromatic world.

We are grateful to the four artists whose paintings form this volume for their courage in proceeding with the project in the face of criticism from their fellow Hopis, and for the devoted interest with which they worked to make this a well-balanced document. To Mr. Harvey goes our appreciation for his persistence, and, more importantly, for knowing just how far to go without intruding into the work itself. Without his wisdom, the project would not have attained completion.

The interest of many friends, notably Mrs. Kathleen Harvey, and the support of the Huntington Fund, is most cordially acknowledged. It is hoped that this volume will further strengthen the bridge of understanding between the Indian and the Bahana. Pas Lólomai!

FREDERICK J. DockstadeR Director

June I5, I970 



\section{FOREWORD}

W ORKING with five Hopi artists was a pleasure and a challenge. So many reservation scenes familiar to the artists had never been painted by villagers that it was possible to learn a great deal about Hopi culture in commissioning, examining and asking questions about the paintings. Ideas led to ideas and the paintings became a means for the artists to recall experiences and relive the past as well as record the changing present. Suggestions contributed by them provided many cultural practices which my several years of on- and off-reservation contact with the Hopi had not brought to light.

Sometimes we did not understand each other completely. For example, a painting which was proposed to depict "getting ceremonial evergreen" unaccountably and laughably became "everything is getting greener," a spring landscape! At times we were exasperated, but the experience was also intensely rewarding as I learned about areas of life which are not well known despite many thorough Hopi studies.

At least two and often more paintings were completed each week and brought to me for documentation. Several later discussions covered details in each painting. Relatives sometimes offered suggestions for topics or helped in interpreting the activities depicted. The artists usually were given a "want list" of four or five subjects so there was a certain amount of choice available. At times ideas and enthusiasm lagged, to be balanced by sudden bursts of painting and documentation. A single painting of a medicine man, for example, grew into a whole sub-series on curing and illness, most of which is illustrated herein.

This painting project was originally inspired by the paintings of Hopi kachinas collected by Fewkes, and by the Isleta paintings gathered by Parsons. Each such collection is unique, and I felt that this record of Second Mesa village life would become increasingly valuable as time passed.

I would like to acknowledge the interest and coöperation of the artists involved in this project, the enthusiastic support of Dr. Frederick J. Dockstader, Director of the Museum of the American Indian, and the assistance of my wife, Joy, throughout the several years which have gone into this effort.

Phoenix, Arizona

Byron HARVEY III

December I969 



\section{THE HOPI PAINTINGS}

A LTHOUGH many collections of American Indian paintings were gathered, especially after I9I5, not many of these were systematically documented. Furthermore, the topical emphases inherent in Indian cultures or the bias of particular artists often combined with the special interests of collectors to limit the scientific utility of collections. Many areas of cultural life remained undocumented while repetitive illustrations of favorite subjects added little to scientific knowledge. An attempt to improve this situation resulted in a controlled effort to elicit and document a series of paintings by Hopi artists which would have a broad usefulness as an exposition of Hopi life and, where possible, belief.

The result of two years' experimentation was a corpus of 270 paintings which were added to the collections of the Museum of the American Indian, Heye Foundation. Of these almost exactly half reflect ritual life, and ritual is further seen as an aspect of many of the other paintings. Marshall Lomakema completed IIg watercolors; Arlo Nuvayouma finished Ioo paintings; Narron Lomayaktewa provided I3, and Leroy Kewanyama completed I4. Melvin Nuvayouma contributed 24 paintings including both realistic scenes and abstract designs.

Although the original selection of the artists was partly fortuitous, it was possible to include members of different clans and ceremonial groups. Each of the two principal artists had a tie to a major village ceremonial group which he at first concealed. Unlike many successful Indian artists, both major artists were originally well-integrated in their own society, being members of religious groups not open to all. Characteristically they now seem to be orienting increasingly to life in Phoenix, Arizona, returning to the reservation for major initiations and rituals. The artists had different rates of production, Lomakema being motivated by the piecework rates, Nuvayouma finding a consistent individual style and slower "workman's pace" rate of work.

\section{Historical Review of the Project}

In April of 1964 Marshall Lomakema arrived in Phoenix to look for work. As I had a temporary living space available I suggested that he use this until he located his own quarters and paint a picture as rent. This initial work, "Trademarks of the Hopi Clans," became the first of the 270 paintings comprising the Hopi project. By November, I964, 30 paintings by three artists were ready to be taken to the Museum of the American Indian. There, Dr. Frederick J. Dockstader, the Director, agreed that they were significantly different and important, and arranged financial support. No restrictions were set upon subject matter. A price was set which allowed payment at a level above that for beginning paintings paid by the Hopi Arts and Crafts Guild or Polacca Trading Post. 
The selection of topics was by mutual agreement with frequent diversions to maintain interest. A core of paintings was usually built up and then added to by other artists to complete coverage of a topic. After the summer of I 965 , concentration upon curing and economics bettered the treatment of these aspects of Hopi life. Where possible the artists were given only the most general suggestions as to the specific content of the pictures. Gestures, costuming of the subjects, or colors were never specified. The number of people to be depicted was occasionally suggested, but variation was accepted without comment. Canvass of the literature and the suggestions of viewers and experts resulted in additional topics. The commercially-rewarded kachina genre was discouraged, but approximately half of the masked dancer subjects which were included cast light on cult practice or wider meanings of the cult. It is probable that the artists would have submitted only kachina representations if left unguided, but the point was made to them that these were readily available in the trading posts. Lomakema periodically attempted to return to these familiar subjects, whereas Nuvayouma, by contrast, submitted only three kachina paintings, which were specifically agreed upon before their completion.

The criteria which guided the selection of the artists emphasized their ability and willingness to extend the cultural record. Breadth of treatment is not possible without a reasonable rate of production since the corpus of paintings, however brilliant, will remain too small for analytical treatment. If other aims were achieved variety in composition was considered to be desirable, but little attempt was made to achieve artistic success as such. The exhibit which Nuvayouma obtained at Heard Museum in Phoenix near the end of the project was granted him as an untrained artist and the critical opinion was that his innate style had not been influenced by the project. Ability to document the work was held to be exceedingly important. Failure in any of the above criteria tended to limit an artist's role in the project, or to preclude it. A few volunteers offered their work, but either returned to the reservation or clearly preferred to work only on familiar topics.

Both of the principal artists lived in Phoenix for long periods of time during the two years of work. Lomakema returned to the village to live twice and came back, while Nuvayouma visited the village only occasionally; both now appear to regard Phoenix as a possible permanent home. The paintings and related work provided part time work and an economic cushion in periods of unemployment and suggest a means of bettering relocation projects in other cities.

Rapport with both artists was good during the period of work. I had known Lomakema casually for a number of years, while Nuvayouma is related to Otis Polelonema, a well-known Hopi artist who has been a family friend of many years standing. Lomakema's nearer age and the coincidence that we each had five children tended to make social contact easier, while Nuvayouma's being ten years older made a typically Hopi teaching relationship possible. Each artist held three jobs during the two-year period; working for a trailer building firm, a theater under construction, a metal working firm, a hotel kitchen, and part-time construction work, the artists gained job experience and supported their families.

It is only fair to report some straining of the original rapport at the conclusion of the project. Economic need, personal conflicts, and the social pressures to which the artists were exposed were all responsible. Three other artists submitted work 
after the project; Lomakema's brother, Milland, in particular produced work in an abstract vein which was of exhibition quality.

\section{Analysis of the Paintings}

Although the catalog numbers reflect the original order in which the paintings were obtained, they have been described in this volume as they reflect the Hopi life cycle and ritual, general ritual life, the Kachina Cult, clowning and curing. Topics emerged during the course of the research and an index was found useful in building sub-series on various aspects of Hopi culture. Each description contains the data obtained from the artist, from other informants who viewed the picture, together with relevant citations of the literature on the Hopi. Specific corroboration of cultural practices and native terms was particularly aided by Alexander M. Stephen's Hopi Journal (Parsons I936).* The descriptions themselves furnish the best idea of the variety of data which were obtained by the elicitation and further use of the paintings as a stimulus to informants. In accordance with customary Pueblo practice, the artists originally did not wish to be identified, since some of their work goes beyond culturally sanctioned guidelines and they desired no personal prominence from their work.

The aspects of Hopi life shown in the paintings appear in context. Economic techniques tend to have ceremonial implications in Pueblo life, and these appear in some of the paintings and data. Others of the paintings were intended to be more purely secular or economic. To give some idea of the approach employed, by the eighth painting, "Men Smoking in the Kiva," the artist had produced a group scene which bore less on specific ritual than on Hopi ritual usage generally. With a hunter in traditional dress (not illustrated), economic activity was introduced to be eventually developed into a further treatment of hunting, the corn complex and other farming, and forms of barter or exchange. Curing and acculturation were developed later. Although these categories were distinct in my own mind, the artists' attitude was usually that of working on farmers, hunters, or whatever. But at times they would outline an economic process or other activities in great detail and have a very specific idea of what they wanted to paint, which was carefully followed out and became a basis for planning future work. Paintings of Hopi economic life especially were encouraged whether or not they bore upon the original theme of Ritual in Pueblo Art.

When the first 66 paintings had been completed in I964, it was found that slightly over half reflected ceremonialism-the Kachina Cult, the less familiar Eagle Hunt, and the Salt Expedition. It was clear that ritual would have been even more predominant without planning of the series. Social interactions and economic life were felt to be of great importance for the record and both principal artists responded with suggestions and paintings. They were allowed to return to ceremonial topics from time to time, whenever an interview had not resulted in a new topic or when they found a gap in the record or in my knowledge. About a fifth of the final paintings refer to economic life and attest to the validity of this basic category of culture

*Throughout the balance of this work, citations from this source will be referred to as (S:I032) instead of the usual (Stephen I936: I032). 
as a focus for the artist's work. Hopi social interactions shown in the paintings tend to be expositions of the individual's role in the ceremonial cycle which is so basic to the culture, but some 50 paintings may be regarded as referring to social life primarily as against economic or ceremonial life. Very few paintings show individual activity in this largely group-oriented culture.

Within each category there arrived a point at which further paintings became redundant or the artist felt he had communicated his conception of the process or cultural feature. Several economic techniques were treated in terms of four steps which reflects the Hopi use of the number four as a favored ceremonial concept. Thus there are actually four paintings of the rabbit hunt (\# I3-I6), and four stages to making a piki stone (\# I62-I65), as well as four steps in basket making, in which gathering wild yucca, drying, splitting, and weaving were supplemented by a painting illustrating a related ritual practice. These sub-series of four furnish an example of leads from the artists which were carefully explored. The series of paintings became useful as a general cultural record by the time it contained some seventy paintings. With elimination of esoteric topics or unsuccessful efforts, 20 paintings each of social, economic, and ceremonial life permit a rapid introductory view of Hopi culture.

The principal aspects of Hopi culture as defined were ceremonial (IOo paintings), economic (56), and social (50), with the count varying according to the setting of criteria. Thirty-four paintings depicting kachina dancers usually in a frontal pose did not add to the knowledge of the culture in general, though several unusual types were included. Twelve paintings which were abstract "design work" recorded various rain and agricultural symbols and like the paintings of kachinas were referrable to ritual life. Of the 270 paintings, 206 may be broadly described as paintings of Hopi people engaged in ceremonial, economic, or social activity, thus at least half reflect the importance of ritual in Pueblo art.

\section{Ritual in Pueblo Art: The Hopi Ceremonial}

The complexity of Hopi ceremonialism made it almost an obstacle to the coverage of other aspects of the culture. The artists' knowledge of the religious observances and the requisite costuming and the tremendous visual appeal of these parts of Hopi life furnish us with many examples of ritual in Pueblo art. Many Hopi ceremonies are included: two women's cults, the Flute rite, as well as others which are present by implication. Secret rituals were not made a special object. If we conceive of stages in Hopi ceremonialism ranging through ordinary minor ritual, public ceremony, ritual of members of a restricted society, secret observances known only to society officials, and finally highly taboo practice, we may say that the paintings only occasionally penetrate into secret society ritual though some of the accompanying data reach more esoteric concepts. The artists were sometimes willing to paint minor rituals of a society, but no altars are shown, no ceremonies of investiture of officials, and no ceremonial idols. In contrast to Parsons' Isleta Paintings (I962), the Hopi artists depicted ordinary social life but generally refused to paint the ritual details shown by the Isleta artist. Such paintings were volunteered on occasion, but never completed. I felt it was better to hope for a soundness in the willingly given data, which is not always present when the artist feels he is breaking the rules. 
Thus we see Hopi ceremonial life from the point of view of the Hopi participant. This is much more explicit in the series than it is in the commercially-sold panoramic paintings of Pueblo ritual which do not so often emphasize the role of the individual in group ceremony. Wood must be gathered for use in the kiva or ceremonial chamber, food contributed by the women, ritual offerings prepared, fetishes used. Many paintings show the interdependence of the ceremonial and economic systems principally as food is distributed in ceremonies and as gifts or exchanges. As in some Laguna paintings, there is an emphasis upon preparation for ritual in contrast to the finished effect and ritual rightness of performance in completely unsolicited paintings.

The artists, being men, illustrated a great deal of men's ceremonial activity, but coverage of women's rituals was encouraged by their female relatives. Ritual is recorded as private (\# 54), group (many paintings), involving crafts (\# I8), the hunt, curing, and the life-cycle-birth, wedding, and death. Ceremonies also relate to social organization (\# 48), discipline (\# 8), clowning (\# IIO), shrines (\# 52), and racing (\# 23). The picture of ceremonialism as a functionally complex mechanism in Pueblo life reaffirms the multiple interrelationships outlined by Parsons in Pueblo Indian Religion.

Because many major ceremonies like the Home Dance, Snake Dance, and the kachina performances have been frequently painted by Fred Kabotie, Otis Polelonema, and recently by Ray Naha, I encouraged paintings of minor rituals and sidelights of the major ceremonies. These scenes were easier for beginning artists, and the lack of specific taboo against paintings of them allowed the artists to follow their $i_{1}$. clinations. Private rituals or ritual incidents which were recorded include "washing" a baby with ashes (\# 3), naming of a newborn child (\# 2), curing by ceremonial whipping (\# 83), and some I3 others. Kachina Cult functions which were depicted include: blessing of a house (\# 84), curing (\# 83), symbolic fertilization, and racing (\#82). Minor rituals and ritual incidents which contrast sharply with group ritual are: girls offering their first baskets to the sun (\# I8), a man invoking animal spirits (\# 54), the decoration of a slain deer (\# I72), a girl being initiated by grinding corn (not illustrated), and men going after evergreen for ritual use (\# 93).

The predominance of Kachina Cult representations continued consistently through the first Ioo paintings. Approximately 20 per cent of these were kachinas or closely related subjects and the final number of these paintings remained in virtually the same proportion. Certainly the cult functions of education, discipline, curing and entertainment-to say nothing of the basic purpose of rain bringinghave remained important features of Hopi life.

If positively-valued cult activity and the less secret portions of ritual were willingly recorded, it was also true that those topics which were unsuitable, improper, or otherwise unpainted reveal the boundaries of Hopi secrecy and good taste. Two paintings violated a precept that no action may reveal the fact that the kachinas are masked humans. One depicts unmasked dancers (\# 75), while another portrays masks ready for use (\# 74). While the artist felt no objection to these paintings being shown to Whites, he did object to their being shown to fellow Hopis. Other paintings clearly at or over the borders of secrecy include: a painting of a shrine (\# 53), the ceremonial execution of an eagle (\# 69), planting ceremonial beans $(\# 76)$, and a few of the curing scenes. Equally interesting were the total re- 
fusals: a representation of the burial of the eagle or one of a human burial could not be obtained, and it has been mentioned that no altars or esoteric rituals were recorded. A rumor was started that one of the artists had sold a portion of a secret altar; it seemed to express the fear that the artist might have painted secret ritual. He did not, nor was he encouraged in any way to do so.

Curing, although ostensibly secret in the New Mexican Pueblos, is under little specific prohibition by the Hopi. While the artists did not welcome the showing of the slides of curing to fellow villagers, the series of $3 I$ paintings represents an effective sub-series depicting Pueblo curing as it is carried out by individual Hopi doctors. The activities of the bone doctor and magician and various forms of diagnosis and treatment were clearly recorded by the artists. Cures involving plant specifics, shock treatment by scaring, sucking shamanism, manipulation, and divination by crystal exemplify another area where the paintings produced better data than my field interviews had obtained.

The Hopi painting series, like its Isleta and Laguna counterparts, evidences ritual and ceremonial life to a high degree. Nevertheless, the Hopi artists were much more eager to record ordinary family life than the Isleta or Laguna artists, whose detailed records of highly tabooed rituals remain unusual. The artistic skill of a Laguna artist and his courage in depicting certain rituals are more like the iconoclastic record made by the Isleta artist. The series demonstrates that Hopi artists show a wide variety of approaches to a visual problem: primitive realism, symbolism, abstraction, attempts at a sophisticated style, and often achieve success in an artistic realm.

The Pueblo artist, like any artist or craftsman, may be average or brilliant, deeply philosophical or quite literal, a rebel or a conformist, a rapid painter or extremely limited in production. He may enjoy depicting the past with nostalgia, but those aspects of it which he selects may be motivated by his experiences, his clan and ceremonial affiliations, his patron, the art he sees about him, or by his own personality. The record which he makes has the advantage of being made by a member of the culture. The complexity of the influences upon it do not destroy its virtue of intimate knowledge.

\section{ABOUT THE ARTISTS}

$\mathrm{T}$ THE FIVE ARTISTS are all from Shongopovi, Second Mesa, Arizona, and have been through the tribal initiations normally undergone by all Hopi men. They all take part in Hopi ceremonies and rituals and participate in kachina dances. None has accepted Christianity. Their wives, with one exception, are members of the two religious groups to which women of the village belong. While no artist is a chief, several of their close relatives are.

Each artist had off-reservation school or job experience, but typically finds the village an important focus of life. None wants to abandon traditional Hopi life and obligations permanently; all who have children have put them through the customary initiations. Objections to city life seem to be felt most strongly when it interferes with participation in village ritual life. Given better employment at home, all might have remained on the reservation. Life in the village is hard; jobs are few. In the city, pay is better, but the supportive background of a whole way of life is lost. 
In the artists' Indian backgrounds experiences and affiliations may be found which qualify them to depict their culture. Their contact with village life, particularly ritual, has been sufficiently close to enable them to know it well. Also to be seen in their backgrounds are other sources of their knowledge; such as relatives and membership in religious societies; to this, of course, personal observation must be added.

Leroy Kewanyama (b. I930) is a member of the Cloud Clan and the Wüwüchim, Soyal and Flute Societies. Claude Kewanyama, his father, is the village chief of Shongopovi. Hismother is a member of the Antelope Society while his wife is in the Snake Society. He has sponsored kachina dances and taken significant roles in a number of ceremonies. Like all of the artists he has consulted medicine men on various occasions. Kewanyama worked for a number of years at Grand Canyon, for about a year for the Forest Service in Heber, Arizona, and has traveled to New York. He also is an accomplished silversmith. He and his wife, Elvira, have eight children.

Marshall Lomakema (b. I935) is a member of the Corn and Cloud Clans. Some of the ritual responsibilities of the Corn Clan have given him knowledge of particular ceremonies. His father is Antelope Chief, the head of the group of singers at the Snake Dance. $\mathrm{He}$ is a member of the Powamü Society which requires full initiation and also belongs to Wüwüchim, Soyal, and Antelope, other groups with ceremonial responsibilities. His wife's father served as Kachina Chief.

Lomakema attended Shongopovi Day School, and the Hopi High School at Oraibi. He worked at Grand Canyon in the summers after high school. Since I954 he has spent most of his time in Phoenix but has regularly returned to the village to take part in ceremonies. In town he has worked as a carpenter, craftsman, custodian at a museum, and a variety of other jobs. In addition to painting, Lomakema makes a number of craft items and has won prizes for his kachina dolls. He has never claimed to be primarily an artist but has taken an interest in the making of this record and suggested various areas of Hopi life to be covered. Those Hopi, he feels, who are fully initiated sometimes know ritual details as well or better then full time village residents, especially if their uncles, the traditional teachers, have taught them.

Narron Lomayaktewa (b. I946), whose father is from the neighboring village of Mishongnovi, is a member of the Snake Clan. His mother's father is the Kachina Chief related by marriage to Lomakema. Because of his clan affiliation, Lomayaktewa has taken part in the Snake Dance as well as in Kachina performances. His wife is from Santo Domingo Pueblo, New Mexico. After graduating from Albuquerque Indian School in I965, he was admitted to Phoenix College, but found expenses prohibitive. On his return to the village he ceased participating in the painting project but sold a few paintings to collectors. Two illustrations which he provided depict shrines, a possible reason for his withdrawal.

Arlo Nuvayouma (b. I925), a member of the Antelope Clan, provided many illustrations and achieved an exhibit at Heard Museum, in Phoenix, Ariz. Although a member of the One Horn Society which has the function of selecting the village chief, he never cited this fact or mentioned being a member of two other religious societies. Nuvayouma's grandfather was a One Horn Chief. His wife Elizabeth 
helped to provide the descriptions for many of his illustrations. Her brother, Otis Polelonema, is a well-known Hopi painter who is also a chief. Nuvayouma attended Shongopovi Day School and worked off the reservation in the I950s and again from I964 to I969. Like Lomakema, he returns to the reservation frequently to take part in ceremonies. He is especially noted as a clown.

Melvin Nuvayouma (b. I946), Arlo's son, is a member of the Sun Clan and the One Horn Society. He is fully initiated, Lomakema's brother having served as his ceremonial father. Melvin graduated from the Phoenix Indian School in Ig65. 


\section{DESCRIPTIONS OF THE PAINTINGS}

L

INGUISTICALLY correct versions of many Hopi terms are given by Voegelin and

Voegelin (I957), while other terms corroborating my recordings are cited where relevant from Stephen (I936). Where a standardized, simple orthography exists, I have conformed to it. There are occasional variations which are the result of dialect. Work on a Hopi lexicon is in progress by several scholars, notably Voegelin, Greene, and Dockstader, so that considerable precision in the translation of Hopi terms will ultimately be possible. It is felt, however, that the native translations are of interest in that they reveal something of the connotation of the terms to the speaker. In a number of translations it is clear that the speakers are, in fact, explaining the term.

Hopi ceremonial lore, even within a single village, is extremely complex. Alternate versions are sometimes put forth by different clans, while seemingly endless details, all regarded as important, plague the investigator who wishes his work to be complete. Agreement that a painting, a story, or a description is absolutely authentic is rare. The native critic is interested only in perfection! Similarly, scientists have recorded enormous segments of Hopi culture with unusual fidelity. For example, ritual events (Stephen I936 and others); dyes and dyemaking (Colton I965); and ethnobotany (Whiting I950), to mention only a few. The present paper offers illustrations spanning portions of ritual and economic life and constitutes another independent record of Hopi belief and practice.

For thosereadersinterested in the precedent for Hopi painting, the names of Fewkes' three artists are given by Tanner (I957:85); a Hopi painting bought by Aitken in I9I2 is cited, while the careers of the well-known Hopi artists Fred Kabotie and Otis Polelonema are discussed (I957:88ff.; 94ff.). A collection formed by Henry R. Voth before IgI2 contained one Hopi drawing (tutubene) of a Cow Kachina, present whereabouts unknown.

\section{Life Cycle and General Ritual Life}

(Paintings Nos. I through 46)

As the Hopi villager grows up many experiences mold him. Typical incidents in an individual's life are naming rituals, disciplinary and ceremonial bathing, hunt initiation, courtship and marriage. Activities of youth, middle age and old age are depicted in the paintings of this section, most of which are by Arlo Nuvayouma. No portraits were intended, but the life of the imaginary family which he often depicted can be followed through many of the illustrations as the members court, marry, take care of their children, and finally grow old. In most of the paintings the thread of ritual may be seen as it runs through Hopi life. Despite increasingly rapid change, marked especially by the installation of electricity in I965 (see \# 44), much effort is devoted to preserving traditional life. 


\section{BIRTH AND EARLY CHILD CARE}

(Paintings Nos. I through 4)

\section{1}

\section{A Prenatal Examination by a Hopi Doctor Arlo Nuvayouma MAI/HF 23/7532 II $\times I 4 \frac{1}{2}$ in.}

Before a villager is born his mother commonly consults a Hopi doctor, the positaka (eye man), or tihikya (doctor). Nuvayouma depicts a visit to the medicine man for prenatal consultation. In his childhood babies were often born at home. He explained the doctor's problem: 'He's trying to loosen the stomach. Sometimes the little baby was going the wrong way. He try to turn him around to the right. It's about to be born." The doctor's hands are placed firmly on the woman's abdomen in order to locate the parts of the foetus. The woman's husband is present, to help and probably to satisfy rural ethics as well.

\section{2 \\ NAMing THE BABY \\ Arlo Nuvayouma \\ MAI/HF $23 / 7337$ \\ II $\times I 4 \frac{1}{2}$ in.}

Only when a child is named does it have an identity by which the supernatural powers can identify it. The baby's mother and grandmother (father's mother) take him outside, put cornmeal on his face and offer a prayer. The grandmother, wearing braids, carries the baby on her back wrapped in a shawl, and the mother follows. Kuivato, "going out to see the sun and offering cornmeal," includes this rite, which is more specifically described by the form tungwayane. A simplified version of the naming prayer might be, "This is going to be your name so you can live long. You have the sun have first look at the child. You declare the name to the sun."

Another identification of the painting explains that for the first twenty days of a child's life neither the baby nor its relatives eat salt. At the end of this period the restrictions are removed:

\footnotetext{
"That's the twentieth day (nafwalkuiva). The mother and child eat salt. First they feed the baby a little juice of a stew...tiqachnonova, 'baby eating,' 'feast for the baby. They go outside before they wash the baby and mother's hair. They dry the baby with cornmeal numanpölö, from numani, 'cornmeal,' (thus: 'cornmeal rub it all over him'). Then after this the father's sister gives little blankets (pusalhoya) or little quilts (tavufhoya)."
}

Two versions of the naming prayer contain the wish for long life:

\footnotetext{
"Yep e tawa $i$ yep tiyö yan tuwati Here sun, this (here) boy will be Machiökyang wiyöngmiök hakami kachi ökangni Named so and so towards old age his life......."
} 
and:

"Um yan machiökyang wiyongmiök ukatchi navökyangnane

You how they name it down to your old age living wishing for it happiness."

Naming ordinarily takes place at a bush near the edge of the mesa cliff, but as at other pueblos also, naming may take place just outside the door of the home.

3

WASHING THE BABY With Ashes
Marshall Lomakema
MAI/HF 23/73I3 $\quad 9 \times$ I2 in.

One of several ritual washings, rubbing with ashes removes lanugo, the excess skin present at birth, and is also believed to prevent hair. Ashes from the bush sïwafchoki are said to be used, although Whiting (I950:62) states that juniper is used.Lomakema explained the custom:

"They wash them with ashes so that dirty stuff when you are first-born peels off. It's just like when you're sunburned, that skin peels off. So then they don't have any long hair on their arms, legs, and cheeks when they do it real good."

When I observed a baby being "washed," soot from the stove was used. The aunts in the painting are seated upon sheepskins. Kochvi is "to rub the baby with ashes."

4

\section{A Boy's First HaIrcut Arlo Nuvayouma MAI/HF 23/749I II $\times$ I4 $\frac{1}{2}$ in.}

Other beliefs affect child care. For example, a boy's first haircut must be extremely close or it is believed that the hair will not grow properly. Here a father shears his son while the mother holds the little boy. On the wall hang a lightning stick and a rattle.

\section{CHILDHOOD}

(Paintings Nos. 5 through 20)

\section{5}

\section{A Scene fRom Hopi Family Life Arlo Nuvayouma \\ $\mathrm{MAI} / \mathrm{HF} 23 / 7540$ II $\times$ I $4 \frac{1}{2}$ in.}

"Married couple make their children happy" is another translation supplied by Nuvayouma for the Hopi title of this painting. The children enjoy the presents they received at the Bean Dance. A boy carries his buffalo stick and rattle while his father beats a drum. The responsibilities of a parent include teaching the children the ceremonies. 


\section{6}

\section{Children on the FAmily BuRro Arlo Nuvayouma \\ $\mathrm{MAI} / \mathrm{HF} 23 / 7570$ II $\times$ I $4 \frac{1}{2}$ in.}

A man and his wife give their three children a ride on a burro. The father carries his canteen ready to take to his cornfield, and the wife feeds the burro. The human quality of the illustration epitomizes the style developed by Nuvayouma who had a one-man show at the Heard Museum, Phoenix, Ariz. Nevertheless, a reviewer described him as a self-taught artist and felt that no outside influence had affected his work appreciably. This painting was the last of those completed by Nuvayouma for the project.

\section{7}

\section{Disciplining a Child By Water-Pouring Arlo Nuvayouma MAI/HF $23 / 7338$ \\ II $\times I 4 \frac{1}{2}$ in.}

An example of water-pouring as a theme in Hopi culture. A song with the words anoska'i si' $i$ wa (cf. also Qoyawayma I964:6), invites people to pour water on the bad boy so that he will say "yes" (instead of "no"). The song indicates that the water-pouring is planned so that when a house is visited, the women will douse the boy. Although punishment is the aim of this particular occasion, the idea of rainbringing is also implicit. In the scene, the boy's uncle, wearing a loin cloth, is carrying the naked boy on his back. As they stand near a doorway, a woman pours a pan of water over the boy's head. Since this may not be enough, she also has a bucket handy. Stephen clarifies the meaning of anoskaya by citing it as anoshkuyi (S:I203), which clearly means "water pouring."

In a variant upon the custom, children themselves sing the song in the hot summer "when it doesn't rain for a long time," and invite the villagers to pour water on them. The children sometimes carry each other just as the uncle carries the bad boy in the illustration.

\section{8}

\section{A BOy's OFFERING TO SÖYÖKÖ Marshall Lomakema $\mathrm{MAI} / \mathrm{HF} 23 / 73 \mathrm{I} 5 \quad$ I2 $\frac{1}{2} \times$ I $4 \frac{1}{2}$ in.}

Traditional standards of good behavior are enforced by the kachinas. The arrival of the ogres has changed very little from the 1890 s and children are quite afraid of them. Although this event occurs at the time of the Bean Dance, it is considered as a separate ritual. Children must offer food to the ogres Söyökö and Atosle and must comply with their orders or undergo various humiliating punishments. Naughty children are forced to smoke cigarettes, run errands, and otherwise publicly exhibit their bad behavior. In the illustration an awestruck boy must give his mice to Söyökö for her food. The mice, spitted upon a yucca stalk, represent deer and are spoken of as deer. Formerly eaten, today they are sometimes put in a shrine. 


\title{
9
}

\section{BATHing AT THE SPRING FOR Long Life Arlo Nuvayouma MAI/HF $23 / 7345$ II $\times I 4 \frac{1}{2}$ in.}

At the spring Kochatspelvi, now sheltered by a protective masonry wall, a man bathes his son or nephew with water from a bucket. Bathing at the spring is believed to develop manliness and strength:

\footnotetext{
"They just go out to the spring and have a nice cool bath early in the morning before sunrise so he won't get old right away. That's how the older people do, get strong and healthy. This man is the little boy's uncle taking him. The old people take a bath like that every morning-that's how come they don't get old right away. That's why the white man never believes the Indian's age; they look younger than their age."
}

Bathing at the spring is believed to be part of becoming a Hopi. Another man quite correctly pointed out that "That's the way they do in the sacred initiation four mornings early in the morning." Bathing in the spring by initiates, however, is a real ordeal, that is, in mid-winter the young men are expected to spend a few minutes in the icy water as part of the Wüwüchim ritual.

\section{0}

\section{Girls Bathe at the Spring} Arlo Nuvayouma

$$
\mathrm{MAI} / \mathrm{HF} 23 / 7472 \text { II } \times \text { I } 4 \frac{1}{2} \text { in. }
$$

Three girls bathe at the spring. A little girl is ashamed and modestly "doesn't care to wash her legs," so she washes separately from the others.

\section{1}

Boys Practicing ARChery SkILls
Leroy Kewanyama
MAI/HF $23 / 7504 \quad$ II $\times$ I $4 \frac{1}{2}$ in.

One of a small group of paintings by Leroy Kewanyama which were included in the series. Two boys in kilts using bows given them by the kachina dancers aim at kopöchöva or rabbit brush.

\section{2}

\author{
Playing with Tops \\ Arlo Nuvayouma \\ MAI/HF 23/744I II $\times$ I $4 \frac{1}{2}$ in.
}

Three boys enjoy playing with their homemade tops. The top is first wound up on a string attached to a stick. One boy is ready to spin his top. Another has just done so, while the third is still winding his. The boys variously wear blue jeans, and green and light blue trousers. In the background is a house on the plaza, the house 
next to the Bear Clan house. The alleyway or underpass is called kiskya. Dancers leave or enter the plaza through it. A pipe for drainage of the dance plaza runs under it, added in 1965 .

\title{
13
}

\author{
Three Hunters and Two Fires \\ Arlo Nuvayouma \\ MAI/HF 23/7329 IO $\frac{1}{2} \times$ I $4 \frac{1}{2}$ in.
}

With the initiation or "blooding" of a boy at the rabbit hunt, the selection of a temporary hunt chief, and the hair washing of the young hunter, the basic ceremonial ingredients of the lore of the Pueblo Hunt Society are present. Like clowning, however, hunting seems to have lost much of its original formal organization.

The hunt sponsor is called mak möngwi, "hunt headman." The artist explained:

\begin{abstract}
"At night they call out. Next morning mak möngwi gets there first and makes the fires. The small fire is to heat up their hunting sticks. It has leaves of plants that rabbits eat in it. After everyone gets there, the leader covers the small fire, but leaves a small hole uncovered because if he covers the whole thing up, they won't see any rabbits. Then they scatter out and start hunting. The big fire marks the meeting place."
\end{abstract}

The hints of magic in the use of "leaves that rabbits eat" and the belief that the small fire must not be covered up are confirmed by the use of rabbit dung at the four directions in the pit forming the fire's foundation (S:I023). Similar magic rabbit hunt fires were illustrated by the Isleta artist (Parsons I962:249, 26I), one of which is a fire "to blind the rabbits." Although I have the term awinta, "signal," for a large fire made by hunters, both the artist and Stephen specify maköhi, "hunt fire," as describing both fires on the rabbit hunt. The patterning of Pueblo esoteric terms leads one to expect a specific term for the small fire, considering its magical significance.

Three men appear in the painting. To the left is mak möngwi, the hunt headman or sponsor, who stands at the large signal fire. At the smaller fire, a kneeling hunter warms his two rabbit sticks. One is the curved püchko or flat stick (cf. also I68), while the other is a cylindrical muriko (S:I255 mözriko) of teve or greasewood. The smoke from the small fire rises onto the two sticks. A third hunter, carrying both a flat and a round rabbit stick, is joining the others. The men wear homemade cloth trousers and moccasins.

\section{4}

\section{INITIATING THE Young HUNTER Arlo Nuvayouma $\mathrm{MAI} / \mathrm{HF} 23 / 7330 \quad$ IO $\frac{1}{2} \times$ I $3 \frac{1}{2} \mathrm{in}$.}

This painting depicts a little-known custom. A boy has killed his first rabbit. $\mathrm{He}$ selects a ceremonial father who rubs the rabbit's nose on the boy's buttocks "so that he will be a good hunter; so that rabbits will find their way back to him." He does this four times, once for each direction, while all the hunters shout.

"The boy has to choose one of the men... as his father. Then he gives that rabbit to

him. So he's the one who rubs its nose on the boy's (buttocks). They shout, yell." 
The custom is known as kurita, from kuri, "buttocks." The boy may be called Kuritäkä, "Buttocks Man," for four days, but this nickname ends when the aunts have washed his hair and given him a new name (cf. \# I6). The ceremonial father is seen holding the rabbit near the boy who has already dropped his blue jeans and bent over. Two other hunters, one in cowboy dress, shout as the boy undergoes the ritual. Not all of the younger generation are familiar with this custom.

The rabbit hunt ritual was reënacted by clowns at one of the kachina dances. One of the kachinas had brought a rabbit. When a small boy took the rabbit, the clowns prepared to put him through the rubbing rite. He was told to select a ceremonial father and also required to bathe in the spring.

\section{5}

\section{A Boy's First Rabiit Hunt Arlo Nuvayouma $\mathrm{MAI} / \mathrm{HF} 23 / 733 \mathrm{I} \quad$ IO $\frac{1}{2} \times \mathrm{I}_{4} \mathrm{in}$.}

Learning to hunt rabbits was a boy's first real chance to help support his family. An initiation forms a portion of the activity. The third of four paintings depicting the rabbit hunt shows "Going out for the hunt on the last day." The newly initiated boy and his ceremonial father (wimna'at) prepare to go on a hunt the fourth day after the original hunt. The ceremonial father takes on the role of the Hunt Chief (mak möngwi). He has given the boy two painted rabbit sticks and carries sweet cornmeal as food for the two hunters and also as an offering for the hawk, which is skillful at killing rabbits. The swiftly thrown stick is likened to a hawk's wing and its design bears related symbolism (S:99, I00).

. The boy, painted yellow, wears his kilt and necklaces. Eagle prayer feathers are tied in his hair. Over his right shoulder and across his chest is a red cloth bandolier (palatotorikpi) as worn by Wüwüchim initiates and certain kachinas.

\section{6}

\section{Ritual Hair Washing: The Naming Rite of a Hunter Arlo Nuvayouma \\ MAI/HF 23/7332$$
\text { IO } \frac{1}{2} \times I_{4} \text { in. }
$$

Completing the series of four paintings of the ceremonial rabbit hunt, this illustration shows two aunts (father's sisters) washing the hair of the successful young hunter. A pottery vessel contains rabbit stew, already being cooked on the stove. The accompanying explanation describes the scene:

\footnotetext{
"After the hunting is over, they start to wash his hair and name him. They use the chöchmingwö (perfect ear of corn; naming ear), to wash four times over the top of his head. They dip it in the yucca suds and put it on his head four times, then they use their hands. Every time when they have someone initiated, they use that corn ear first on him."
}

The boy's aunts may simply mention the new name they wish to assign the young hunter or they may make a short speech, such as: "Have the name of . . . . and be 
good and healthy in your life." Then they instruct him to go out in the morning to the sun and tell him the new name. The hair washing is simply referred to as "washing" as in the statement kavu itam asnaiyani, "Tomorrow we him wash." As the father's sisters, the aunts are both members of the same clan, or may be members of linked clans (closely related clans which do not intermarry). For example, one may belong to Rabbit Clan, the other to Tobacco. "If this lady [left] is Rabbit Clan, she might call him Makya (Excellent Hunter); the other one might call him Piva, (Tobacco)."

A room with vigas is shown.* The boy kneels over a pottery bowl. Having just used the corn ear as described above, the aunt on the left is washing the hunter's hair with her hands. The other aunt waits on the right with a gourd dipper full of water. To the left of the fireplace is a stack of rolls of piki corn wafer bread. On the wall hang red, yellow, and blue ears of corn-with the white naming ear on the floor, the colors identified by the Hopi with the four directions are included.

\section{7}

Hopi Children Playing at Adult TASKs
Arlo Nuvayouma
MAI/HF $23 / 7442 \quad$ II $\times$ I $4 \frac{1}{2}$ in.

Girls make mud piki at a mock marriage. Placing a paper over the piki stone, one girl "grinds" the mud while another rolls the "piki." A little boy carries wood for them to use in their work.

\section{8}

\section{Offering the First Basket to the Sun Arlo Nuvayouma \\ $\mathrm{MAI} / \mathrm{HF} 23 / 7377$ II $\times$ I $4 \frac{1}{2}$ in.}

For girls, basketweaving is one of the first important lessons. Here again, ritual is involved. When a girl completes her first basket she displays it to the sun with a prayer that she will be a good basket maker. Baskets are placed under a bush at the head of the trail leading down below the mesa. One girl prays by holding the cornmeal to her mouth; the other has turned to run all the way to her home "so she'll be a fast basket maker." Sometimes a girl is told to run around the kiva four times, again so that she will be successful at basket making. The basket placed under the bush is an offering to the Sufmamant or Sumac Girls, for Whiting (I950:84) identifies suvi as squaw bush or sumac. By virtue of the offering the girl is believed to avoid sickness, especially sores.

\footnotetext{
*Terms such as viga (Spanish for roof beam), and kiva (Hopi for the underground ceremonial chamber), are not italicized, as they are in wide use throughout the Southwest.
} 
19
A Harvest Game: Smearing Corn Smut
Arlo Nuvayouma
MAI/HF 23/7455
II $\times I 4 \frac{1}{2}$ in.

Children enjoy a popular harvest time amusement. Among the corn plants, boys and girls chase each other and smear corn smut over their victim's face or body. A girl rubs the smut over the face of a boy in the foreground while toward the back another boy chases a retreating girl who is only his own size and seems likely to be caught. The smut is nanha, hence the name nanhat'aoktaita for the activity.

\section{0}

\section{A Hopi Mother Dresses Her Daughter's Hair Marshall Lomakema

MAI/HF 23/7397 I8 $\times 24$ in.

While her husband sits smoking, a woman dresses her daughter's hair. The oak frame (nasömöla, cf. S:I26o nasomnuela), is not shown, as it is covered by the girl's hair.

YOUTH, COURTSHIP AND MARRIAGE

(Paintings Nos. 2I through 29)

21

Yahaha, a Snake Dance Game

Narron Lomayakterwa

$\mathrm{MAI} / \mathrm{HF} 23 / 73 \mathrm{I} 7 \quad$ IO $\frac{1}{2} \times 13 \frac{1}{2}$ in.

The game ensures plenty and takes its name from the shout of " $y a$-ha-ha" which means that an object which has been carried out by a man from a store or home is up for grabs. It is also called nuitivea (Cf. S:I263). Although outsiders are sometimes encouraged to play, I was once warned that "this game is serious business." Men exhibit scratches and bruises with great pride and it is not considered sporting to let the women win too easily.

A man in blue jeans with a cowbell tied to his belt loop holds a corn plant aloft while a girl in a red and white manta attempts to seize it. Her mother, in the black Pueblo dress, holds her arms outstretched and encourages her daughter. Her baby is on her back wrapped in a shawl. The game was originally played (as depicted) with cornstalks, melons or other produce, but it is now played with store-bought items. At least two Hopi men commented that an authentic painting of this game ought to show a corn stalk or melon, so my attempt to have the artist depict the now more typical box of crackers or other store-bought item was unsuccessful. 


\section{GRAPPLING FOR A WATERMELON Levoy Kewanyama \\ $\mathrm{MAI} / \mathrm{HF} 23 / 75 \mathrm{I} 2 \quad \mathrm{I} 4 \frac{1}{2} \times \mathrm{II}$ in.}

Another painting of the popular Snake Dance amusement. A woman and girl grapple for a melon held by a man, the three forming an arresting group. The taunting with prizes is reciprocal between the sexes at different seasons as shown in the following picture in which a girl holds the prize.

23

RACING FOR A BASKeT
Leroy Kewanyama
MAI/HF $23 / 75 \mathrm{II} \quad$ II $\times I 4 \frac{1}{2}$ in.

A girl in manta and black dress attempts to escape a man who is trying to get the basket which she carries as a prize.

A Hopi Couple
Arlo Nuvayouma
MAI/HF $23 / 7362 \quad$ II $\times$ I $4 \frac{1}{2}$ in.

A courting couple by Nuvayouma depicts the boy pointing down below the mesa to show the girl how far he has had to run in a ceremonial race. She is properly impressed. This couple appears in traditional clothing, but girls are now "ashamed" to be seen in mantas or the elaborate Hopi "butterfly" hair whorls. Fifteen years ago these were still fairly commonly seen, now almost never. Courtship is one of the occasions when Pueblo reticence and avoidance of boasting does not prevail. Nuvayouma explains:

"At the edge of the cliff, they meet over there before the sun goes down. They're just talking together. The boy was telling the girl (that) early in the morning he ran a race down below."

One man defined this painting as oveknawisa, "a little courting session." Another explained, "When I was a kid all the boys and girls would go and ovekna after a dance." Another man caught the artist's idea exactly and said, "He's bragging about his cornfield or something maybe to his girl friend." The subtle implications of village gossip are easily gotten across. Puma namaningwa, "they go together," has no special implications, but puma haka minamaningwa implies that "they go somewhere unknown together," escaping the watchful villagers; the crucial implication of intimacy is present. 


\title{
25
}

\author{
DRESSING THE BRIDE \\ Arlo Nuvayouma \\ $\mathrm{MAI} / \mathrm{HF} 23 / 7498$ II $\times$ I $4 \frac{1}{2}$ in.
}

The boy's father kneels, placing the mö'öngtochi or wedding shoes on the bride's feet. Their manufacture is one of his duties. A cousin prepares to comb her hair. The boy's mother carries the wedding robe (right) while a shawl and atöhö hang on the pole described in the next illustration. The cousin wears a print dress, but the bride and her mother wear the Pueblo black dress.

\section{6}

\section{Grinding Corn for the Wedding Ceremony Arlo Nuvayouma MAI/HF 23/7497 II $\times I 4 \frac{1}{2}$ in.}

Part of the elaborate series of wedding interchanges and exchanges of visits and work projects takes place at the groom's house. The muwitaka (mother-in-law) and the bride (muwi) are seen together. The girl grinds corn and after four days her maiden's hair whorls are removed. On a pole above them is tsököviki, "clown bread," which is like somiviki, but is named for the pointed shape which resembles the horns of a clown. The pole (tuleta-tulethaiyi), is also used for storage in New Mexico, especially in the northern pueblos. The mother-in-law knocks corn ears together to shell them. She wears a yellow dress, but the girl is dressed ceremonially in the traditional costume.

\section{7}

\section{The Mock Mud Fight at the Wedding Festivities Narron Lomayaktewa MAI/HF $23 / 7327$ IO $\times$ IO $\frac{1}{2}$ in.}

The mud fight at a wedding has all the excitement of a baseball game and lasts for several hours. In the painting two aunts rub the young bridegroom with mud and reproach him for every possible variety of misbehavior. Anything in the past which he has done that is memorable is described in great detail. One of the women is hitting the groom with a stick. The artist explains:

\footnotetext{
"The women mock the groom's father: one time he got drunk and was trying to fight with his wife and his mother-in-law and he's no good to let his son marry this girl. She doesn't know how to cook and take care of him. She is bad looking and not worth anything to them. They just joke and afterwards they forget all about it and there's no hard feeling and they all eat together. The lady that's getting married serves them."
}

The insults are very specific, often sexual. 


\title{
28
}

\author{
A Hopi Wedding Feast \\ Marshall Lomakema \\ MAI/HF 23/740I I8 $\times 24$ in.
}

This formal feast is muwi ep nonova, "wedding there eat." Piki, sömiviki, and beans are served. $P i k i$ is prepared on a special stone griddle (see paintings \# I62 - I66). Sömiviki, another corn product, is wrapped in corn husks.

29

\section{Clan Marks Painted on the Wedding House Arlo Nuvayouma$$
\mathrm{MAI} / \mathrm{HF} 23 / 7448 \text { II } \times \text { I } 4 \frac{1}{2} \text { in. }
$$

In another event at the time of the chökananaiwa or "mud fight" at a wedding, women paint their clan marks on the wall of the house where presents are brought to the young couple. In yellow and black clay are the symbols of the Sun, Spider, Eagle, Bear (human hands), Cloud, Corn, Sun's Forehead, and Bluebird Clans. Each aunt or other relative or participant places her marks on the wall, lending her clan's support to the new couple. These are usually plastered over later but rarely may be left in place. Feasting takes place in the decorated house which serves as a repository for the many presents of flour and useful household articles which supplement the exchanges of traditional woven garments, baskets, and other articles for ceremonial and everyday use.

\section{DAILY LIFE}

(Paintings Nos. 30 through 43)

\section{0}

\section{A Women's Barter Party Arlo Nuvayouma

$\mathrm{MAI} / \mathrm{HF} 23 / 7436$ II $\times \mathrm{I} 4 \frac{1}{2}$ in.

Stephen describes women's trade for basketry and supplies in Shongopovi (S: r39, I036, I222), and his mention of it served as a stimulus for the painting. Nuvayouma explained: "Any lady has something...like a dye. She puts it up for sale (trade) like for coffee...hires a man to call out." This is called huiyan chalani, "calling out for barter or announcing trading." To the left is the woman who offers articles: sheep fat, ashes for parching corn, yellow, green and red dyed yucca for basket making, and sweet corn. Two women have cornmeal. . . one in a dish, the other has a bucket. Four women are shown, two in modern clothing, two are dressed traditionally. Asked if the trade shown was fair, the artist said that it was.

A more detailed description explains:

\footnotetext{
"They just been trading for their materials that she needs for something to work with. This lady [second from left] has white cornmeal. She wants to trade for yellow yucca. This is sheep fat [property of woman second from left] and this is fine ashes for soda;
} 
they call it köchvi... This center bunch [of basket materials] is söhö [wild grass for basketry bundle] and this is palatufhoni, red-dyed yucca. This one is hotomni, strong dried sweet corn. The old lady is going to trade blue corn meal for the sweet corn."

"A lady that needs something," the artist explains, "hires a man... one that knows" how to make the traditional announcement. For example, a man with a good voice may call out: Huiyan chalaoni yapik huyanwai ovi uma pok kuivawusnu, "Trading calling. Right here they have trading you come and see!" Any man with a strong voice serves to replace the Crier Chief, whose post has lapsed at the village. His more ceremonial functions, however, are filled by the Village Chief.

\title{
31
}

\author{
Food TRADING \\ Arlo Nuvayouma \\ $\mathrm{MAI} / \mathrm{HF} 23 / 7450$ II $\times$ I $4 \frac{1}{2}$ in.
}

A food sale may be announced on the bulletin board of a trading post or other center. Earlier custom may be seen when "neighbors tell someone sometimes to call out," inferably originally the Crier Chief. The artist views the trading situation quite specifically and supplies many details, both of the particular scene and of the process of trading among Hopi women:

"Two ladies are partners (nasöngwam). This girl was trying to decide what she was trying to trade for her cake (kwangwanova, 'sweet eat'). When you try to decide you scratch your head. She wants to trade for something else. She is trying to look at those foods. The leader used to tell them when the trade was completed, now its different.

This girl, she brought her pie to trade for a bowl of parched corn (kötöki). Other foods there are sömiviki, doughnuts and kötökdosi, 'powdered parched corn.' They take it to their homes. They have a big dinner."

The trading parties take place in a cycle or in a "round." The upside-down dish indicates that the trading is in progress:

"After they all finish, the leader (möngwi) picks the bowl up and gives it to another lady to give the next sale. This goes around... when it gets to the same lady, the round of food sales is over."

\section{2}

\section{A Woman Drying Peaches \\ Marshall Lomakema \\ $\mathrm{MAI} / \mathrm{HF} 23 / 7485 \quad \mathrm{I} 8 \times 23$ in.}

A woman is on the roof of her house which is used for laying out peaches for drying. Her husband is feeding the family dog. Dogs are given names but usually live outside, and are not pampered. Some are just "village dogs" and receive harsher treatment. 


\author{
Building A House \\ Arlo Nuvayouma \\ MAI/HF 23/7364 \\ II $\times I 4 \frac{1}{2}$ in.
}

A man chops sandstone blocks for his house (oalalwa, "stone making"). The walls are partly in place. Traditionally the labor was divided between the sexes and there were ceremonial customs and prohibitions which formed an integral part of building a house:

"A long time ago, the ladies had to fix the mud for them by hand. Sometimes they used an old ax to make up the blocks. First they have to dig around the foundation and they put a round cactus on each corner so the house will not get cracks. After they make the house, in December they make a prayer stick for their new house."

As the man chops, the woman kneels and kneads the mortar. Chökalalwa, "making mud," refers to mixing the mortar. An older man disapproved of the perfection of the house: "It isn't really true, the way he's doing it, because if he's building up the house, it should be rough. He's using his hands... This is too perfect. The woman is all right." Whiting (I950:22) gives some of the many plants used in construction; he does not mention the custom of placing cactus at the four corners of the house. Since witches are said to eat cactus, it is possible that the cactus buried at the corners of the house serves to keep them away from its occupants.

Recent objections have been expressed to stucco-type houses known somewhat derisively as Castilki, "Spanish houses."

\title{
34
}

\section{Washing (Plastering) The Walls Melvin Nuvayouma$$
\mathrm{MAI} / \mathrm{HF} 23 / 745^{2} \text { II } \times \text { I } 4 \frac{1}{2} \text { in. }
$$

Women put plaster (palwi) on the walls; palwi is the grey clay used for this, sometimes mixed half and half with white clay (tüma). Palwita is "washing the walls with palwi." Three women are shown, one holding a can of palwi. Another, standing on a chair, plasters while the third kneads clay. Melvin Nuvayouma, Arlo's son, completed a few paintings of village scenes, but preferred to work on designs and finally painted several abstractions based upon traditional symbolism.

\section{5}

REPAIRING OR RENEWING A House
Marshall Lomakema
MAI/HF $23 / 745$ I $\quad$ II $\times 14 \frac{1}{2}$ in.

When the artist returned to the reservation, he was caught up in the round of daily obligations, practical and ceremonial, which form the substance of Hopi life. 
For example, he added a room to his family home. In the painting a man holds a mason's trowel and plasters a new doorway. On the wall are a doll (Hahai), a basket and a painting of a palm tree, an imaginary souvenir of Phoenix.

\section{6}

\section{A Family Feast \\ Arlo Nuvayouma $\mathrm{MAI} / \mathrm{HF} 23 / 7363$ II $\times \mathrm{I} 4 \frac{1}{2}$ in.}

The four participants are seated side by side. Even at the modern table Hopi seating arrangements tend to place people side by side where White custom would place the same diners opposite each other. A number of traditional dishes are shown: hominy and meat (nökwivi) is in two bowls. Sweet corn (töpovö), peaches, and flat unrolled piki bread may also be seen; the tamale-like articles are sömiviki. A mother, her son, the father, and a grandmother are seated upon sheepskins. The boy wears only a loincloth. One viewer stated: "My grandmother used to eat like this. You don't see it very often... They're having a feast-piki, qömi. There should be a lot of people."

The closest modern equivalent is the feast following a work session, but this is either all men or all women. "In a naiya, 'employ yourself; volunteer one's work,' the women and men don't eat together, the working people eat first." Na'aiyat ef noneva is a "work party feast." Nonova, "eating," was given as a title for this painting by two young men and also by a small child who looked at it.

\section{7}

\section{Borrowing CoAls for LAYIng a Fire Arlo Nuvayouma \\ $\mathrm{MAI} / \mathrm{HF} 23 / 7339 \quad \mathrm{I} 8 \times 24$ in.}

Before matches were in general use, women prepared a temporary "firelog" of shredded cedar bark arranged roughly in the form of a bird's nest, tying a string loosely around it. In the illustration, a woman takes the cedar bark from her neighbor, an older woman with a cane, who will be spared having to light her own fire. Cedar and soksi (identified by Whiting as four o'clock), are used to start the fire. Few informants identified this scene readily. An example of a response to the picture which, though incorrect, identifies another culturally significant event is that of a young man who explained: "There are stories about a lump of cornmeal. They give it away to signify that the woman who is receiving it is the godmother."

Shredded or powdered cedar bark has another use as well; it is a remedy for bedbugs. Doors and windows are closed and the smoke is believed to drive the bedbugs away. As Whiting reports no use for Cucurbita foetedissima, the Hopi (including my informants), appear to be unfamiliar with an Isleta practice of making a stew of "stinking melon," spreading this everywhere and closing the house for several days, reportedly effecting the removal of vermin. 


\title{
38
}

\author{
DIVORCE \\ Arlo Nuvayouma \\ $\mathrm{MAI} / \mathrm{HF} 23 / 7473$ II $\times$ I $4 \frac{1}{2}$ in.
}

What Eggan (I950) described as "brittle monogamy" is exemplified. A family conference is taking place and will result in a divorce (namatavi). "This man," the artist explains, "was going with another woman so that's how come they are getting after this man. They don't want him to stay married... trying to get rid of in-law.... He's going to leave." Traditionally the man will return to his mother's house, his "real home."

\section{9}

Fighting Over a Hoe Arlo Nuvayouma

$$
\text { MAI/HF 23/7557 II } \times \text { I } 4 \frac{1}{2} \text { in. }
$$

Two men struggle in a field. One claims that the other has stolen his hoe. Theft is not common among the Hopi; it seems possible that the gravity of theft in a small community evoked serious punishment in former times. Asked about the punishment given to a habitual thief, the artist and his wife simultaneously exclaimed, "Kill him." This ostensible jest perhaps hints at a reason for the rarity of the offense.

The theme of theft was suggested; the incident of the hoe was the artist's response.

\section{0}

Family Meeting

Arlo Nuvayouma

$$
\text { MAI/HF 23/7474 II } \times \text { I4 } \frac{1}{2} \text { in. }
$$

Nanahim nangwatota, "relatives argue," describes the scene depicted. Specifically, the informal litigation taking place is pasnanakasya, "arguing over a field." Again, as in painting \# 38 , in-law friction is evident, for a man's planting has infringed upon his brother-in-law's field. Repayment is to be made when the crop is gathered, the loser of the discussion forfeiting some of his harvest.

\section{1}

\section{An Old Man Visits the Doctor \\ Arlo Nuvayouma \\ $\mathrm{MAI} / \mathrm{HF} 23 / 7533$ II $\times$ I4 $\frac{1}{2}$ in.}

Masivö or wall eye has brought an old man to the doctor. A boy, perhaps a grandson, has led him. The doctor uses his tohofko or wildcat fetish. He has "already got something from his eye and is trying to get it away from it...to make it well." The Hopi medicine man must remove the quill or other foreign object with which sorcerers are believed to wound their victim. For many ailments, the doctor will 


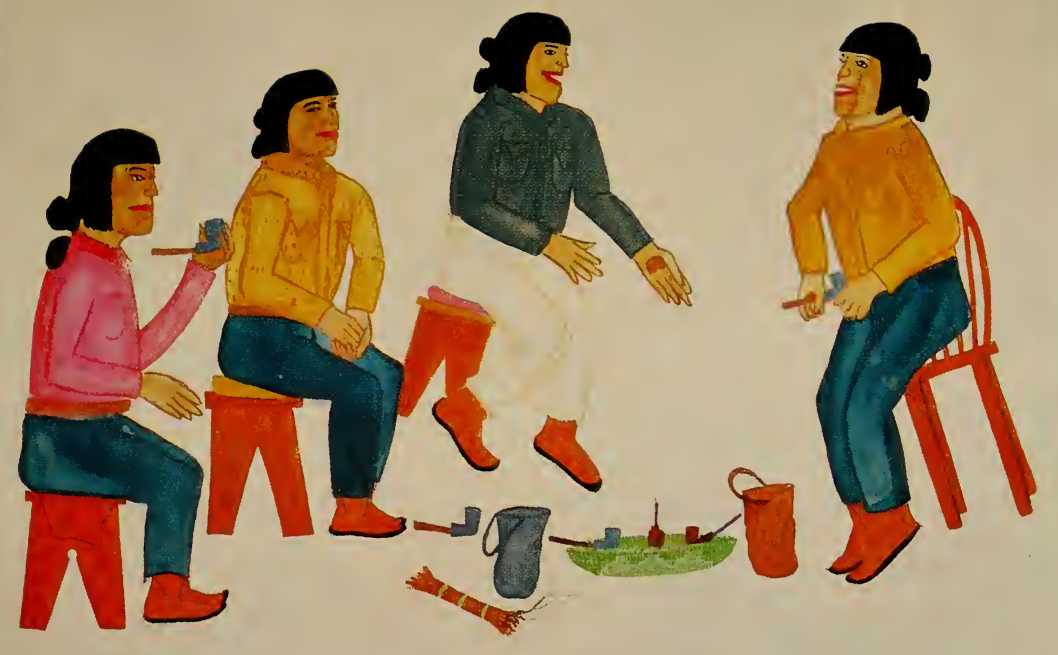

The Ritual Smoking of Chiefs $\left(\#_{4} 8\right)$ 


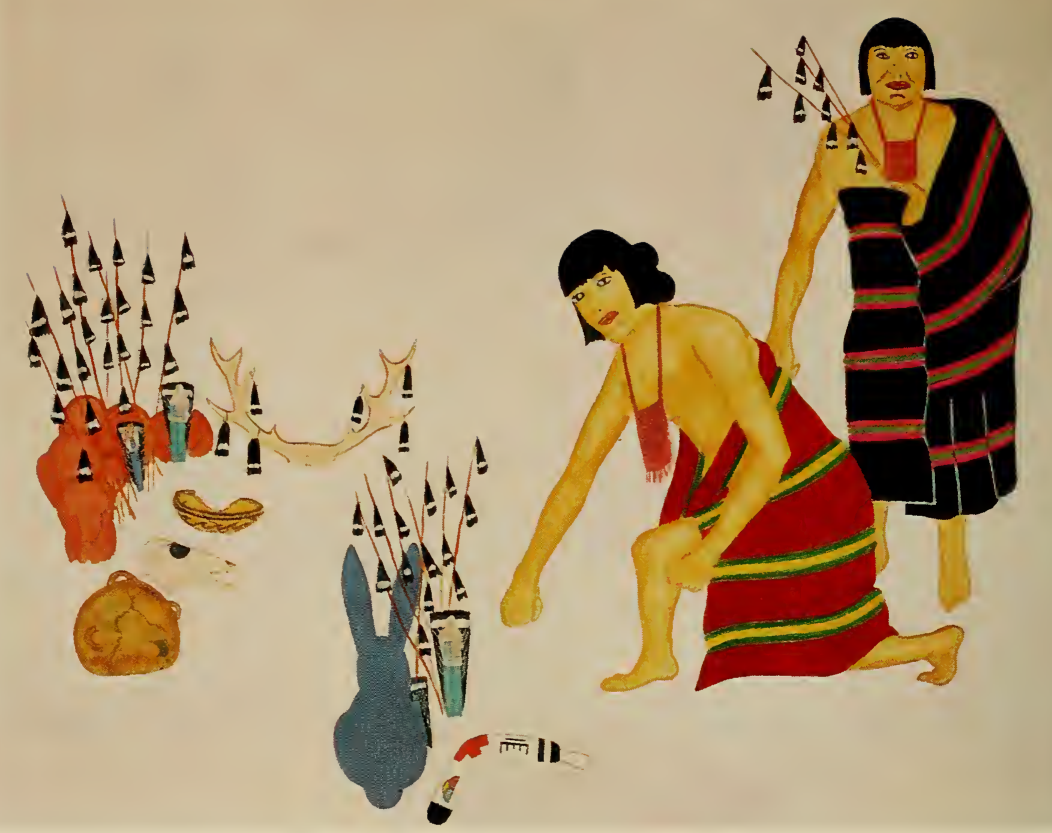

Young Men at the Shrine $\left.\#_{53}\right)$ 
refer his patient to the hospital. When a man becomes old and is subject to the ailments of old age, he may relinquish his ritual position, but often he is kept on in an advisory capacity.

\title{
42
}

\section{A Seriously Ill Patient is Visited by the Doctor Arlo Nuvayouma MAI/HF $23 / 7542$ II $\times$ I $4 \frac{1}{2}$ in.}

A request for depiction of an illness which would be terminal resulted in Nuvayouma's painting of a particular complaint. Severe cramps and abdominal distress, possibly accompanied by impaction were described as "Older people get upset stomach and feel like to be die." The emaciation of the senile male patient is marked. The doctor kneels, perhaps hoping to find magical causes of the severe illness. Önangtöpötöiva or önangtöpökhongva is the Hopi term for this ailment. Gastro-intestinal ailments may be quite severe on the reservation and are a persistant cause of infant mortality, as well.*

\section{3}

\section{LANDSCAPE: The Hopi Country Marshall Lomakema $\mathrm{MAI} / \mathrm{HF} 23 / 7563$ II $\times$ I $4 \frac{1}{2}$ in.}

Indian artists find that their occasional efforts at landscape are seldom rewarded, for collectors prefer ceremonial scenes. This volunteered scene is typical in its emphasis on animal life. A prairie dog sits up on the right, while a bush on the left conceals a rabbit.

\author{
SOCIAL CHANGE
}

(Paintings Nos. 44 through 46 )

\section{4}

\section{The Family Buys a Television Set Arlo Nuvayouma $\mathrm{MAI} / \mathrm{HF} 23 / 7500$ II $\times$ I $4 \frac{1}{2}$ in.}

With the arrival of power poles, even the older generation tended to accept new conveniences. A family shops in town for a television set; Father prefers one model, but Mother holds the family purse. In some Hopi homes appliances were in place for over five years, awaiting the I 965 settlement of religious objections to electricity. Change is becoming increasingly rapid. Many Hopi find television a useful aid for children learning English.

*I am indebted to Dr. Eduardo Eidelberg of Phoenix and Lima, Peru, for his opinions as to the ailments depicted. 


\section{5 \\ Celebrating Christmas Marshall Lomakema \\ $\mathrm{MAI} / \mathrm{HF} 23 / 7368 \quad$ I8 $\times 24 \mathrm{in.}$}

Christmas was readily adopted by the Hopi, though they are less easily converted to Christianity. The same visit allows a Hopi living in town to celebrate both Christmas and prayer stick making. A family has gathered near the Christmas tree. A man in a yellow shirt is giving a present to his friend who has put on a green shirt for the occasion. A man's woven belt has been used as an additional decoration for the tree. Presents under the tree include a pottery bowl and a basket. Since the evergreen symbolizes longevity to the Hopi and trees are used in some of the Pueblo dances, it is natural that Christmas trees became popular: "Almost everybody has a Christmas tree. This year the baseball team had a tree near the first kiva. That's how I saw the belt on the tree." Or again, "Celebrating Christmas, that's all. To the Indian it's a different thing, something new!"

\section{6}

\section{"WATER FILLING" Marshall Lomakema $\mathrm{MAI} / \mathrm{HF} 23 / 743 \mathrm{I} \quad \mathrm{I} 8 \times 24$}

This is Lomakema's "modern picture" and is intended to show acculturation rather than ceremonial or traditional village life. It was extremely hard to elicit, the artist preferring to depict "Indian" subjects. A man standing behind a pick-up truck uses a siphon to fill his water barrel from a barrel hauled from a spring or windmill. A boy with a wagon and another boy with a wheel barrow are in the foreground. To the right is a tractor.

\section{Ritual Life}

(Paintings Nos. 47 through I05)

Some of the activities typical of the many Hopi ceremonies appear in the following paintings in more detail. Hopi religious practice is quite complicated, but in smoking for prayer, making offerings at shrines, and invoking the aid of magical helpers such as the eagle, may be seen some of the basic essentials of Hopi religion.

\section{CEREMONIAL ACTIVITIES}

(Paintings Nos. 47 through 6I)

$$
\begin{gathered}
47 \\
\text { Clan Symbols } \\
\text { Marshall Lomakema } \\
\text { MAI/HF 23/7300 I8 } \times 24 \text { in. }
\end{gathered}
$$

The major matriclans of the village (Shongopovi), are depicted (left to right, top to bottom): Eagle, Sun's Forehead, Sun, Fog, Snow, Snake, Cloud, Strap, Spider, Bluebird, Parrot-Kachina, Bear, Antelope and Corn. 
Every Hopi is a member of a clan, this membership descending through the mother. The ritual and social duties of each clan are based upon happenings in the legend recounting the discovery of the village site. For example, the Village Chief is chosen from among the Bear Clan, while Fog, Snow or Rain Clan members are selected to obtain sacred water. Each clan has a chief who is in charge of the clan fetish, a stone regarded as an ancestor symbol. Some clans have become extinct and one clan has only one male member. Lomakema omitted Rabbit and Tobacco clans which are linked; that is, members must marry outside both clans. Linked clans are spoken of as nanahim, "relatives."

\section{8}

\section{The Ritual Smoking of Chiefs Marshall Lomakema \\ $\mathrm{MAI} / \mathrm{HF} 23 / 7324 \mathrm{I} 8 \times 24 \mathrm{in}$.}

Two ceremonial meetings are held, reflecting the division of the year into two ritual segments. All the chiefs, both of clans and societies, meet in winter and summer to smoke for rain. The winter meeting is held at the house of the Snow Clan and the summer meeting at the house of the Cloud Clan. The smoking continues for as many days as required, that is, until rain comes. In case there has been too much rain, the chiefs smoke "for nice sunny days." They meet every night after they come back from their fields. Smoking at a clan house is less rigidly formal than it must be at the kiva. Stools or chairs may be used and farm clothing is worn.

The first speaker, of the Bear Clan, is the Village Chief. Lomakema describes the scene:

"First, they pray on the cornmeal. They pray silently, holding the cornmeal to the four directions. Then they say:

'Well, I am thinking for my side that I wish we have more rain this summer and have a better crop in our fields and let it rain all over our fields and when the first crop comes, let the children eat first and then we'll eat after them.

Let the grass grow and all the flowers and let the birds and butterflies have fun in the flowers and the rabbits and deer eat the grass and be happy. And the eagles eat the rabbits so when the time comes we'll get the eagles and pray with their feathers to all directions and have better seasons and rain and let us all have a long life."'

Then the next headman speaks. "He starts right away, says the same thing, maybe a little bit different." Lomayaktewa supplied a typical speech, more modern in its emphasis on livestock:

"Well, I think this is the way I'm thinking. Tomorrow when the morning comes up first, let there be a nice sunny day and let the gods then bring us good rains so that our crops could really grow and produce what they are supposed to so that our children will be the first to eat from the crops.

And may the grass be greener so that our livestock could eat and drink so that they be fat in order for us to have good meat. May there always be nice and rainy days forever and may all the people in this world of ours never be sick, be forever healthy." 
Each chief speaks for his own clan in the order of precedence determined by the origin legend, but he makes no specific reference to it, since everyone knows his authority and position. After all the clan and society chiefs have taken part, a relative of one or another of them may be asked to speak. As a nephew, perhaps, of a clan chief he may someday have to succeed his uncle. The first time he speaks he must compose a prayer following the general pattern. On the floor, the smokers' equipment is laid out: four pipes with reed stems, three of them in a yucca basket. A cloth and a buckskin bag hold the tobacco. To the left of the cloth bag is a fire-log (kopöchöva), made of shredded cedar bark and used for lighting the pipes.

\title{
49
}

\section{Making Prayer Feathers Marshall Lomakema $\mathrm{MAI} / \mathrm{HF} 23 / 7367 \quad \mathrm{I} 8 \times 24 \mathrm{in}$.}

Prayer stick or prayer feather making in many pueblos is a part of winter solstice ritual.

A portion of the Hopi Soyal ritual is depicted and described by the artist:

\begin{abstract}
"Men in the kiva making pahos (paho, 'prayer feather, prayer stick'). First, they cut the sticks to the same length. Then they paint it with copper paint (using a yucca brush). When they get through with that then they start with feathers to put on that stick. If one doesn't have any feathers, they just share them. Kivamöngwi (kiva chief), is the leader."
\end{abstract}

The man on the left is making a prayer feather, attaching it to the twisted cotton string (pahosomtoni). The man in the center is sharing turkey feathers with the first man, while the third man smokes. "When they finish, they just whisper a prayer over them." On the kiva floor are the men's feather boxes, completed prayer feathers, and the painted willow sticks awaiting the addition of the feathers. Eagle feathers have the power of the eagle to rise through the sky and carry the prayer message to the gods. Turkey feathers are used when eagle feathers are not available.

\section{0}

\section{Giving Prayer Feathers \\ Marshall Lomakema \\ MAI/HF 23/7365 I8 $\times 24$ in.}

After the Soyal ritual, a man carries a willow prayer stick to his sister or aunt. The woman and her daughter are kneeling to receive it. One of the sticks may be placed on the wall of the house, another taken to the cliff or to a shrine. Another man has already brought the family a yucca basket of prayer feathers. The man has another bunch of prayer feathers which is intended for the next family he will visit. Formal exchanges are very much a part of Hopi economic life and ritual life as well. 


$\mathbf{5 1}$
Sun Watching (TAwANGaOKTAITA)
Marshall Lomakema
MAI/HF $23 / 7382 \quad$ I8 $\times 24$ in.

Religious officers must set the date for their particular ceremonies by watching the sunrise. As the sun rises exactly behind a particular landmark, the time of year for a given ritual or for planting is indicated. In this case, the Kachina Chief watches so that he may be guided in announcing his ceremony. He will also have to consider the availability of men who may be working in nearby towns, so that the Bean Dance, Home Dance, and most other rituals set by him may be expected to fall on the weekends. On the rock upon which he stands are the marks of the Bear, Kachina, Sun, Sun's Forehead, Snow and Cloud Clans recording the visits of their members to the spot.

\section{2}

\section{Two Boys at a Shrine \\ Narron Lomayaktewa}

$\mathrm{MAI} / \mathrm{HF} 23 / 7323 \quad 9 \times$ I2 in.

Lomayaktewa depicts Somaikoli, a particular shrine at the edge of the mesa where the hunt deities are said to live. In December boys go there to place willow prayer sticks and offer prayers for success. "It's up to the individual what he says...just like a wishing well...for his future, what he wants to have, to have a good time hunting, kill big deer, be the fastest hunter...live long, whenever he goes hunting to have luck, be the fastest racer." One boy kneels inserting his prayer stick, while another waits.

\section{3}

\section{Young Men AT the Shrine Narron Lomayaktewa $\mathrm{MAI} / \mathrm{HF} \mathrm{23/7328}$ I2 $\frac{1}{2} \times \mathrm{I}_{5} \frac{1}{2}$ in.}

Further details of the hunt shrine are given in this painting. It is among the many visited in the Soyal ritual in December. New initiates learn the locations of shrines which are honored and renewed or repaired as necessary. Somaikoli, the home of the hunt deities, is quite near the village- "down by the cliffs, almost by the footpath, a little ways down." Broken pottery lies near the shrine and when a newborn baby's hair is washed, the bowl which has been used may be placed there. A deer skull is shown at the shrine, and antlers and rabbit skulls may also be left as offerings:

\footnotetext{
"Someone that killed it takes it there for further success. They believe that the skull goes back to its home; another forms in its place. The same goes for the deer antlers. You put prayer feathers on the antlers if you want to pray on it."
}

The most significant item at the shrine is a pottery vessel, a large canteen:

\footnotetext{
"There are a lot of different things in there-pieces of animals, maybe a piece of stomach, of skin, a foot (rabbit), or maybe a piece of an ear from a deer. The parts are inside with prayer feathers."
} 
The canteen is closed with a corn cob used as a stopper. The vessel is usually kept partly hidden "to avoid someone stepping on it or dropping a rock on it." Lomayaktewa did not supply the secret term which describes the vessel and ended his explanation by stating:

"That's more precious than any of the items where the shrine is. It contains another world of itself. They pay it by making prayer feathers and putting in a piece of each animal just like an offering."

\section{4}

\section{Invoking Animal Fetishes \\ Marshall Lomakema \\ MAI/HF 23/7387 I8 $\times 24$ in.}

During Soyal ceremony men take effigies of their clan animals to the kiva. While stone fetishes were originally used, toy animals are sometimes substituted. In the kiva, a man kneels ready to tie a prayer feather on a miniature bear. On the same ledge are fetishes of a bear, frog, and wildcat. Hiksöna is "to give breath;" hiksönaya also signifies "giving prayer feathers to animals." The remainder of the year the clan fetish is kept in the home of the clan member, and protects the house.

\section{5 \\ Hopi WARRIORS HIDING \\ Marshall Lomakema \\ $\mathrm{MAI} / \mathrm{HF} 23 / 7402 \quad \mathrm{I} 8 \times 24 \mathrm{in}$.}

Two warriors hide from the enemy in a wash. Quiver, moccasins, and the sakwavitkuna or blue loin cloth are their only costume. Tu'ukam naöyi'yungwa puvat epo, "Warriors hiding in wash there," was the artist's title for this painting. A kaletaka, "warrior," must be brave, but tu'ukam, "army, enemy," are just men at war, perhaps brave, perhaps not. Tovöta or naqoita is "war." The war paint of the warriors is like that worn by hunters in later years. There is a further general similarity between the warrior's costume and the ceremonial costuming of a medicine man.

\section{6}

\section{The Flute Ceremony: Obtaining Ritual Water Leroy Kewanyama MAI/HF 23/7509 I8 $\times 24$ in.}

A boy in Wïwrïchim costume brings water in a sacred gourd and receives cornmeal from an older man wearing a white loin cloth. This incident in the Flute ritual was volunteered by Kewanyama who explained that Pisisvayü (Colorado River water) is sought. The Flute Ceremony is alternated with the Snake Dance every other year and is less often seen by visitors. 
57

\author{
Bear Clan Racer \\ Arlo Nuvayouma \\ MAI/HF 23/7333 \\ I $2 \times 9$ in.
}

Clan members compete in a race and receive water from their aunts as depicted in painting \#58. The race for the aunts (kyananamunwa) is represented here by a single Bear Clan racer, a boy painted light blue with a bear claw in black on his chest. As he runs, his kilt and hair stream in the wind.

\title{
58
}

Bear Clan Race
Avlo Nuvayouma
MAI/HF $23 / 7322 \quad$ I2 $\times$ I4 $\frac{1}{2} \mathrm{in}$.

Racers of the Bear Clan, each with a bear claw painted on his chest, come to their aunts for water at the close of the race. The racers are painted blue, yellow, and red, three of the four colors which imply the cardinal directions. Red lines which resemble the body painting with which clowns are painted are optional on the yellow racer. Other clan racers would wear their own particular clan marks, such as antelope, bluebird, etc. Kyananamunwa is the race for the aunts; nahinana implies "for their clan," while muwinanamunwa, "bride race," implies that a race is run for their sisters-in-law.

\section{9}

\author{
OAQÖL MANa Throwing Darts \\ Leroy Kewanyama \\ $\mathrm{MAI} / \mathrm{HF} 23 / 75 \mathrm{IO}$ II $\times$ I4 $\frac{1}{2}$ in.
}

Mötövötöftima, from mötövi, the Hopi corn-cob dart, is the name of the painting. The Oaqöl Mana is a feature of one of the two major women's rituals, and is seen here throwing darts at a basket effigy.

\section{0}

Prayer Sticks at a Snake Dance
Narron Lomayaktera
MAI/HF $23 / 73$ I $6 \quad 9 \times$ I2 in.

Before the Snake Dance two morning races are held, one for the Antelope singers and one for the Snake society itself. The Snake society racers, termed kaletaka, "warrior," are costumed like the dancers. One of the warriors is placing a prayer stick; the other holds cornmeal to his mouth, praying, "talking to the cornmeal." Rather than at a shrine, this takes place at a bush. The Snake Dance was widely publicized by the early I90o's; from Stephen (S:589) we learn that 25 Whites were present at the Walpi dance in I889! 


\section{1}

\section{Men Smoking and Exchanging Kiva Terms Marshall Lomakema \\ MAI/HF $23 / 7308$ \\ $9 \times 12$ in.}

Ceremonial smoking takes place in the kiva and also at the Clan houses of the Snow and Cloud clans when the chiefs meet to smoke for rain (cf. \# 48). Men smoke ritually on other occasions such as the eagle hunt or the deer hunt. Only the brief sakwavitkuna is worn in the kiva. Tobacco is carried in small buckskin bags, while the most usual pipes are made of twice-fired pottery. The orange Hopi clay becomes quite black on the second firing.

According to Lomakema's interpretation of his painting, the man on the left is engaged in recounting a hunting exploit while the smoker on the right is reaching for more tobacco. A later explanation reveals more about the functioning of Hopi socioceremonial organization. Each Kiva Chief may have a möngwi-söngwa, "the one who likes the headman." According to one interpretation this man is the presumptive successor to the Kiva Chief; according to another he is a man from a different clan chosen as co-headman to function in case of the kiva headman's absence. Thus the möngwi-söngwa, together with the headman's nephew, the more usual successor, provides for the occasional absence of the kiva head. Whatever the details of the role of the möngwi-söngwa, the painting represents a Kiva Chief and the möngwi-söngwa planning to put on a ceremony, "so they smoke." Once a successor to a head man is chosen, the chief must step down from his office within four or five years.

Men smoke "for their good future and for rain, for crops." The exchange of kin terms during smoking is described by Stephen ( $\mathrm{S}: 546)$; while Whiting (I950:39-40) includes significant data regarding ceremonial tobacco. The addition of anise to native tobacco, a practice at Isleta to sweeten it, is unknown at Shongopovi. Some smokers complain that Hopi tobacco makes one dizzy and, indeed, it is extremely strong.

THE EAGLE CULT

(Paintings Nos. 62 through 69)

62

\section{Three Men Smoking at the Shrine Arlo Nuvayouma \\ $\mathrm{MAI} / \mathrm{HF} 23 / 7346$ \\ II $\times$ I $4 \frac{1}{2}$ in.}

The eagle hunt is a ceremonial expedition undertaken by members of a clan. Each clan has its own eagle hunting territory which may lie as far away from Hopi villages as Winslow and the Grand Canyon. Clan territories differ between the various villages, but men of the same clan from adjoining villages sometimes hunt together. Eagle hunting techniques have changed so slightly that traditionally-minded older men objected to certain of the paintings.

At Kwatifkya, "Eagles, their home," a shrine located within each clan's eagle hunting territory, three seated men smoke over prayer sticks and a basket upon which 
an offering is placed. The men's farm clothing marks the picture as depicting a recent hunt, for kilts were originally the correct costume. Nuvayouma explains: "They have been going out for eagle hunt. After they get to the place where they hunt eagles, they pray and smoke." The artist described a trip taken in 1962 :

"We took one or two baskets. First we smoked over there. Then after we were through with all our pipes, then we pray that we'll see at least one eagle and get to take it home."

Prayer sticks are shown in the basket. One was offered to the sun at the beginning of the hunt, for the sun's rays are essential to success. The illustration depicts the three clan members seated on rocks. Two are smoking. At their feet are a denim bag of tobacco and a yucca sifting basket containing the two prayer sticks and a small eagle basket (kwa bota).

Shown the picture without explanation, a young man immediately commented, "They're blessing something." Another man reacted similarly: "They're smoking; is that prayer feathers?" Another description provided the term möngchochongya, "chiefs smoking." A more critical viewer said that in his clan, "Only old people smoke, five to eight old people at our clan house..."

63

\section{LOWERING A CLOTH ON THE EAGLE Arlo Nuvayouma$$
\mathrm{MAI} / \mathrm{HF} 23 / 7347 \text { II } \times \text { I } 4 \frac{1}{2} \text { in. }
$$

An episode in the hunt is described by Nuvayouma: "And then they found that eagle. One man was hanging that cloth to get the eagle down (from his nest). They were trying to fly that eagle away from his nest."

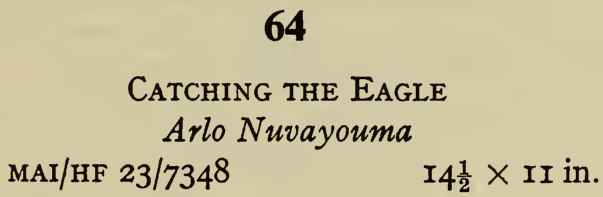

"After he gets tired he flies down to the canyon. Down in the canyon one man was down there watching and they catch him down there by the wings."

The hunter reaches his arms out toward the eagle. Folding the eagle's wings back onto his body, he easily subdues the tired young bird.

\section{5}

\section{A Hunter Being Lowered to the Nest Marshall Lomakema

$\mathrm{MAI} / \mathrm{HF} 23 / 7349 \mathrm{I} 8 \times 24 \mathrm{in}$.

This painting was added to the eagle hunt series by Lomakema. A hunter is lowered by a rope sling as another hunter (upper right) calls out that the first man has 
been lowered to the correct ledge. Older men objected to this picture, but since no younger men commented especially upon the use of the sling, it is possible that firefighting experience (the village has a fire-fighting team) has been profitable to the hunters.

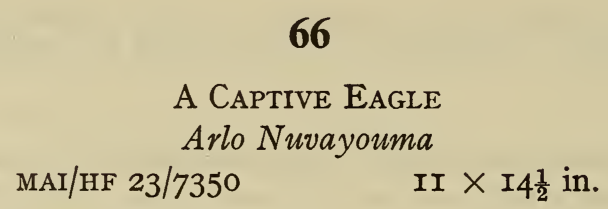

"After they catch that eagle, they come up from the canyon. They make him a cradle board (tapu), and they tie him on that and they put it against the rock just to rest." On the right is a burro, awaiting the load of live eagles. Placing the eagle in a cradle board is only one of the many instances in which the eagles are treated as human children. The cradle board is about $6 \times$ ro inches and made of flexible wood. This painting was identified as Kwahut somiya, "Going to pack eagle up," or Kwahut taput angsomya, "Eagle on cradle board tied."

\section{7}

\section{Naming an EAgle (Washing an EAgLe) Arlo Nuvayouma MAI/HF 23/735I II $\times$ I $4 \frac{1}{2}$ in.}

Nuvayouma stated: "They take it to their clan home. The next morning they wash it with mud water (kaolin in water) before they put it on the clan house roof." A woman holds the naming ear to the eagle's head, paralleling the ritual washing of a young hunter (cf. \# I6). A man kneels holding the eagle; he is possibly the clan chief. One informant specified that the eagles struggle and that the illustration is unrealistic. He pointed out that a braided string was used to fasten the eagle's legs together and that they were then tied to a long stick.

\section{8}

\section{EAGLES With GifTS Marshall Lomakema $\mathrm{MAI} / \mathrm{HF} 23 / 7309$ Io $\times$ I3 in.}

When the eagles have been washed, they are placed on the roof of the clan house. Since the members of the clan often are uncertain of the sex of the eagles, they give them presents suitable for human children of both sexes-the kachina doll as given to girls and a small bow and arrow like that given to boys.

The eagles are believed to take the prayers of the people through the zenith (abafhuchiwa, "square doorway or entranceway"), to the higher gods. The ritual execution (cf. \#69), releases them to become rain eagles (yoyivkwa, "rain eagle"), in the sky. The eagles are said to prosper and almost never die before ritual execution, but Stephen cites a case of accidental death ( $\mathrm{S}: 540)$. 
69

\section{The Execution of an EAgLe Arlo Nuvayouma \\ $\mathrm{MAI} / \mathrm{HF} 23 / 7352$ \\ II $\times I 4 \frac{1}{2}$ in.}

This painting was felt to be objectionable by several viewers. One man, at first ostensibly criticizing the artistic work asked, "Why did he paint these things like this?" The picture also brought an interesting division of opinion as to the correct identification. Approximately half of the viewers employed the Pueblo euphemism "sending the eagle home" (hona $a^{i}$ yane), for the ritual execution.

According to the artist, the clan chief or his nephew kneels on the bird's sternum, holding its throat to prevent biting. According to another man, a member of the clan who becomes specially skilled in the ritual execution carries out the ritual. Differences in the practices of the various clans are perhaps responsible for the discrepancy; however, other data state that the executioner must merely be a man initiated into a higher ranking religious fraternity. Here the eagle has been placed upon a rectangular area of sand. A bag contains tobacco for use after the bird has been killed. The eagle's bow, basket, kachina doll, and miniature piki bread lie near its head.

Although the artist was willing to depict the eagle's execution he would not depict the burial and found the very thought thoroughly unpleasant. The many analogies with funeral practice probably explain his reluctance. Parson's Isleta artist remains unique for a Pueblo man in his willingness to depict burial (Parsons I962). The execution takes place the day after the Home Dance, ovekniukat epe ("day after dance," from ovek, "holiday" [?] and epe, "there" [cf. S:569]).

\section{THE SALT JOURNEY}

(Paintings Nos. 70 through $7 \mathrm{I}$ )

\section{0}

\section{A Salt Expedition; Gift for an Aunt Marshall Lomakema MAI/HF 23/7334 I8 $\times 24$ in.}

Salt getting has been infrequent since I940, but one man went to Zuni in the early I950's. Although the Second Mesa villagers originally traveled either to Zuni or the Grand Canyon for salt, traditions state the original mine was located eight miles south of the village (Shongopovi) at Hukyatwi or just below the village where an alkali (sionga) deposit is now found. The people's greed was believed to cause the mine to "move" to the Zuni area.

\section{Lomakema describes the painting:}

"Early in the morning they come back from the south. They build a fire way over at the mountain. Then they build a second one and keep coming closer. They have to stay about two miles away from the village. They stay there one night. In the early morning, they come over and their aunts meet them at the trail. They go after their aunts to their aunt's house." 
In the illustration, a man (left) brings salt to his aunt. He carries a handwoven bag full of salt over his right shoulder and the short digging stick used at the mining site. The aunt, in red and white manta, prepares to offer cornmeal from a small bowl. The salt miner himself wears a black blanket and an eagle feather tied to his hair.

\section{1}

\section{SMOKING OVER THE Gift of SALT Marshall Lomakema $\mathrm{MAI} / \mathrm{HF} 23 / 7335 \quad \mathrm{I} 8 \times 24$ in.}

At the aunt's home two men smoke over the salt or "on the salt." The first man smokes over a pile of salt while the second waits for the pipe. After smoking, the miner will recount his adventures in getting the salt in a speech comparable to other formal Pueblo ritual reports.

\section{MORE IMPORTANT CEREMONIES}

(Paintings Nos. 72 through 76 )

The following five paintings portray sensitive aspects of Hopi ritual, but are a part of the record. Four of them involve masking while the fifth depicts the ceremonial growing of beans in the kiva. No artist's names will be listed for these paintings. Their publication is solely the author's decision.

$$
\begin{aligned}
& \text { MASK MAKING } \\
& \text { MAI/HF } 23 / 735^{8} \times 24 \text { in. }
\end{aligned}
$$

A skilled leather worker makes a young man's first mask. As the mask is ceremonially called $i k w a c h i$, "my friend," mask making is kwachlawö or "making a friend." The description explains:

\footnotetext{
"This guy in the black shirt, he wants to have a mask, so he goes up to this guy and asks him if he can make him one. So he says 'Okay, we'll do it in the kiva.' So they went over there and he starts making it and also teaching him how to do it. So he's sitting there saying 'What size do you want it?' The other man says, 'Maybe a little bit bigger."'
}

The projecting piece of leather at the top of the mask is the strip which holds the top in place. A mask is traditionally prepared from buffalo hide (ikali) but as at New Mexican pueblos, steer hide and commercial leather must most often suffice. Two men hopefully interpreted the painting as tochlawisa, "shoe making or moccasin making." 
73

\author{
EATING FOR THE MASK \\ $\mathrm{MAI} / \mathrm{HF} 23 / 7359 \quad \mathrm{I} 8 \times 24 \mathrm{in}$.
}

Opening the eyes and mouth of the mask is an important moment in its manufacture. "They open the eyes and mouth so they feed them. The women, maybe the wife of the maker, bring the food." Piki bread is in a basket, beans in the bowl. The mask has only one coat of paint (white clay). They feed the mask, then they eat after." The opening of the eyes takes on special significance because of the power possessed by the kachinas over eyesight (cf. Earle and Kennard I938:9). Another statement describes the scene:

\footnotetext{
"The eyes are opened just a little bit with an ordinary knife by a man who is experienced in fitting masks. The mouth and ear holes are opened next. When a mask is made for the first time for a new initiate, his mother, sister or other (female) relative prepares food for the family members to eat. The mask is taken to the kiva. Food is taken to the kiva and all eat."
}

"Opening its eyes" has the double implication of the making of the literal opening and of "giving it a life." Thus, poshutak nawa" $a$ is "he opens the eyes, giving them food." Poshuta is "they cut the eyes out;" kwachnakwayi, "feeding a friend," also describes the scene. A few people declined to comment on the picture, but one explained, corroborating the data, "They bring the food really for the friend (mask); they're eating for the mask that's being made."

\title{
74
}

\section{Masks on the Kiva Ledge $\mathrm{MAI} / \mathrm{HF} 23 / 7355 \quad \mathrm{I} 8 \times 24$ in.}

At the Bean Dance, the masks belonging to the members of the kiva are placed upon the kiva ledge. In the illustration masks of Ho'e, Cháveyo, Qöqle, Huhunaka, and Sakwa Wükoktu have been arranged where initiates and spectators will see them during the night dance. They are placed in no special order, but when many masks are displayed the more important ones may be placed in the center. The painting was identified as kwachmui nasöngnaya, "friends resting," using the euphemism for mask. Another man described the picture as kwachmui o' yiyiuma for which the same translation was given. Two men carefully identified each mask, a normal Hopi response, while two others spoke of kachina qötö, "kachina heads." Another identification of the scene was Powamuitikive mihök, "Bean Dance night."

\section{5}

\author{
Kachina Dancers at Rest \\ $\mathrm{MAI} / \mathrm{HF} 23 / 7340 \quad$ I $8 \times 24$ in.
}

This painting, showing the dancers without their masks, is also unsuitable and inappropriate in native terms. It should not be shown to Hopi children for they are theoretically not supposed to know that the dancers are masked. 
After the morning dances are over, the dancers customarily rest to the south of the kachina plaza. The place where they rest was originally only a bare area towards the edge of the mesa, but in I 957 masonry seats and a ledge were added, using dressed sandstone. Spoken of as "The Kachina Home," the area was littered with discarded bits of mask paraphernalia: beaks, ears, feathers too worn to be used, etc. An enormous amount of such litter was removed from various parts of the village refuse areas by tractor in 1964 and again in 1965 .

In the illustration three Mak' Kachina dancers smoke and pray. Two are seated. They are not allowed to eat until mid-afternoon, but they may sip water. They remove their masks and place them in a row. The dancer on the right wears a handkerchief around his head which aids in fitting the mask and prevents undue sweating. The costuming of the dancers is typical for Mak' Kachina: yellow and orange body paint, blue kachintochi (kachina moccasins), black yarn leg-ties, armbands (machöksoma), necklace, and bowguard. Pipes and a bag of tobacco lie at the dancers' feet. Nasöngnaiyane, "rest," or kachinkivök chochongyam, "smoking at the kachina house," and similar descriptions identified the scene, but silence on the part of several viewers firmly indicated their disapproval.

\section{6}

\section{Planting the Beans $\mathrm{MAI} / \mathrm{HF} 23 / 738 \mathrm{I} \quad \mathrm{I} 8 \times 24 \mathrm{in}$.}

Tangalalwa, "digging in" or "putting beans inside," is said to refer only to beans. Oyilalwa, "planting," was another term said to describe this Bean Dance scene. The planting takes place in each kiva. Two men and a boy kneel to plant the beans. Curious twin-spouted vessels of utility ware used to hold the beans, as collected by H. R. Voth at Oraibi, do not occur at Shongopovi. Most informants did not recognize or appear to want to recognize this picture; their objections were partly artistic and partly ceremonial. Knowledge of magical secrets relating to growth forms a major part of Hopi ceremonial secrets. It is doubtful if any outsider will ever obtain any worthwhile knowledge of the details.

\section{THE KACHINA CULT}

(Paintings Nos. 77 through 96)

The Kachina Cult embodies ritual visiting, feeding of participants and gifts of food to the village, discipline of children, curing, and house blessing. It is the many needs which kachinas fill and the adaptability of the cult which has made it survive for so long, for the performances are enjoyed as theater as well as ceremony.

77

Kiva Chief AND Kachina Exchanging Gifts
Marshall Lomakema
MAI/HF 23/7356 I8 $\times 24$ in.

"During the morning, when the Qöqölöm came, the Ho'e came to give out dolls. When they finish, they go to the kivas. They give every kiva chief bean sprouts and they tell 
him there are some more kachinas coming this evening...'You'll be waiting for them. Here's the present I have so you can eat this.' Then the kiva chief asks, 'Naybe you can dance before you go?"'

When the Kachina complies, he sings amusing songs.

Ho' $e$ and Hïhïwa "have the same mask; you can tell them by their legs" (Hühüwa is the Cross-leg Kachina). The giving of the bean sprouts is called nakwachlaren, "making friends."

\title{
78
}

\section{Ritual Feeding of Participants Marshall Lomakema $\mathrm{MAI} / \mathrm{HF} 23 / 7370 \quad$ I $8 \times 24 \mathrm{in}$.}

This painting is "Feeding Baholalwakamui, Feeding the prayer stick makers." Women feed the men who are in the kiva. They just hand the food to one of the men at the entrance. Feeding the men is a task of the women at every Hopi ceremony. The men return the favor during the women's rituals. A woman carries food wrapped in cloth while her daughter carries a pottery bowl.

\section{Another man described the scene in more detail:}

"During our special ceremonies, we men folks are down in the kiva. On the fourth day, they come along with lots of piki, pie and cake. They come up to the kiva and say 'Hawa.' They call in: 'Uma piök nönga ke tangatotane, You come out, take it down, eat."'

\section{9}

\section{Dance Practice Scene Marshall Lomakema $\mathrm{MAI} / \mathrm{HF} 23 / 7380 \quad$ I8 $\times 24 \mathrm{in.}$}

Men practice a song either for a kachina dance or an unmasked presentation. Formal dance practice takes place for four ritual days in the kiva.

\section{0}

\author{
BORROWING FOR THE DANCE \\ Marshall Lomakema

MAI/HF 23/7366 I8 $\times 24$ in.

The man on the right is borrowing dance paraphernalia from the man on the left, in whose storeroom the scene takes place. He has already borrowed a fox fur for use as part of his kachina costuming and the owner is saying: "If you want this belt, too, it's still a good one." A box of clothing is in the background. Hanging from a pole suspended from the ceiling are bags containing ceremonial articles. The bag in the center contains a mask. Hopi storerooms contain seemingly endless costume supplies; one storeroom in Mishongnovi, for example, held at least thirty pairs of moccasins. Families may have as many as four separate storerooms. 


\title{
81
}

\author{
A Kachina Pouring Water \\ Marshall Lomakema \\ $\mathrm{MAI} / \mathrm{HF} 23 / 73 \mathrm{I9} \quad$ IO $\frac{1}{2} \times \mathrm{I}_{4} \frac{1}{2} \mathrm{in}$.
}

In an episode reflecting the disciplinary function of the Bean Dance, Heheya gives a small boy a bath. Drawing from his own experience as a child, Lomakema explains:

"Heheya tells him that he never took a bath in the mornings with the cold water (at the spring). So he's giving him a bath with cold water. After the ceremony is over, then he goes every morning to the spring to take a bath."

The Nuvi Heheya wears a cartridge belt around his sheepskin garment. His leggings are gunnysack cloth. The marks on his legs and arms symbolize luwa, "vagina," from these he is also known as Luwaason Heheya, "vagina-liking Heheya." Stephen (S:2245) describes an episode in which Heheya lassos girls; the lasso is still carried by the kachinas. Two often appear at the Bean Dance to assist in enforcing Söyökö's commands.

\section{2}

\section{A Man and a Kachina Racing \\ Marshall Lomakema \\ $\mathrm{MAI} / \mathrm{HF} 23 / 7522 \quad \mathrm{I} 8 \times 24 \mathrm{in}$.}

The kachina is quite similar to a number of racers, especially Greasy Kachina and several others. His mask is black with red circle eyes and mouth. His costume enables him to run rapidly-green armbands and blue loincloth. This illustration shows upright ears of corn tassels (cf. Colton 1949:62, 72).

The Kokopel Mana will try to hinder the victim. Quite a large man may take the part of a Mudhead and block any escape so that the game is "fixed" and victims will be caught for sure. This kachina, regarded as the most unpleasant of the racers, will rub excrement on his captive.

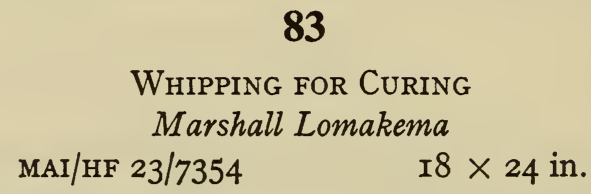

A woman tells her children that she has decided to ask Wüpamo's help for her sickness. "I'm going to pray through him," she announces. Walking up to the kachina impersonator and giving him cornmeal, she says:

"You take this and you whip me and I'll be better. Because of this inside me, I've been sick and don't feel well for so many days. If you whip me, I'll feel better again."

Although Parsons remarks, speaking of Hopi kachinas, that "the curing aspect has been kept esoteric, away from Whites" ( $\mathrm{S}: 350)$, this applies only to casual observers. The jurisdiction of kachinas over eye disease is fairly explicit, as is their power over infertility. 


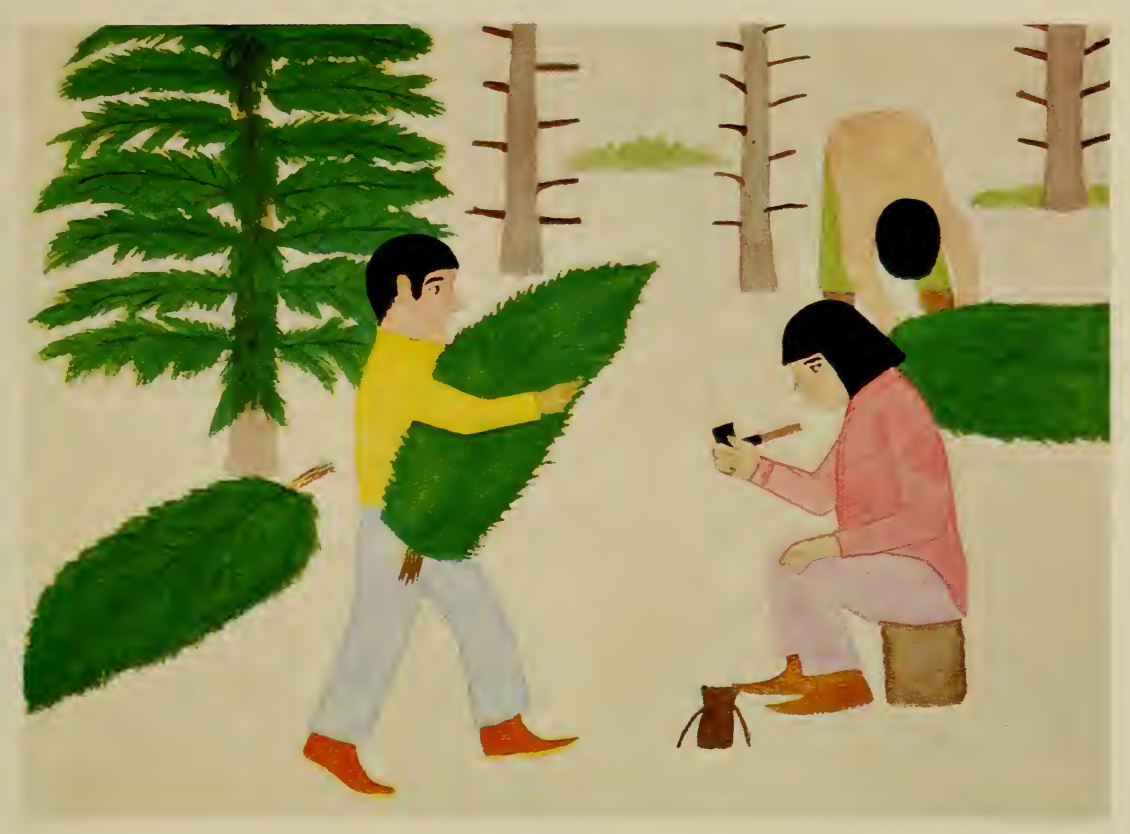

Gathering Evergreens (\#93) 



\section{4 \\ Ritual Blessing of a House \\ Marshall Lomakema \\ $\mathrm{MAI} / \mathrm{HF} 23 / 7369 \quad \mathrm{I} 8 \times 24$ in.}

An additional ritual part of Soyal is depicted. "The day after baholareu, "prayer feather making (cf. \# 49), Ahöla comes over to the house." The man of the house speaks to the kachina who merely gestures. "What are you doing around here?" The kachina indicates, "Well, I've come over to make a house for you." "Thank you," is the reply and then Ahöla goes over to the house and makes four stripes with cornmeal. Following Ahöla, Ahöla Mana carries seeds of various types from the fields of the Kachina Chief. The artist defined the marking of the house simply as penta, "paints or marks," agreeing with Stephen's record (S:II92).

Ahöla Wötaka, "Old Man Ahöla," was described by another viewer:

"Ahöla is the first one that comes in February. He wobbles around because he was just wakened and after he goes home Soyal Kachina comes in and after that they all get strong and they can run around. They come to the headman of the kiva and he prays to Ahöla and Ahölmana."

\section{5}

\section{Two Kachinas and a Hopi Policeman Marshall Lomakema

MAI/HF $23 / 7379$ I8 $\times 24$ in.

Since the kachinas served partially to discipline the Hopi public, they sometimes conflict with newer forms of authority. Reservation police supervise the crowds at weekend dances, checking for liquor violations and sometimes directing the parking of the visitors' cars. At one Bean Dance, the kachinas forced a policeman to leave. Lomakema explains:

\footnotetext{
"They had a Bean Dance at our village and at this certain time when $H e$ ' $e$ ' $e$ goes up on the roof whirling her quiver (hotnga) these kachinas get mad and they chase everybody into the houses. They have secret things to do; nobody wants to see them. This policeman tried to help them to chase the people away and the kachinas didn't want him to help them, so they chased him away, too."
}

The "secret things" include the planting of prayer sticks at a shrine near the plaza. The kachinas crowd around the shrine to conceal the activity, while the various whippers strike the windows of the houses as a warning to the people not to look.

To the left is a blue-masked Hilili. The Snake Kachina, Chu Kachina or Sitinini, is next, holding out his yucca whips as the policeman escapes the scene. This incident was planned ahead of time and dramatized previous critical murmurings about the unwanted activities of the police at the dances. A similar incident occured when a policeman received the amorous attentions of Kokopel Mana. As an Indian he had to permit this privilege to the kachina, but felt he should remove his badge and side-arm first. 


\author{
86 \\ Burro Kachina Dance \\ Marshall Lomakema \\ $\mathrm{MAI} / \mathrm{HF} 23 / 7423 \quad$ I8 $\times 24 \mathrm{in.}$
}

Presented some years ago as a dance, Burro Kachinas appeared in the plaza, some with saddles on their backs. The song stated:

"We are the famous burros. During the winter we used to haul coal and in the summer, we took men to their cornfields... but now when the people see us, they just chase us away from the house."

Two burros with pack saddles are seen; one with a grey mask, one black. Ho'e Kachina stands to the left. Each Burro Kachina has a staff and the atöhö or woman's robe worn as a kilt, both attributes of many animal kachinas. A brief chorus at the end of the regular dance song mocks the noise ("ruk, ruk"), made by an old burro bearing a heavy load.

87

\title{
The Mudhead Magician Marshall Lomakema
}

$$
\mathrm{MAI} / \mathrm{HF} 23 / 734 \mathrm{I} \quad 24 \times \mathrm{I} 8 \mathrm{in} .
$$

As the Mudhead gestures and sings, corn appears to grow magically from the floor. Ears of corn, one in each directional color, rise from a painted box, perhaps by means of strings, perhaps by some other device. It is no wonder that the trick is known as the Mudhead guessing game (mamaslalwa, "guessing"). Another description of the painting was Powak Koyemsi nanavö'o," "Magician Mudhead playing a game." Wichilawu, "playing tricks," was another verb elicited by the painting, derived from wöchi, "something artificial." Powaka implies a magician, "evil or good." The Mudhead sings a special song composed for the occasion.

\section{8}

\section{Wolf and Cow Kachinas Arlo Nuvayouma

MAI/HF 23/7468 II $\times$ I4 $\frac{1}{2}$ in.

Wolf Kachina appears as a side-dancer at a Cow Kachina line dance to "guard" the Cows from predators. Brown-and-white and black-and-white Cow variants are depicted. The staffs represent the animals' forelegs.

\section{9}

\section{Corn Kachina and Mudhead Kachina Leroy Kewanyama

$\mathrm{MAI} / \mathrm{HF} 23 / 75 \mathrm{I} 8 \quad$ I8 $\times 24$ in.

These are two popular kachinas which often appear in unsolicited drawings. The Mudhead may make amusing speeches, unlike most kachinas, while the Corn Kachina represents the most important crop of the Hopi. 
90

\section{Corn Kachina Dance at Easter Time Marshall Lomakema $\mathrm{MAI} / \mathrm{HF} 23 / 74 \mathrm{I} 7 \quad \mathrm{I} 8 \times 24 \mathrm{in}$.}

Three variants of the Corn Kachina are shown. In this dance the kachinas are "not the same," that is, each dancer impersonates a slightly different variant. One mask in the picture, for example, is yellow, another blue and brown, another blue with minor differences. All the dancers carried evergreen. At the dance Easter eggs were given out.

\section{1 \\ CORN KACHINA \\ Narron Lomayaktewa \\ $\mathrm{MAI} / \mathrm{HF} 23 / 74 \mathrm{IO} \quad 9 \times \mathrm{II} \frac{1}{2}$ in.}

Lomayaktewa appeared as this Corn Kachina variant at an Easter kachina dance in I965 (cf. \# 90). Although the variants at the dance closely resemble those known for Laguna, these are claimed as truly Hopi. They take their name Yowi'a (plural Yowi'am), from the word which begins their song. At the top of the mask are black and white stripes. The left portion of the divided mask is pink; the right, blue. A yellow lightning element is placed between. Evergreen ruff, pink body paint with white rings, and a Zuni kilt complete the costuming.

\section{2}

\section{Owl and Rattle Kachinas Melvin Nuvayouma $\mathrm{MAI} / \mathrm{HF} 23 / 746 \mathrm{I} \quad \mathrm{I} 8 \times 24 \mathrm{in}$.}

The artist is a member of the Sun Clan and adds the sun to the rain clouds which are found appropriate to masked kachina dancers by Fewkes' artist and many other Pueblo painters.

\section{3}

Gathering Evergreens
Arlo Nuvayouma
MAI/HF $23 / 7475 \quad$ II $\times I 4 \frac{1}{2} \mathrm{in}$.

On the ritual trip to gather evergreen branches for kachina costuming, men smoke and pray for rain. Evergreen is taken from the San Francisco Mountains near Flagstaff, Arizona. At a sacred spring signs of the real kachinas may be seen. Ancient pictographs are sometimes said to be their fingerprints made on the wall of the spring as the spirits emerge. 


\section{4 \\ Cleaning the Ash Pit Arlo Nuvayouma \\ MAI/HF $23 / 7433$ \\ II $\times$ I $4 \frac{1}{2}$ in.}

Part of the mythical journey of the Qöqlöm (Qöqölö Kachinas) is depicted in paintings \# 94 and \# 95. The artist was at first unwilling to paint a portion of the journey: "I'm afraid to paint those Qöqlöm..." and wanted to substitute two men roasting corn. To justify his objections a minor car accident occurred quite close to the time of completion of the paintings.

The kachinas, at their mythical home near Piñon, Arizona, clean out the roasting pit, kö'isi: "They clean it and burn wood, teve (greasewood), and siwafko (sumac; cf. Whiting I950). Build a fire."

To the center is the bottle-shaped pit; the kachinas' corn field is to the upper right. A Qoqle bends over the pit, the other must be imagined to be in the roasting pit.

\section{5}

\section{Kachinas Roasting Sweet Corn Arlo Nuvayouma$$
\mathrm{MAI} / \mathrm{HF} 23 / 7434 \text { II } \times \text { I } 4 \frac{1}{2} \text { in. }
$$

Part of the legendary kachina journey of the Qöqlöm which is re-enacted annually is depicted by Nuvayouma. To the left is the pit. The two kachinas have their bags of corn; one of them has dumped his buckskin bag out on the ground. The birdskins attached to their masks are from birds caught when the heavy rains make it impossible for them to fly; a brown bird, bluebird, and parrot may be seen.

\section{6}

QöQLÖM DANCING with SweEt CORN
Arlo Nuvayouma
MAI/HF $23 / 7440 \quad$ II $\times$ I $4 \frac{1}{2}$ in.

After the two kachinas arrive in the village, they dance, carrying the sweet corn they will give away. They wear their robes of buckskin.

\section{UNMASKED (SOCIAL) DANCES}

(Paintings Nos. 97 through IOO)

97
BufFalo DANCE
Marshall Lomakema
MAI/HF 23/7486 $\quad$ I8 $\times 23$ in.

Unmasked or social dances sometimes resemble related kachina dances. In this example a drummer and two singers provide the music for a clown, a buffalo dancer, and a girl. This is a men's dance. 


\section{8 \\ UNMASKED ELK DANCE \\ Marshall Lomakema \\ $\mathrm{MAI} / \mathrm{HF} 23 / 7430 \quad$ I $8 \times 24$ in.}

The girls closely resemble the participants in the Buffalo Dance, but do not wear a Sun plaque on the back. A single vertical red line on the cheek, wedding belt, black dress, boots and two feathers in the hands are features of their costuming. The man has a kilt, standard body paint, blue gourd horns, chevron over the nose, and a red sash.

\section{9 \\ Laguna Eagle Dance Arlo Nuvayouma $\mathrm{MAI} / \mathrm{HF} 23 / 7353$ II $\times$ I $4 \frac{1}{2}$ in.}

This dance is held as an interlude at the Butterfly Dance, for example, as at Mishongnovi during the summer of I964. "Hopak Kwahu, Eastern Eagle (Dance)," is the Hopi name. It is one of a number of dances which can be performed either commercially or on the reservation. While the first figure is the Laguna Eagle dancer, the second figure, equivalent to the hunter in New Mexican pueblo dances, is said to be either a Comanche commercial dancer introduced by Laguna at Gallup or a "Kiowa singer." Another man points out that all the Pueblo eagle dances are the same type of dance, and are "all for rain." Kwative is eagle dance; kwawunima, "eagle dancer." In one example, the eagle helmet is of cotton over a framework of metal screen with a beak of cottonwood.

\section{0}

\section{ButTERFLy DANCE \\ Marshall Lomakema \\ MAI/HF $23 / 7429$ \\ I8 $\times 24$ in}

The man, Palhiktiyö, "Butterfly Boy," wears a kilt, standard body paint, sash, fox fur in back, flower headdress as worn by the Flute Kachina (nakwa, "flower"), a back tablet, and carries the standard called talava ya, "morning." The girls have headdresses, rain elements on their cheeks, black dresses, white belts, and kilts worn as blouses.

\section{A HOPI LEGEND: THE BOY WHO BECAME AN OWL}

(Paintings Nos. IOI through I05)

\section{1}

\section{The Boy Misbehaves}

\section{Arlo Nuvayouma}

MAI/HF 23/7393 II $\times$ I $4 \frac{1}{2}$ in.

"What do bad Hopi boys do?" "Poking into Father's weaving," is the artist's answer. The boy has a long stick with which he interrupts his father working at a belt loom. The mother prepares to stop him, while the father, unconcerned, weaves on. 


\author{
102 \\ The Mother's WARNING \\ Arlo Nuvayouma \\ MAI/HF 23/7390 \\ II $\times I 4 \frac{1}{2}$ in.
}

The naughty boy is warned by his mother that he must behave or the owl will get him and peck out his eyes. The crying child sits at the threshhold while the owl waits in a tree.

\title{
103
}

\section{GEtTING ON THE OwL's BACK Arlo Nuvayouma}

$\mathrm{MAI} / \mathrm{HF} 23 / 739 \mathrm{I} \quad$ II $\times$ I4 $\frac{1}{2}$ in.

"In the night the owl comes. The boy thinks it might be a godfather or an uncle asking him to go on an errand so he climbs on the owl's back." This scene is mongwö koyvisat ö'öyi, "owl bad boy steals."

\section{4 \\ Changing INTO AN OWL Arlo Nuvayouma $\mathrm{MAI} / \mathrm{HF} 23 / 7392$ I4 $\frac{1}{2} \times$ II in.}

At the owl's cave (mongwöfsö), the boy's parents go to the owl's nest, but it is too late; the owl will not release the boy. Sitting in the nest, he is already changing into an owl. Feathers have begun to grow and the father's request for the return of his son is refused. The mother is crying. The tragic scene is pai mongrö napala, "owl beginning to be." Napala is also used for "to catch a disease." Anniu'iuma is "changing" in the sense of "little boy turning into owl."

\section{5}

The Mourning Parents

Arlo Nuvayouma

$$
\text { MAI/HF 23/7394 II } \times \text { I4 } \frac{1}{2} \text { in. }
$$

The two parents mourn, hands clasped together, eyes down, and seated on sheepskins. Even the fire in the corner fireplace has failed to cheer them. The scene was described as yumat sölmokyota, "both lonesome."

\section{Clowning}

(Paintings Nos. I06 through II7)

No Clown Society exists at Hopi, but the temporary clown leader is nevertheless referred to as the Clown chief and practice takes place in the kiva. Each of these features reflects the former existence of an organized group of clowns. 


\author{
106 \\ Arrival of the Clowns \\ Marshall Lomakema \\ $\mathrm{MAI} / \mathrm{HF} 23 / 7554 \quad$ II $\times$ I $4 \frac{1}{2}$ in.
}

The clowns' usual entrance to a summer kachina performance is by a complicated and humorous descent from a housetop by means of a rope. Three clowns appear in the painting; one is assisted by another as he descends almost vertically.

Lomakema enjoyed the topic of clowning, for no infringement of secrecy was involved.

\title{
107
}

\section{A Mudhead Game Scene Marshall Lomakema $\mathrm{MAI} / \mathrm{HF} 23 / 756 \mathrm{I}$ II $\times$ I $4 \frac{1}{2}$ in.}

A clown sets a sacred water gourd on a basket which he has specially painted (chukovota, "clown basket"). He challenges a woman to knock it off using a bow and arrow. This rain-bringing contest inspires the Hopi title: Nanavö' $i$, "Playing a game."

\section{8}

FeEding A Clown

Narron Lomayakterea

$\mathrm{MAI} / \mathrm{HF} 23 / 73 \mathrm{I} 8 \quad 9 \times \mathrm{I} 2 \mathrm{in}$.

The woman brings piki bread to her nephew, who is taking part in a dance as a ceremonial clown. He places his hand on his forehead in delight and amazement and is about to say: "Kwakwai, kwakwai, Thanks" (male speaker). He wears a necklace of fresh green chile and shorts improvised from blue jeans. Another Hopi viewer corroborates the aunt-nephew relationship, defining the painting as kya'amanakua'i, "his aunt giving him food."

Clowning is chukulalua, "doing something funny." A great deal could be said about it, but a statement endorsed by a Hopi in 1963 seems to express the essential truth behind the clown's significance:

\footnotetext{
"A Hopi clown is a merry maker in a plaza. He is an actor, imitator without restriction of human behavior. He delights in dramatizing the experiences of people, their short successes and tragedies. His special delight is marital troubles in which he ridicules his victims to the extreme.

During his half-a-day life span as a clown he experiences happiness, sorrow, seeks to better or worsen himself and commits sins through blunders as a mortal. At the end he is justly rewarded by being punished and then forgiven and purified by the kachinas."
} 


\author{
Three White Man's Clowns \\ Marshall Lomakema \\ $\mathrm{MAI} / \mathrm{HF} 23 / 755^{2}$ II $\times$ I $4 \frac{1}{2}$ in.
}

This volunteered painting depicts modified circus clowns which may appear at Powamuya or Bean Dance. The orange and green costumes, boots or tennis shoes, and face paint are quite close to their prototypes. Two of the clowns carry canes, while the center figure has a miniature drum.

\title{
110
}

\section{A Women's Chorus of Clowns Marshall Lomakema MAI/HF $23 / 732 I \quad$ I $8 \times 24$ in.}

This depicts the chorus at the women's mock Buffalo Dance (Marau Mosairö). From the hasty costuming of the dancers, done as a sort of competition with the men, the dance takes the name kipokyungyiuma; kipokö is elsewhere the competitive costuming of dancers. Mamzraut nonönga, "Mamzraut coming out," is another expression describing the scene.

A Mexican theme in the women's clowning is quite old, for Stephen identifies an I893 performance as a Mexican Wïw ïchim exhibition (S:934). A performer in the present painting is similarly a Castil Mamzrau wïhti, "Spanish (or Mexican, sometimes Negro) Mamzrau woman." The chorus makes fun of various men in the village: "So-and-so is a dirty man, always peeping in windows," or they sing comic songs such as one which mocks a lover's promises: "What if I buy you White man's shoes, a White man's car, and we sing White man's songs, tra-la-la, tra-la-la..."

\section{1}

\section{Clowns Feeding a White Spectator Marshall Lomakema $\mathrm{MAI} / \mathrm{HF} 23 / 7565$ II $\times$ I $4 \frac{1}{2}$ in.}

$K i$ 'avakvi töchamiya conveys the thought that someone in the audience is invited (by the clowns) to eat in the plaza. A bespectacled White is seen being encouraged to enjoy a reward of piki bread and mutton stew, after he has served as the butt of a number of the clowns' remarks and stunts.

Clowns are usually careful to select people whom they feel will understand the humor and forgive the license. Lomakema would not admit his satire of White physique and costume and said that the man was "just a visitor, anyone." His carefully tucked-in necktie, however, seems a guarantee that he is a caricature of a teacher, government worker or just a tourist. 


\title{
112
}

\author{
Clowns Performing a Bullfight \\ Marshall Lomakema \\ $\mathrm{MAI} / \mathrm{HF} 23 / 7567$ II $\times$ I $4 \frac{1}{2}$ in.
}

Another volunteered example of the infinite number of possible clown skits. The clown bullfighter carries a red cape while the cornhusk horns of the other clown and the conventional staff for forelegs of an animal suffice to identify him as the bull. Chuchkut wakasitao nanaiwa, "clowns cow-at fighting," was the artist's Hopi title for the incident.

\section{3}

\section{A Clown Imitating AN OGRe Woman Marshall Lomakema$$
\mathrm{MAI} / \mathrm{HF} 23 / 7555 \text { II } \times \text { I4 } \frac{1}{2} \text { in. }
$$

An episode in the Söyökö appearance seems to embody the idea that the Ogre Woman is not only a punisher of bad children. Söyökö, wearing a tablita, dances as the partner of a clown, as if she had relented in her role as disciplinarian. The children themselves, however, rarely see the night dances. This volunteered painting is one of many which evidence Lomakema's interest in depicting kachina activities. It is seldom that this type of minor episode appears in Hopi painting, though races and certain other scenes have become accepted subjects. The limitation placed upon kachina representations which merely documented types, however, and the previous acceptance of similar episodes no doubt conditioned the artist's choice.

\section{4}

\section{The Clowns Imitate Kachinas Marshall Lomakema $\mathrm{MAI} / \mathrm{HF} 23 / 7566$ II $\times$ I $4 \frac{1}{2}$ in.}

Söyökö is seen participating in clown play. The kachina carries his spear and a yucca whip. Two clowns mock him-one with a bucket over his head for the mask and a broom "spear." Episodes such as this are followed by eventual punishment of the clowns by the kachinas and are a well-liked portion of the summer dances.

\section{5}

\section{Piftukas or Imitator Clowns Marshall Lomakema $\mathrm{MAI} / \mathrm{HF} 23 / 7553$ II $\times$ I $4 \frac{1}{2}$ in.}

In a dialogue between a clown and two piftukas the clown enacts the role of a Carlisle Indian School coach with "CC" painted on his jersey. To the right another piftuka is dressed as a Carlisle team member. In the skit the team member claimed that he could beat Louis Tewanima, the Olympic winner of I906 (d. I968). But when 
Tewanima actually raced the clown, the aging champion won. The imitators then encouraged Tewanima to display his many racing trophies on the plaza. Aside from honoring the old man's achievement, the high values which the Hopi place upon racing and physical fitness were reasserted.

\author{
116 \\ IMITATOR KACHINA AND Clowns \\ Marshall Lomakema \\ $\mathrm{MAI} / \mathrm{HF} 23 / 7342 \quad \mathrm{I} 8 \times 24 \mathrm{in}$.
}

As three clowns, one carrying a soft drink bottle, approach an Imitator Kachina, one of them holds a flaming bit of cedar bark aloft. The kachina, mocking his victims, is in danger of setting his mask on fire. According to the artist:

“This piftuka, he's just an Imitator, so they're making fun of this Imitator. They said how they were going to get rid of this guy. They're tired of him. They were going to burn his head off, so he did the same thing and sets fire to his bark (headdress). So that's how they got rid of him; he runs."

Another description of the painting was piftuka chuchkutui aopitö, "Imitator comes to the clowns." Mishongnovi clowns are red and yellow; Shongopovi ones are yellow and black. The distinctive body paintings of the two New Mexican Pueblo clown societies, Koshare and Kwirina have thus been adapted by separate villages.

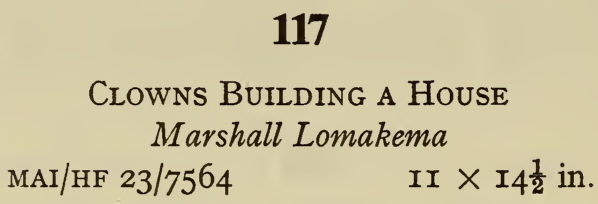

The clowns obtain an evergreen for "their tree" four days before the dance. It is believed that a rain cloud may be seen to hover about the tree during the dance. They build a house, actually outlining it in ashes and living in it "just like camping out." Various episodes then take place. The three clowns have the usual yellow paint and blue jean shorts over which they wear the woven blue loincloth which was their former costume.

\title{
Curing
}

(Paintings Nos. II8 through I44)

Illness and disease can be frightening in a small village. Although everyone knows a few simple cures, the medicine man is believed to have special knowledge of the types of sickness and their cure. The Hopi bone doctor serves as a native chiropractor and has a good practical knowledge of sprains, dislocations and other ailments. The magician, however, has a magical crystal with which he can divine the causes of illness. His powers over animal spirit helpers enable him to cure the victim of witchcraft and quite a few of his techniques have a sound psychological basis. 
Home remedies and medicines which are the property of particular religious societies such as the Snake Society round out the record of Hopi medicine and curing ritual provided by the paintings.

HOME CURE

(Paintings Nos. II8 and II9)

\section{8}

A Man Treating His Wife's Eye Disease

Arlo Nuvayouma
MAI/HF $23 / 7490$

Conjunctivitis is frequent on the Hopi Reservation and cases can become quite serious and difficult to eradicate, thus it is not surprising that native home remedies exist. A man uses a spoon to treat his wife's eyes with a boiled sunflower seed decoction. A more drastic remedy is human urine, with which the eye is washed. Other eye treatments are employed by the Hopi doctor, who will refer a person to the hospital if he suspects trachoma.

\section{9}

\section{Taking Snake Dance Stomach Medicine Arlo Nuvayouma MAI/HF 23/7493 II $\times$ I $4 \frac{1}{2}$ in.}

A boy watches his mother drink the medicine from a bowl while his father sits to the right. The medicine, prepared by members of the Snake Society, is distributed at the close of the snake ritual and most of the village take it as a preventative.

\section{CAUSES OF SERIOUS ILLNESS \\ (Paintings Nos. I20 through I26)}

\section{0}

THE DREADED TÖALÖNG

Marshall Lomakema

$$
\mathrm{MAI} / \mathrm{HF} 23 / 7385 \quad \text { I8 } \times 24 \text { in. }
$$

A feared apparition is shown in this painting. People asleep on the roof are about to see "a man with a bone on his face," the Töalöng, "going to the family to make them sick." The figure wears a pelvis bone as a mask, and his costuming is that of a woman, reminding us of kachina impersonation. Parallels between witch figures and the kachinas occur at other pueblos and certain highly secret Hopi rituals involve dressing in ghostly costumes. It is possible that the Hopi public sees members of an esoteric society, but is convinced that the apparition is a ghost or witch. Witches are: "Mostly in stories... Certain people might be suspected... about two families... People who are seen out at night alone or in unusual places." A witch may also be 
described as a lu'ukönangwat-taka, "two-heart." The sexual aspects of the witchcomplex are reflected in a viewer's remark: "A witch...Töalöng...she might be tümaiya, 'going around for boys in the night.",

\section{1}

\section{Curing an Old Man of the Effects of a Witch Bundle Arlo Nuvayouma \\ MAI/HF $23 / 7548$ \\ II $\times$ I4 $\frac{1}{2}$ in.}

Holding his crystal, the doctor attempts to divine the cause of the old man's illness. The old man is very ill. His wife is on the left and another relative, possibly a cousin, very upset by his illness, is on the right, covering his face because he is unhappy. The magician stands holding his crystal in which he can locate the source of the illness that is bothering the old man. The evil charm or witch bundle inserted in the rafter to the left is some bones wrapped up in an old rag and placed up in the rafter by some person, "maybe a relative," who doesn't like the old man. "The magician will find it, take it down, and throw it outside. The old man will get well. That's the way they do it at the village." The medicine man has just located the bundle; his diagnosis is now complete.

Malevolent relatives or fellow villagers are commonly believed to be the source of Pueblo events interpreted as witchcraft incidents.

\section{2}

\section{Behavior Toward a Suspected Witch Arlo Nuvayouma

$\mathrm{MAI} / \mathrm{HF} 23 / 755^{\circ}$ II $\times$ I $4 \frac{1}{2}$ in.

Avoidance behavior is shown as a young mother looks away from a superficially pleasant woman whom she suspects of being a witch. As in New Mexico, an "Indian broom" may be placed on the cradle to protect the baby. The mother's averted face belies any hospitality she may judiciously offer the potential menace to her child.

THE MEDICINE MAN

(Paintings Nos. I23 through I34)

\section{3}

A Husband Accompanies His Wife Arlo Nuvayouma

MAI/HF $23 / 7539$

II $\times I 4 \frac{1}{2}$ in.

One of the several paintings which show what is in effect a native clinic. Yoinapaliöta, "rheumatism," and kötötöya, "head sickness," have brought the woman to the magician. Her husband waits as the doctor performs his cure. Several members of a family may seek treatment at the same time. 


\title{
124
}

\author{
Using a Crystal and Fetishes to Locate Illness \\ Arlo Nuvayouma \\ MAI/HF $23 / 7453$ \\ II $\times I 4 \frac{1}{2}$ in.
}

The magician or eye-man (positaka) stands to the right and holds his crystal aloft, examining a man, his wife, and their son. Three fetishes facing the patients have been arranged in a rectangular area on the floor. A buckskin bag contains the doctor's plant medicines. Lomakema emphasized the magical powers of the doctor's wristlets and bear-claw necklace (cf. \# I25 and \# I26), but Nuvayouma omits these completely.

\section{5}

\section{The Patient is Seated on an Adobe Platform Marshall Lomakema MAI/HF 23/7360 I8 $\times 24$ in.}

The magician treats a man for internal illness or witchcraft. Strange actions may have formed part of his symptoms, or he may have been affected by any one of a number of distinct syndromes. The doctor holds his crystal. On the floor is a pottery vessel containing water. Beside it are a wing feather asperger used in blessing and two prayer feathers. The patient is seated upon a platform (tüwi) of stone and adobe. These used to be fairly common in old houses, but are seldom seen today. The painting is tötöiyakat taita, "sick person looking at." Another man looked at the painting and explained philosophically: "This fellow has trouble, the one sitting down. $\mathrm{He}$ depends on the medicine man to see to it what is wrong...feel him all over. It works out sometimes; you just have to trust them."

\section{6}

\section{DIAGNOSIS FOR INTERNAL ILLNESS Marshall Lomakema $\mathrm{MAI} / \mathrm{HF} 23 / 7325 \quad \mathrm{I} 8 \times 24$ in.}

The doctor wears only the loincloth and moccasins. His hair is long and he has black bravery marks (yalaha) on his cheeks. Since magical vision is involved, the ceremony may be quite brief.

\footnotetext{
"You don't know what's wrong with you... inside, something. The magician looks at you, what's wrong with you inside. You don't know, don't feel good. You go over there and let him look you over with his crystal. On his wrists he wears the bones and teeth of wild animals like leopard, mountain lion, wild pigs. On his right wrist are the claws of the animals. They make him strong, make him look strong at people, fix them right."
}

The many types of illness recognized and named by the Hopi constitute a special study in themselves and vary considerably from illness types as understood by 
Whites. Among some twenty known to him personally, an informant identified one as tuskafkiöta. In a child this produces what we may define as extreme nervousness, over-reacting, especially to siblings; the child cries continually and will not sleep. In adults or in a serious form, the mind is affected.

A brief portion of a legend relates to the bonesetter specifically, but pertains to the magical skill needed for curing:

\footnotetext{
"A boy wanted to be a medicine man. A bear took him to a cave. He took off his fur and became a man. He came out with fur on and tore the boy's body to pieces (i.e., tore the bones apart). Then he covered the boy's body with a wedding robe and sang and pretty soon something was moving; it was the same boy."
}

It has been suggested that bone doctors are possibly permitted to dissect a bear to observe the joints which are somewhat similar to human joints.

\section{7}

The Medicine Man "Consults his Animals"
Arlo Nuvayouma
MAI/HF 23/7549 $\quad$ II $\times$ I $4 \frac{1}{2}$ in.

Before performing a cure the magician prays to his fetishes which symbolize his control over helpful animal spirits. "They have to watch for the medicine man when he is working on the patient."

\section{8}

\section{A RituAl OFFering Arlo Nuvayouma MAI/HF 23/7492 II $\times I 4 \frac{1}{2}$ in.}

The medicine man is gathering a plant whose root is chewed to cure diarrhea. Equipped with his cornmeal bag, the doctor digs down into the earth with his hands and places a bit of cornmeal into the ground as a prayer. Without the prayer it is believed that the plant would magically disappear as he leaves the area. A man from the village is said to have gathered a number of the plants for sale. Not believing in prayer, he left. When he had reached his home, every plant had disappeared!

\section{9}

\section{The Doctor Treats a Sick Baby Arlo Nuvayouma $\mathrm{MAI} / \mathrm{HF} 23 / 7556$ II $\times$ I $4 \frac{1}{2}$ in.}

A small child or baby may be given clay as a treatment for diarrhea. Although this natural equivalent of Kaopectate might be prescribed by a medicine man, it could also be administered as a home remedy. 


\title{
130
}

\author{
SHOCK TREATMENT For Mental Illness \\ Arlo Nuvayouma \\ MAI/HF $23 / 7543$ \\ II $\times$ I $4 \frac{1}{2}$ in.
}

The value of shock is recognized by the Hopi magician. "If someone is nervous and scared of something then these men have to scare him so he can get over his nervousness." A woman has been afraid of witches and is waiting for treatment. The medicine man, standing behind her, will make a noise to scare her. Chawintötöya is "scaring a sick person." Tuskyaftötöya, "crazy sick person," is the closest equivalent to a term for a mentally ill patient. There is a clear distinction made between mild disturbance and insanity.

\section{1}

\section{The Doctor Offers Sacred Cornmeal to his Patient Leroy Kewanyama MAI/HF $23 / 7508$ II $\times I 4 \frac{1}{2}$ in.}

Although scattered illustrations of curing had been obtained early in the series, explicit concentration upon curing took place only after two hundred paintings had been completed. Thus Kewanyama was asked for "a medicine man" and given several other suggestions for subjects. Here, the magician has his crystal, buckskin bag, and fetish. He offers his female patient cornmeal. Both are in traditional clothing. The term povoska links directly with the Pobosh-wimkya or extinct Eye Priesthood, the difference being dialectic. The more usual term for the doctor, however, is simply tihikya, or the term ifwantihikya, which refers to his powers as a sucking shaman.

When any of the artists' children became ill they tended to feel that the curing paintings might have been responsible. The two who had young children each expressed misgivings about particular curing scenes.

\section{2}

\section{Ants ARE Removed by Sleight-Of-Hand Marshall Lomakema MAI/HF 23/7525 $18 \times 23$ in.}

Based upon a cure which took place $c a$. I950, the scene embodies the Pueblo belief that boils may be caused by ants. Lomakema commented, "The doctor takes out something, that's what I don't believe," and explained: "One time . . . . .'s breasts had a boil (pönö). The magician came over and said, "There's ants in there, the black ants (tökö 'ant), so I'm going to take them out!'” Gathering the ants together the doctor warned the patient, "You'd better see it yourself. Give me your silakvö (cornhusk); I'm going to put them there. There are five ants. They're alive." And the artist adds. "That's when I believed it." 
The boil is indeed shaped like an anthill. The Hopi term for such a boil occurs in the title for the painting: Sökyachi ep ankiöta, "Shoulder there ant house." The ants have been deliberately given exaggerated size for emphasis. In chopping wood a Hopi will not disturb a log on which there are ants, since it may be their home and they may retaliate by causing swellings, irritations, or boils.

\section{3}

\section{A Woman Doctor Treating Cloud Eye (Keratitis) Marshall Lomakema MAI/HF 23/7526 I8 $\times 23$ in.}

One of several eye ailments depicted in the curing sub-series is treated by a woman doctor. Cloud eye (ömaöposki), is said to be caused by "looking at clouds too long." It may be one of serveral eye ailments which are caused by the kachinas, since they are associated with clouds. As Lomakema comments: "You look at the cloud... your eyes hurt just like you have trachoma. Something went into your eyes. You may look at clouds, but not too long." The eye is red, badly inflamed. Two doctors who looked at the painting felt that conjunctivitis and keratitis were involved. One pointed out that a similar belief obtains in his native Peru where clouds are considered to be a source of eye ailments.

Both women are in traditional dress and kneel on sheepskins. Hospital treatment has made trachoma known, but the less serious pink-eye is often ignored.

\section{4}

Treatment OF A SkIn UlCER
Marshall Lomakema
MAI/HF $23 / 7524 \quad$ I $8 \times 23$ in.

A skin ailment identified as single-center ulcers is treated with Lacapa, or mistletoe. The doctor kneels, having mixed the decoction with water. As usual the patient kneels on a sheepskin.

\section{THE BONE DOCTOR}

(Paintings Nos. I35 through I42)

\section{5}

\section{A Bone Doctor Treats a Dislocated Neck Arlo Nuvayouma \\ MAI/HF 237547 \\ II $\times$ I $4 \frac{1}{2}$ in.}

A topic elicited from two artists, the doctor is shown grasping a seated male patient by the crown of his head, bracing him by holding onto the shoulders. The patient's wife holds his knee to reassure him. The neck has been the source of pain in the back according to Nuvayouma's version of the hypothetical problem. 


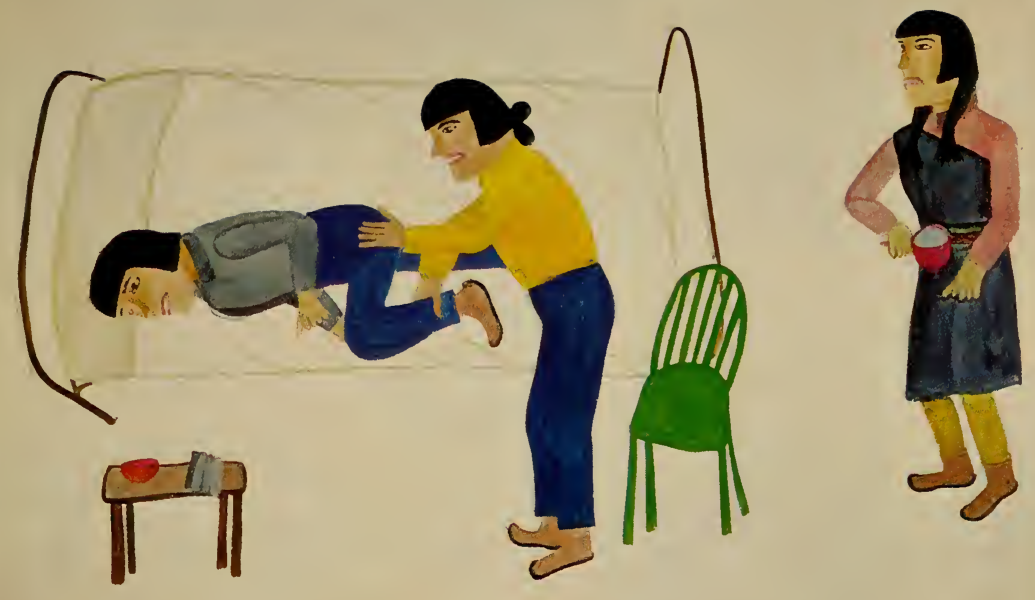

Treatment for a Dislocated Hip (\# I 39) 



\title{
136
}

\author{
A Bone Doctor Treats a Dislocated Neck \\ Marshall Lomakema \\ MAI/HF $23 / 7529$ \\ I8 $\times 23$ in.
}

The bone doctor manipulates a dislocated neck (kwafi' $i$ 'ama, "the neck is out"). The patient is seated and braces himself by holding his left knee. The doctor grasps the patient's jaw, preparing to readjust the neck. A simple dislocation may be the complaint but sometimes fever is present. The patient had fallen from his horse or burro.

137

Treatment of Muscle Spasm or Rib Dislocation
Arlo Nuvayouma

MAI/HF 23/754I II $\times$ I $4 \frac{1}{2}$ in.

One of several pairs of paintings by Lomakema and Nuvayouma assigned as a check on accuracy. Neither artist knew the other had been assigned the identical scene.

\section{8}

Treatment of Muscle Spasms or Dislocation of Ribs Marshall Lomakema

MAI/HF 23/7527 I8 $\times 23$ in.

The bone doctor stands behind the man and manipulates his ribs which are out of alignment (chöngyamakiöta, "the ribs are out"). Both men wear their hair long.

\section{9}

\section{Treatment For a Dislocated Hip Marshall Lomakema $\mathrm{MAI} / \mathrm{HF} 23 / 7530 \quad \mathrm{I} 8 \times 23$ in.}

The bone doctor treats a dislocated hip by having the patient lie in bed for manipulation. The painting describes an actual experience of the artist. In his account, we have a shortened version of what is probably a typical doctor-patient dialogue:

\footnotetext{
"I go over to the bone doctor and I ask, 'Is the bone doctor here? (Ukatihikya ka yepe)' and explain that one of our family is sick (um itaki'aoni itam tötöya). 'You go over to our house, one of us is sick. Come over, look at him, see how he is'. He says, 'Very well, I'll go (ta painö' aoni).' He never refuses-pam pai ka hisat hin nawakna. Then the bone doctor treats the hip. He bends the knee almost double as the patient lies on the bed and afterward may explain, ' $O$ piala kös'a yamakiöta, Your hips were out of joint,' adding 'Pai sonka kwangwahintini, You'll probably be all right.'”
}

The doctor is seen bending the leg "almost double." The patient, who has not been able to get about after his hunting accident, is brought water by his wife. Pialtötöya is "hip illness;" pialmakiöta is "dislocation of hips." The doctor's technique conforms pretty closely to White practice. 


\title{
140
}

\author{
A Husband Assists the Bone Doctor \\ Arlo Nuvayouma \\ MAI/HF 23/7544 \\ II $\times I 4 \frac{1}{2}$ in.
}

A woman patient, seated with her legs outstretched, clasps her husband's knee for support. The doctor kneels and extends the affected limb. Tihikya hokyahikput maiyanta, "doctor fixing broken leg," was admitted by the artist to be something of a Hopi tongue-twister. Hokya'at köhi is "leg broken." Coöperation of the patient's relatives is quite frequent in the paintings.

\section{1}

\section{A Child's Arm is Treated Marshall Lomakema $\mathrm{MAI} / \mathrm{HF} 23 / 7528 \quad \mathrm{I} 8 \times 23 \mathrm{in}$.}

The bone doctor manipulates the little boy's arm which he has fallen on or injured in play. The child's mother holds him securely as the doctor takes hold of the arm to check its articulation and to manipulate it if the joint still is not aligned properly.

\section{2}

The Doctor Locates a Pain in the Patient's Back

$$
\text { MAI/HF 23/7449 Arlo Nuvayouma } \quad \text { II } \times \text { I } 4 \frac{1}{2} \text { in. }
$$

The bone doctor essays a group cure: tihikya pömöi maiyanta, "doctor fixes them," or "they are trying to fix the whole family." The details cast light upon Hopi curing, indeed clinical, procedure:

"First thing, they try to get on this boy. He's got a bad trouble, a broken back; his muscles are out of place, so he's trying to fix it. So the medicine man touches his back and tries to put his hand on the source of the pain. The man yells... This is his medicine kit (ngamoki).

This lady is waiting to be the next one. Her pregnancy...maybe she lifted heavy things....she isn't feeling good."

In the medicine kit are "a lot of things," especially plant medicines.

PAYMENT OF FEES

(Paintings Nos. I43 through I44)

\section{3}

\section{Paying a Medicine Man's Retainer Arlo Nuvayouma$$
\text { MAI/HF } 23 / 7466 \text { II } \times \text { I } 4 \frac{1}{2} \text { in. }
$$

A patient or the head of the household makes an offering of cornmeal to request the medicine man's service. 


\section{4}

\section{A Final Payment to the Doctor Arlo Nuvayouma \\ $\mathrm{MAI} / \mathrm{HF} 23 / 7467$ II $\times$ I $4 \frac{1}{2}$ in.}

Payment to the medicine man is initiated by giving blue cornmeal. The wife has also prepared bread and rolls of piki bread. She wears a yellow dress, her hair in the usual braids of a Hopi matron. The offering is voluntary, "up to the patient."

\section{Economic Life}

(Paintings Nos. I45 through I85)

As the Series of paintings developed, the economic context of Hopi ritual life was illustrated. Most of these paintings do not reflect the ceremonies, but they record a way of life which has inevitably been changing. Corn, gourds, squash, deer and rabbit are no longer as important in Hopi life as cash economy, credit, and employment. The significance of the agricultural and hunting base, however, must not be underestimated even today. Many older people survive largely upon it with partial aid in many cases from the government through one or another program of assistance.

In the illustrations of economic life the contributions of the Spanish missionaries may also be seen: sheep and peaches. The Hopi economy thus has a basis which is tri-cultural in origin but has become thoroughly Hopi.

As a background for Hopi ritual, economics is essential; for the Hopi pass easily from economic activity to ritual-the two are in fact so intertwined that many students of economic practice in the Pueblos have found themselves instantly engaged in studies of ceremonies, ritual exchanges, and related beliefs.

\section{CROPS}

(Paintings Nos. I45 through I6I)

\section{5}

LOAdING THE PEACHES
Arlo Nuvayouma
MAI/HF 23/74I4 $\quad$ II $\times$ I $4 \frac{1}{2}$ in.

A burro with a balanced load of two peach boxes takes the peaches to the sipalki, or "peach house," a small building used for storage. The man uses a tumpline (the strap is ngata), and carries peaches in a ho' $a p u$ or burden basket. He carries a staff and wears the split homemade "Indian pants." Peaches were introduced by the Spanish and there are far fewer ritual practices connected with them than with the more important aboriginal crops, especially corn. 


\title{
146 \\ Getting Peaches \\ Arlo Nuvayouma \\ MAI/HF 23/7465 \\ II $\times I 4 \frac{1}{2}$ in.
}

Two men are walking. One carries a five-gallon tin covered by a cloth; the other has a $h o^{\prime} a p u$ or burden basket. A peach tree stands to the right.

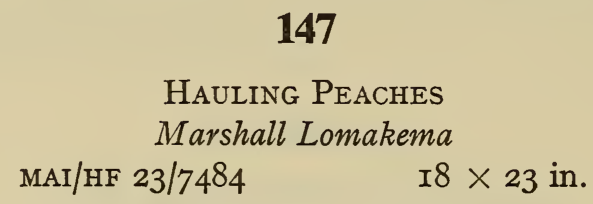

A man with a can and also the traditional ho'apu (burden basket) is followed by a boy with a staff.

\section{8}

\author{
DRYING PEACHES \\ Arlo Nuvayouma \\ $\mathrm{MAI} / \mathrm{HF} 23 / 74 \mathrm{I} 3 \quad$ II $\times$ I4 $\frac{1}{2}$ in.
}

A man and his wife are spreading out peaches for drying before they are stored. The man wears farm clothes; the woman has braids and the black Pueblo dress. The peaches have been carried in yucca sifting baskets.

\section{9}

\author{
HARVESTING BEANS \\ Arlo Nuvayouma \\ $\mathrm{MAI} / \mathrm{HF} 23 / 747 \mathrm{I}$ II $\times$ I4 $\frac{1}{2}$ in.
}

A man beats pinto bean plants in the field and a woman winnows the chaff, blowing on the beans if there is no breeze. She wears a red homespun dress, while the man has a tan shirt and white trousers.

\section{0}

\section{A Farmer Gathering Gourds Arlo Nuvayouma$$
\mathrm{MAI} / \mathrm{HF} 23 / 7447 \text { II } \times \text { I4 } \frac{1}{2} \text { in. }
$$

Gourds are allowed to grow in the fields, the naturally occurring Lagenaria and Cucurbita being suitable for rattles, mask parts, and for other uses. They do not necessarily require watering. In the painting a man with a wicker basket with a tumpline is aided by a boy in gathering the gourds. The two wear only their loincloths and moccasins. 


\title{
151
}

\author{
GATHERING GOURDS \\ Arlo Nuvayouma \\ MAI/HF 23/7459 \\ II $\times I 4 \frac{1}{2}$ in.
}

Gourds are taken to the "gourd house," a lean-to or kisi for drying. Gourds are seen piled on both sides of the structure. A jug and digging stick are inside; a hoe is on the roof. The immaculate farmer wears white pants and carries the gourds in a cloth bag. He is probably engaged in a ceremonial errand.

\section{2}

GATHERING MElons for YahaHA Marshall Lomakema

$\mathrm{MAI} / \mathrm{HF} 23 / 7488 \quad$ I8 $\times 23$ in.

Yahaha (depicted in \# 2I), is a game in which women attempt to pry articles away from the men. Reminded of the game at the time of the I965 Snake Dance, the artist depicted a farmer selecting melons from his crop to be used in the play.

\section{3}

\section{Planting the Fields \\ Melvin Nuvayouma \\ $\mathrm{MAI} / \mathrm{HF} 23 / 7462$ \\ II $\times I 4 \frac{1}{2}$ in.}

Two men work in one of the desert-like Hopi fields. Using a digging stick or dibble the first man makes a hole in which to plant the corn kernels while the second follows with a hoe. A lean-to (kisi) is in the background.

\section{4}

\section{SPRINKLING THE FIELDS} Marshall Lomakema
MAI/HF 23/7404
I $8 \times 24$ in.

A man in farm clothing uses a plant to sprinkle a mixture of water and manure over the young corn plants; two boys assist in the work. Dog manure is sometimes saved for this purpose. Rats and rabbits do not like the smell and tend to stay away from the plants, so each plant must be carefully sprinkled. Stephen $(\mathrm{S}: 707)$ translates makwanta as "asperger," corroborating the general meaning of the word, here applied to the sprinkling of crops.

\section{5 \\ WOMEN STORING CORN Arlo Nuvayouma MAI/HF 23/7454 II $\times$ I $4 \frac{1}{2}$ in.}

Women arrange a harvest of blue corn in the family storeroom (kaniki). To the right, a woman in a red dress brings ears in yucca sifting baskets while an older woman places them neatly in long rows. Melons may be seen piled in another corner of the room. Corn is life to the Hopi and is regarded as being alive. 


\section{6 \\ SHELLING CORN \\ Melvin Nuvayouma \\ $\mathrm{MAI} / \mathrm{HF} 23 / 7457$ II $\times$ I $4 \frac{1}{2}$ in.}

A woman rubs two corn ears together to remove the kernels as another brings a yucca basket full of ears. The seated woman has a green dress; the standing one wears bright red. This was Melvin Nuvayouma's first painting.

\section{7 \\ DRYING CORN KERNELS \\ Marshall Lomakema \\ MAI/HF 23/7428 I8 $\times 24$ in.}

Before grinding, corn kernels must be washed to eliminate contamination by rat urine during storage. A grey-haired woman in a print dress with a woven belt spreads the kernels out to dry after washing. A small boy pours water from a ladle.

\section{8}

PARChING CorN
Arlo Nuvayouma
MAI/HF $23 / 7435 \quad$ II $\times$ I $4 \frac{1}{2}$ in.

Two women parch corn, working out-of-doors; each wears the black dress and is barefooted. The seated woman uses a bundle of stirring sticks to stir the corn which is roasting in a utility jar. A simple star fire and an arrangement of squared stones serves as the fireplace, with a storehouse shown to the rear. The second woman carries a yucca sifting basket containing ears of corn. Corn is parched on occasion as a special treat at Indian fairs.

159

An Old Lady Grinding Corn ANd Singing
Arlo Nuvayouma
MAI/HF $23 / 7496 \quad$ II $\times$ I $4 \frac{1}{2}$ in.

Older people preserve many of the customs of their generation. This elderly woman rises early to set an example and also to be useful to her family. Perhaps an equally early rising child will learn her song. Wühti ngömanta is "woman grinding corn;" wühti talavai its taomömöikyang ngömanta is "woman is singing in early morning grinding corn." Matasiwu is the stone box for the metates (mata); mataki is the mano, while the brush for cleaning it is the mataosi. Matavuma, "house around mata" is another term for the box arrangement. The woman kneels; on the wall is corn and a string of chili, perhaps traded from New Mexican Indian visitors. 


\author{
160 \\ Women Grinding CoRn \\ Arlo Nuvayouma \\ MAI/HF 23/7495 II $\times$ I4 $\frac{1}{2}$ in.
}

Three woman grind at the mealing bins placed in series. Matavyönga is the stone used as a crusher to crack the corn. Pinampta and honampta indicate stones with varying degrees of fineness in crushing capacity. Different informants apply these terms specifically to the mano or the metate. The mano is mataki, which being "house for mata" is perhaps correctly the term for metate, but the informant is insistent.

\title{
161
}

\author{
MAKing PikAMi \\ Arlo Nuvayouma \\ MAI/HF 23/7494 \\ II $\times$ I $4 \frac{1}{2}$ in.
}

Two women kneel and stir the cooking pikami or corn mush with a bundle of stirring sticks. A fire has been started in the kuitski or smokehouse, a hooded fireplace. The women wear orange and green dresses.

\section{MAKING A PIKI STONE}

(Paintings Nos. I62 through I66)

\section{2}

\author{
Getting the Piki Stone \\ Arlo Nuvayouma \\ MAI/HF 23/7443 II $\times$ I $4 \frac{1}{2}$ in.
}

The piki stone making sub-series documents the four-fold process of preparing this native griddle. Locating and mining the stone, smoothing the stone, preparing the surface, and testing the surface comprise the steps depicted.

Tüma'oa, "clay stone," is used for the stone. It is said to be harder than sandstone and is obtained two or three miles to the west of the village. A man has already located a suitable stone: "He took one right here already and they try to make it even and chop it off with a metal tool... oavikyangwö, 'stone hatchet."' The pick or chökövikyangwö may also be used; vikyangwö serves to describe the mattock, familiar from fire-fighting activities. The man, wearing green pants and a blue shirt, checks the stone for squareness. His pick is upper center, his hatchet to the right. A netcovered gourd serves as his canteen. 


\title{
163 \\ Smoothing the Piki Stone Arlo Nuvayouma MAI/HF 23/7444 II $\times I 4 \frac{1}{2}$ in.
}

The stone is smoothed with cobbles and rubbed for a final smoothing.

"After he brought it home, they start smoothing it using talvitapi, little pieces of stone like small gravel. When it's rough it sticks to it."

Two women smooth the rock using flat-ended cobbles. Both wear braids, as this is a typical task of married women.

\section{4}

\section{Putting Pitch on the Stone Arlo Nuvayouma \\ $\mathrm{MAI} / \mathrm{HF} 23 / 7445$ II $\times$ I $4 \frac{1}{2}$ in.}

This is part of the process of firing the piki stone. The stone is covered with pitch from tuve'e (piñon pine); the pitch is tuve'esana (or simply sana) and placed over the fire: "She puts that (pitch) on a little stick and burns it and then burns it on every place on the stone... all over. Then she starts a cedar wood fire." To the lower left she has a dish of sana. Above the cooking area is the vent or kuitski, a "shed for the smoke." Anyone may prepare a stone:

"You can ask anybody that knows how to cook that right. She has to start early... at sunrise. She has to finish that in one day or the next day it might crack (if the cooling is allowed to become irregular)."

Further restrictions seem partly ceremonial:

"She has to be alone. No one can make a noise or it might crack. You use piñón wood for the fire...real hot, so she has to be alone. When that stone is still white they put it on top of the fireplace. Then the woman puts on the black pitch. Then it burns, is black."

The piki stone in place on top of two vertically placed stones is kotmangrö; the analogy to a shrine-house or bahoki does not escape the native onlooker. A woman in a yellow dress holds the short stick which is used to apply the pitch to the stone. Chili and corn are on the wall as the artist felt that the wall looked bare.

\section{5}

\author{
Testing The Stone \\ Arlo Nuvayouma \\ $\mathrm{MAI} / \mathrm{HF} 23 / 7446$ II $\times$ I4 $\frac{1}{2}$ in.
}

Tumhenta literally implies painting or actually dyeing the stone, since white and finally blue cornmeal are used to make sure that the surface is fast and non-fugitive. Burro grease is used to rub the pitch-blackened stone. The woman checks to be sure 
that the surface material has adhered and will not come off. After the stone tests clean, the first blue cornmeal is used on the stone. Such a surface has been observed to endure a year's exposure to the weather successfully. Old piki stones are sometimes used as part of house foundations, and may be reclaimed if needed.

\author{
166 \\ Women Making Piki \\ Melvin Nuvayouma \\ $\mathrm{MAI} / \mathrm{HF} 23 / 7464$ II $\times$ I $4 \frac{1}{2}$ in.
}

Using the piki stone set in place and sakwafngomni, "blue flour," two women make rolls of piki bread. The dough is spread by hand on the hot stone griddle and although it is a mark of skill never to burn one's hands, even an expert's hands become reddened by the heat of the stone.

\title{
HUNTING
}

(Paintings Nos. I67 through I73)

167

Hunting RabBITs
Melvin Nuvayouma
MAI/HF $23 / 7440 \quad$ II $\times I 4 \frac{1}{2} \mathrm{in}$.

Two boys prepare to kill rabbits using their rabbit sticks.

\section{8}

\author{
RABBIT HUNT \\ Leroy Kewanyama \\ $\mathrm{MAI} / \mathrm{HF} 23 / 7505$ II $\times$ I $4 \frac{1}{2}$ in.
}

Typical of several rabbit hunt scenes in the series, this one by Kewanyama depicts the use of both the flat and cylindrical rabbit sticks.

\author{
169 \\ "TOGETHER HuNT" \\ Leroy Kewanyama \\ $\mathrm{MAI} / \mathrm{HF} 23 / 7506$ II $\times$ I4 $\frac{1}{2}$ in.
}

Kewanyama's version of a girl's gift in return for a rabbit. The boy wears white trousers, the girl a black dress and buckskin boots. Hunts on which boys and girls go together are common Pueblo practice. 


\section{0}

\section{FEeding the Hunter's FAmily Marshall Lomakema $\mathrm{MAI} / \mathrm{HF} 23 / 74 \mathrm{I} 6 \quad \mathrm{I} 8 \times 24 \mathrm{in}$.}

A woman gives bread to the hunter's mother or aunt. Another woman follows her with sömiviki. The woman in the doorway wears her Indian boots but a store dress; the visiting women are dressed in mantas.

\section{1}

\section{Offering Corn Pollen to the Slain Deer Marshall Lomakema MAI/HF $23 / 7386$ I8 $\times 24$ in.}

A man has killed a deer. From his cornmeal bag he takes pollen (talasi), "putting the talasi on his mouth, feeding the deer." The hunter's gun lies near him. Hopi practice stipulates the offering of six prayer feathers: for the Sun, Moon, Somaikoli, Spider Woman, the deer's own spirit, and for one other special purpose. Hunters may offer the prayer feathers at night: "We sit down at night around the fire and smoke. Around one o'clock two men take them out someplace and stick them there." The scene is Maktaka ninaka nonovna, "Hunter deer killed feeds." As custom changes not all Pueblo men know the traditional practices of the deer hunt; the less stringent offerings and customs of the rabbit hunt are far more commonly known.

\section{2}

Dressing the Slain Deer in Ceremonial Garments
Arlo Nuvayouma
MAI/HF 23/7396

Nuvayouma depicts the widespread Pueblo custom of decorating the slain deer (cf. Parsons I962:263). The male deer wears a kilt; a female must have a manta. A corn ear as used in naming, a tobacco bag and pipe for ritual smoking are laid near the deer's head. The stick next to the pipe is the reamer for cleaning it. Basic to Pueblo belief is the hope that the same deer returns many times to a hunter, each time grown larger. For this reason, the joints were customarily not severed (cf. \# I7I).

\section{3}

\section{TRAPPING BIRDS}

Arlo Nuvayouma

$$
\mathrm{MAI} / \mathrm{HF} 23 / 7478 \text { II } \times \text { I4 } \frac{1}{2} \text { in. }
$$

A boy in a storeroom uses a log with horsehair loops to trap a hukchiro or "windbird," from a group of five. Wivoshöhöwa is "trapping." Mousetraps baited with cracked corn are sometimes used with a string as a trigger. The traditional Hopi bluebird snare is honored in a kachina name (cf. Colton I949:66). 


\title{
BASKET MAKING
}

(Paintings Nos. I74 through I78)

\section{4}

\author{
GATHERING YUCCA \\ Arlo Nuvayouma \\ $\mathrm{MAI} / \mathrm{HF} 23 / 7372$ II $\times$ I $4 \frac{1}{2}$ in.
}

In August, after the Snake Ceremony is over, a man and his wife go to gather yucca. Yucca gathered in winter is suitable only for a natural yellow color, but for most other colors the yucca must have been saved from the previous August. Baskets are made for native use, but also to sell:

"To make the baskets and sell them to get a living, to get groceries.... That's why we have to prepare it for the winter, so we won't have hard times in winter."

If no yucca has been gathered, household supplies such as sugar may have to be traded to a neighbor who has remembered to go out for yucca. Women value their prepared yucca quite highly. Another statement differs only slightly:

"Every year it matures fresh in the middle of the leaf. We pick it in July. I used to take my relatives out and we'd have to reach down and pick the fresh leaves out... to turn them yellow we'd leave them back there and the next year pick them up."

Momoklalwa is going after yucca (mohö); mohefnuma, "looking for yucca;" molawö (molalwa) is said to imply picking it up, but momokwisa was translated as "gathering the yucca." Motinuma was given as "getting the yucca." A mural by Fred Kabotie at Grand Canyon, painted ca. I950, shows a man and wife gathering yucca, using a burro; at least one viewer claimed that this was the source of the present painting.

\section{5}

\author{
SPLITTING THE YUCCA \\ Arlo Nuvayouma \\ $\mathrm{MAI} / \mathrm{HF} 23 / 7373$ II $\times$ I $4 \frac{1}{2}$ in.
}

"Just any lady, neighbors or relatives, when they hear that she went to get yucca, the next day they come over to split it. Then after they get through, she gives a little bunch of yucca to the helpers. They have dinner at the house."

This, then, is the "basket work party" at which a good deal of gossip (kokoliyauya) takes place. Women use sheep or deer bone awls rarely (ökamotsi or in contracted form $\ddot{o k a m c h i}$ ), but the usual motsi or awl is an ice-pick. Most of those who saw this painting confirmed the description of the scene as mochikyanta, but pöchiminta is also splitting; mokapuminta is "splitting fresh yucca," and mohötchikyanta, "splitting white yucca." Pafsilare is "taking the 'hair' off the yucca." Two women kneel, splitting the yucca. 


\section{6 \\ DrYing YUCCA StRIPS \\ Arlo Nuvayouma \\ $\mathrm{MAI} / \mathrm{HF} 23 / 7374$ II $\times$ I4 $\frac{1}{2}$ in.}

"After they split it, they spread it out to bleach it. After two days when it has rained on it, then it gets white." This process is mohutmuiyanta, "drying yucca out." A woman in traditional dress lays the yucca out neatly for the drying and change in color.

\section{7 \\ DYEING \\ Arlo Nuvayouma \\ $\mathrm{MAI} / \mathrm{HF} 23 / 7375$ II $\times$ I4 $\frac{1}{2}$ in.}

The publication Hopi Dyes (Colton 1965) supplies detailed information on the preparation of Hopi dyes. In this case palatufhenta, "dyeing red," is shown:

"She had hot charcoal. She puts (raw) wool in it to make it smoke. On a fire she boils water in a pot. Then she grinds her vegetable dye (in this case red or sita, cf. Whiting 1950:98). Then when the water boils she puts it in there with a piece of siönga (alkali). Then it boils. Then she starts dipping the yucca. She puts it on a sifter basket over the smoking charcoal."

The same informant clarifies her description:

"First she puts it on the stove. When it's boiling she puts sita in it and then she puts that siönga in. Then when it's really cooked she starts dipping the yucca in it. Then it's yellow. She puts that charcoal in that pan and she builds a fire under it. Then she puts the yucca on the sifter with greasy wool to make it smoke. It turns red after it's over the smoke two or three times."

\section{8}

MAKING A BASKET

Arlo Nuvayouma

$$
\mathrm{MAI} / \mathrm{HF} 23 / 7376 \quad \text { II } \times \mathrm{I}_{4} \frac{1}{2} \text { in. }
$$

A mother teaches her daughter to weave coiled plaques (cf. \# I8). The daughter (left) holds up her effort. Emerging from the coils is the söhö or wild grass which serves as the bundle. Placed in damp sand to keep them flexible, the black, white, red and natural green yucca strips await use. The little girl has a squash-blossom hair arrangement while the mother wears braids. Botananatöna, "basket learning," was proposed as a short description of this painting by several viewers. Botayahinta is "starting a basket." Tiny pieces of very finely split yucca are used at the very beginning; momochikva describes this fine splitting.

Women describe their progress in terms of rounds or koniki as in the statement Noq pu lu'uk anka koyni, "And I two rounds (put today)." Addition to the bundle is simply amtane, "adding it up;" the word söhö implies the bundle as well as being the name of the wild grass used for it. Women are so proficient at the art that an insufficient bundle is unthinkable, but even so, avoiding a noun, they would say siyaoma, "it's getting small." 
OTHER ECONOMIC ACTIVITIES

(Paintings Nos. I79 through I85)

179

\author{
GetTing Wood \\ Arlo Nuvayouma \\ $\mathrm{MAI} / \mathrm{HF} 23 / 7427$ II $\times$ I $4 \frac{1}{2}$ in.
}

A man brings wood using a burro and an improvised pack saddle also known in northern Mexico (komokhaiye, "wood tied"). The saddle has center and back cinches. The man carries a staff, wears a pink shirt and green "Indian pants."

\title{
180
}

\author{
STACKING THE WoOD \\ Arlo Nuvayouma \\ $\mathrm{MAI} / \mathrm{HF} 23 / 7342$ II $\times$ I $4 \frac{1}{2}$ in.
}

After the men bring wood to the village, the women must stack the small pieces neatly. Longer pieces are stacked by the men in vertical "star" piles, ready for chopping. A woman in traditional dress stacks the short pieces outside her house. Wood is sometimes put on the roof of the house.

\section{1}

\section{Payment to the Kiva}

Marshall Lomakema

\section{$\mathrm{MAI} / \mathrm{HF} 23 / 737 \mathrm{I} \quad \mathrm{I} 8 \times 24 \mathrm{in}$.}

Contribution of wood to the kiva supply is a special obligation of kiva members at Wüwrïchim, Soyalöng, and Powamü'a:

"The members of each kiva have to pitch in this wood so the next spring the sun gets hot early so the crops grow quick. Every one of them has to pay to the kiva."

From this custom the painting takes its name, Kivami sisviö, "Pay to the kiva." Other descriptions obtained were, Powamuiva kivami sisvito, "during Powamu season to the kiva going to pay;" sisviwisa; and ima sisvito, "the two are paying." The ceremonial implications of heat in the kiva were confirmed by another statement: "Taking the wood over there, they earn the heat for the coming spring for their fields." Whiting mentions greasewood as the chief of four ritual kiva fuels which he cites (I950:38).

On the left a man piles wood and on the right another man carries his load of wood using a tumpline and cane. 


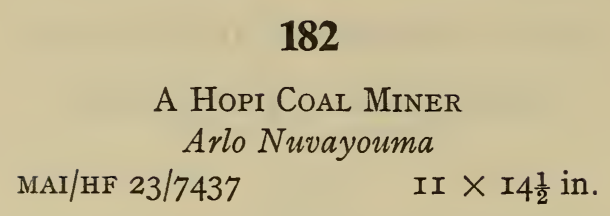

The deposits at Coal Canyon supply a fairly effective but smoky means of heating houses during the winter nights. In the painting the coal miner has adapted clothing suitable to his temporary occupation: bib coveralls, work shoes, and even a miner's cap. He employs a pick to break pieces of the coal out of the beds. He has brought a five gallon can along as well as a bag for the fuel. Mattocks are sometimes used as tools; the true pick bears a name, chöchövikyangrö, which refers to its similarity in shape to the horns worn by clowns on their headdress. Although there is a Coal Kachina (Colton I95I:73), little ceremonialism appears now to be connected with the mining of coal, but older men may offer prayer feathers "to the coal."

\section{3}

TRADE with the Navajo

Arlo Nuvayouma

$\mathrm{MAI} / \mathrm{HF} 23 / 7476 \quad$ II $\times$ I $4 \frac{1}{2}$ in.

The Navajo want melons, piki bread, and other Hopi specialties and staples, while the Hopi like Navajo rugs, mutton, piñón nuts, and certain herbs. Here a melon is being bartered for lamb.

\section{4 \\ Women Making Pottery Bowls \\ Arlo Nuvayouma \\ MAI/HF $23 / 7558$ \\ II $\times I 4 \frac{1}{2}$ in.}

Although pottery is not made at Shongopovi today, it was until about I9oo. As at other pueblos, women worked together with girls helping. Data were obtained from a woman who had helped her grandmother as a girl, but the artist depicts pottery making as it is done at Polacca, Arizona. A variety of vessels are shown: a bowl, kiva bowl, and wedding vase.

\section{5 \\ SHEEP SHEARING \\ Melvin Nuvayouma \\ $\mathrm{MAI} / \mathrm{HF} 23 / 7483$ II $\times$ I $4 \frac{1}{2}$ in.}

Wool for weaving or exchange is obtained by two men. Many Hopi families have sheep and the former location of the village below the mesa contains several ruins used as sheep corrals or camps. 


\section{Reinterview}

When the series of paintings had grown to I06, the interest and cooperation of Miss Ingrid Helms, a professional photographer from Hamburg, Germany, resulted in the production of some 70 slides which were used for reinterview. Each of the original three artists and other informants was able to examine and comment upon the entire series of paintings and especially certain early pictures which were available on slides. A portable viewer was used. Three interviews took place in Phoenix, three at Grand Canyon, Arizona, and four at Shongopovi. Including wives, twelve people examined the paintings. At three interviews a man and his wife were present. Six men were interviewed alone; in two cases a father and son were interviewed separately. Protest by the artists against further showing of the paintings to villagers will probably limit the utility of the slides for reinterview in the future, but no restrictions have been placed upon showing the slides to Whites.

Each of the persons commenting upon the slides was a resident of Shongopovi. With one exception they are members of different clans, though they may include members of clans within a given phratry. An average of five responses to each picture resulted, some pictures provoking considerably more interest than others. Two well-known Hopi artists and one other man offered artistic criticism of the paintings as well as discussion of the subjects. Among those informants were members of several religious societies.

By the time each artist had identified his own paintings and those of the other artists, enough Hopi terms had been recorded so that the typical responses in Hopi could be readily identified. All those who saw the paintings speak English with degrees of skill ranging from literate fluency to a man who has had little formal education. Hopi descriptions of the paintings were requested as far as possible. "How would you call this one in Hopi?" was a typical question which elicited simple verb forms or occasionally simple phrases. The viewers' knowledge that I do not speak Hopi seemed to limit longer story-length explanations, but I think these could be obtained on tape. I did not try to make the interviews completely formal, since I had known some of the people for years. In several cases older people joked to indicate complete familiarity with the subject, describing the Stone Eating Kachina, for example, as a "Rock Crusher." There are many such standing jokes which form a part of an English dialect dealing with native foods, practices, and beliefs. If these are later used in conversations with informants, they are usually found to be familiar to all. Younger men seemed more eager to provide detailed data, probably to indicate their familiarity with traditional life. Since I had met one of the younger men when he was eight years old, this desire was understandable. Nevertheless, the older men provided many significant interpretations. Conversation in Hopi between viewers provided a few additional terms which I was able to note.

The artists had already come under some criticism, which had not been mentioned to me, so that the hypercritical attitude of some of the viewers is perhaps explained. Discussion with the second artist over the advisability of showing the slides to villagers were accompanied by a decision to end the series on May 5, I965. In view of this artist's increasing ambivalence, I felt it would be best for him to cease painting under direction. Illness of his children on two occasions and a minor car accident no 
doubt increased his uncertainty regarding his original decision, for such mishaps are usually interpreted as the result of taboo violation. The second artist was reported to be annoyed by my decision to show the slides at the village and worried by the effects of possible publication. Books have caused a notable reaction in two cases especially: The Truth of a Hopi (Nequatewa I936) and The Book of the Hopi (Waters I963). As existing grant funds were exhausted, the project was formally ended. It remained likely that a few additional paintings would be produced, but resistance to the recessary accompanying interview had increased. The first of the three original artists had continued to paint, selling his work at a reservation trading post and to visitors, while each of the other two artists has entertained similar thoughts.

Certain paintings aroused more comment than others. The women's clown chorus is a subject which to my knowledge had not been previously painted, although it is not secret. The naming of a newborn child was correctly identified by all viewers. Kachina Dancers at Rest provoked two negative responses because the subject is disapproved. Borrowing Coals for Laying a Fire provoked variant interpretations because the subject is unfamiliar to younger viewers. One of the eagle hunt pictures was identified with interest by all viewers. Kachina pictures, which have been permitted and encouraged as a genre, were identified with interest. Celebrating Christmas, Children with Bean Dance Presents, and Two Kachinas and a Hopi Policeman all represent subjects which aroused interesting comment. Planting the Beans infringes upon Bean Dance secrecy. Five informants claimed not to recognize the scene, specifying artistic ambiguity, but two spotted it immediately. The second of the Owl Legend paintings, The Mother's Warning, was recognized instantly; another slide showing only the mother and the crying baby provoked no significant responses. 


\section{LIST OF ILLUSTRATIONS}

\section{LIFE CYCLE AND GENERAL RITUAL LIFE}

Birth AND EARLy Child CARE

I. A Prenatal Examination by a Hopi Doctor

2. Naming the Baby

3. Washing the Baby with Ashes

4. A Boy's First Haircut

\section{ChILDHOOD}

5. A Scene from Hopi Family Life

6. Children on the Family Burro

7. Disciplining a Child by Water-pouring

8. A Boy's Offering to Söyökö

9. Bathing at the Spring for Long Life

Io. Girls Bathe at the Spring

II. Boys Practicing Archery Skills

I2. Playing with Tops

I3. Three Hunters and Two Fires

I4. Initiating the Young Hunter

I5. A Boy's First Rabbit Hunt

r6. Ritual Hair Washing: The Naming Rite of a Hunter

I7. Hopi Children Playing at Adult Tasks

I8. Offering the First Basket to the Sun

r. A Harvest Game: Smearing Corn Smut

20. A Hopi Mother Dresses her Daughter's Hair

\section{YOUTH, COURTSHIP AND MARRIAGE}

2I. Yahaha, a Snake Dance Game

22. Grappling for a Watermelon

23. Racing for a Basket

24. A Hopi Couple

25. Dressing the Bride

26. Grinding the Corn for the Wedding Ceremony

27. The Mock Mud Fight at the Wedding Festivities

28. A Hopi Wedding Feast

29. Clan Marks Painted on the Wedding House
Arlo Nuvayouma

Arlo Nuvayouma

Marshall Lomakema

Arlo Nuvayouma

Arlo Nuvayouma

Arlo Nuvayouma

Arlo Nuvayouma

Marshall Lomakema

Arlo Nuvayouma

Arlo Nuvayouma

Leroy Kewanyama

Arlo Nuvayouma

Arlo Nuvayouma

Arlo Nuvayouma

Arlo Nuvayouma

Arlo Nuvayouma

Arlo Nuvayouma

Arlo Nuvayouma

Arlo Nuvayouma

Marshall Lomakema

Narron Lomayaktewa

Leroy Kewanyama

Leroy Kewanyama Arlo Nuvayouma Arlo Nuvayouma Arlo Nuvayouma

Narron Lomayktewa

Marshall Lomakema

Arlo Nuvayouma 


\section{DAIL y LIFE}

30. A Women's Barter Party

3I. Food Trading

32. A Woman Drying Peaches

33. Building a House

34. Washing the Walls

35. Repairing or Renewing a House

36. A Family Feast

37. Borrowing Coals for Laying a Fire

38. Divorce

39. Fighting Over a Hoe

40. Family Meeting

4I. An Old Man Visits the Doctor

42. A Seriously Ill Patient is Visited by the Doctor

43. Landscape: The Hopi Country

\section{Social Change}

44. The Family Buys a Television Set

45. Celebrating Christmas

46. "Water Filling"

Arlo Nuvayouma Marshall Lomakema Marshall Lomakema

\section{RITUAL LIFE}

\section{Ceremonial Activities}

47. Clan Symbols

48. The Ritual Smoking of Chiefs

49. Making Prayer Feathers

50. Giving Prayer Feathers

5I. Sun Watching (Tawangaoktaita)

52. Two Boys at a Shrine

53. Young Men at the Shrine

54. Invoking Animal Fetishes

55. Hopi Warriors Hiding

56. The Flute Ceremony: Obtaining Ritual Water

57. Bear Clan Racer

58. Bear Clan Race

59. Oaqöl Mana Throwing Darts

6o. Prayer Sticks at a Snake Dance

6r. Men Smoking and Exchanging Kiva Terms

Marshall Lomakema

Marshall Lomakema

Marshall Lomakema

Marshall Lomakema

Marshall Lomakema

Narron Lomayakterea

Narron Lomayaktewa

Marshall Lomakema

Marshall Lomakema

Leroy Kewanyama

Arlo Nuvayouma

Arlo Nuvayouma

Leroy Kewanyama

Narron Lomayakterwa

Marshall Lomakema

\section{The Eagle Cult}

62. Three Men Smoking at the Shrine

63. Lowering a Cloth on the Eagle

64. Catching the Eagle

Arlo Nuvayouma Arlo Nuvayouma Arlo Nuvayouma 
65. A Hunter Being Lowered to the Nest

66. A Captive Eagle

67. Naming an Eagle

68. Eagles with Gifts

69. The Execution of an Eagle

The Salt Journey

70. A Salt Expedition: Gift for an Aunt

7I. Smoking over the Gift of Salt

MORE IMPORTANT CEREMONIES

72. Mask Making

73. Eating for the Mask

74. Masks on the Kiva Ledge

75. Kachina Dancers at Rest

76. Planting the Beans

\section{The Kachina Cult}

77. Kiva Chief and Kachina Exchanging Gifts

78. Ritual Feeding of Participants

79. Dance Practice Scene

8o. Borrowing for the Dance

8I. A Kachina Pouring Water

82. A Man and a Kachina Racing

83. Whipping for Curing

84. Ritual Blessing of a House

85. Two Kachinas and a Hopi Policeman

86. Burro Kachina Dance

87. The Mudhead Magician

88. Wolf and Cow Kachinas

89. Corn Kachina and Mudhead Kachina

9o. Corn Kachina Dance at Easter Time

9I. Corn Kachina

92. Owl and Rattle Kachinas

93. Gathering Evergreens

94. Cleaning the Ash Pit

95. Kachinas Rosting Sweet Corn

96. Qöqlöm Dancing with Sweet Corn

Unmasked (Social) Dances

97. Buffalo Dance

98. Unmasked Elk Dance

99. Laguna Eagle Dance

I0o. Butterfly Dance
Marshall Lomakema Arlo Nuvayouma Arlo Nuvayouma

Marshall Lomakema Arlo Nuvayouma

Marshall Lomakema Marshall Lomakema

Marshall Lomakema Marshall Lomakema Marshall Lomakema Marshall Lomakema Marshall Lomakema Marshall Lomakema Marshall Lomakema Marshall Lomakema Marshall Lomakema Marshall Lomakema Marshall Lomakema Arlo Nuvayouma Leroy Kewanyama Marshall Lomakema Narron Lomayaktewa Melvin Nuvayouma Arlo Nuvayouma Arlo Nuvayouma Arlo Nuvayouma Arlo Nuvayouma

Marshall Lomakema Marshall Lomakema Arlo Nuvayouma Marshall Lomakema 
A Hopi Legend: The Boy who Became an Owl

IOI. The Boy Misbehaves

I02. The Mother's Warning

I03. Getting on the Owl's Back

I04. Changing into Owl

I05. The Mourning Parents
Arlo Nuvayouma

Arlo Nuvayouma

Arlo Nuvayouma

Arlo Nuvayouma

Arlo Nuvayouma

\section{CLOWNING}

I06. Arrival of the Clowns

I07. A Mudhead Game Scene

I08. Feeding a Clown

Iog. Three White Man's Clowns

IIO. A Women's Chorus of Clowns

III. Clowns Feeding a White Spectator

II2. Clowns Performing a Bullfight

II3. A Clown Imitating an Ogre Woman

II4. The Clowns Imitate Kachinas

II5. Piftukas or Imitator Clowns

II6. Imitator Kachina and Clowns

II7. Clowns Building a House

Marshall Lomakema

Marshall Lomakema

Narron Lomayaktewa

Marshall Lomakema

Marshall Lomakema

Marshall Lomakema

Marshall Lomakema

Marshall Lomakema

Marshall Lomakema

Marshall Lomakema

Marshall Lomakema

Marshall Lomakema

\section{CURING}

\section{HOME CURE}

II8. A Man Treating His Wife's Eye Disease

II9. Taking Snake Dance Stomach Medicine

Arlo Nuvayouma

Arlo Nuvayouma

\section{Causes of Serious Illness}

I20. The Dreaded Töalöng

I2I. Curing an Old Man of the Effects of a Witch Bundle

I22. Behavior Toward a Suspected Witch

Marshall Lomakema

Arlo Nuvayouma

Arlo Nuvayouma

The Medicine Man (Povoska)

I23. A Husband Accompanies His Wife

I24. Using a Crystal and Fetishes to Locate Illness

I25. The Patient is Seated on an Adobe Platform

I26. Diagnosis for Internal Illness

I27. The Medicine Man "Consults His Animals"

I28. A Ritual Offering

I29. The Doctor Treats a Sick Baby

I30. Shock Treatment for Mental Illness

I3I. The Doctor Offers Sacred Cornmeal to his Patient

I32. Ants are Removed by Sleight-of-Hand

Arlo Nuvayouma Arlo Nuvayouma

Marshall Lomakema

Marshall Lomakema

Arlo Nuvayouma

Arlo Nuvayouma

Arlo Nuvayouma

Arlo Nuvayouma

Leroy Kewanyama

Marshall Lomakema 
I33. A Woman Doctor Treating Cloud Eye (Keratitis)

I34. Treatment of a Skin Ulcer

Marshall Lomakema

Marshall Lomakema

The Bone Doctor (OKatihikya)

I35. A Bone Doctor Treats a Dislocated Neck

I36. A Bone Doctor Treats a Dislocated Neck

I37. Treatment of Muscle Spasm or Rib Dislocation

I38. Treatment of Muscle Spasms or Dislocation of Ribs

I39. Treatment for a Dislocated Hip

I40. A Husband Assists the Bone Doctor

I4I. A Child's Arm is Treated

I42. The Doctor Locates a Pain in the Patient's Back

Arlo Nuvayouma

Marshall Lomakema

Arlo Nuvayouma

Marshall Lomakema

Marshall Lomakema

Arlo Nuvayouma

Marshall Lomakema

Arlo Nuvayouma

\section{Payment of Fees}

I43. Paying a Medicine Man's Retainer

I44. A Final Payment to the Doctor

Arlo Nuvayouma

Arlo Nuvayouma

\section{ECONOMIC LIFE}

\section{Crops}

I45. Loading the Peaches

I46. Getting Peaches

I47. Hauling Peaches

I48. Drying Peaches

I49. Harvesting Beans

I50. A Farmer Gathering Gourds

I5I. Gathering Gourds

I52. Gathering Melons for Yahaha

I53. Planting the Fields

I54. Sprinkling the Fields

I55. Women Storing Corn

I56. Shelling Corn

I57. Drying Corn Kernels

I58. Parching Corn

I59. An Old Lady Grinding Corn and Singing

I6o. Women Grinding Corn

I6I. Making Pikami

Arlo Nuvayouma Arlo Nuvayouma

Marshall Lomakema Arlo Nuvayouma Arlo Nuvayouma Arlo Nuvayouma Arlo Nuvayouma Marshall Lomakema Melvin Nuvayouma Marshall Lomakema Arlo Nuvayouma Melvin Nuvayouma Marshall Lomakema Arlo Nuvayouma Arlo Nuvayouma Arlo Nuvayouma Arlo Nuvayouma

\section{Making a Piki Stone}

I62. Getting the Piki Stone I63. Smoothing the Piki Stone

I64. Putting Pitch on the Stone

I65. Testing the Stone

I66. Women Making Piki

Arlo Nuvayouma Arlo Nuvayouma Arlo Nuvayouma Arlo Nuvayouma Melvin Nuvayouma 


\section{HUNTING}

I67. Hunting Rabbits

I68. Rabbit Hunt

I69. "Together Hunt"

I70. Feeding the Hunter's Family

I7I. Offering Corn Pollen to the Slain Deer

I72. Dressing the Slain Deer in Ceremonial Garments

I73. Trapping Birds

Melvin Nuvayouma

Leroy Kewanyama

Levoy Kewanyama

Marshall Lomakema

Marshall Lomakema Arlo Nuvayouma Arlo Nuvayouma

\section{BASket Making}

I74. Gathering Yucca

I75. Splitting the Yucca

I76. Drying Yucca Strips

I77. Dyeing

I78. Making a Basket

Arlo Nuvayouma Arlo Nuvayouma Arlo Nuvayouma Arlo Nuvayouma Arlo Nuvayouma

Other Economic Activities

I79. Getting Wood

I80. Stacking the Wood

I8I. Payment to the Kiva

182. A Hopi Coal Miner

I83. Trade with the Navajo

I84. Women Making Pottery Bowls

I85. Sheep Shearing

Arlo Nuvayouma Arlo Nuvayouma

Marshall Lomakema Arlo Nuvayouma Arlo Nuvayouma Arlo Nuvayouma Melvin Nuvayouma

\section{COLOR PLATES}

I. Corn Kachina and Mudhead Kachina (frontispiece)

Leroy Kewanyama

II. The Ritual Smoking of Chiefs (\# 48)

III. Young Men at the Shrine (\# 53)

IV. Gathering Evergreens (\# 93)

V. Treatment for a Dislocated Hip (\# I39)

Marshall Lomakema Narron Lomayaktewa Arlo Nuvayouma Marshall Lomakema 


\section{BIBLIOGRAPHY}

References in the text have been kept to a minimum. The reader will find an excellent bibliography on the Hopi in Frederick J. Dockstader, The Kachina and the White Man (I954). For the present study the following are most relevant:

\section{Life Histories}

Qoyawayma, Polingaysi

I964 No Turning Back: A True Account of a Hopi Indian Girl's Struggle to Bridge the Gap Between the World of Her People and the World of the White Man. As told to Vada F. Carlson. Albuquerque: University of New Mexico Press. I8opp.

A modern Hopi woman's life.

\section{Simmons, LEO}

I942 Sun Chief. Cambridge: Yale University Press. 46opp.

A major work containing a deep insight into Hopi cultural values despite the fact that many Hopi point out that it is not typical of all Hopi.

\section{UDALL, LOUISE}

I969 Me and Mine, the Life Story of Helen Sekaquaptewa. Tucson: University of Arizona Press. 26opp.

The story of a woman who rejected some but not all Hopi cultural values and brought her children up in the modern world.

\section{General}

\section{Beaglehole, Ernest and Pearl Beaglehole}

I935 Hopi of the Second Mesa. American Anthropological Association, Memoir No. 44. 65pp.

Basic ethnographic data which includes the village whose life is depicted in the paintings.

COLTON, HAROLD S.

I949 Hopi Kachina Dolls. Albuquerque: University of New Mexico Press. I50pp.

Designed to identify kachina dolls; the most convenient reference for kachina types as well. 
Colton, Mary-Russell Ferrell

I965 Hopi Dyes. Flagstaff: Museum of Northern Arizona, Bulletin No. 4I. $87 \mathrm{pp}$.

Detailed recipes for dye preparation for basketry materials and other purposes.

Dockstader, Frederick J.

I954 The Kachina and the White Man; the Influences of the White Man on the Hopi Indian Kachina Religion. Cranbrook Institute of Science, Bulletin No. 35. 204pp.

A great deal of material on the history and significance of the Kachina Cult; contains a brief history of the Hopi.

Dunn, DoRothy

I968 American Indian Painting of the Southwest and Plains Area. Albuquerque: University of New Mexico Press. 429pp.

Indian painting considered as art but in proper relation to tribal origin. Several Hopi artists are discussed.

EARLE, EDWIN and E. A. KenNARD

I938 Hopi Kachinas. New York: J. J. Augustin. 40pp., illus. Revised ed., I970. Twenty-eight kachina dancers depicted by Edwin Earle with text by Kennard.

EGGAN, FRED

I950 Social Organization of the Western Pueblos. Chicago: University of Chicago Press. 373pp.

Social organization of the Hopi considered in relation to that of the westernmost Pueblos of New Mexico.

Fewkes, Jesse Walter

I903 Hopi Katcinas, Drawn by Native Artists. Bureau of American Ethnology, Annual Report No. 2I. Igopp., illus.

Containing the famous Codex Hopiensis, this classic study was one of the influences which prompted the present volume.

\section{GOLDFRANK, EsTHER S.}

I967 The Artist of "Isleta Paintings." Washington: Smithsonian Contributions to Anthropology, Vol. V. 227pp., illus.

A follow-up study, summarizing Parsons' Isleta Paintings, with additional data on the history of those works and the man who painted them.

\section{Nequatewa, Edmund}

I936 Truth of a Hopi and Other Clan Stories of Shungopovi. Flagstaff: Northern Arizona Museum Notes, Vol. III, No. 9. II4pp.

Stories which many Hopi tried to suppress as secret. 
Parsons, Elsie Clews

I962 Isleta Paintings. Esther S. Goldfrank, (Ed.). Bureau of American Ethnology, Bulletin No. I8I. 30opp.

The other book which influenced this study; a unique record of Pueblo ceremonies and life by an Isleta man who broke with tradition.

\section{PARsons, Elsie Clews}

I939 Pueblo Indian Religion. Chicago: University of Chicago Press. 2 vols.

The major work on Pueblo Indian religion.

\section{Simpson, Ruth DE ETte}

I953 The Hopi Indians. Los Angeles: Southwest Museum, Leaflet No. 25. 9Ipp.

A good basic treatment of Hopi life which might well be read in connection with Ritual in Pueblo Art.

SNODGRASS, JEANNE O.

I968 American Indian Painters; a Biographical Directory. New York: Museum of the American Indian, Heye Foundation. Contributions Vol. XXI, Part I. 269pp.

A reference volume with sketches of the lives and careers of 1,187 Indian artists.

Stephen, Alexander M.

I936 Hopi Journal. Elsie C. Parsons (Ed.). Columbia University Contributions to Anthropology, Vol. 23. 2 vols.

The most detailed record of Hopi ceremonies and daily life. Contains many references which corroborate the data supplied by the artists with their paintings.

\section{TANNER, Clara LeE}

I957 Southwest Indian Painting. Tucson: University of Arizona Press. I57pp.

Describes Indian painting as art and includes illustrations of the work of some of the best known Hopi artists which may be compared with the present illustrations.

\section{Voegelin, Charles F. and Florence M. Voegelin}

I957 Hopi Domains. International Journal of American Linguistics, Memoir No. I4. 82pp.

Renders Hopi phonemically; the standard authority for the linguistically-correct spelling of Hopi words. Is in sharp contrast to the phonetic translations of field workers.

Whiting, AlFred H.

I939 Ethnobotany of the Hopi. Flagstaff: Museum of Northern Arizona, Bulletin No. I5. I20pp.

Contains many very valuable references to Hopi ceremonial life and customs. A book with greater breadth than the title would indicate. 

PLATES 

FIGURES I,
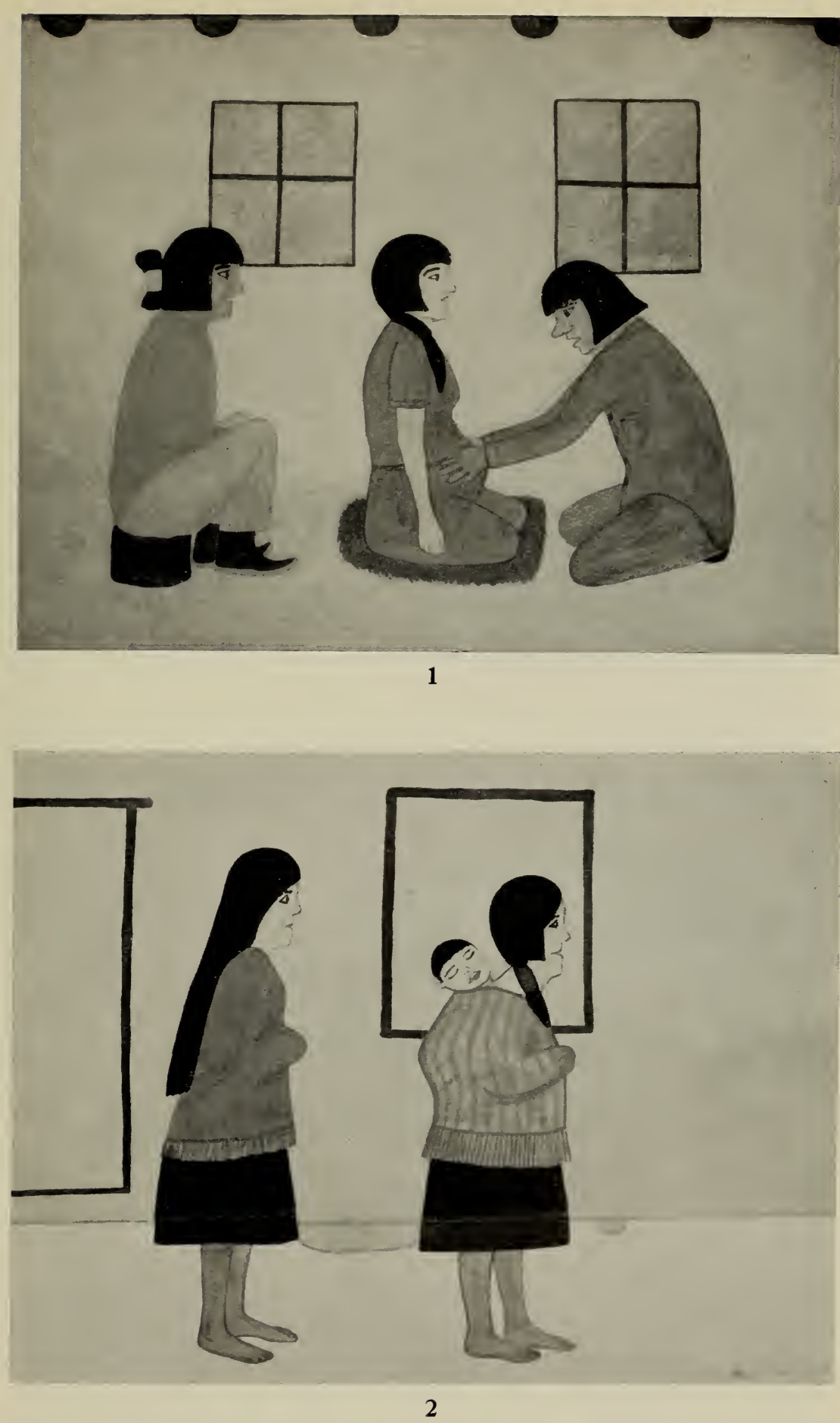
FIGURES 3,4

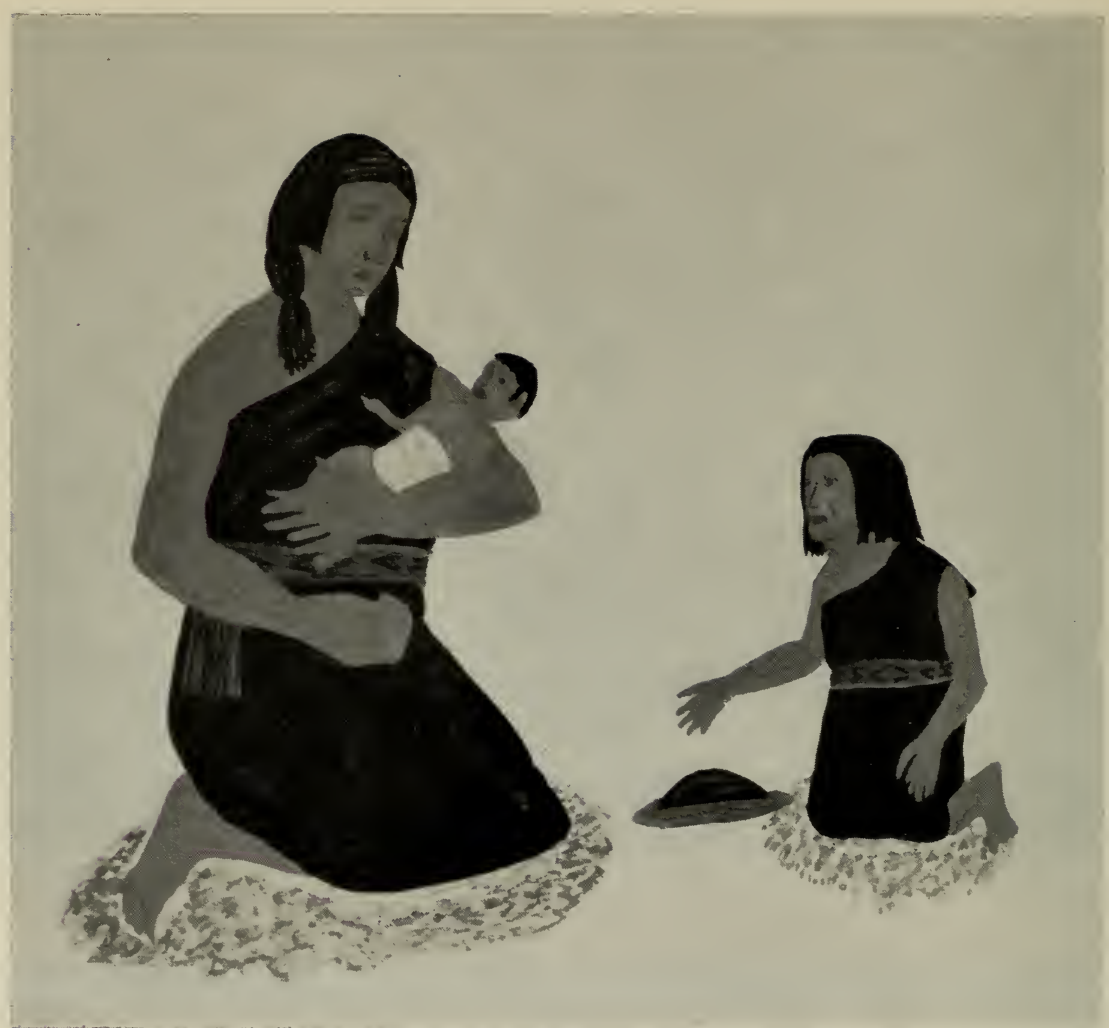

3

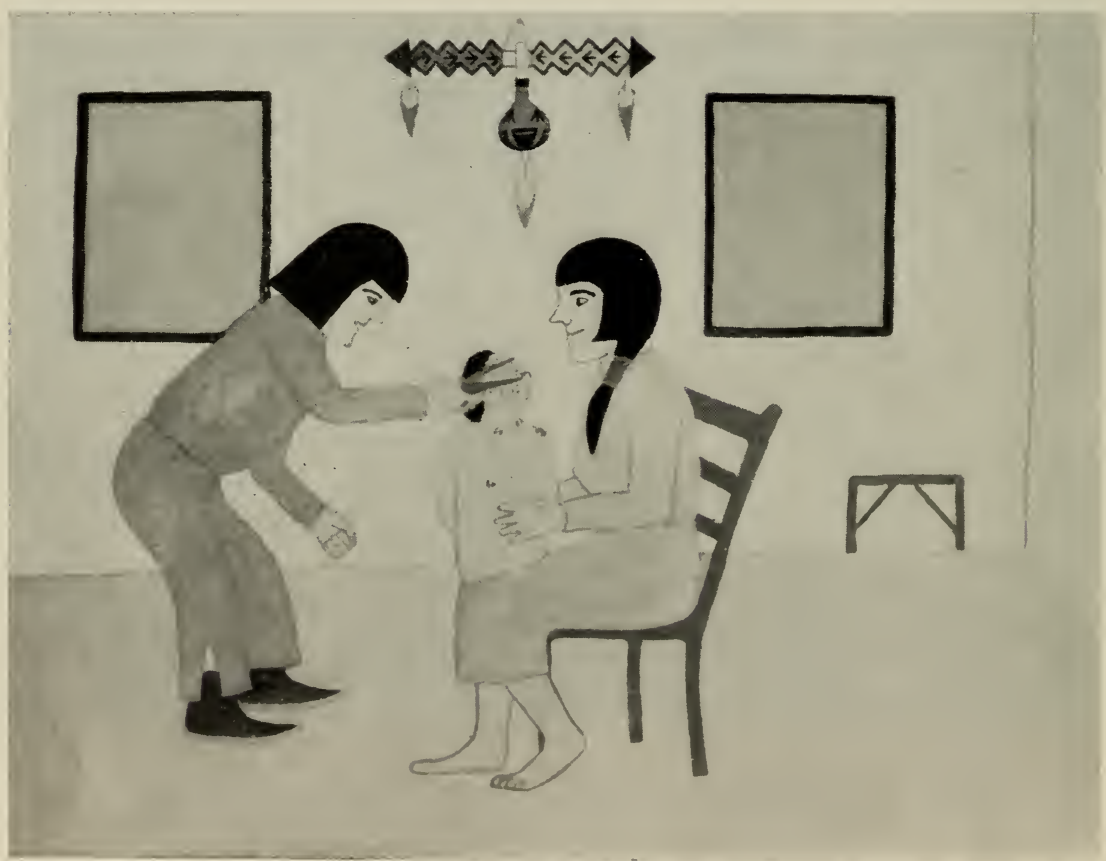


FIGURES 5,6

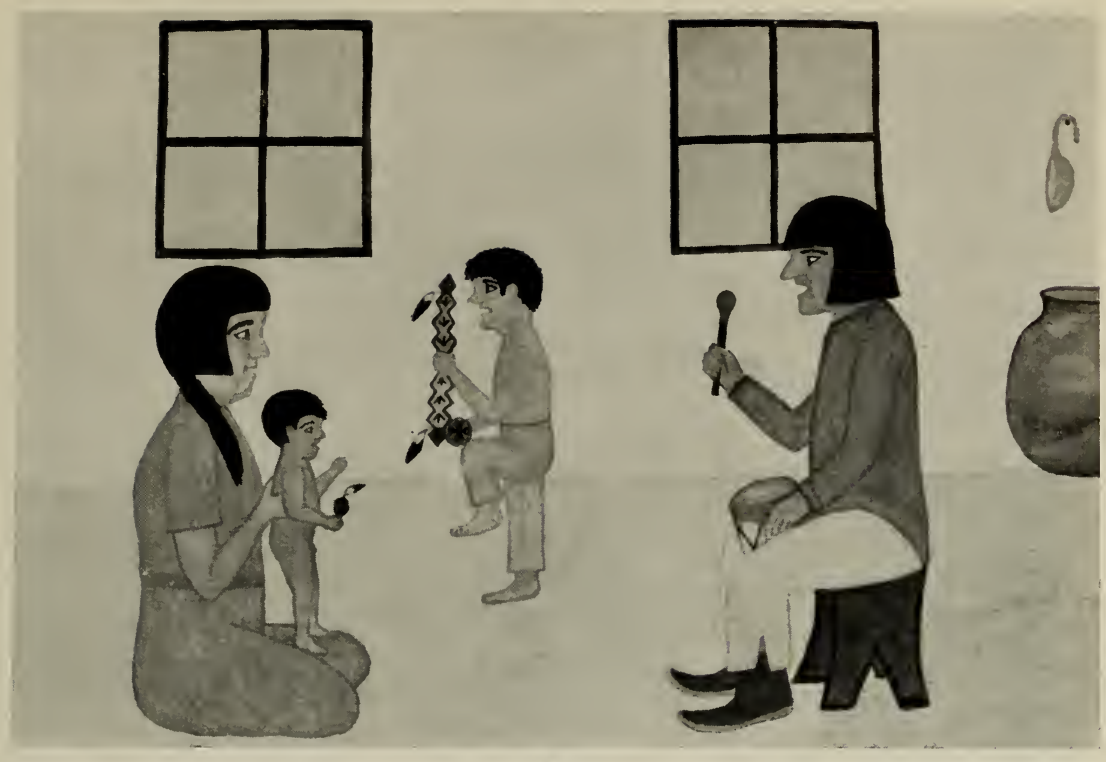

5

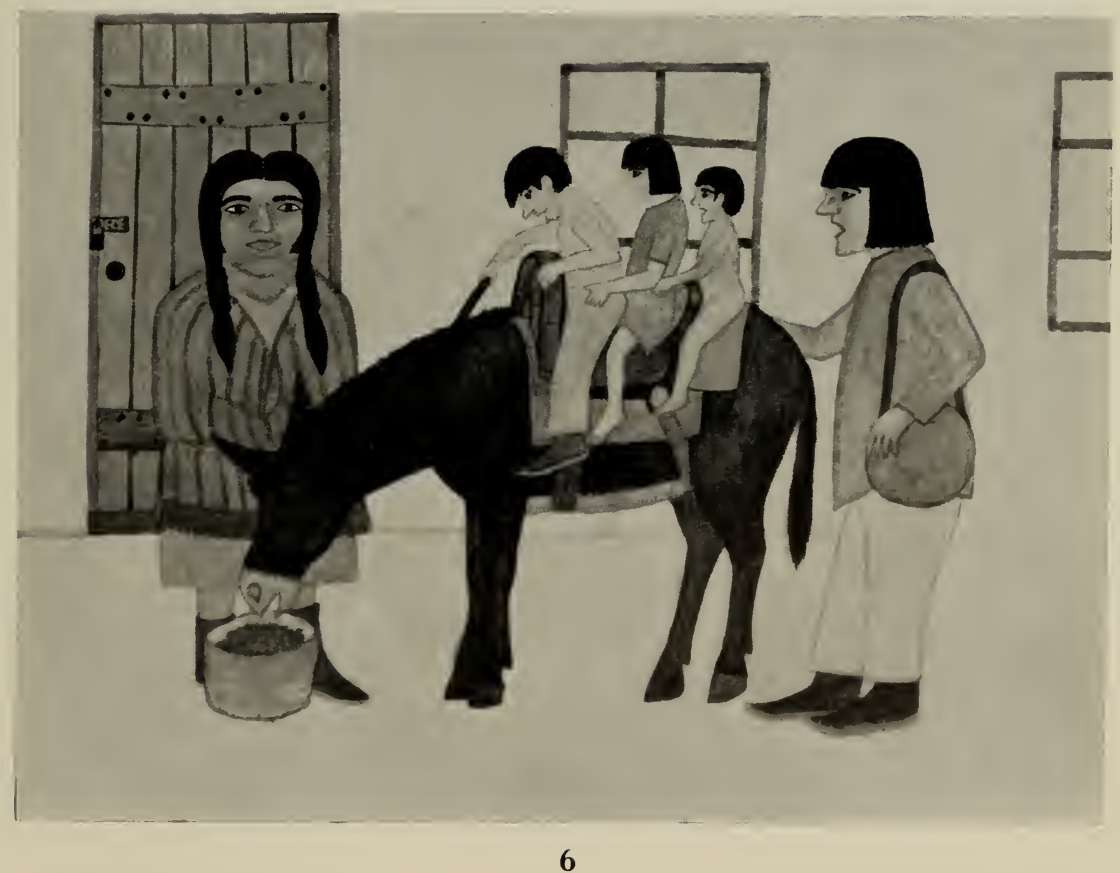


FIGURE 7

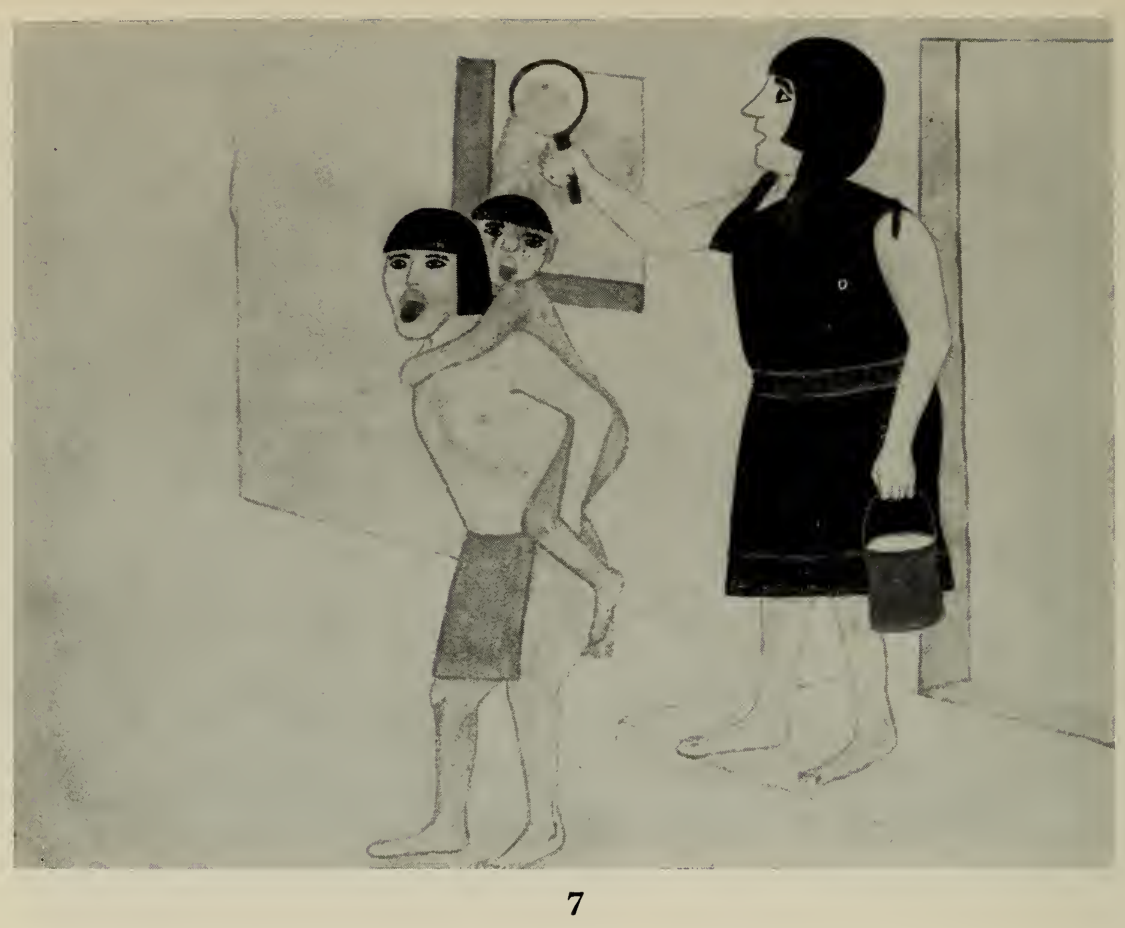


FIGURE 8

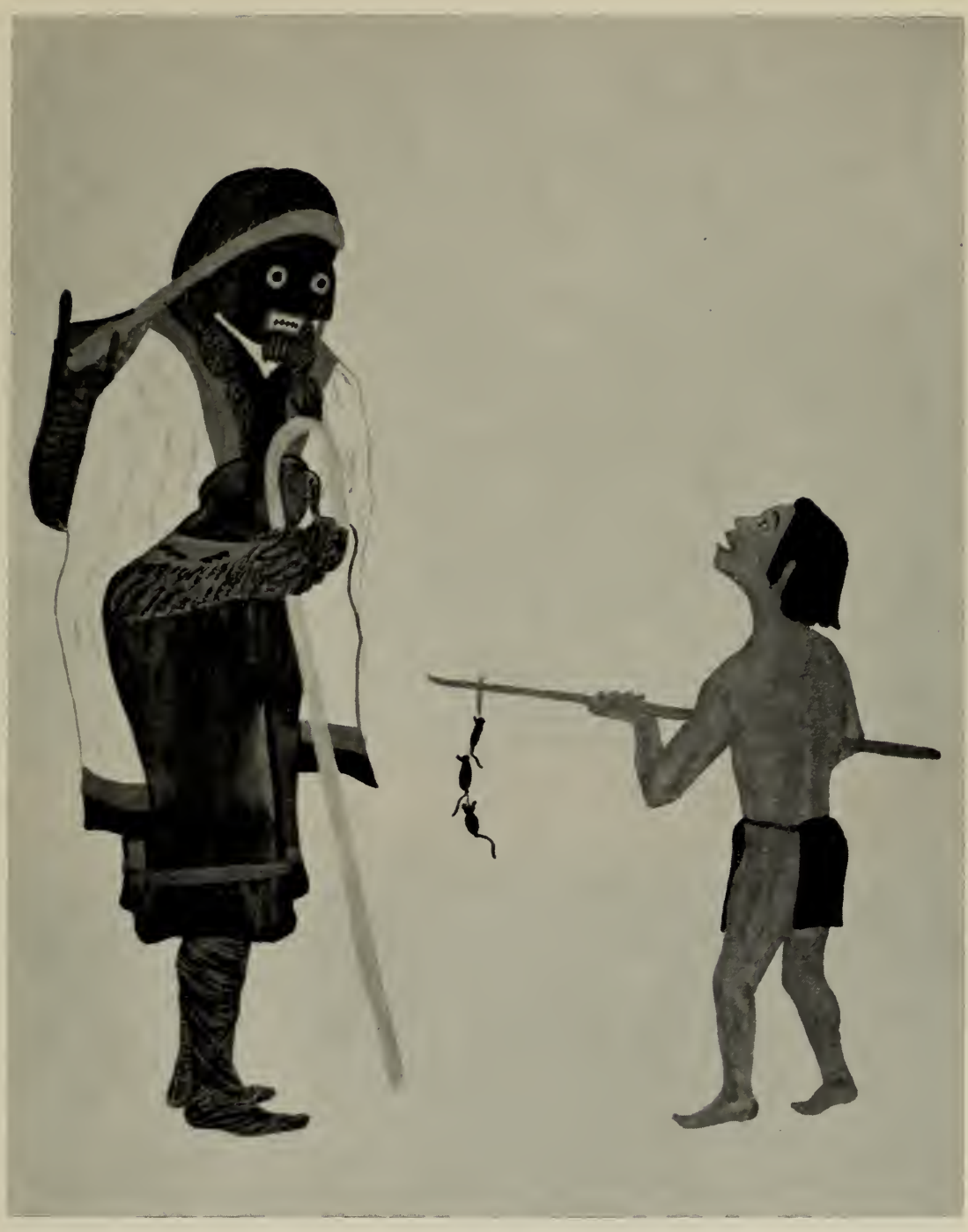


FIGURES 9, IO
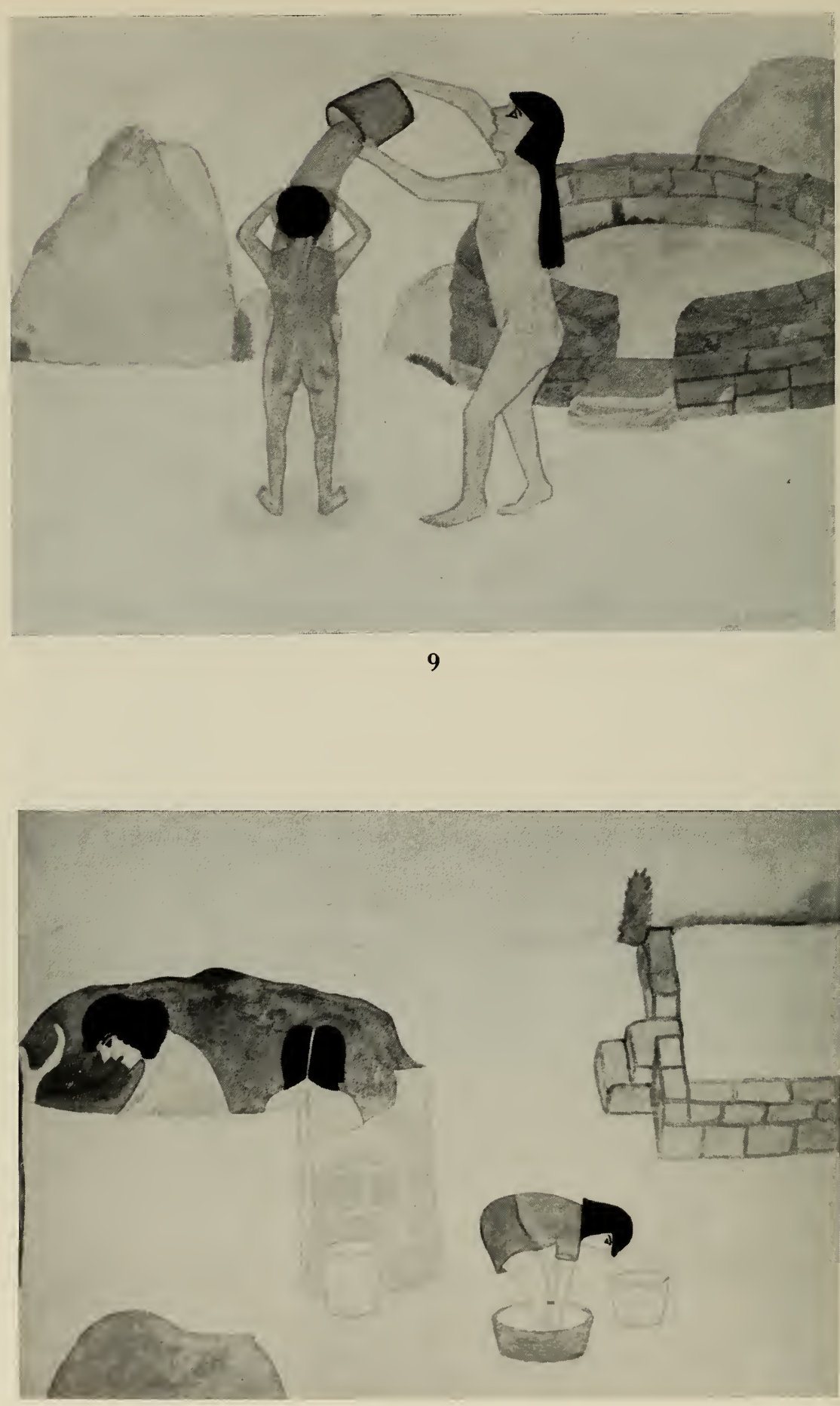
FIGURES I I, I 2
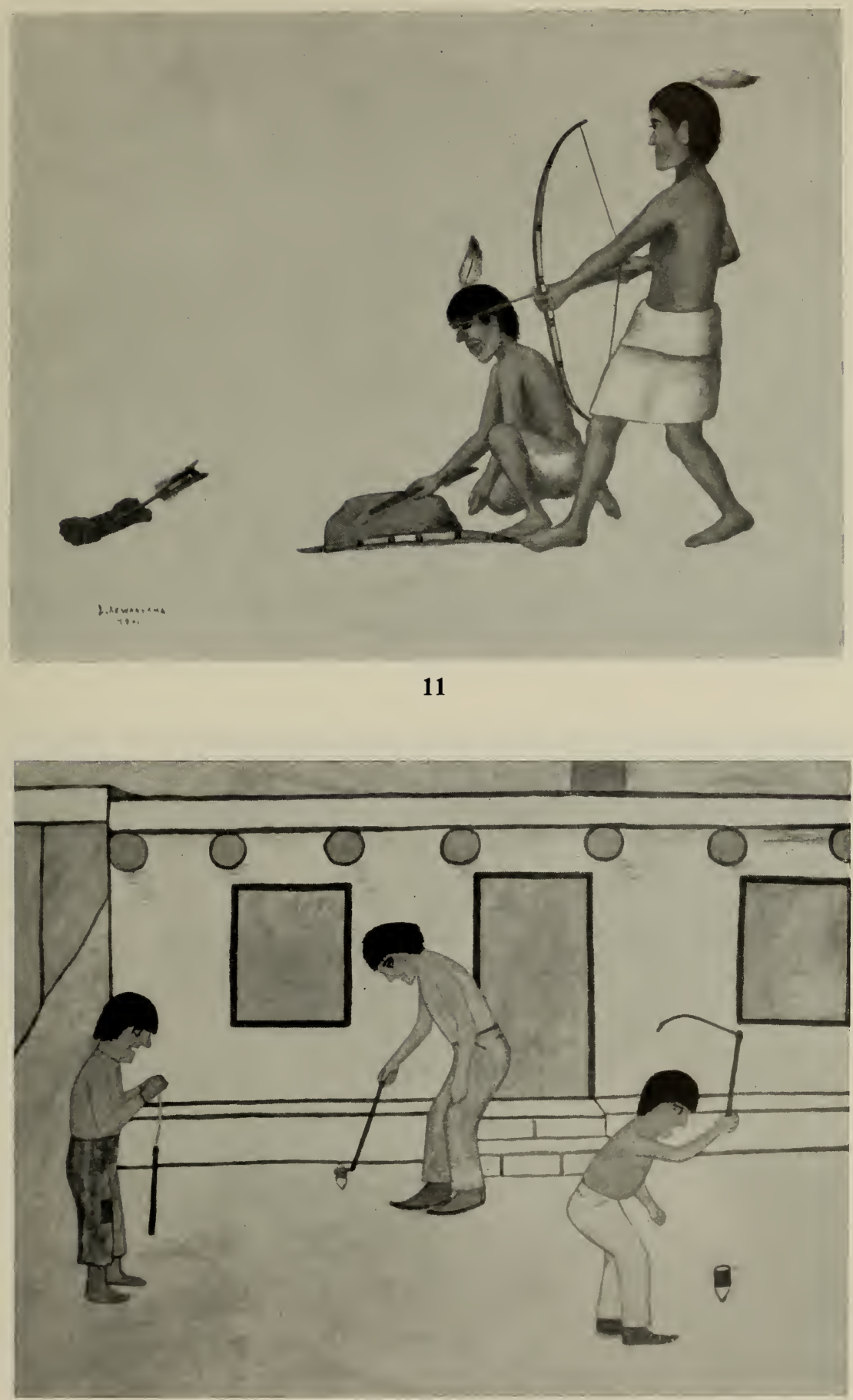


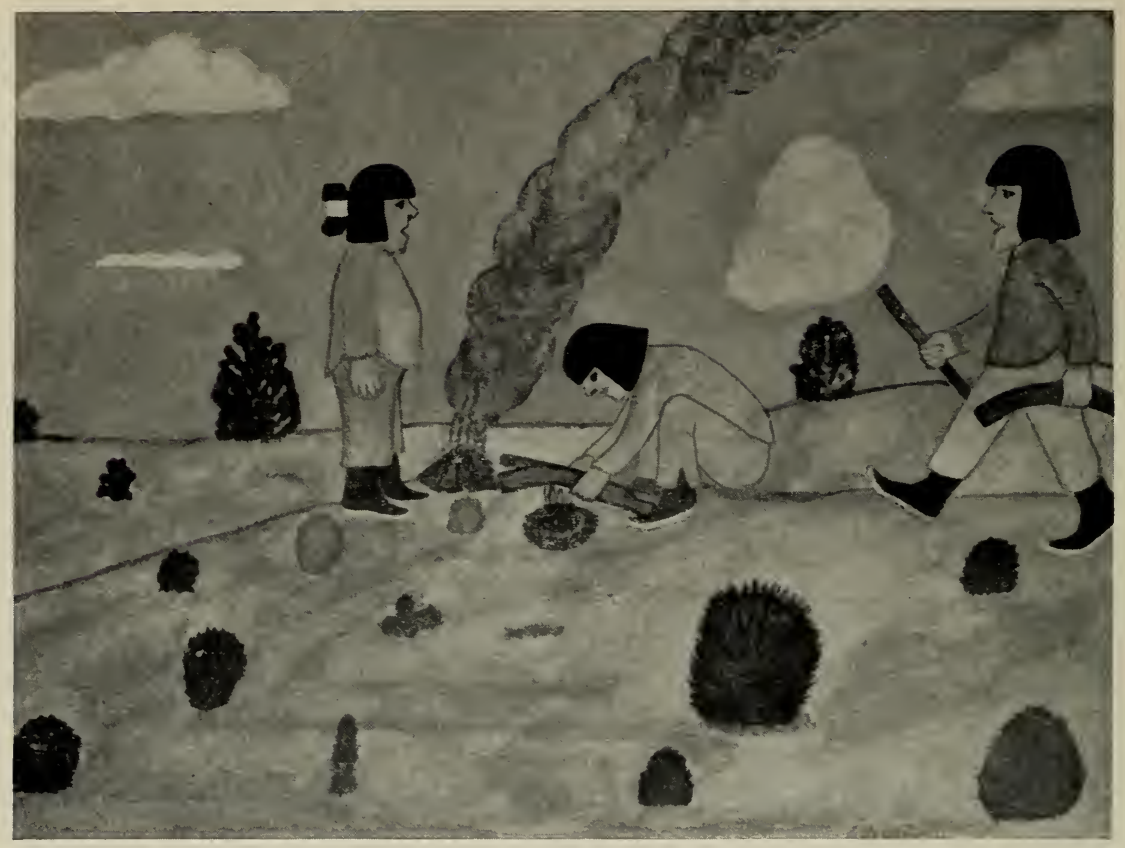

13

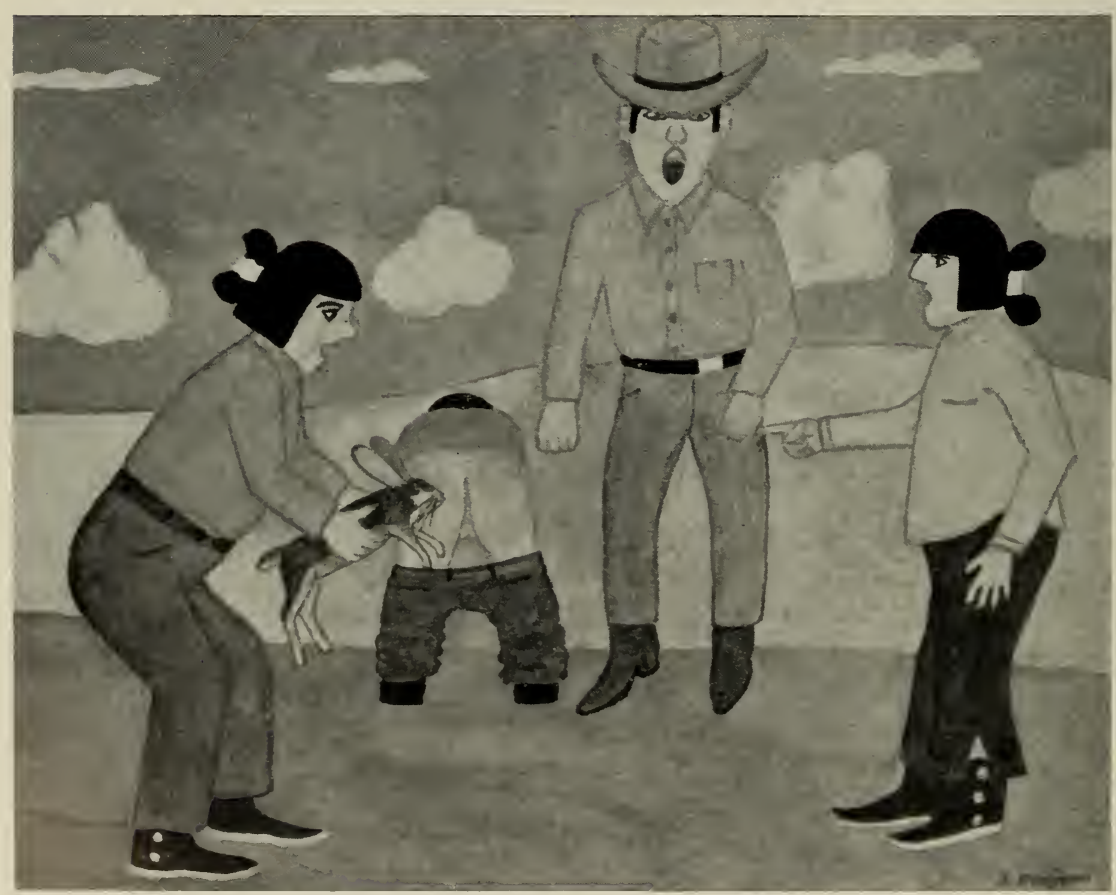


FIGURES I 5, I 6

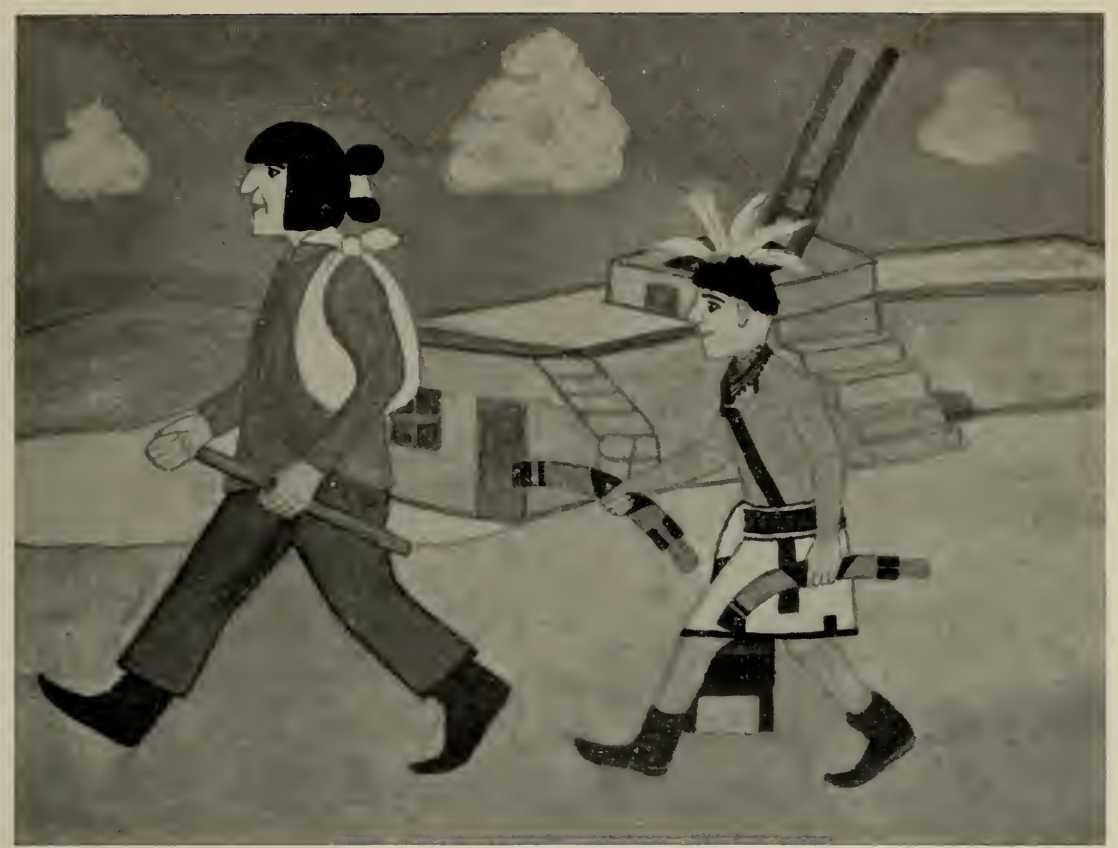

15

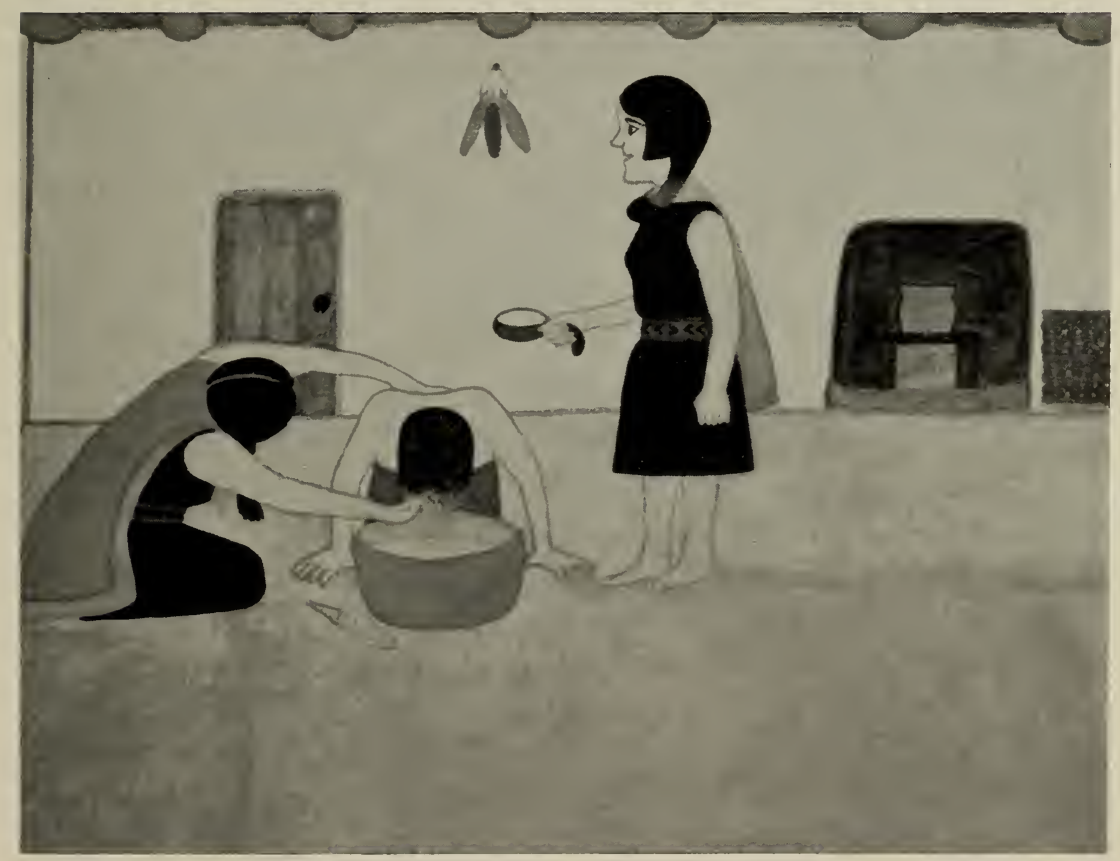




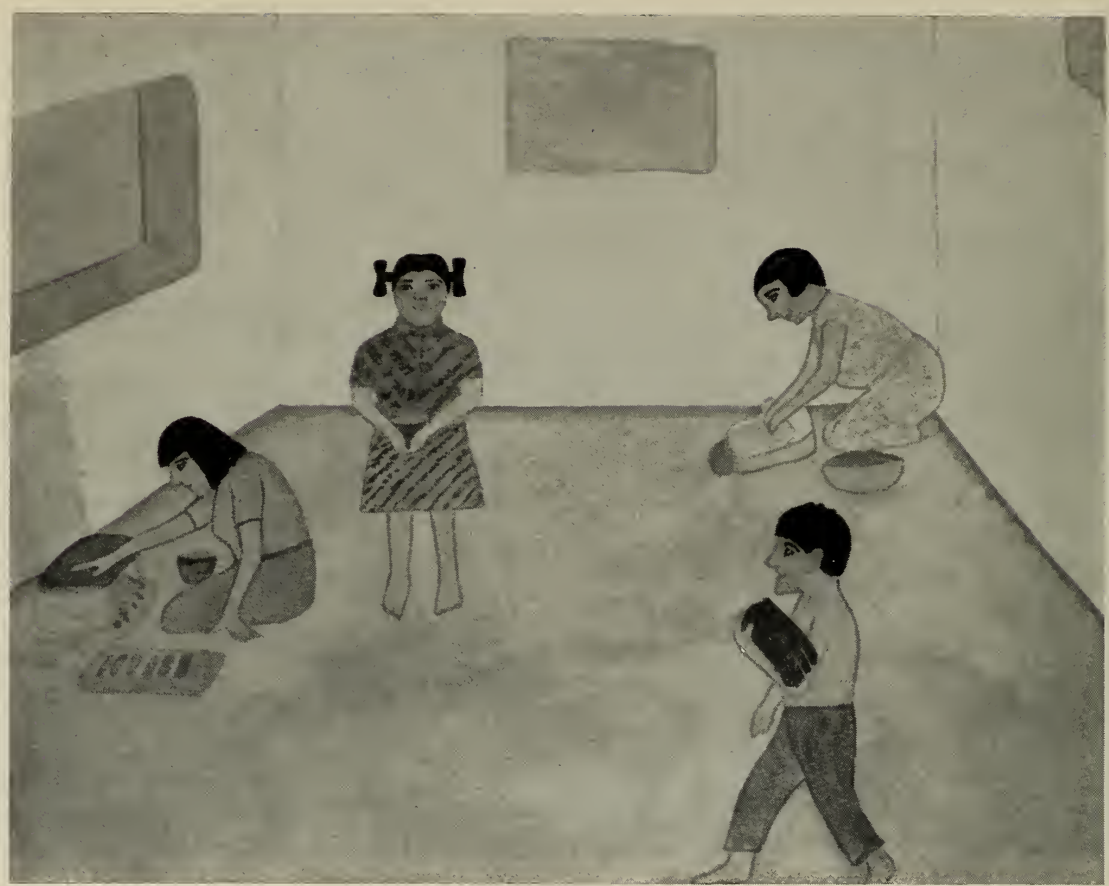

17

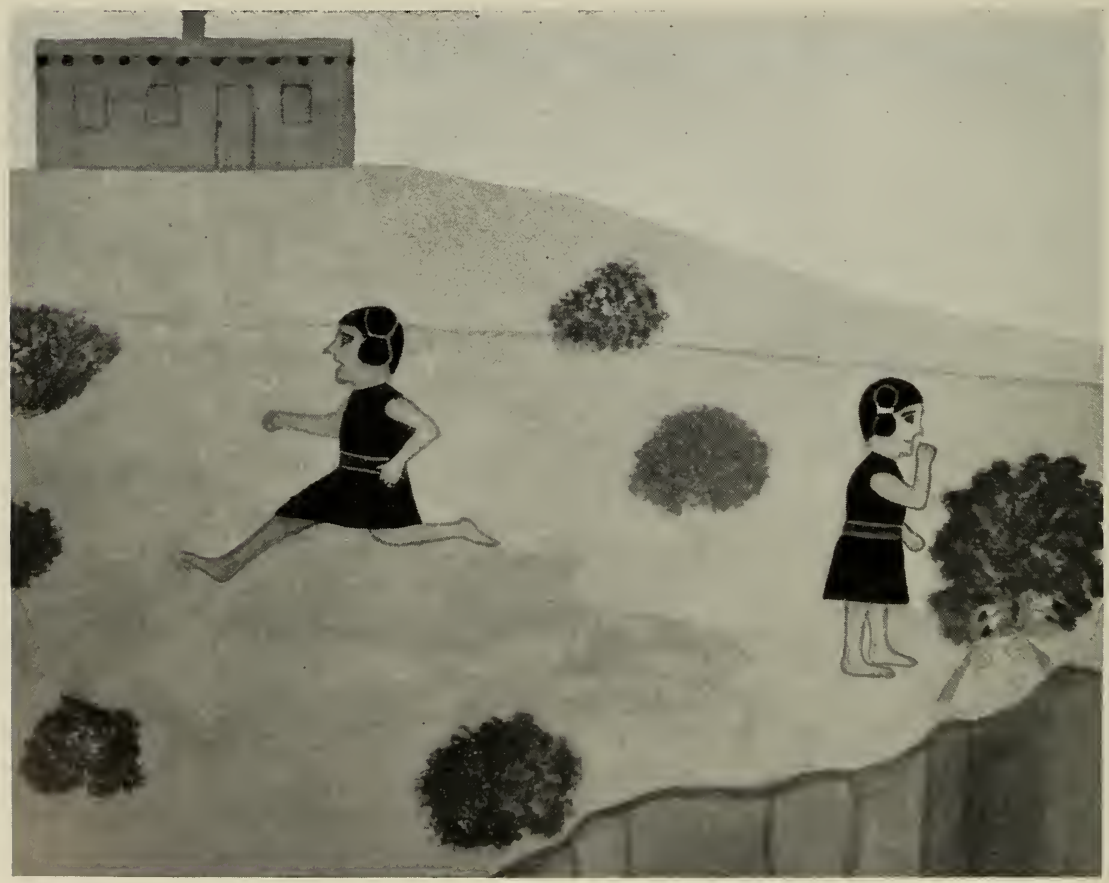


FIGURES I 9, 20
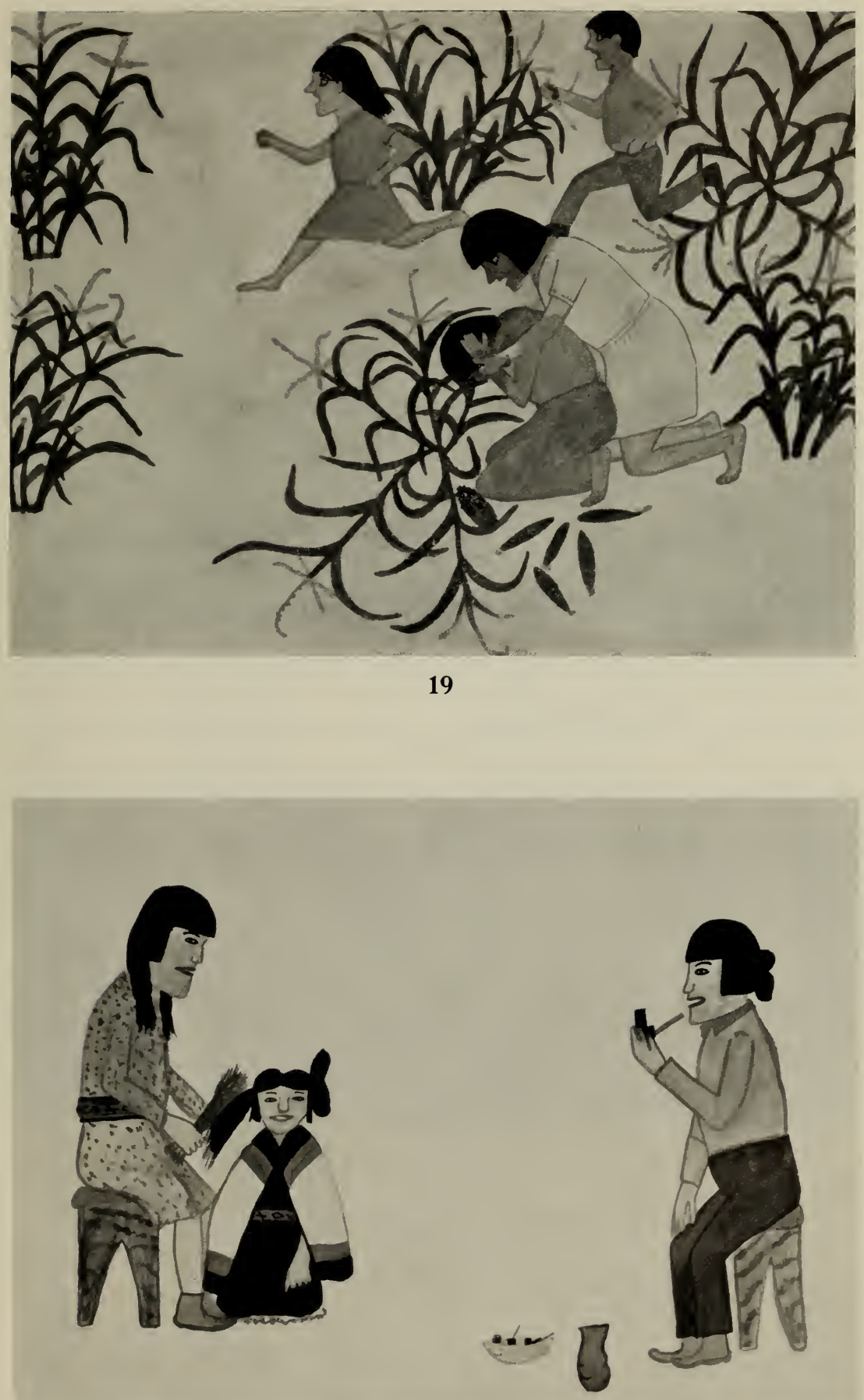
FIGURE 2 I

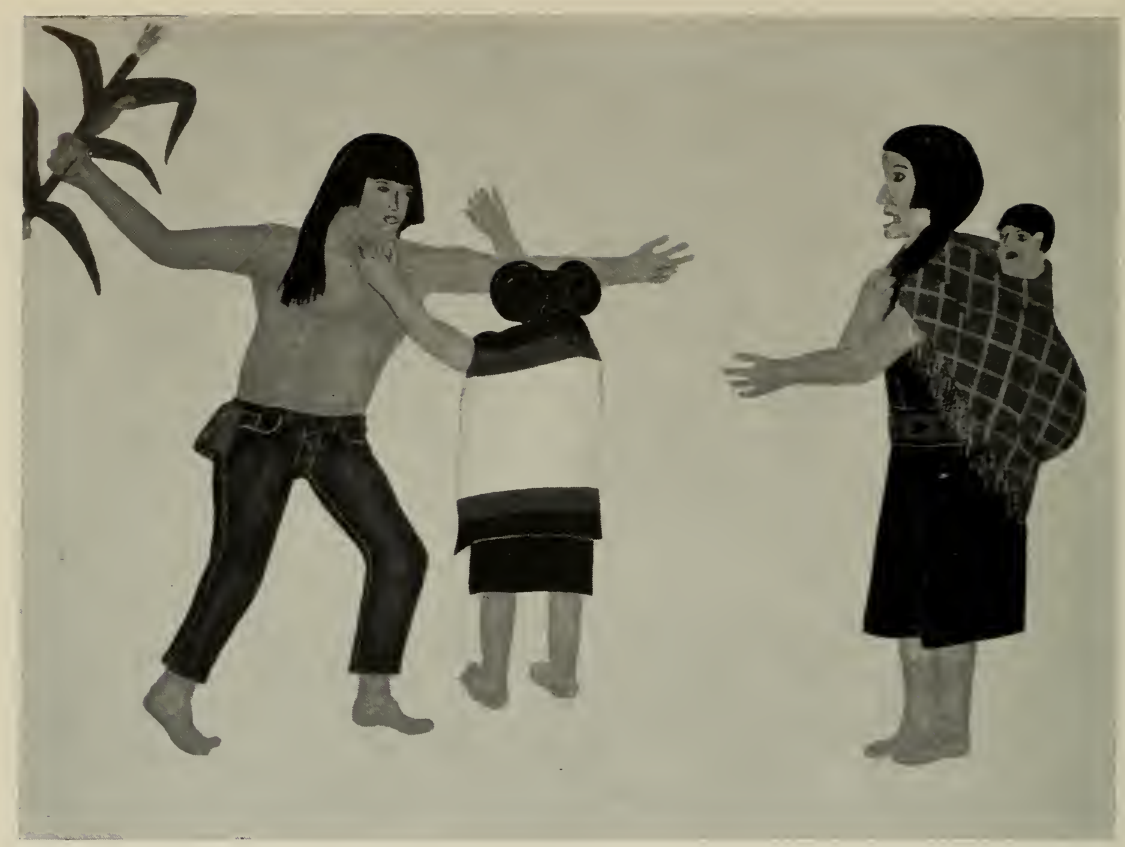


FIGURE 22

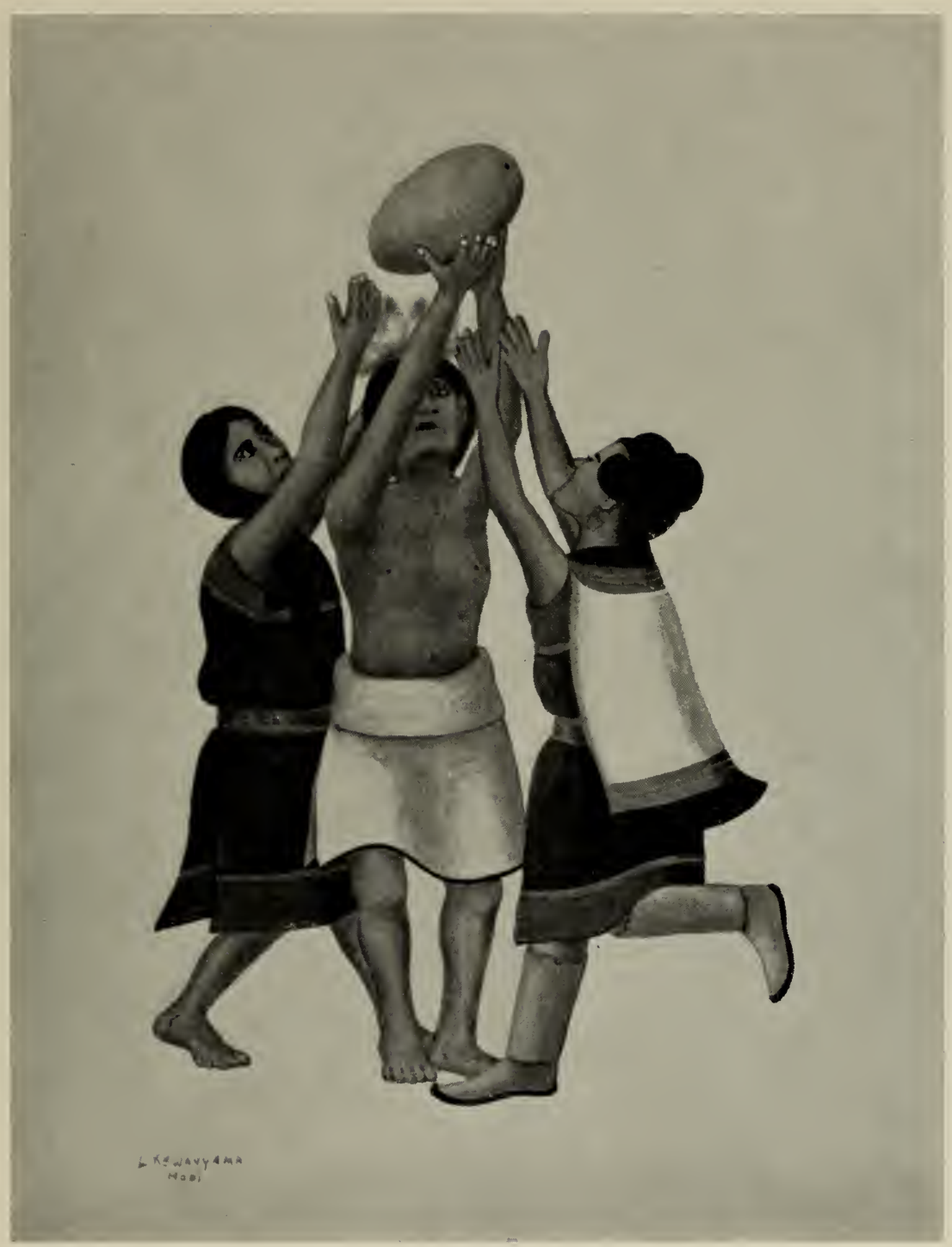



FIGURE 24

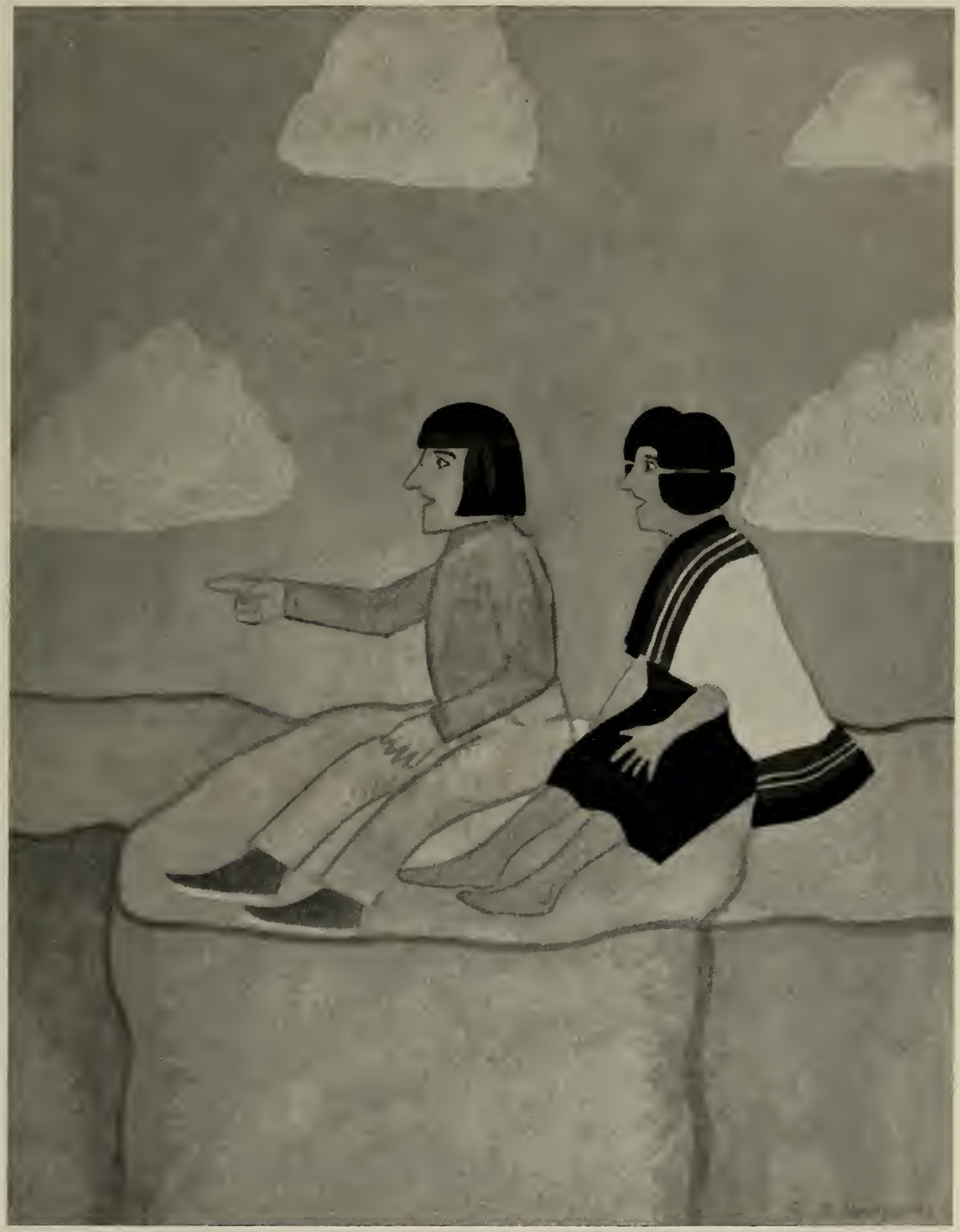

24 
FIGURES 25, 26

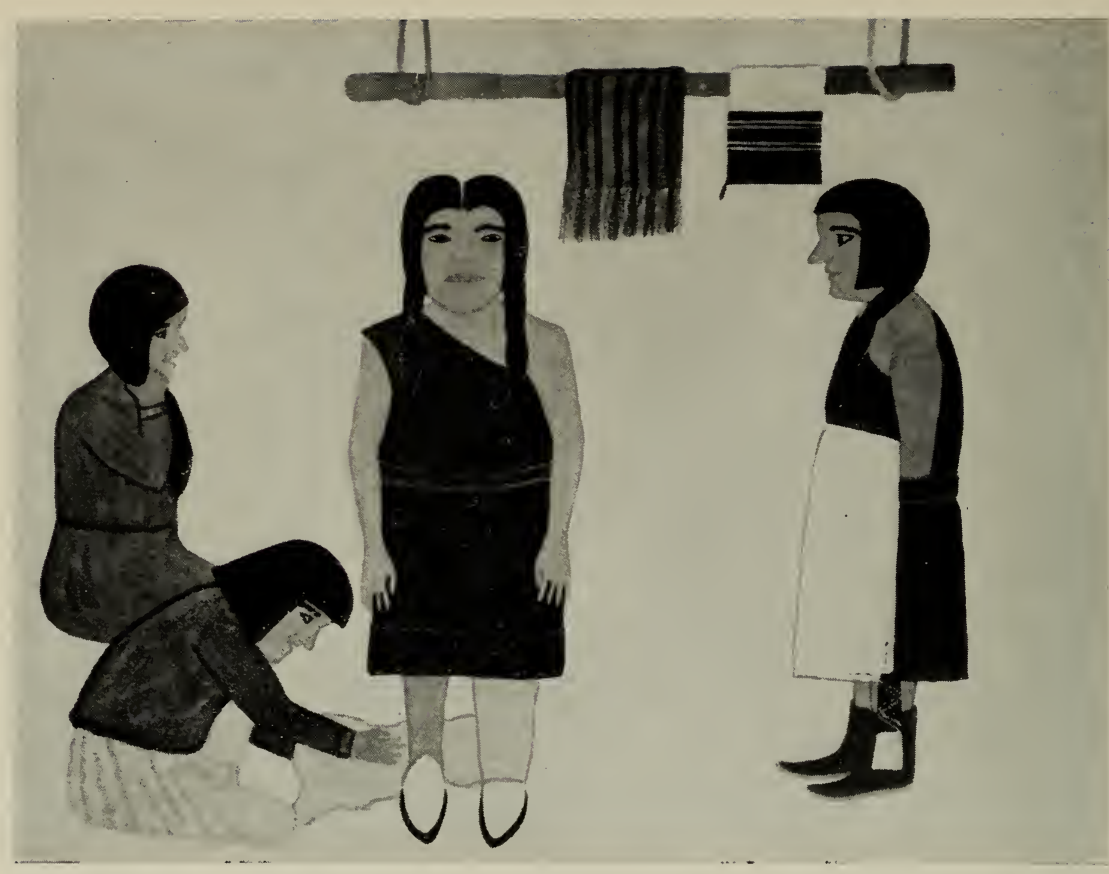

25

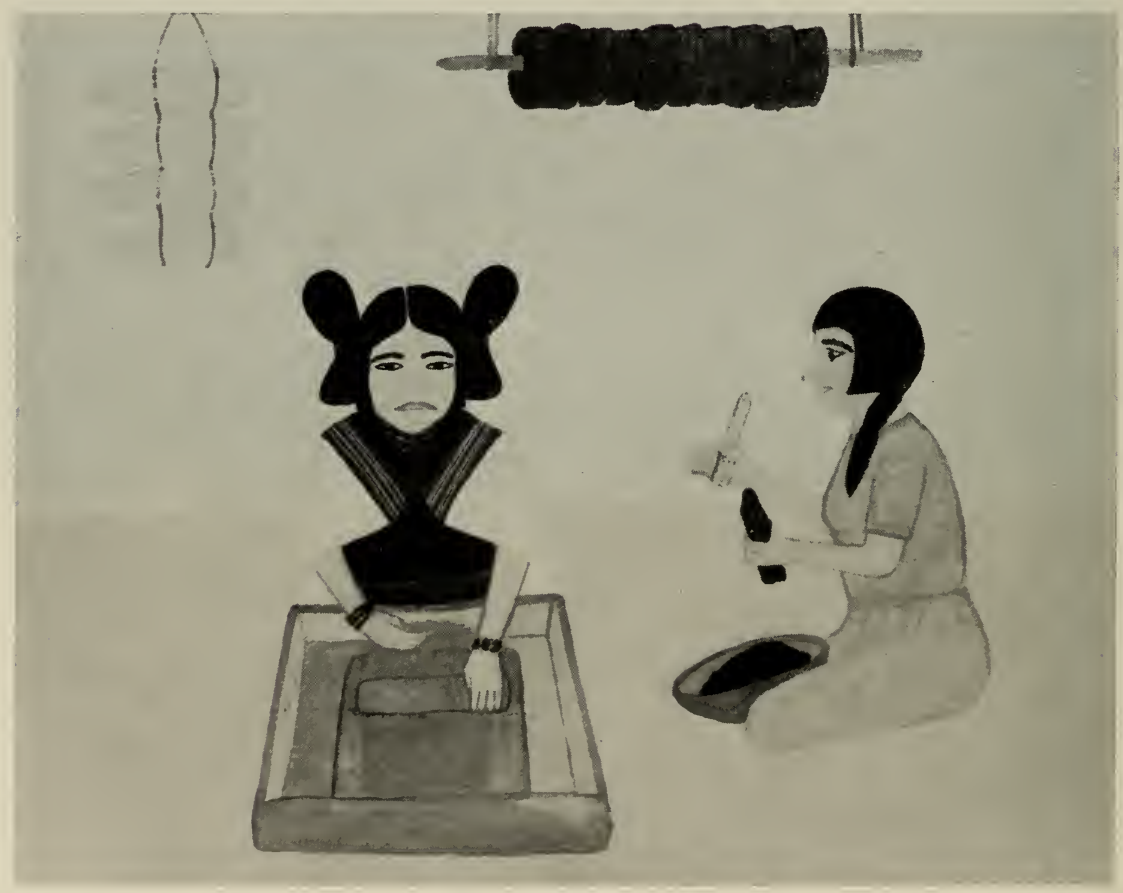


FIGURES 27,28

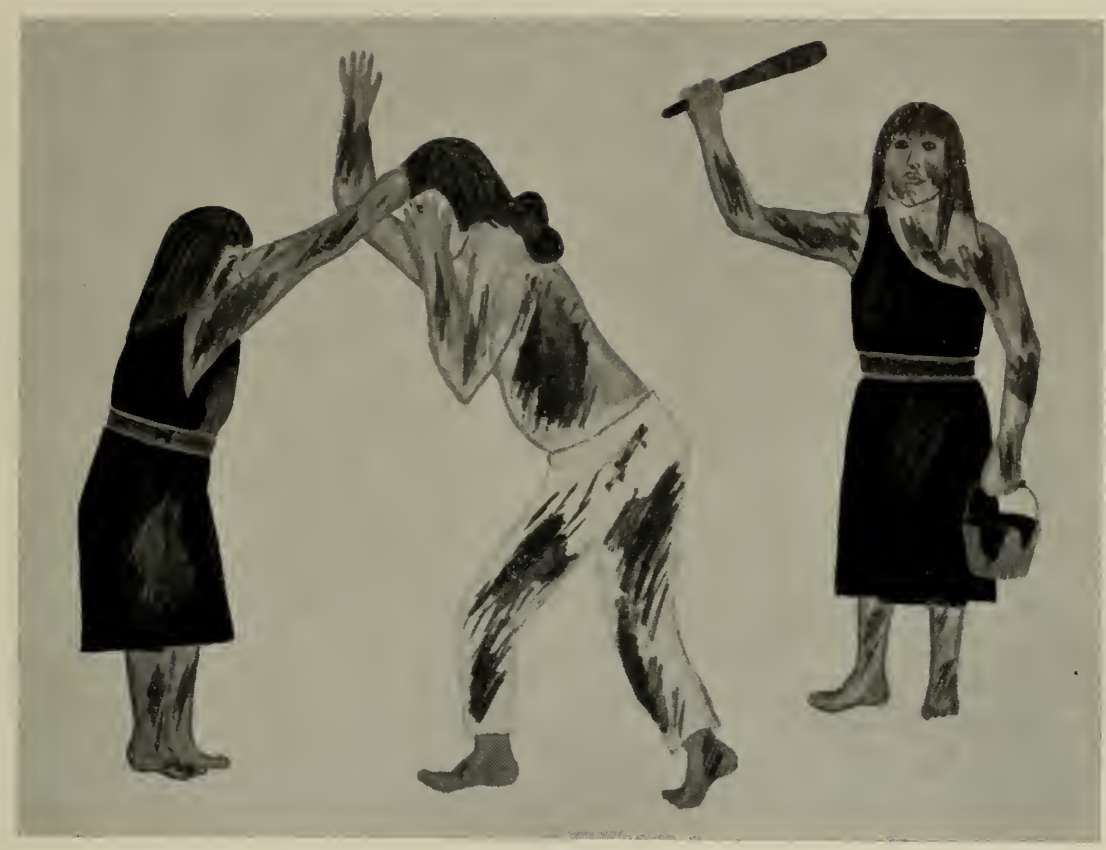

27

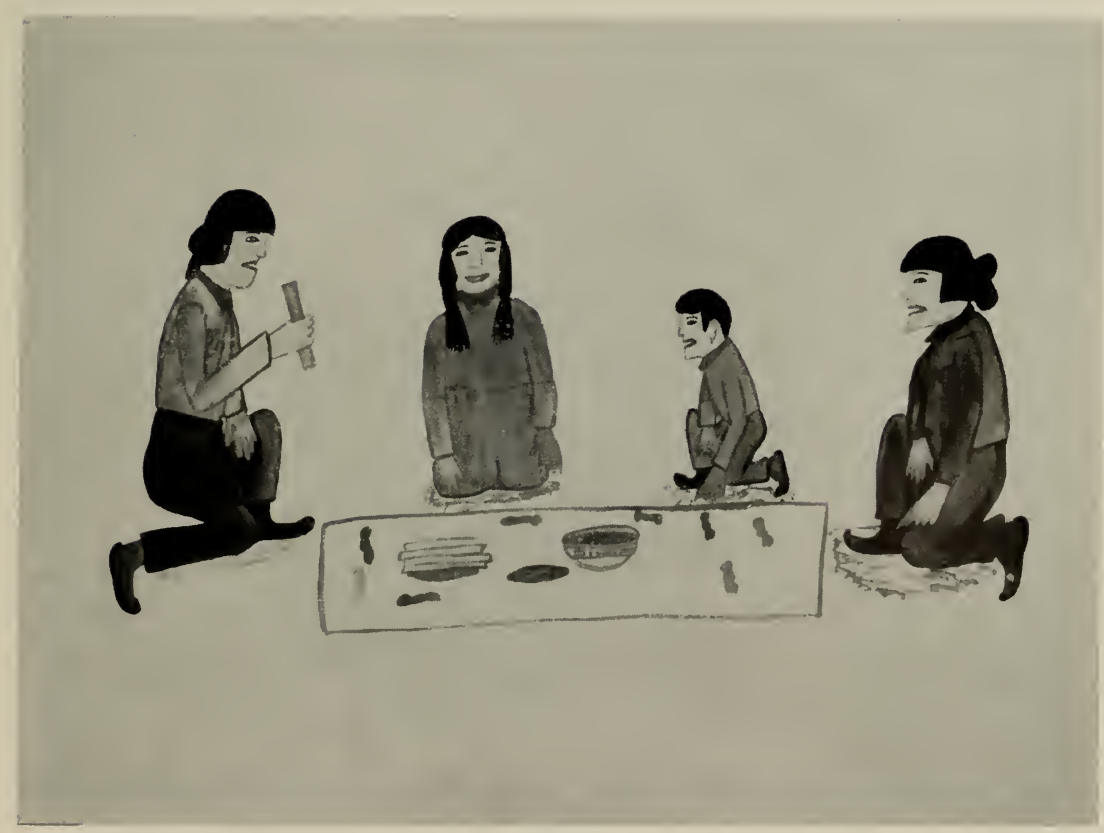


FIGURES 29,30

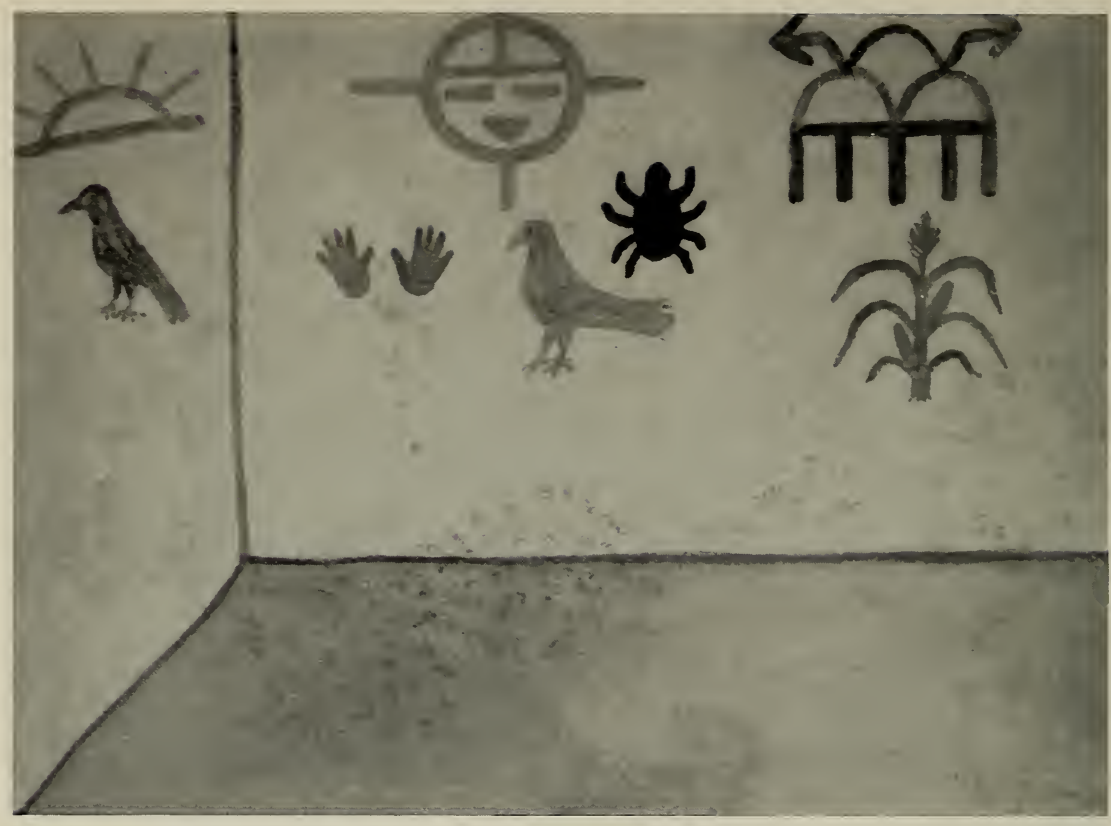

29

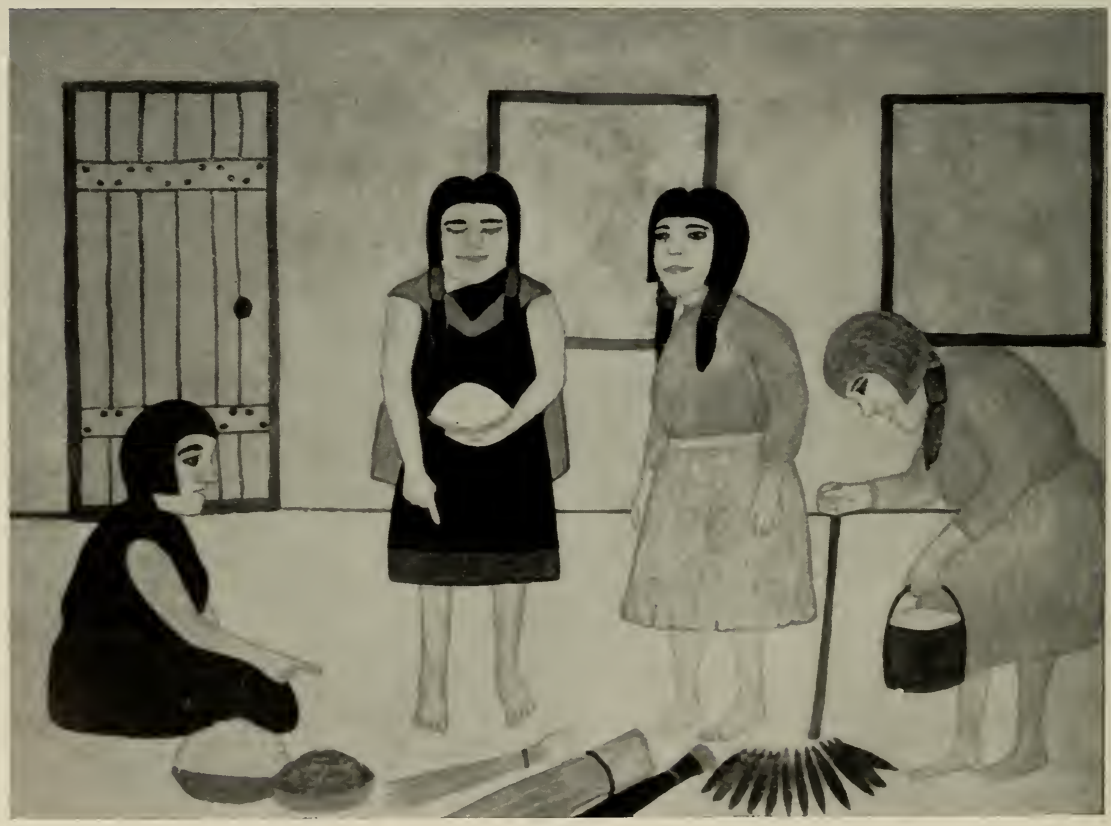


FIGURES 3I, 32

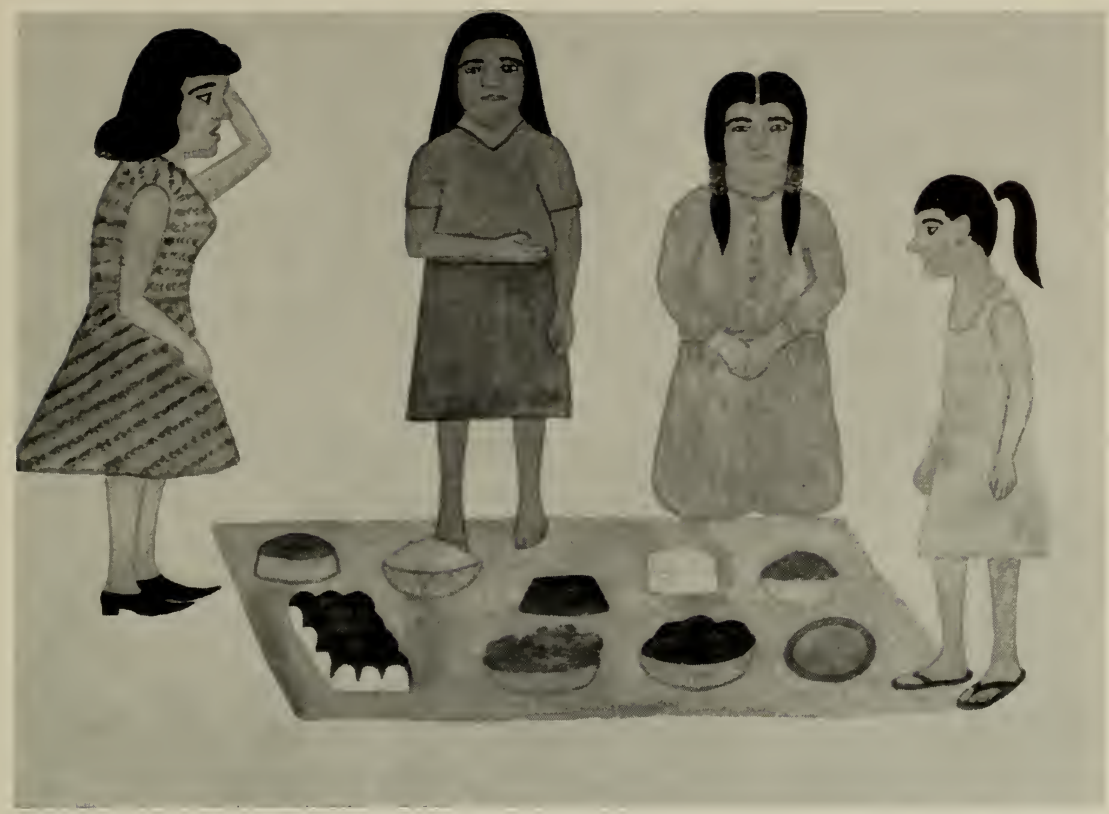

31

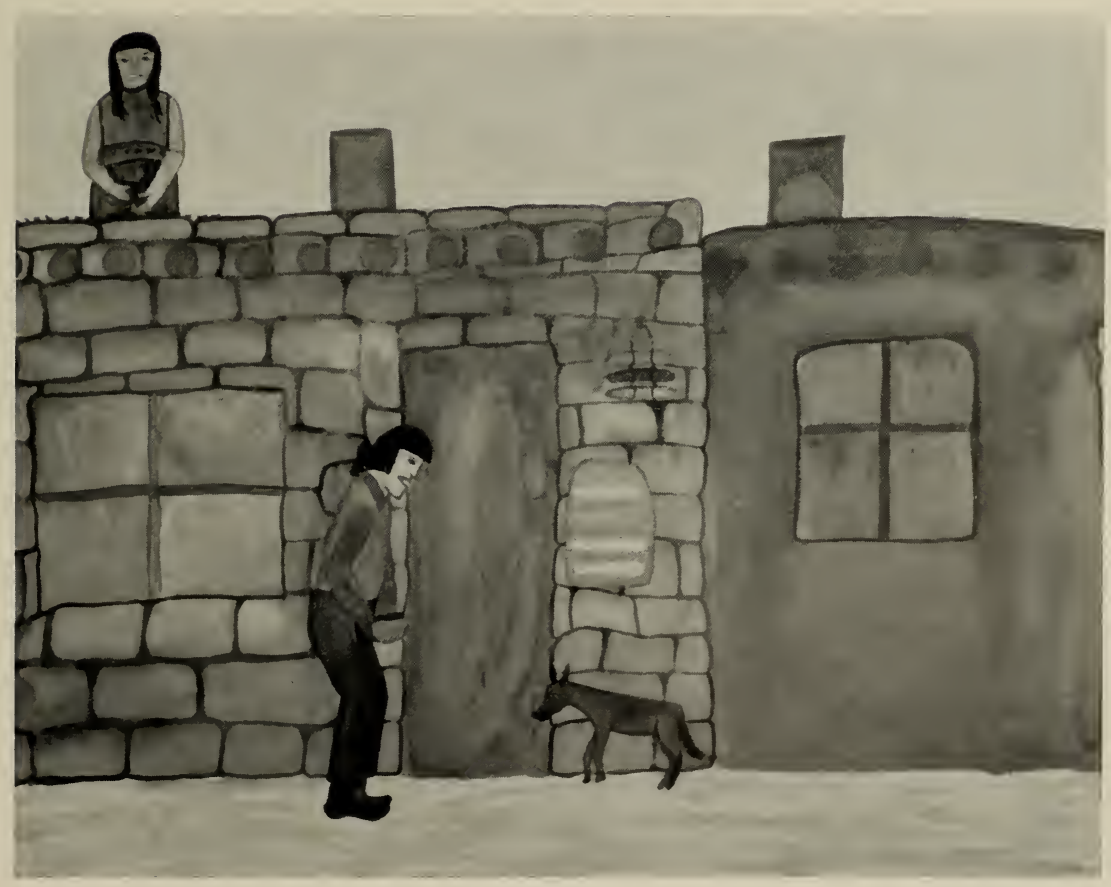




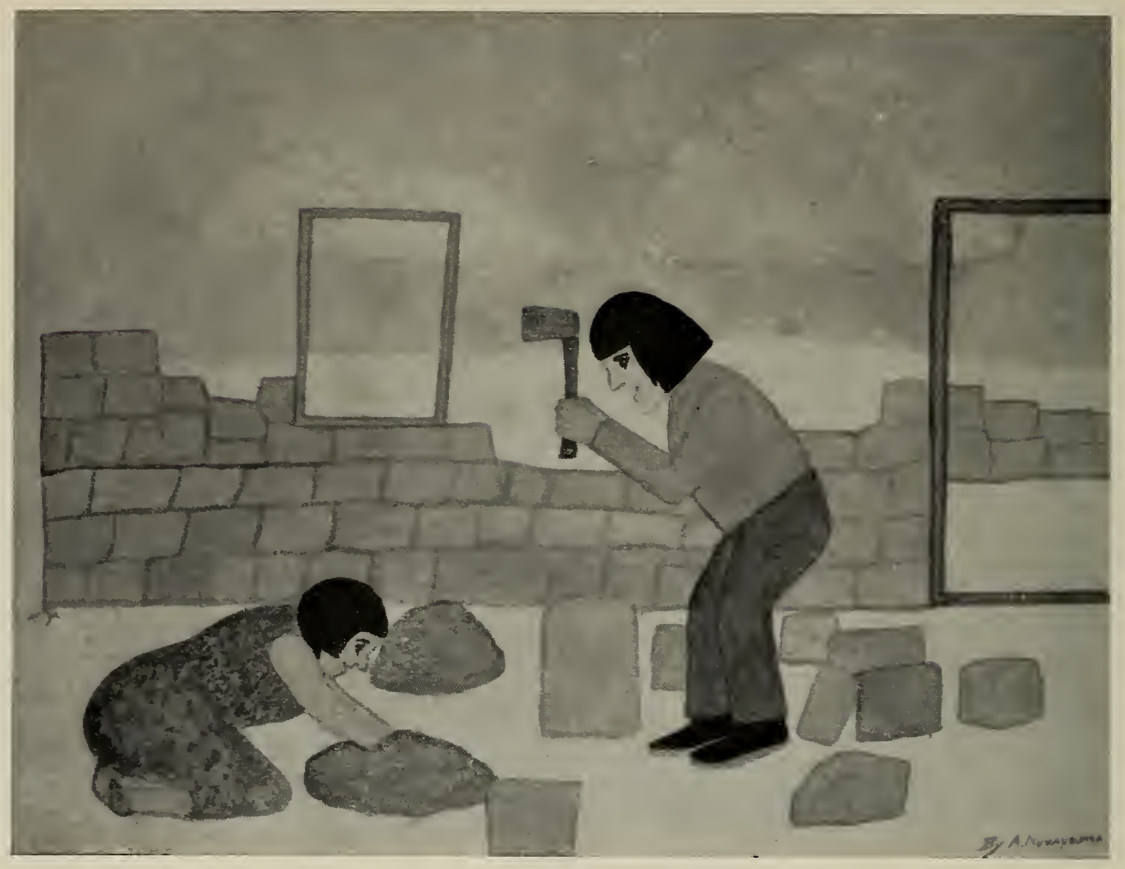

33

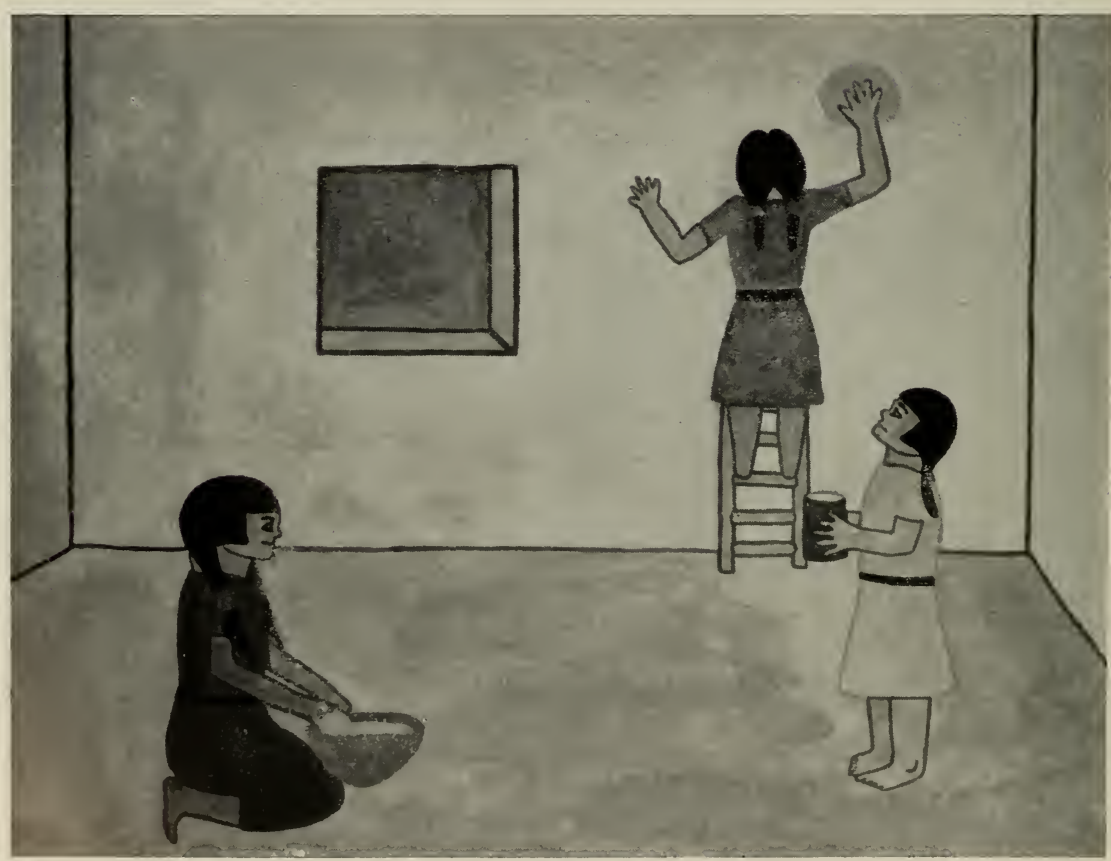


FIGURES 35,36

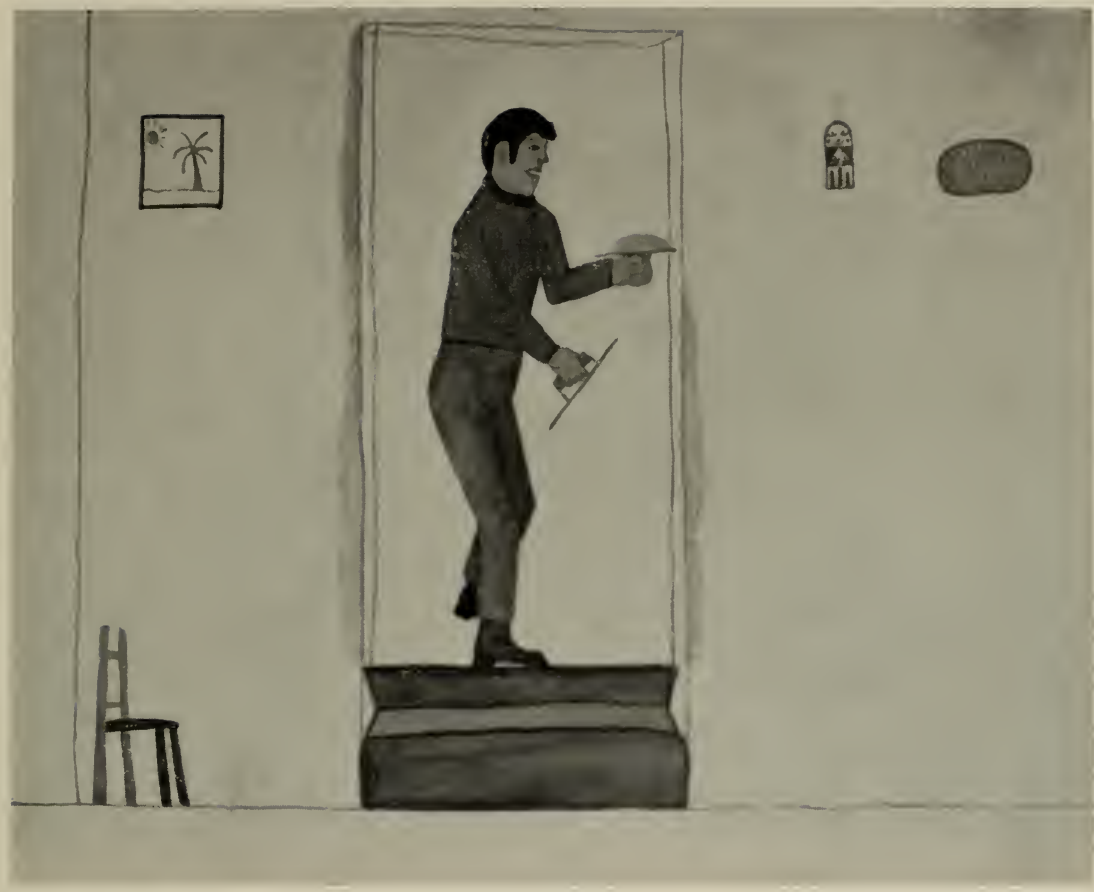

35

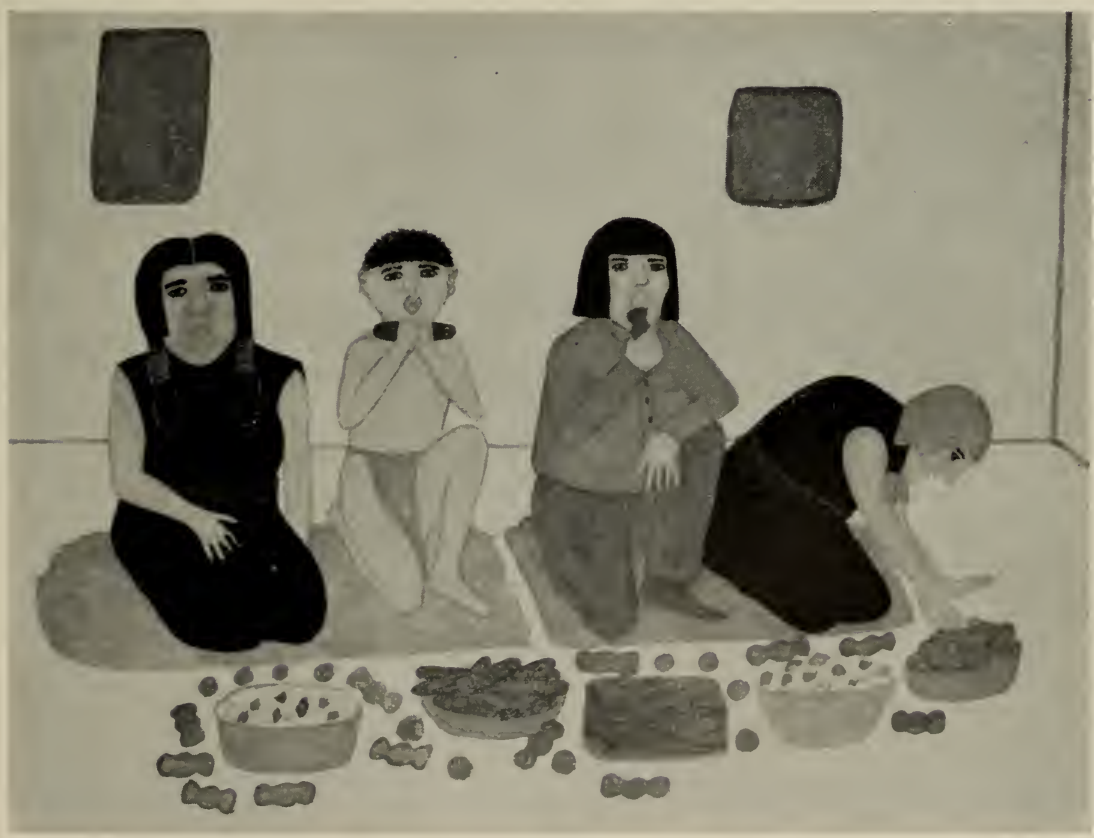


FIGURES 37,38
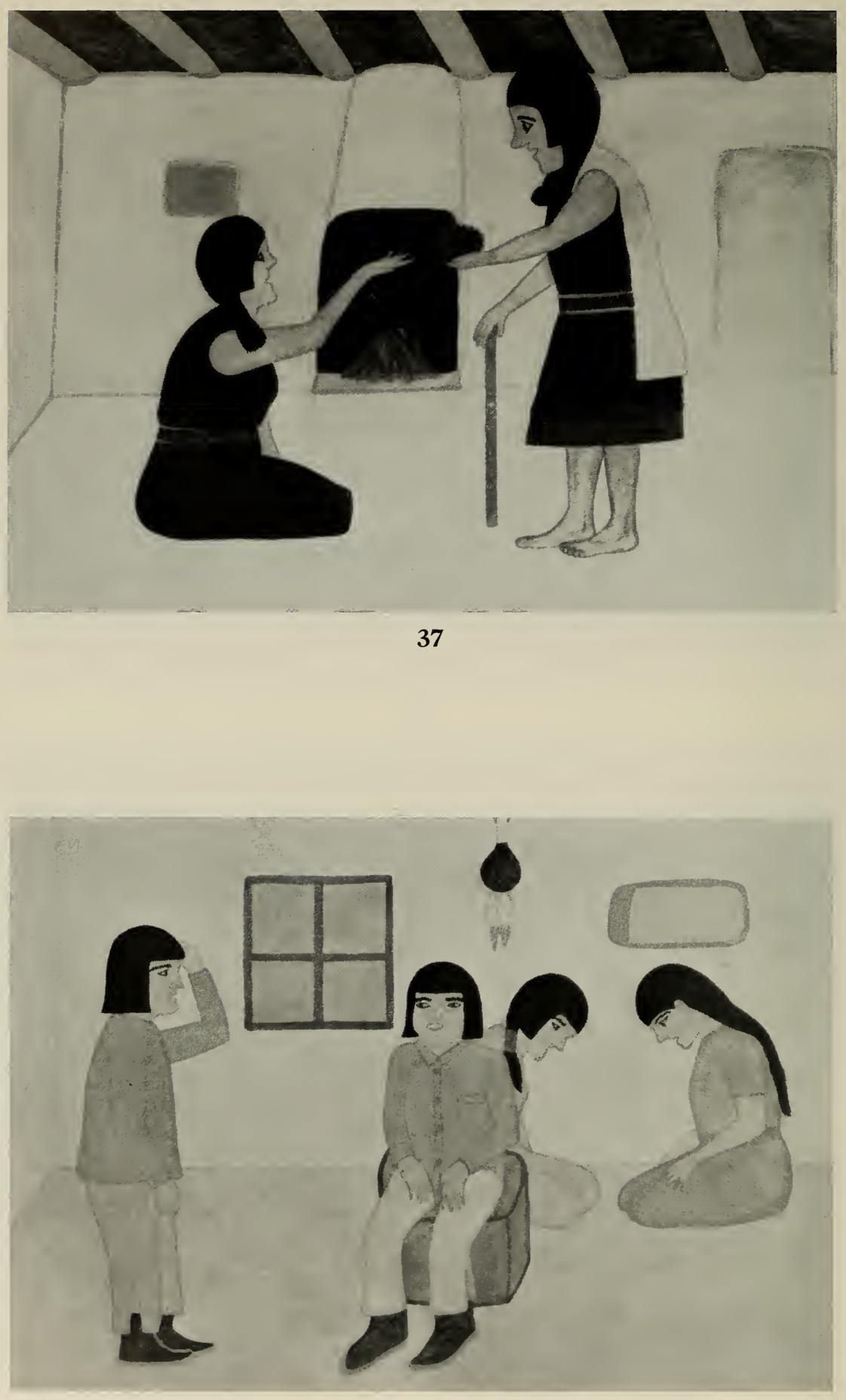
FIGURES 39,40
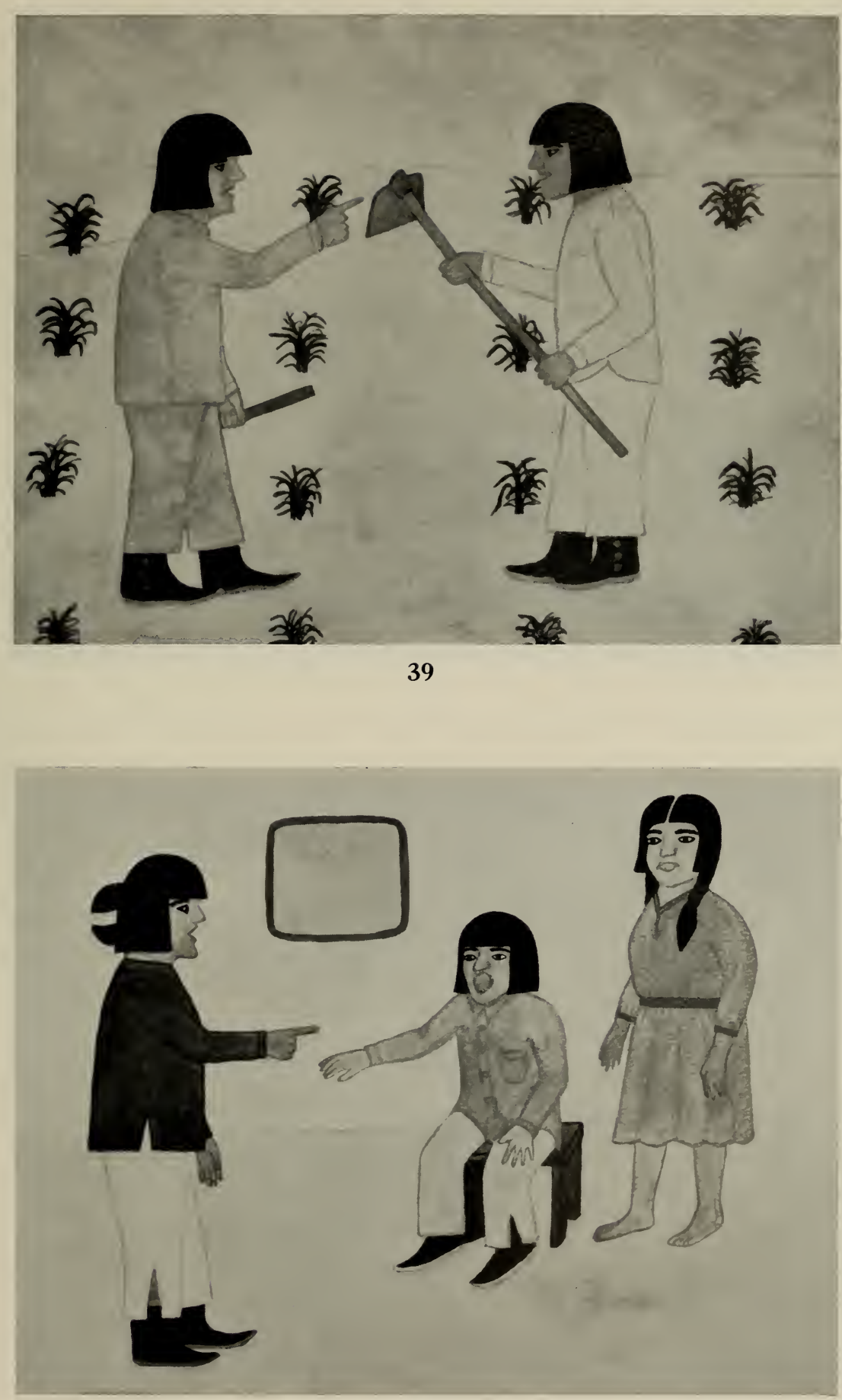
FIGURES 4I, 42

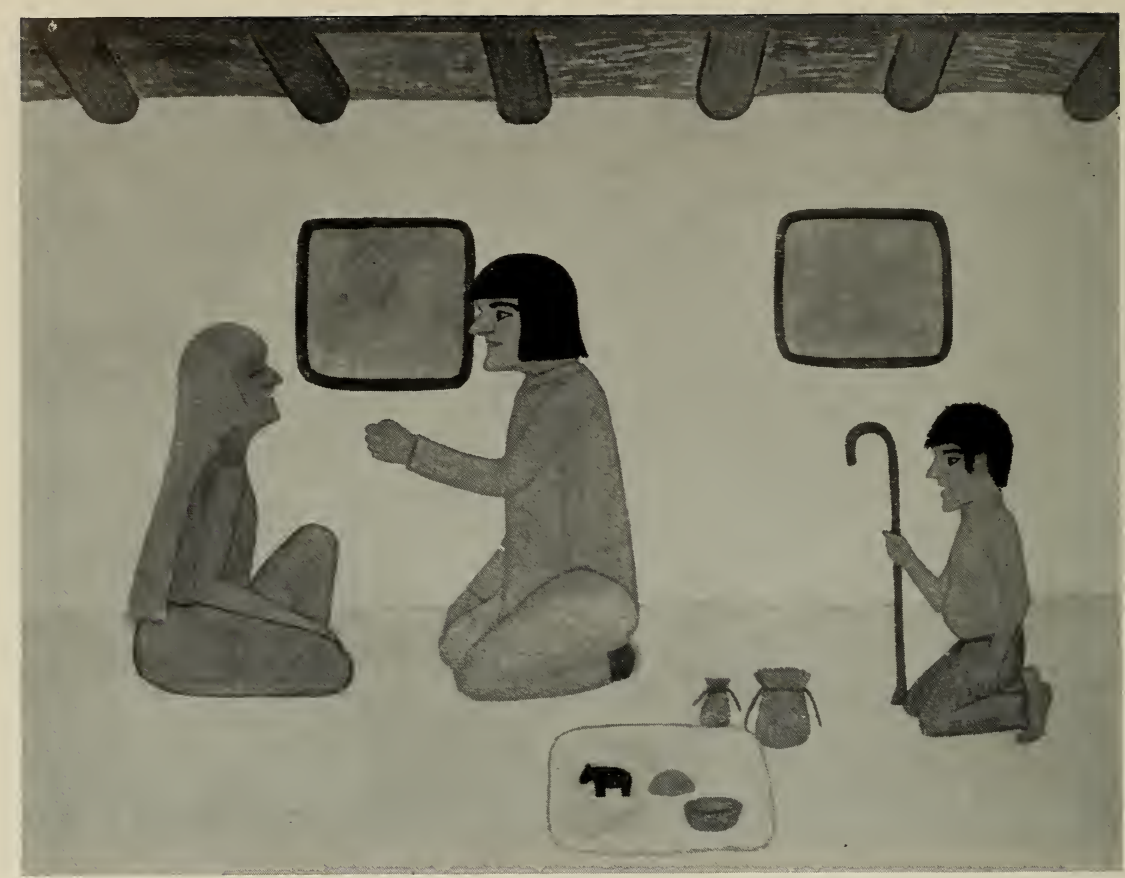

41

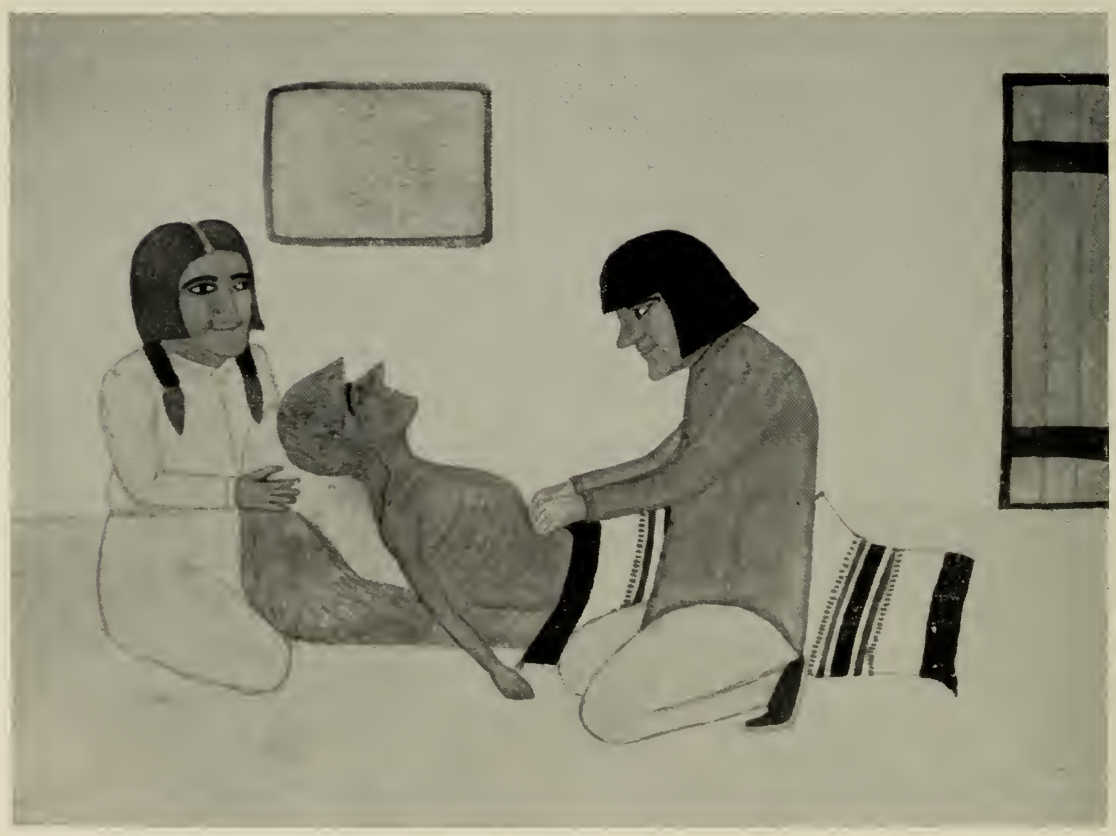



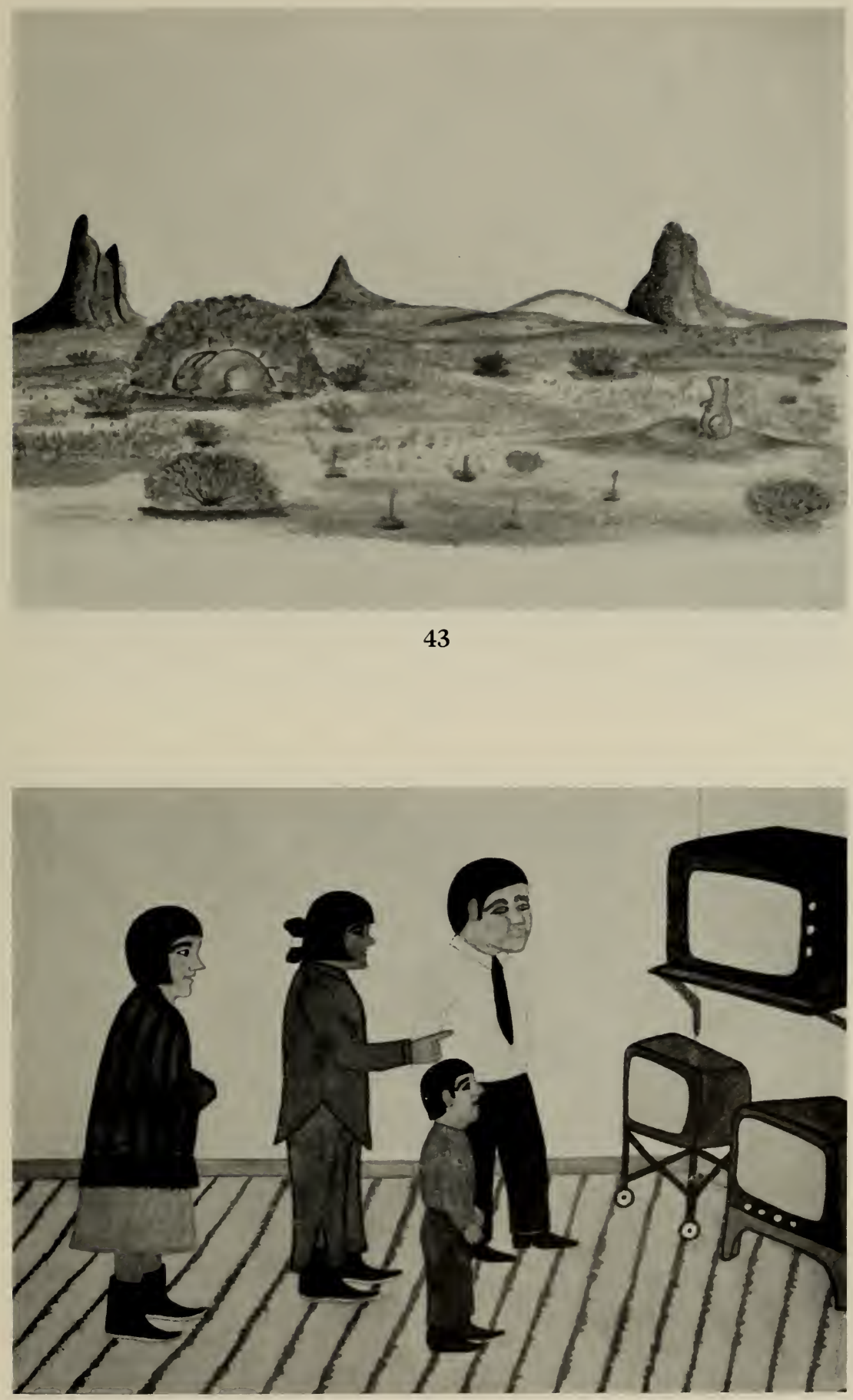


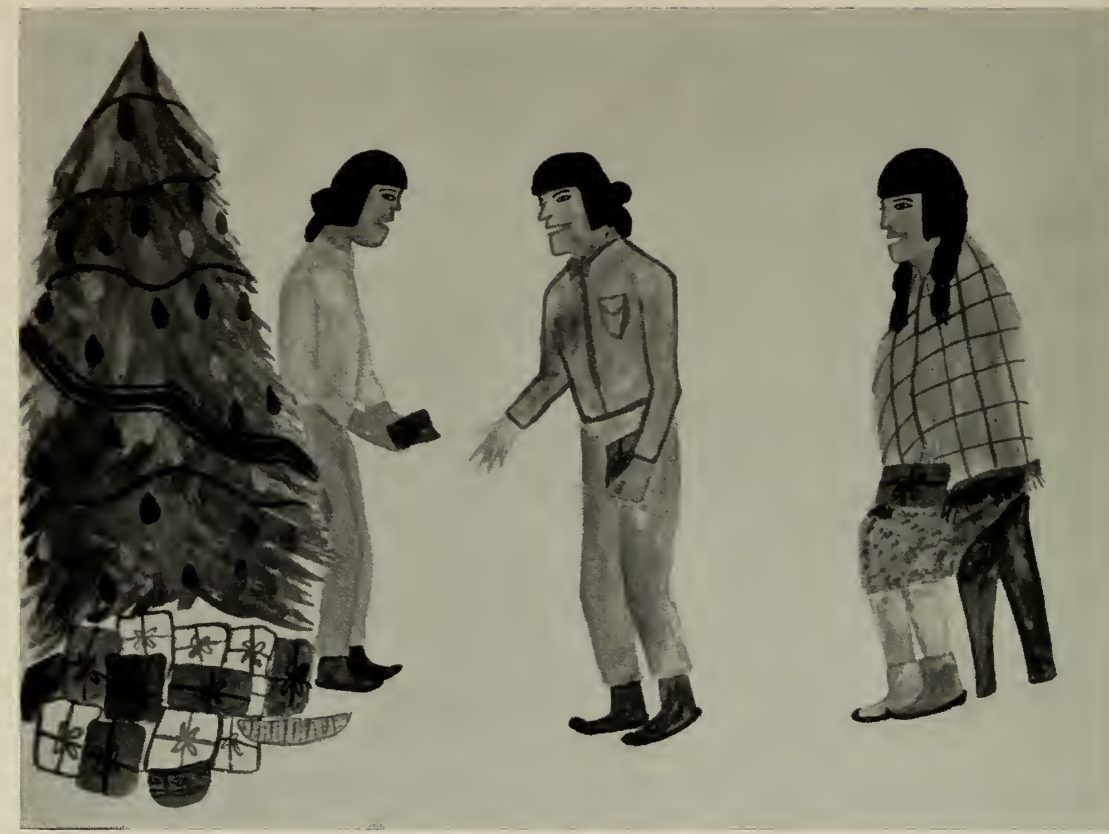

45

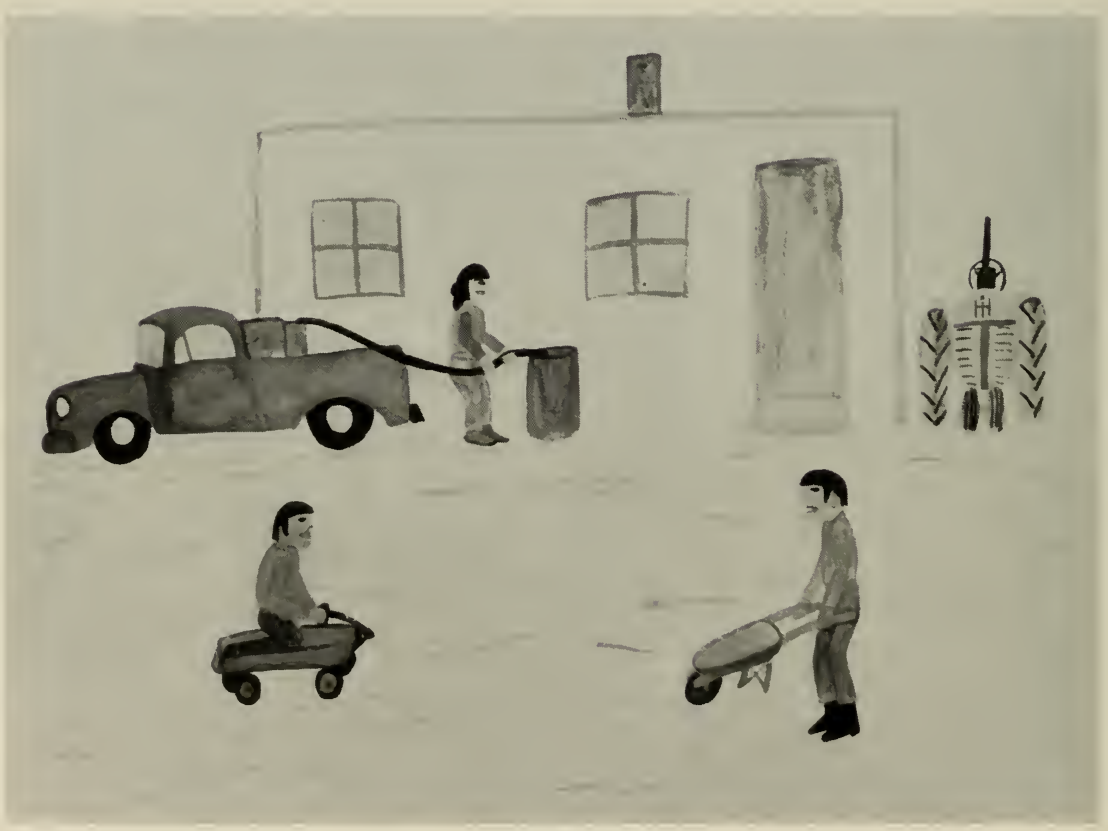


FIGURES $47,4^{8}$
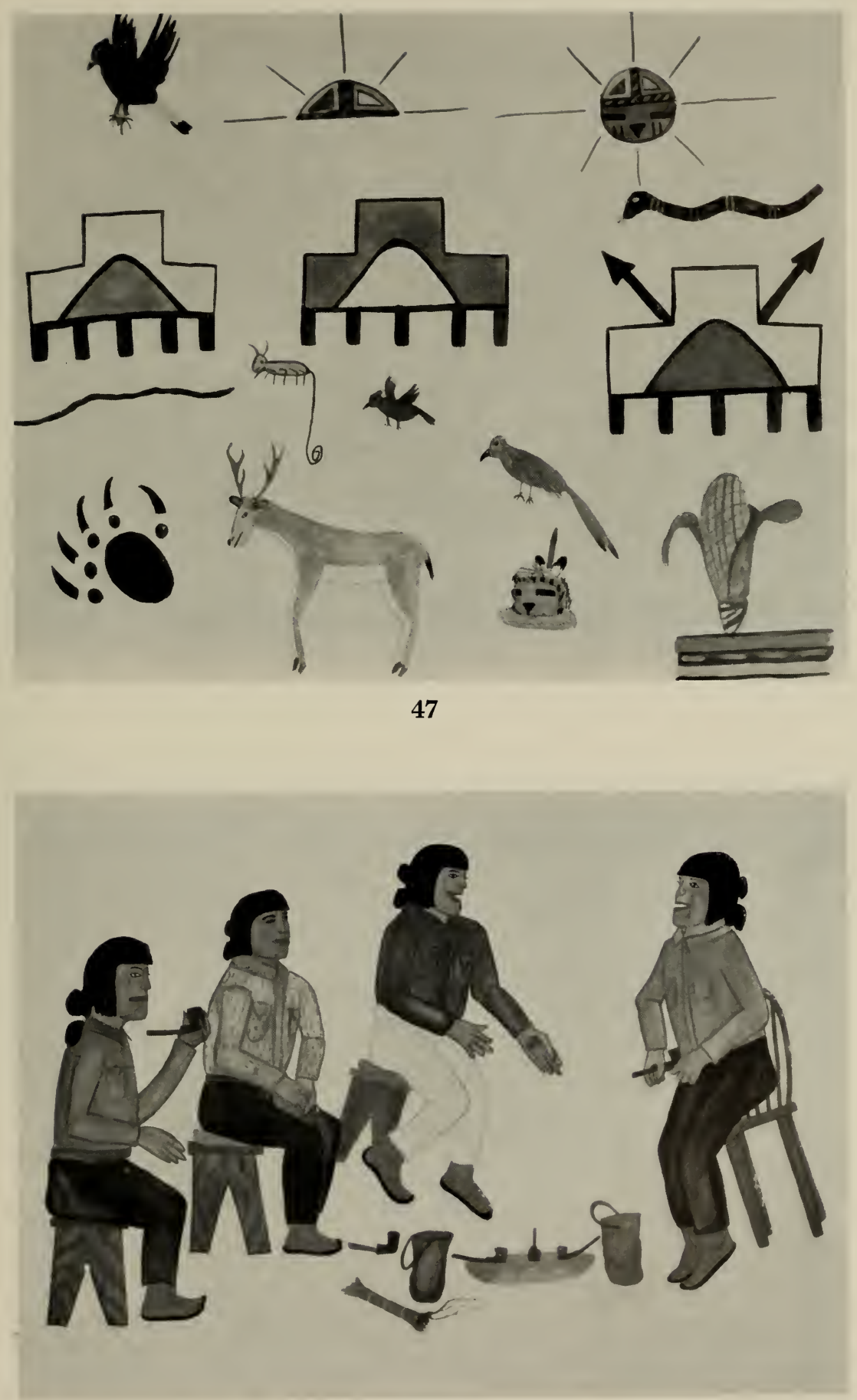
FIGURES 49,50
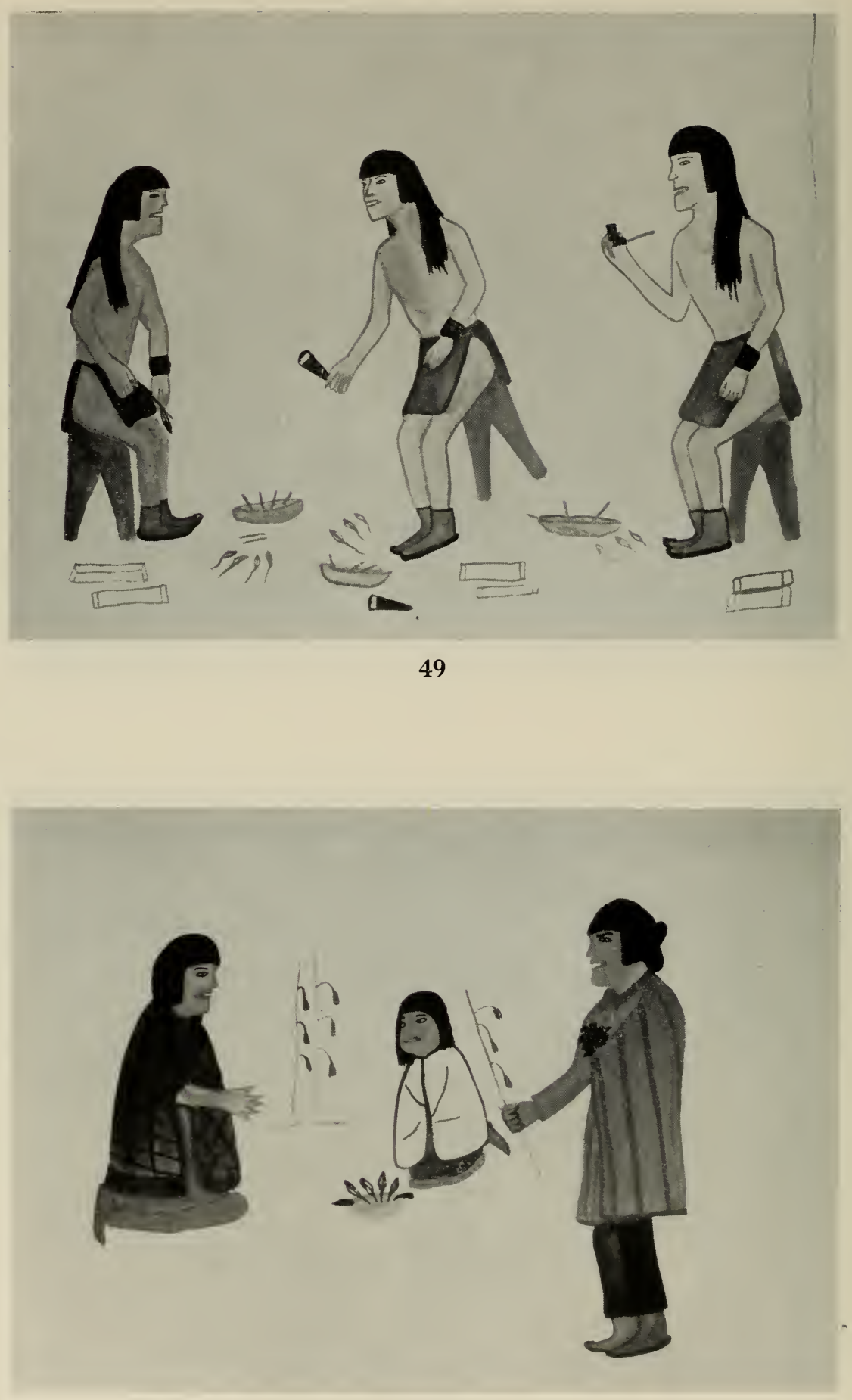
FIGURES 5 I, $5^{2}$

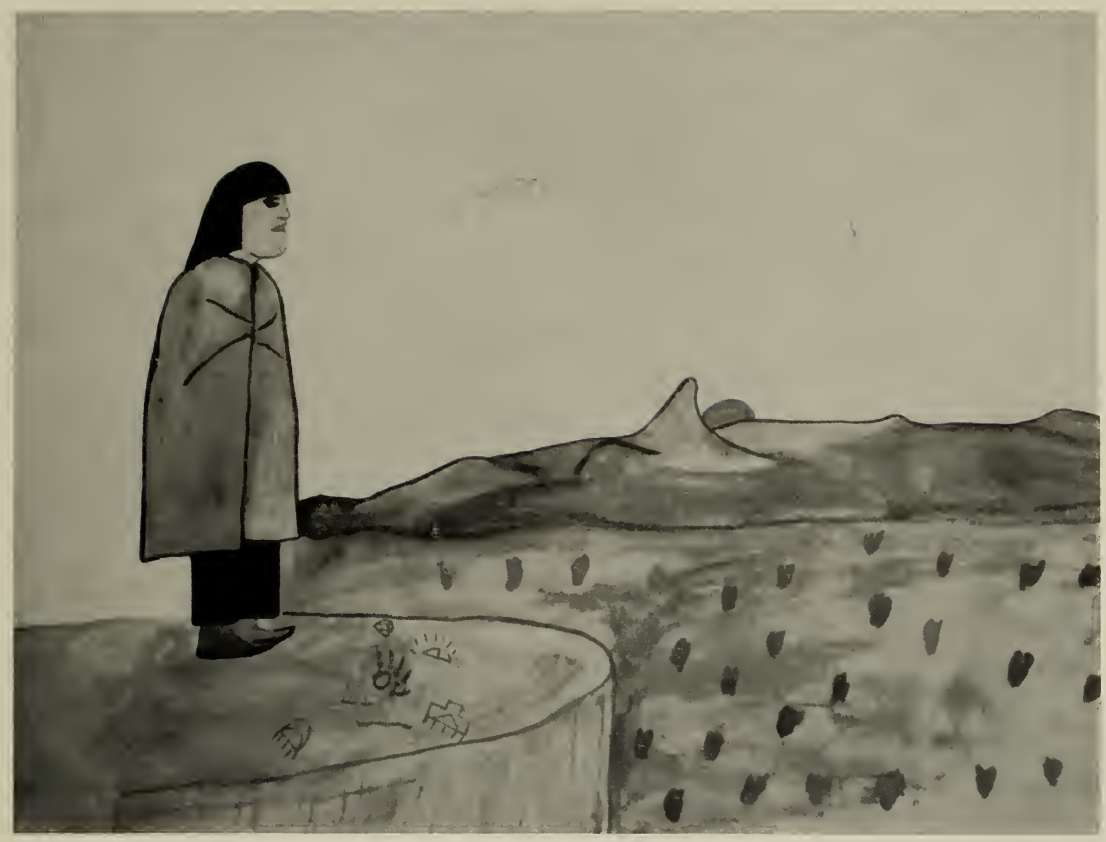

51

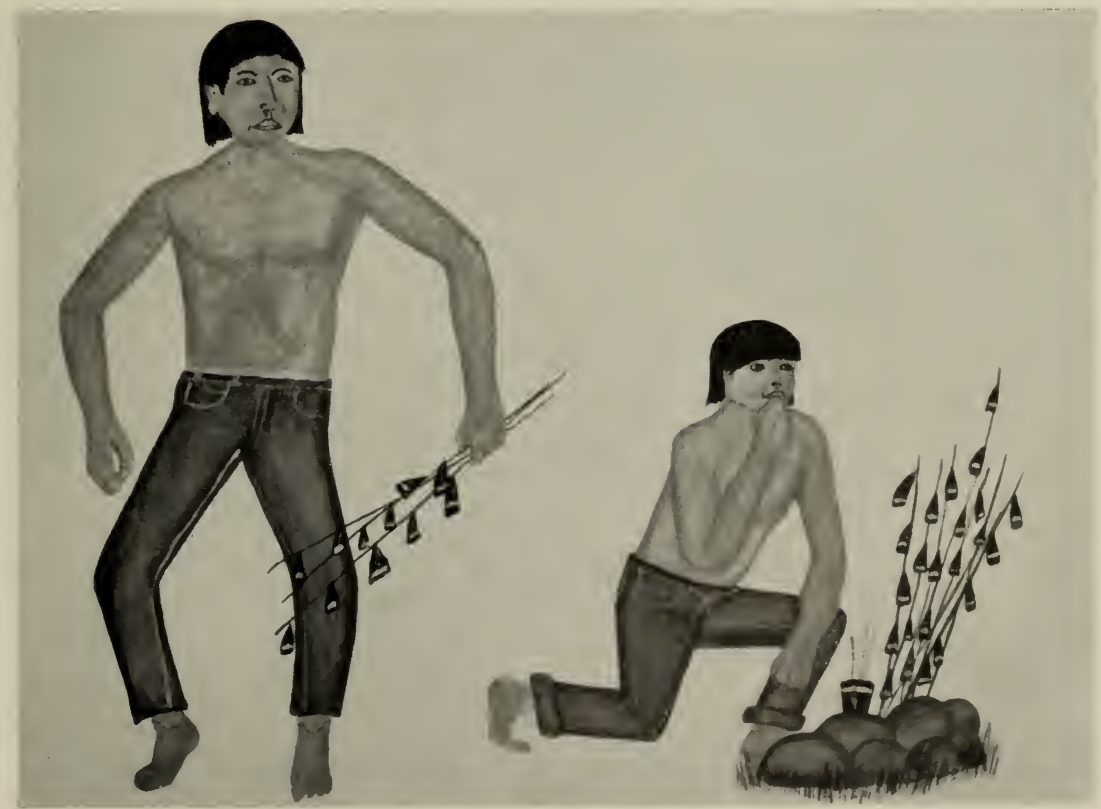

52 

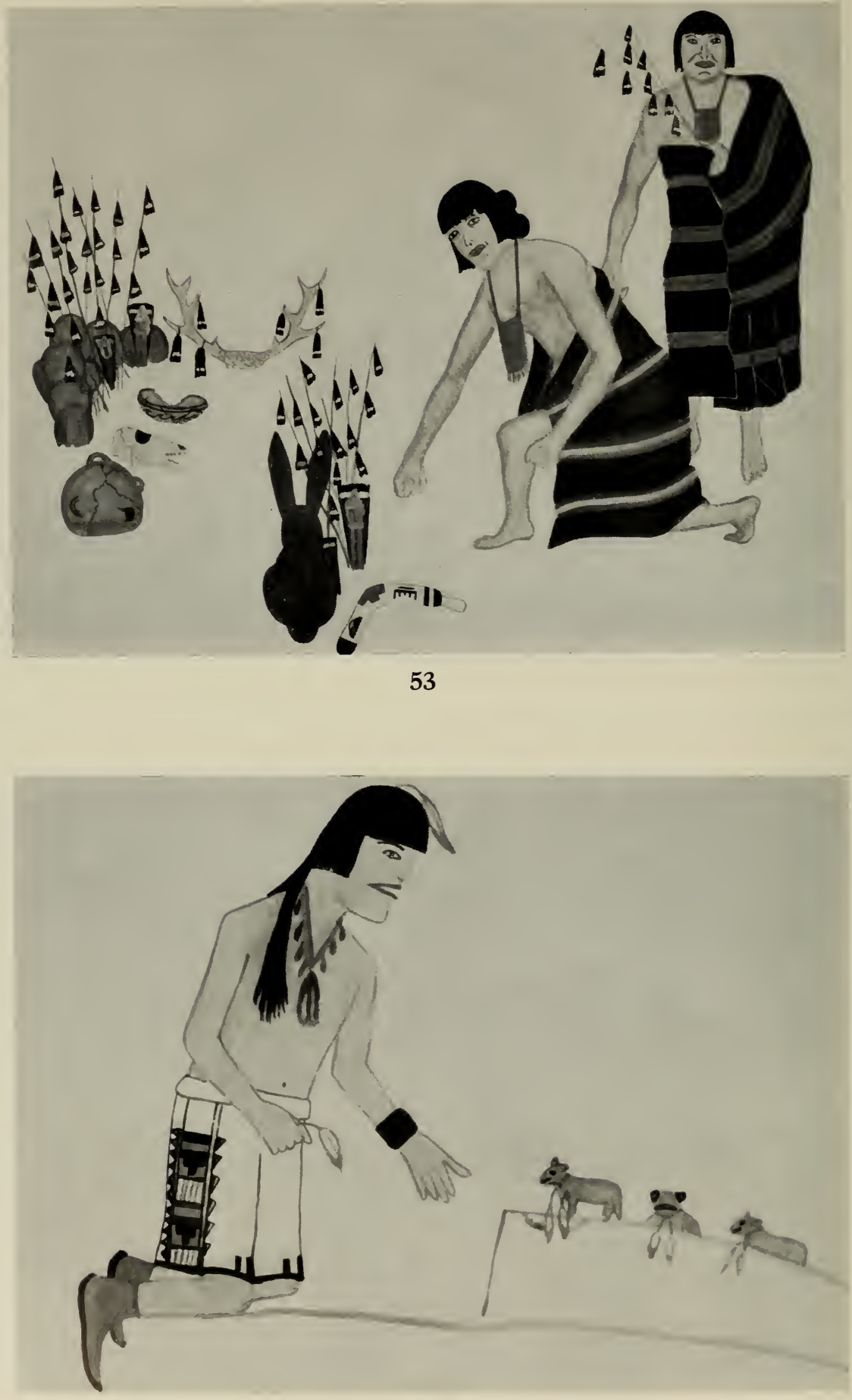

54 
FIGURES 55,56

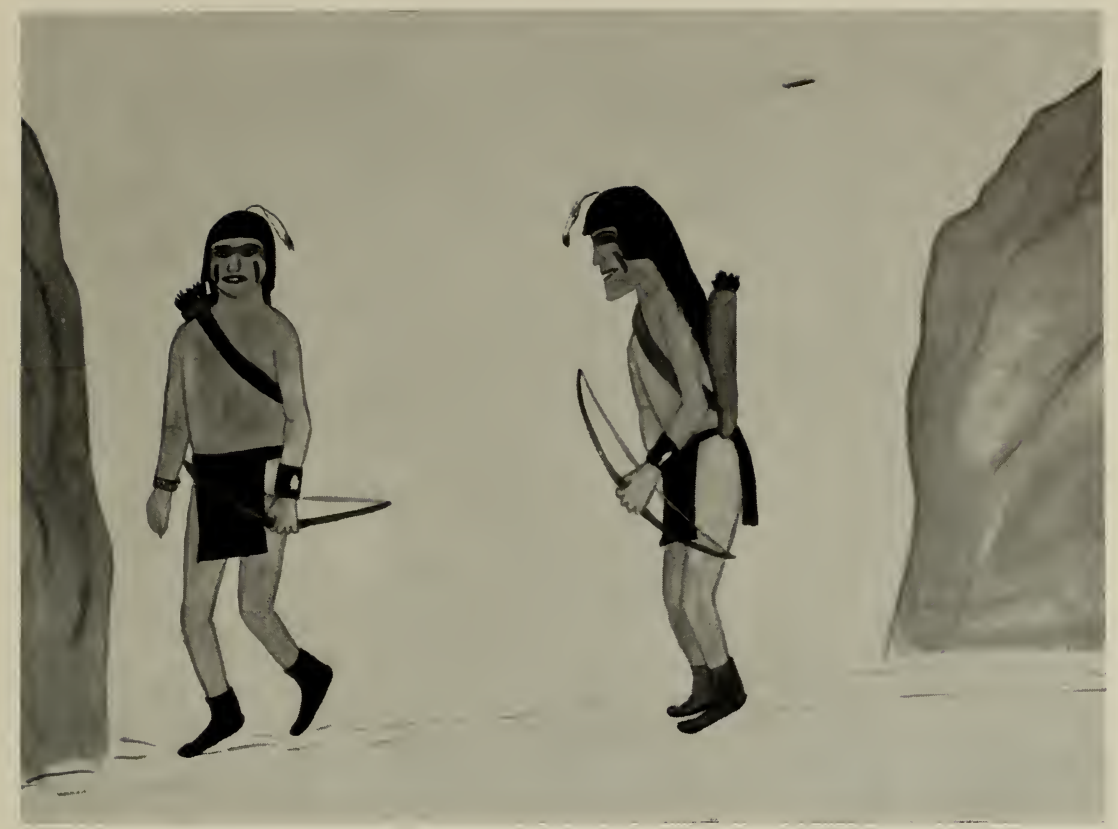

55

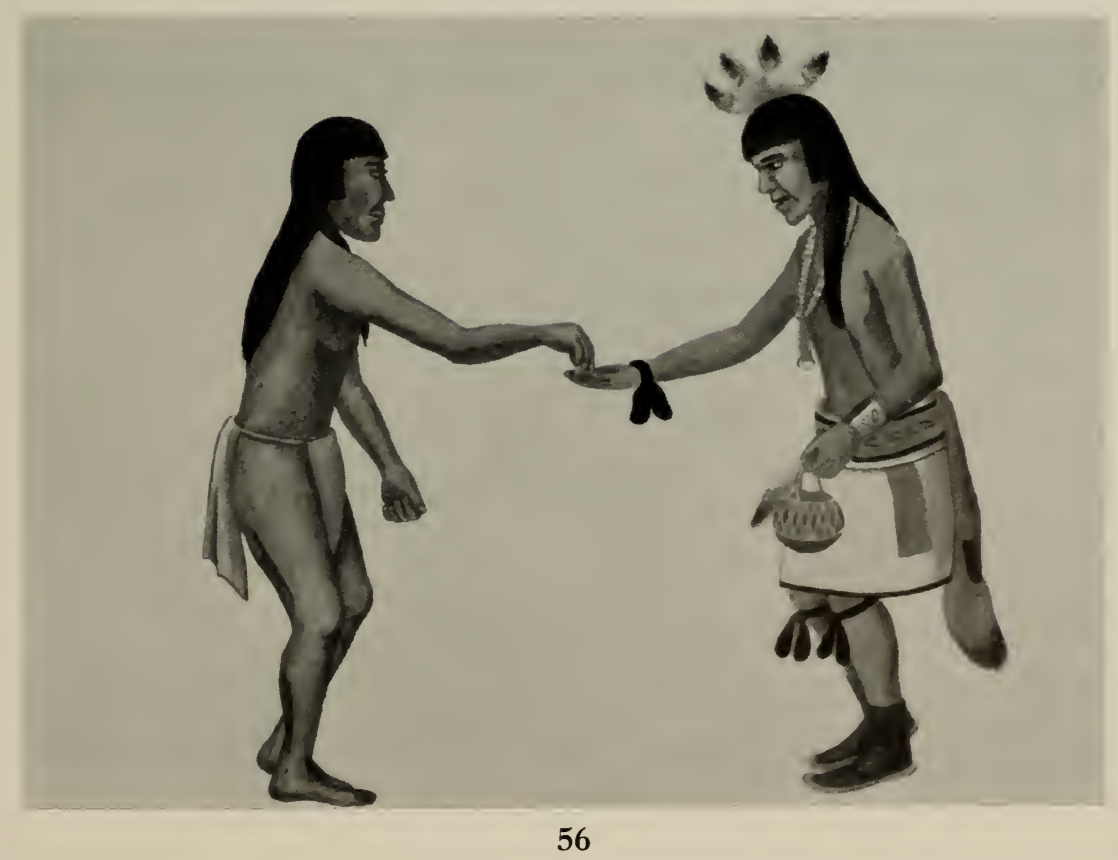


FIGURE 57

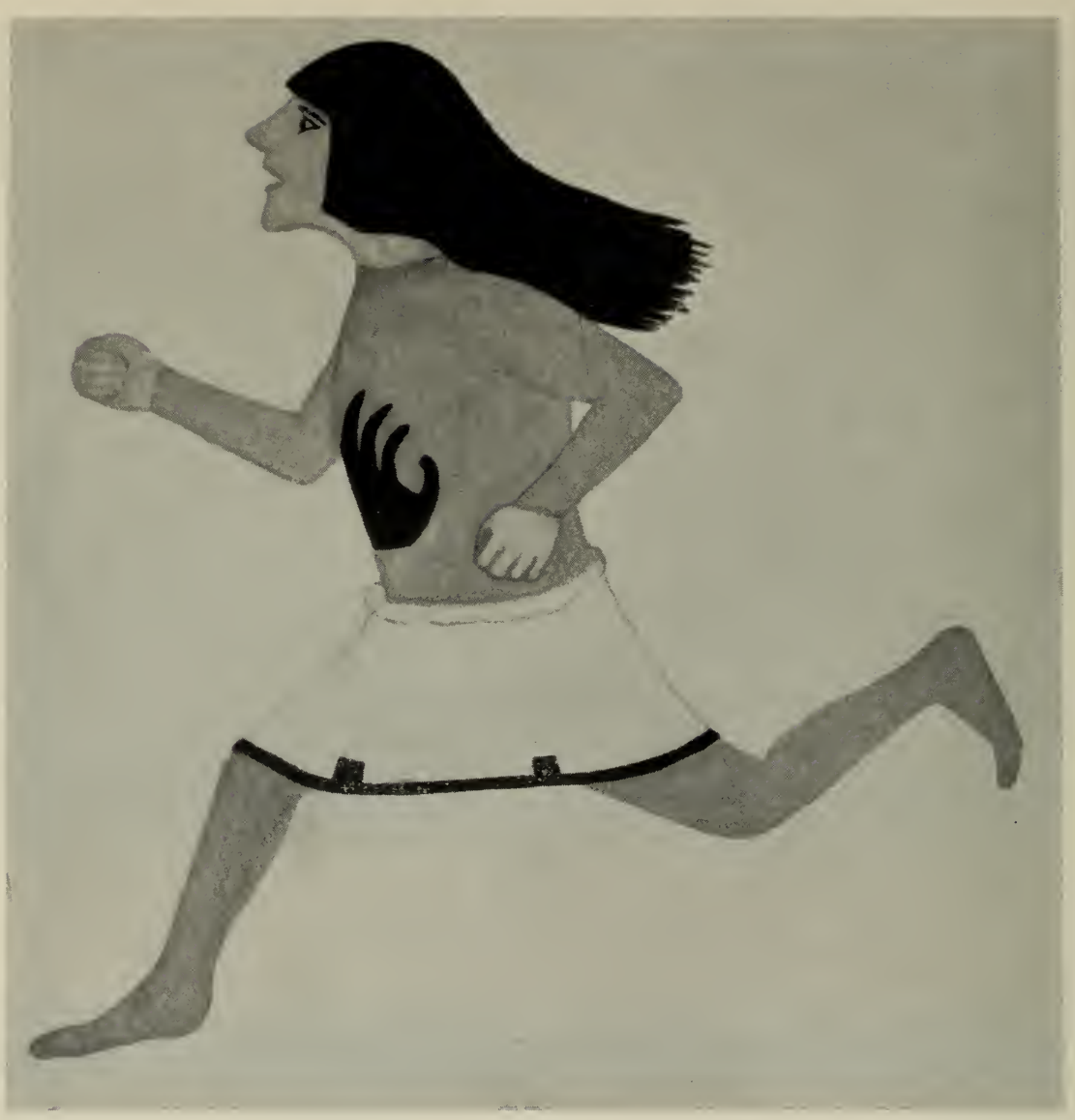


FIGURES 58,59

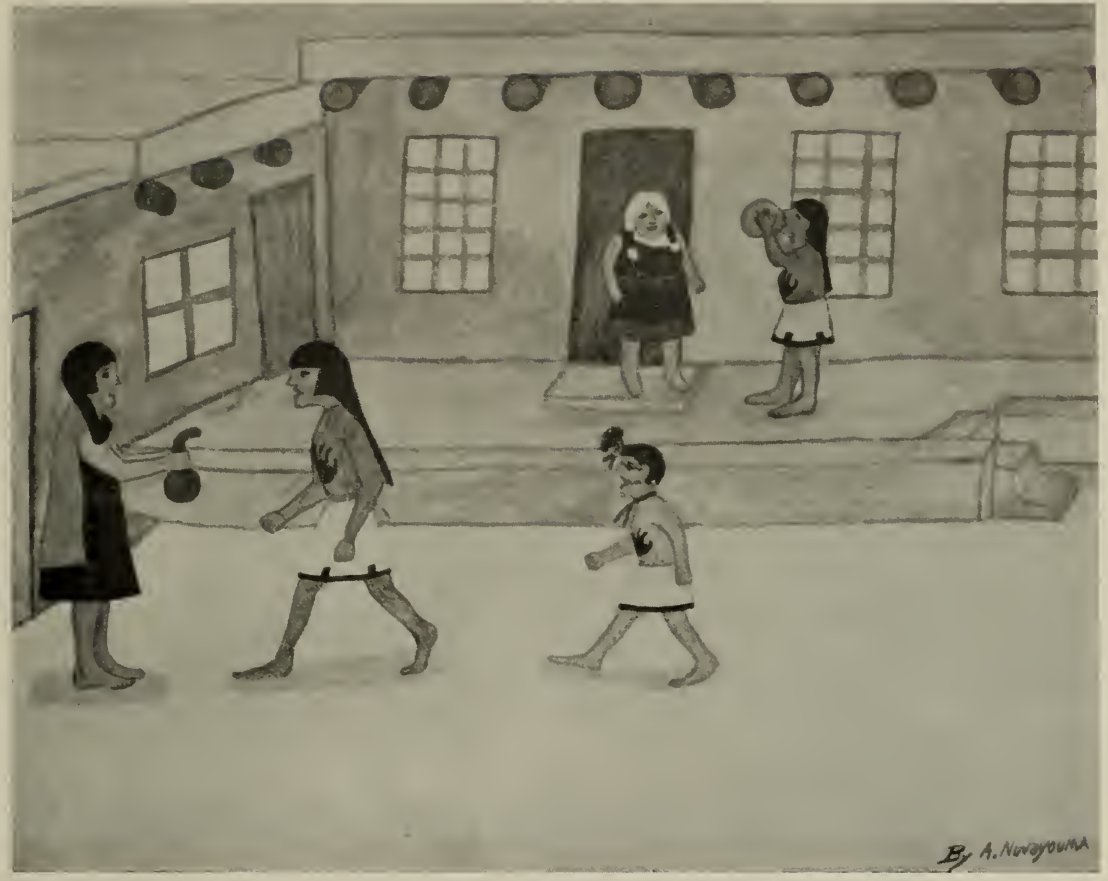

58
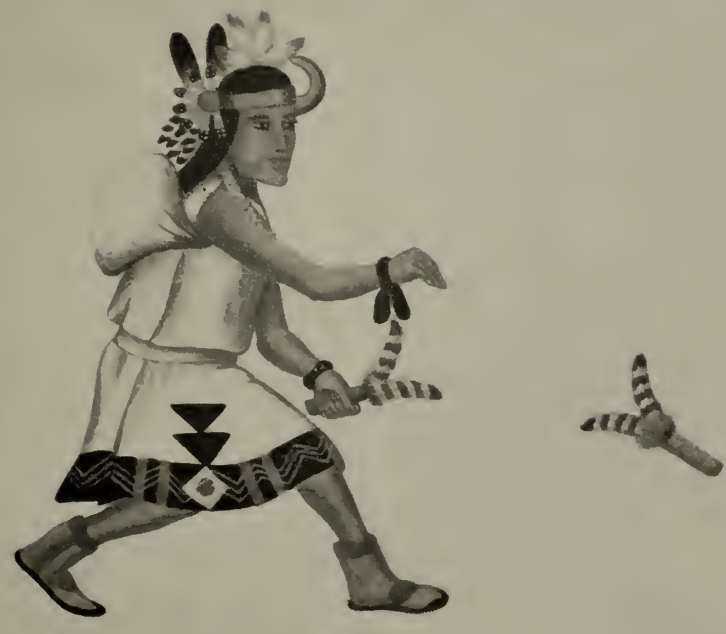

L. Pemanvanas 
FIGURE 60

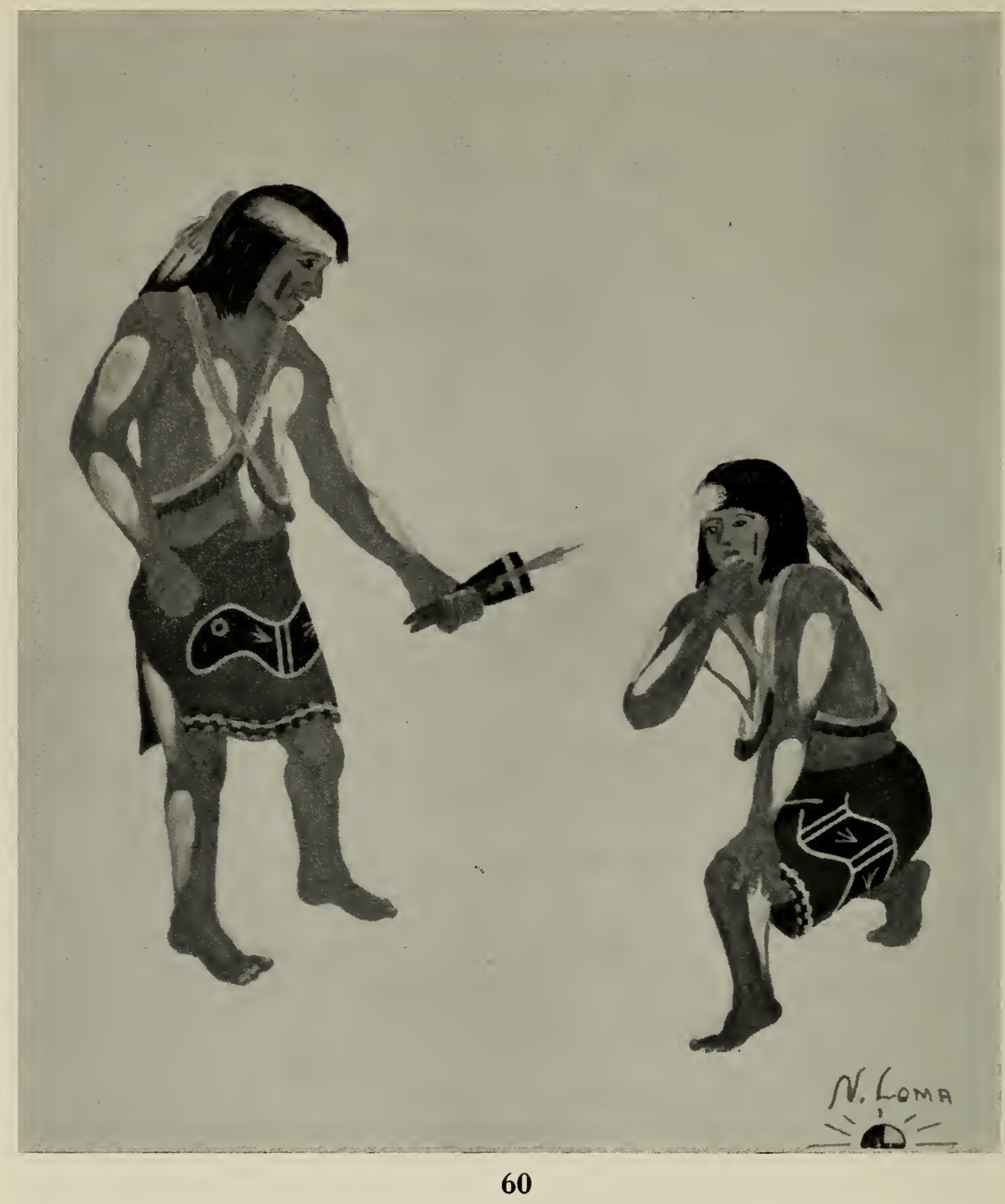


FIGURES 6 I, 62

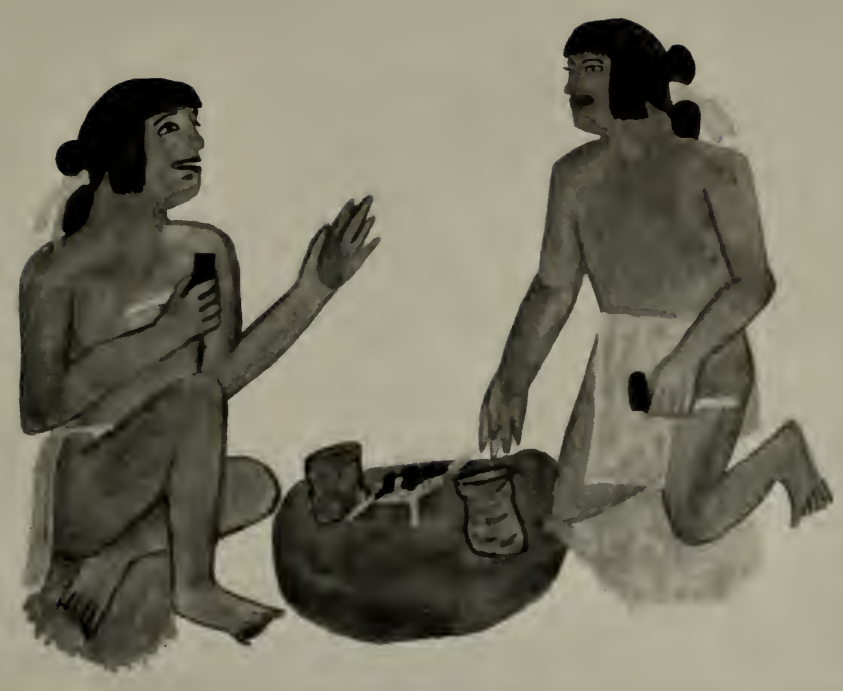

61

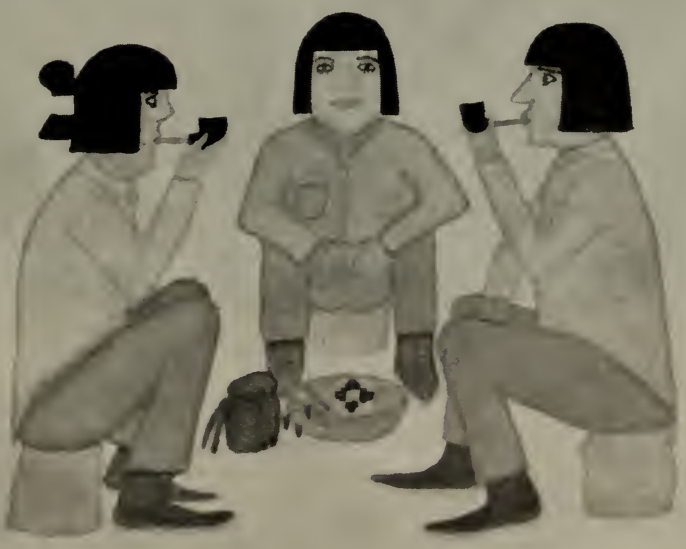




$$
\text { K }
$$


FIGURE 64

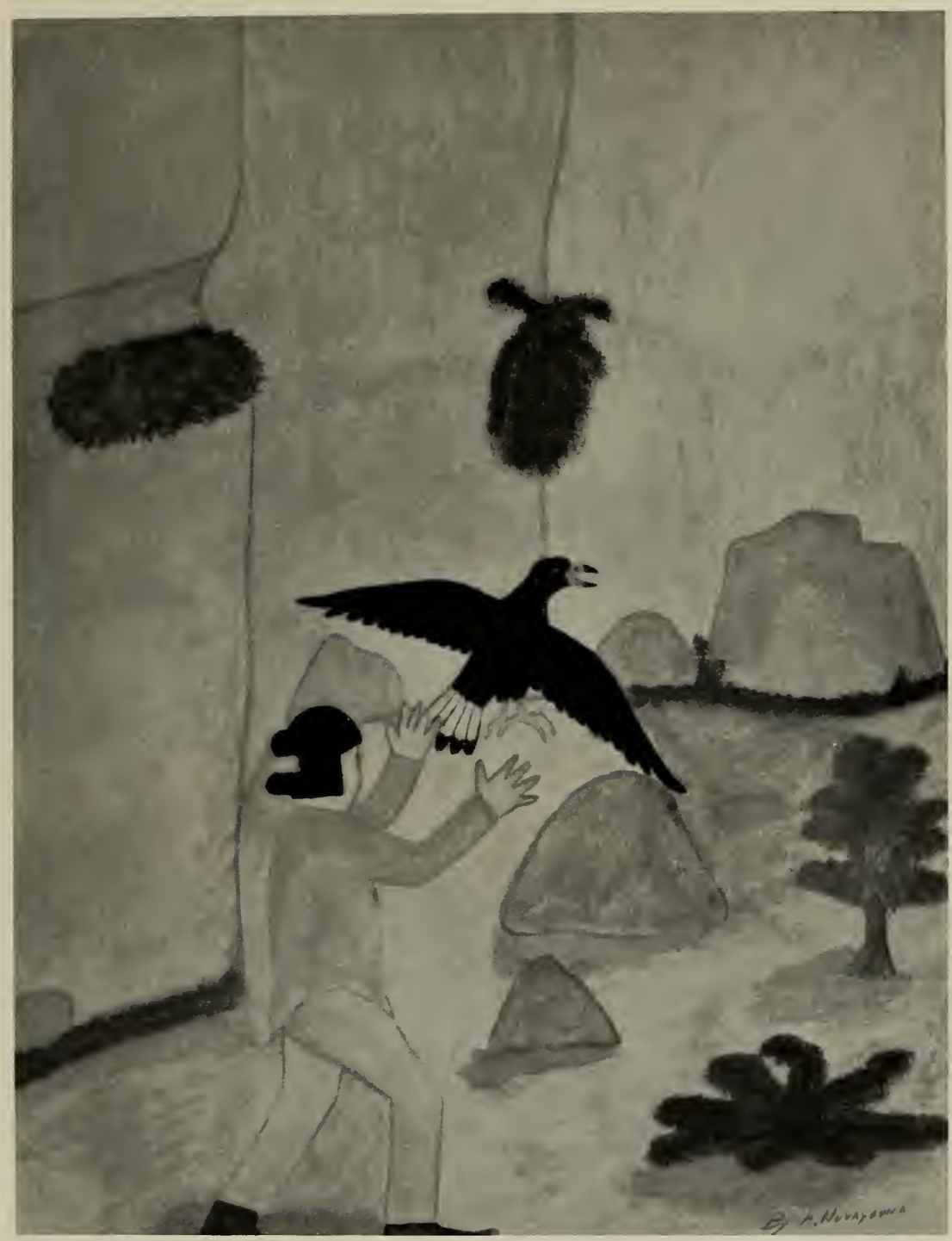

64 
FIGURES 65,66

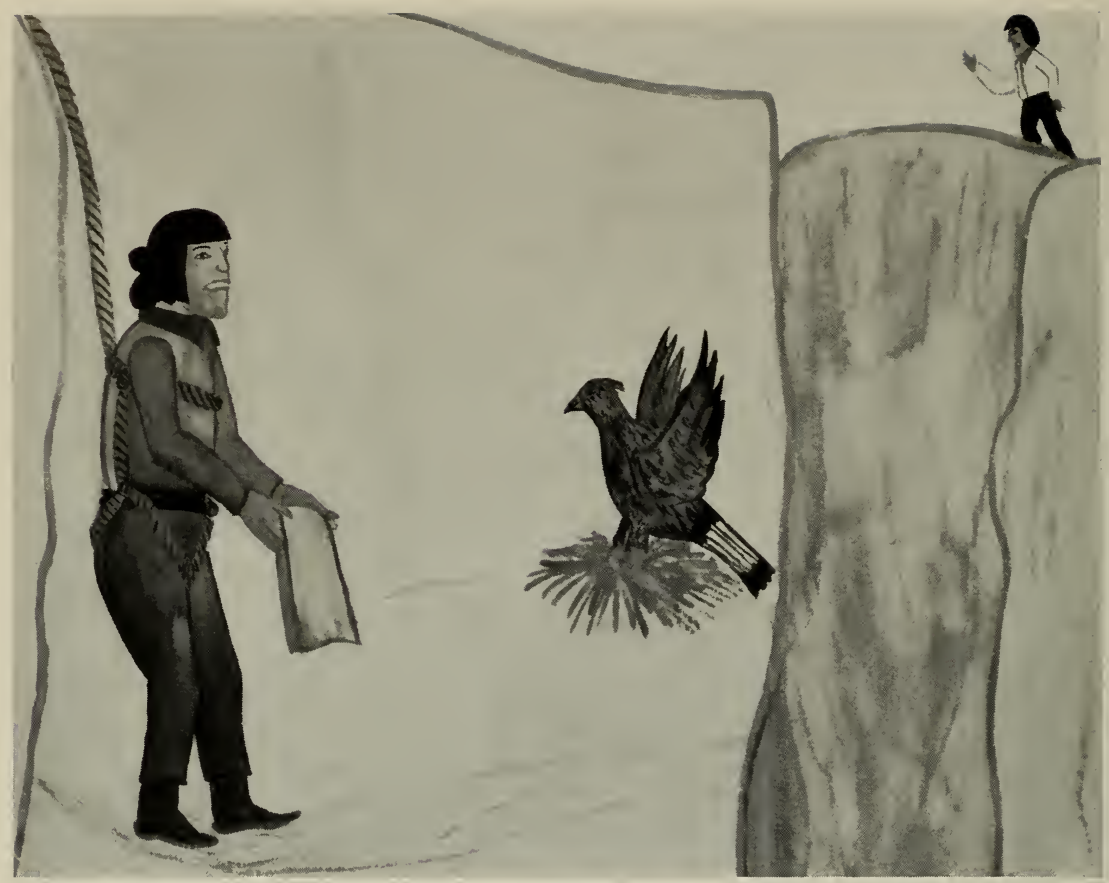

65

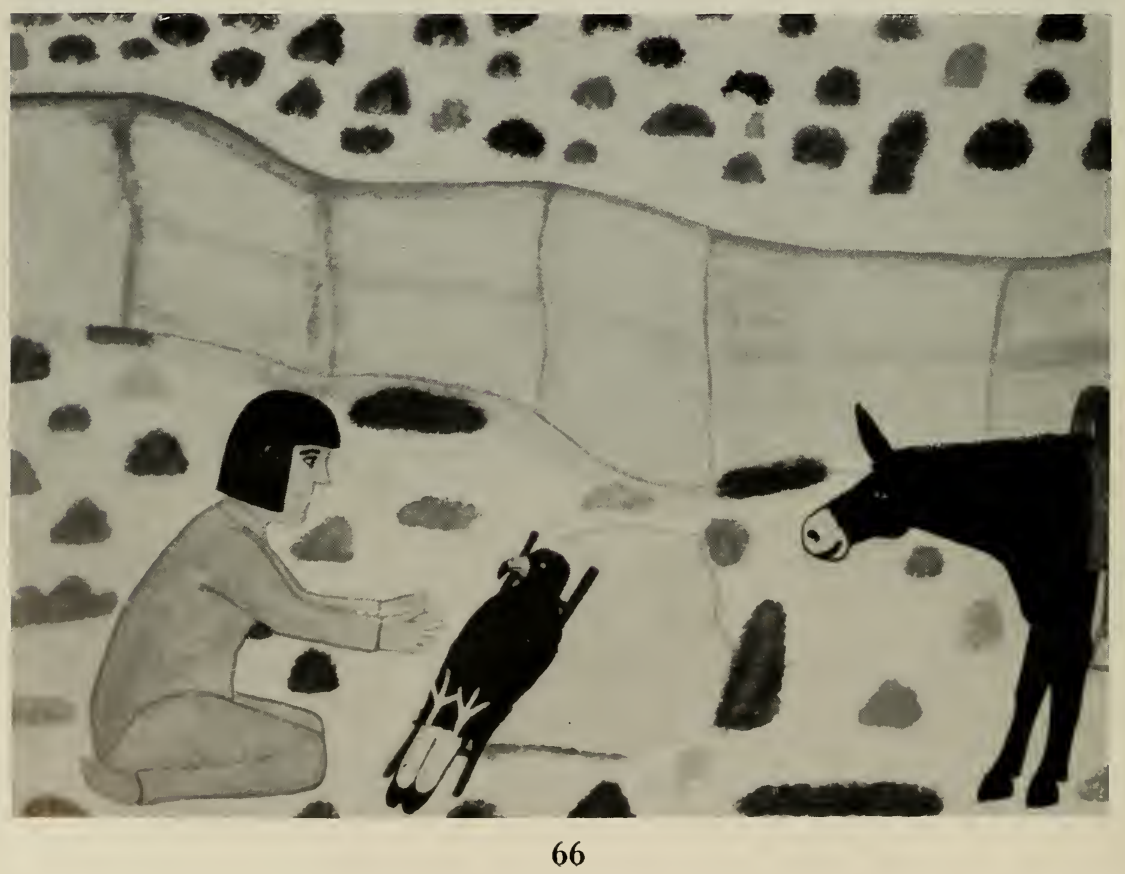


FIGURES 67,68

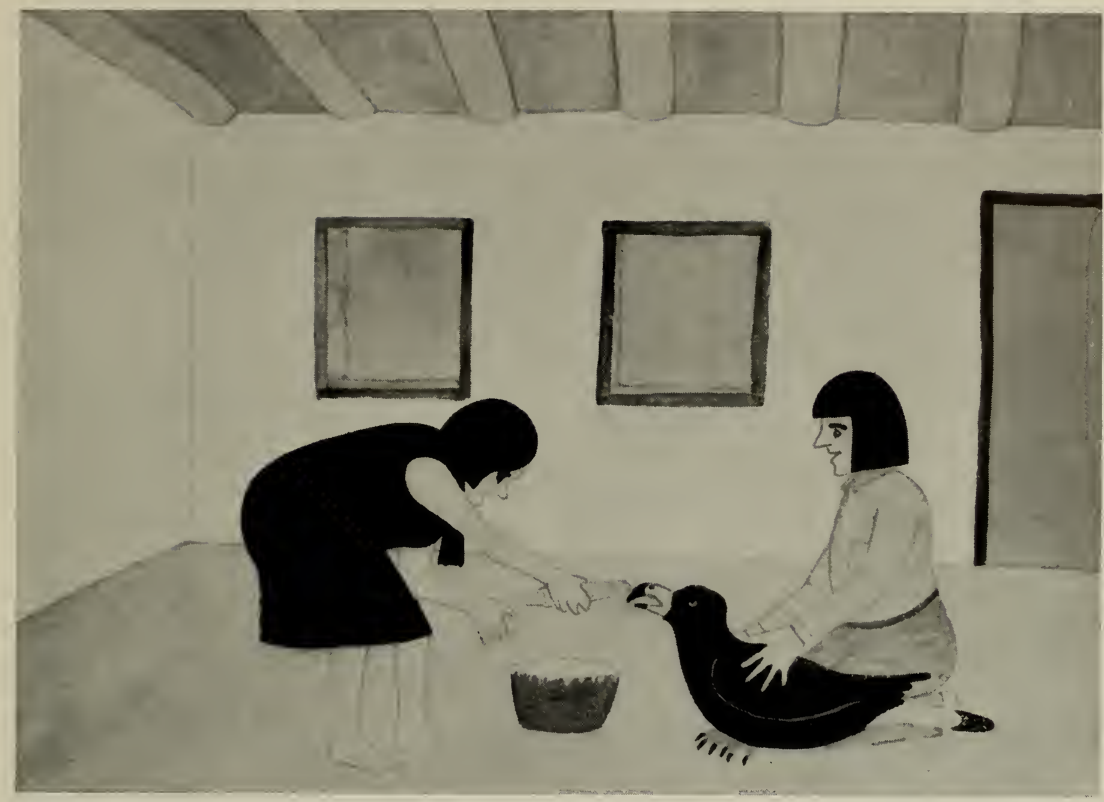

67

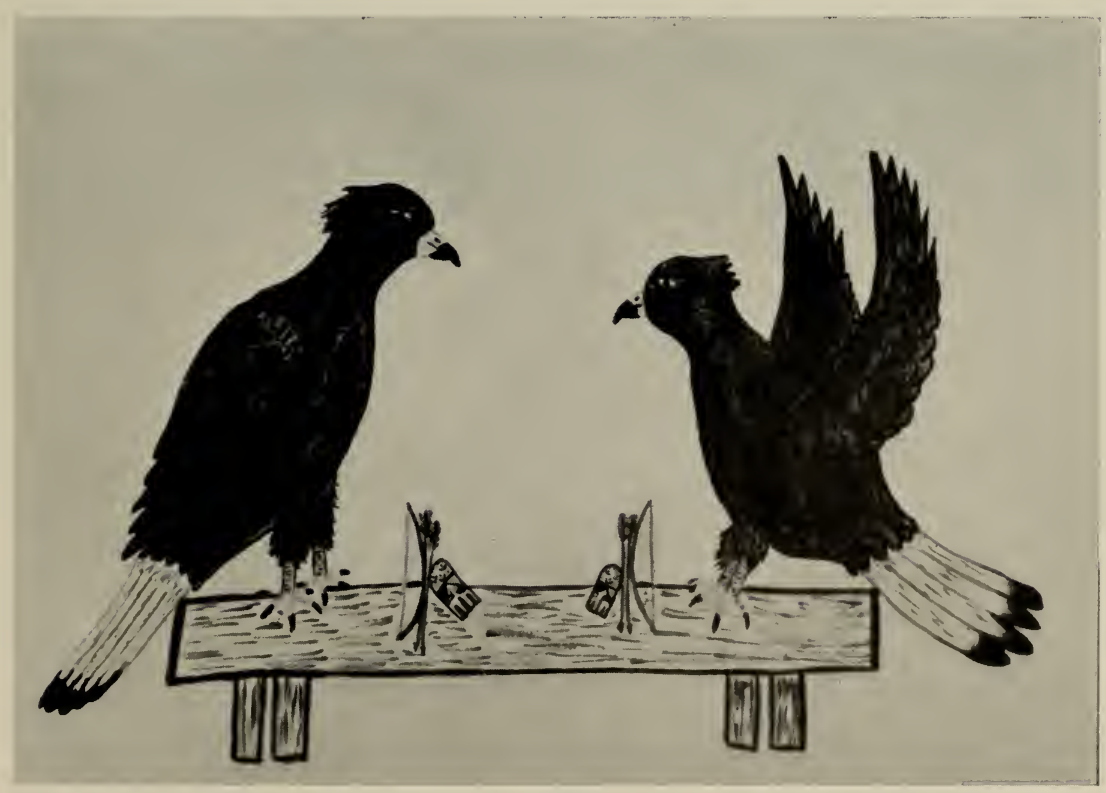


FIGURE 69

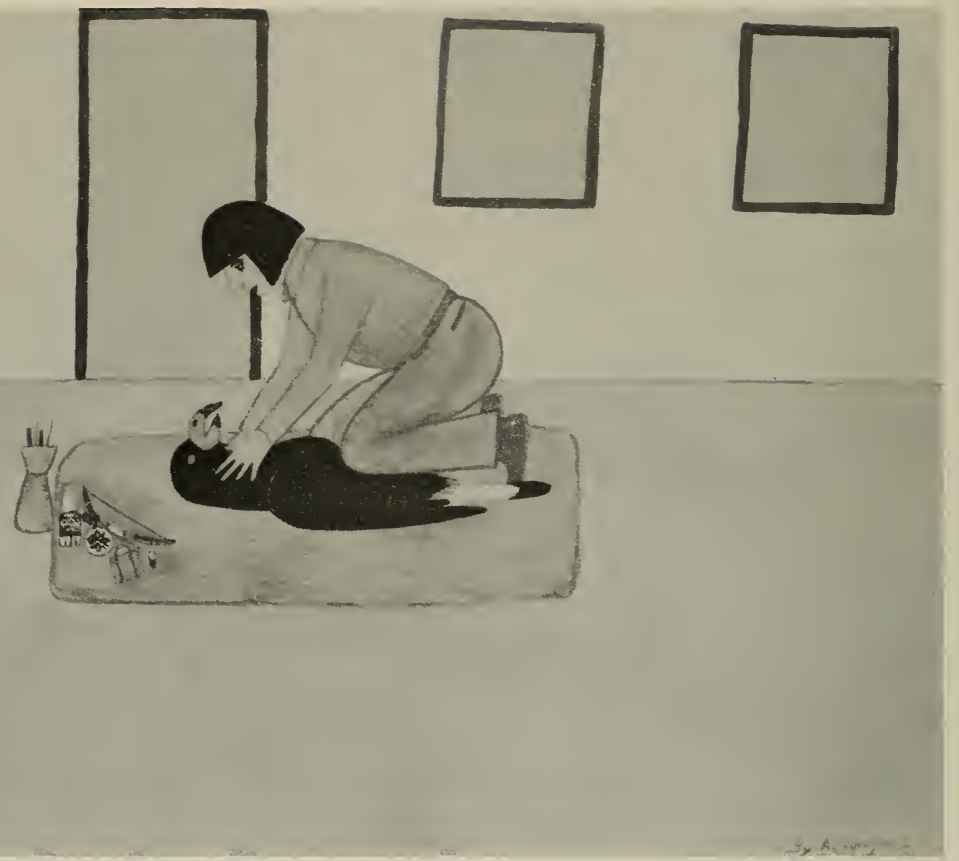


FIGURE 70

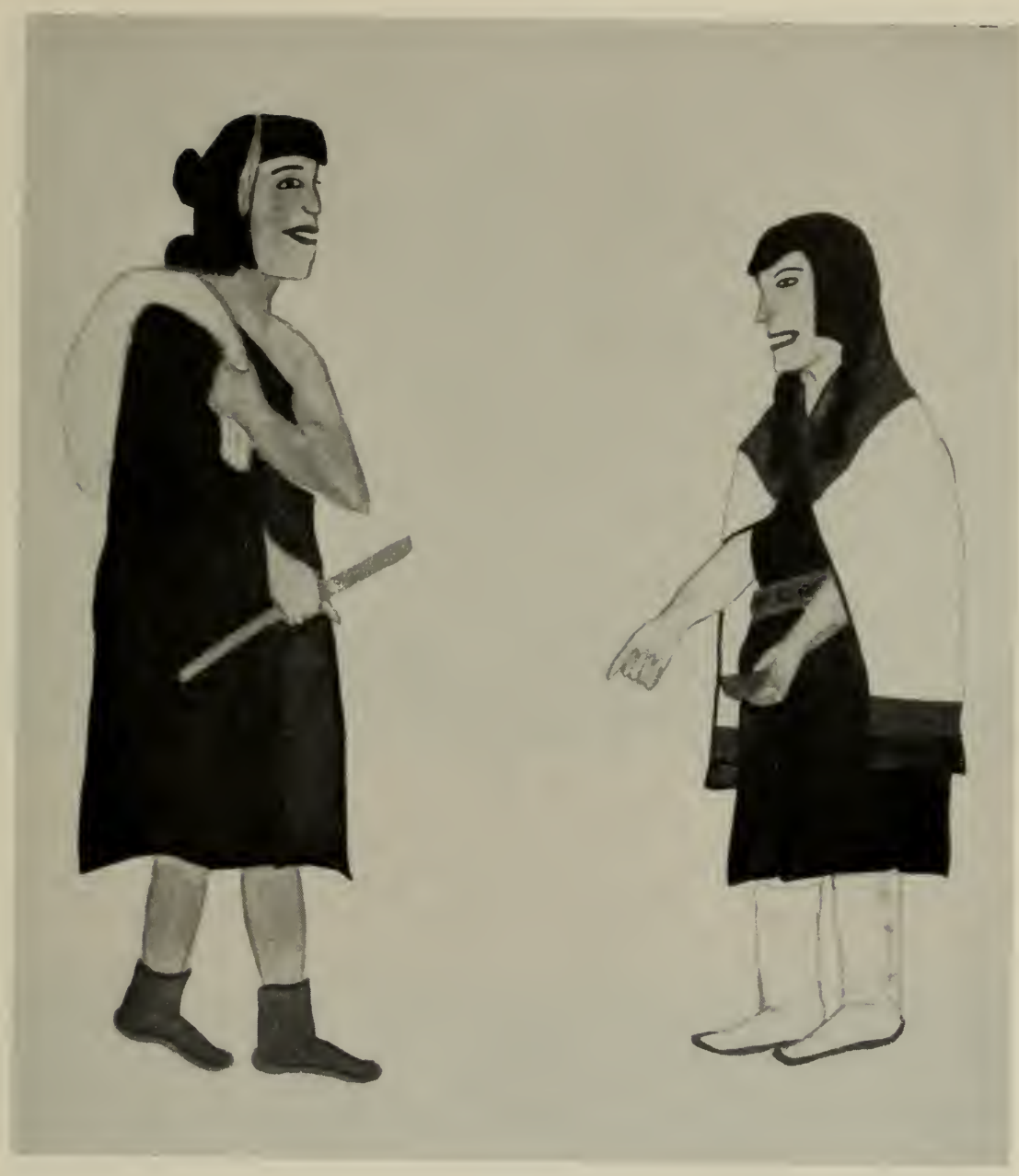


FIGURES 71,72
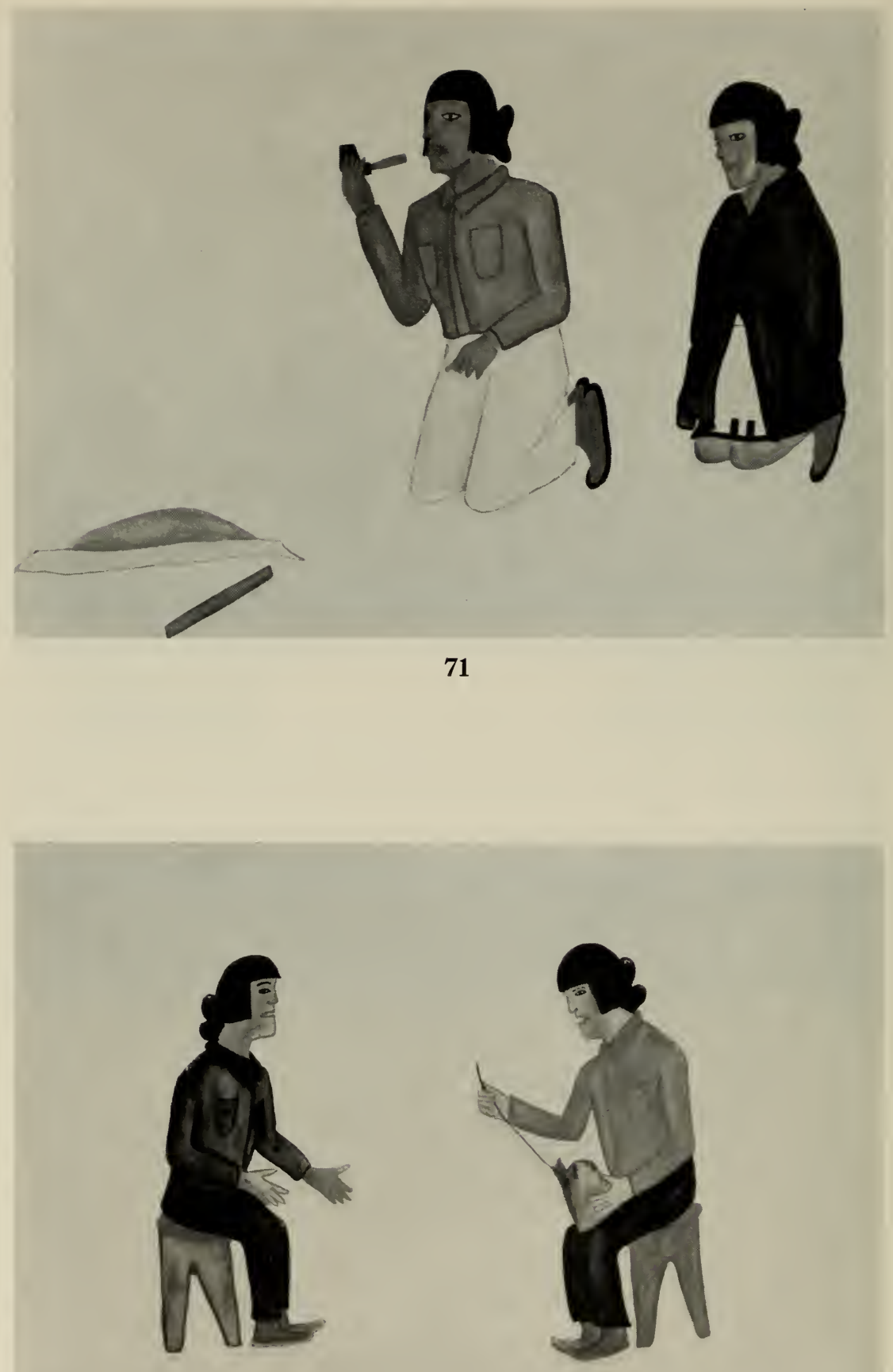
FIGURES 73,74

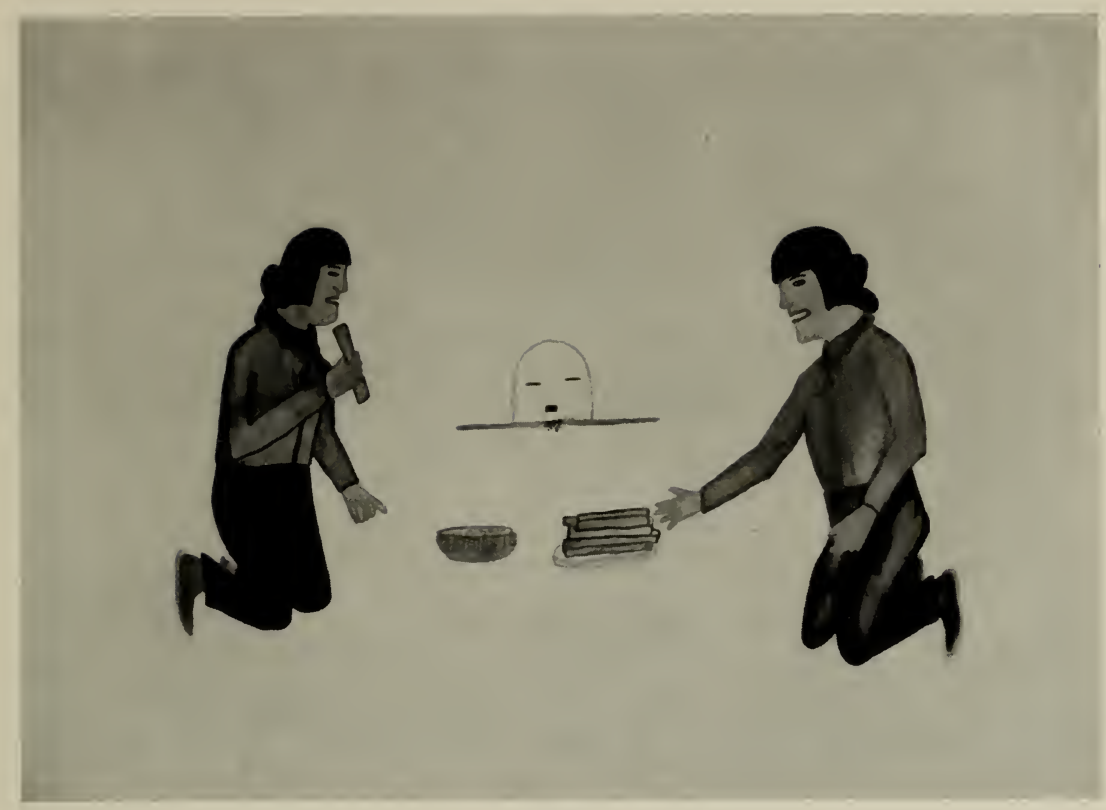

73

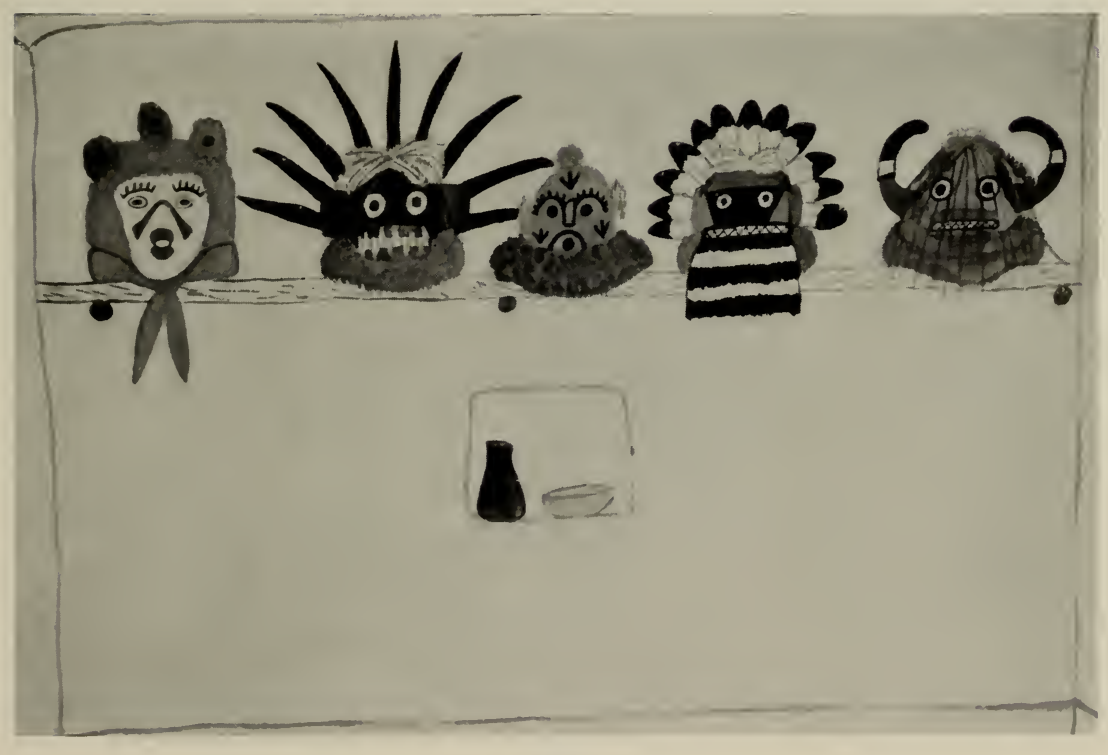



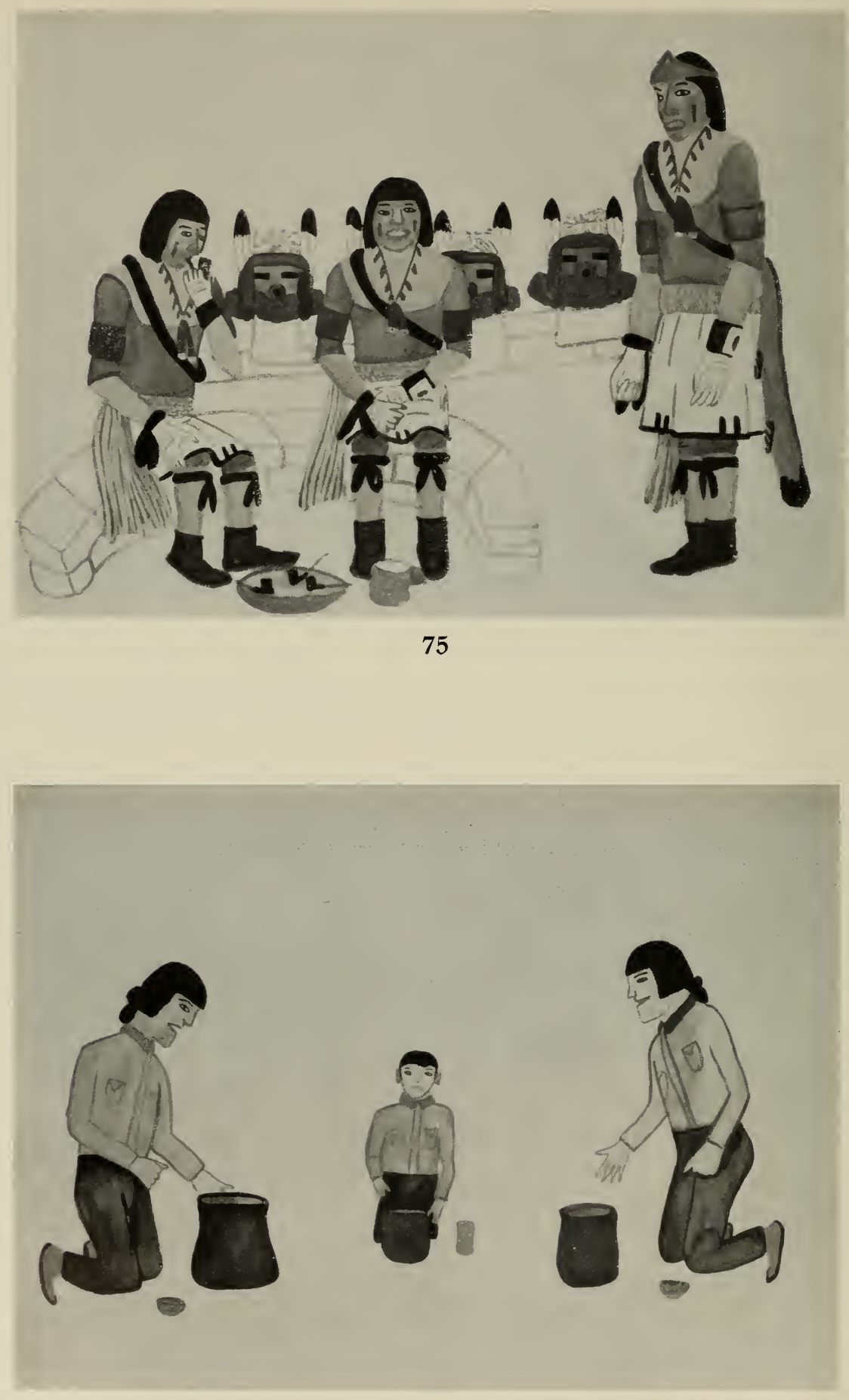
FIGURES 77,78

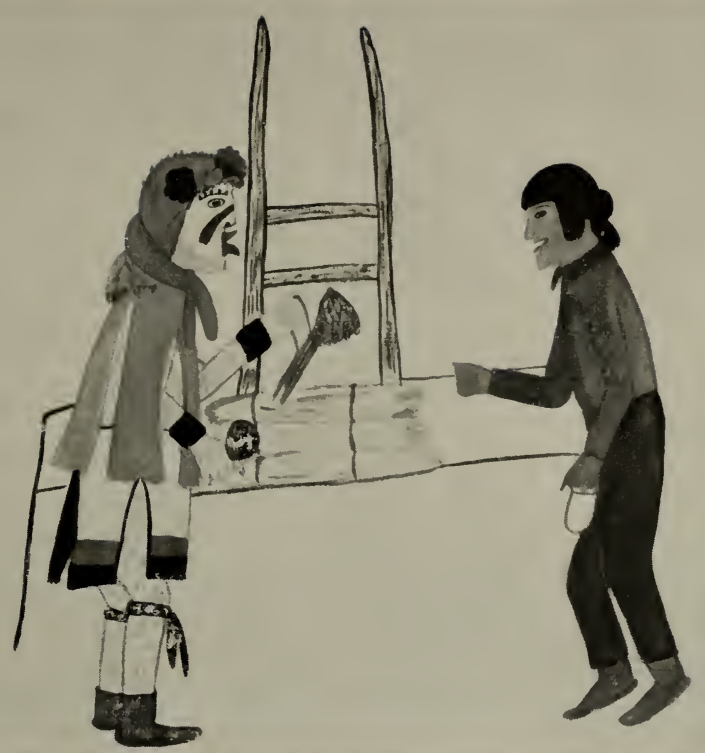

77

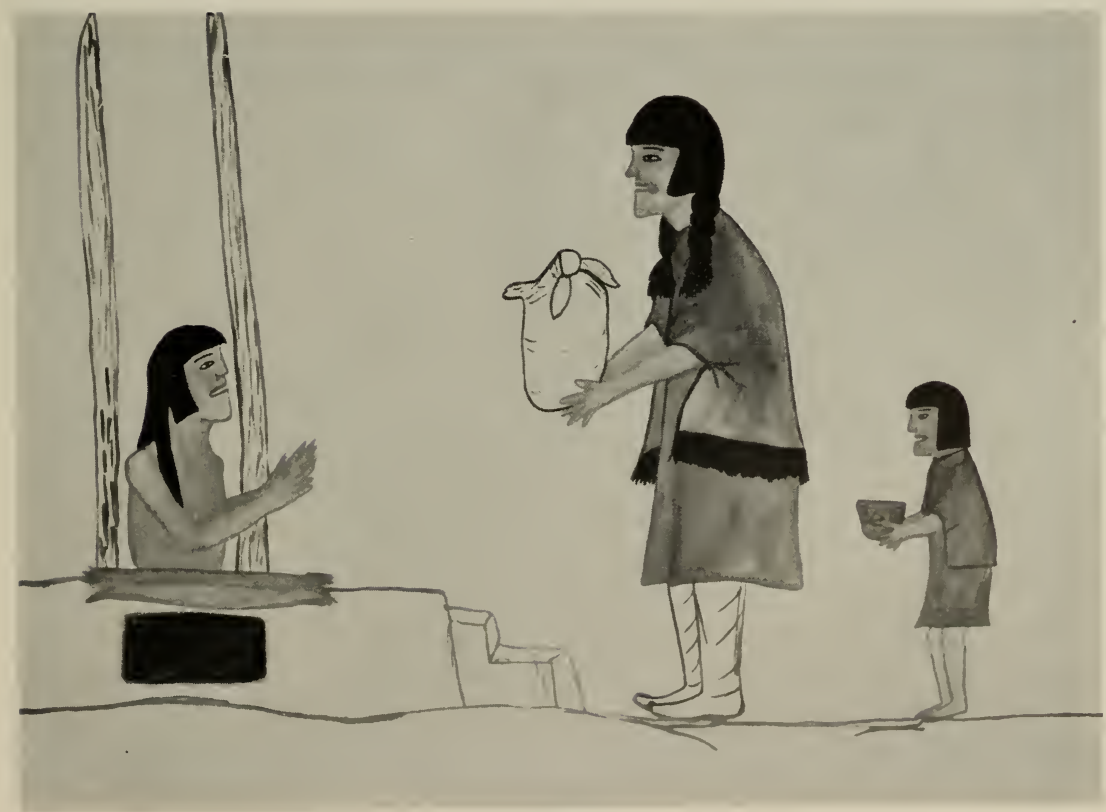




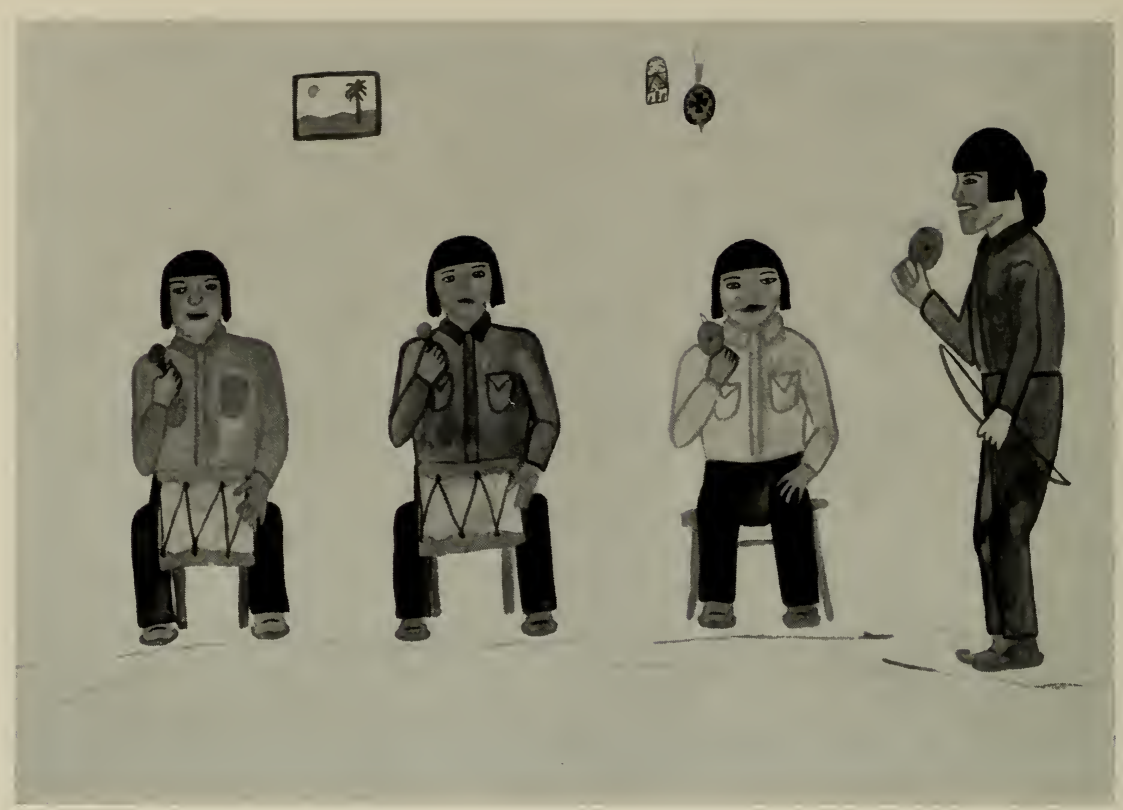

79

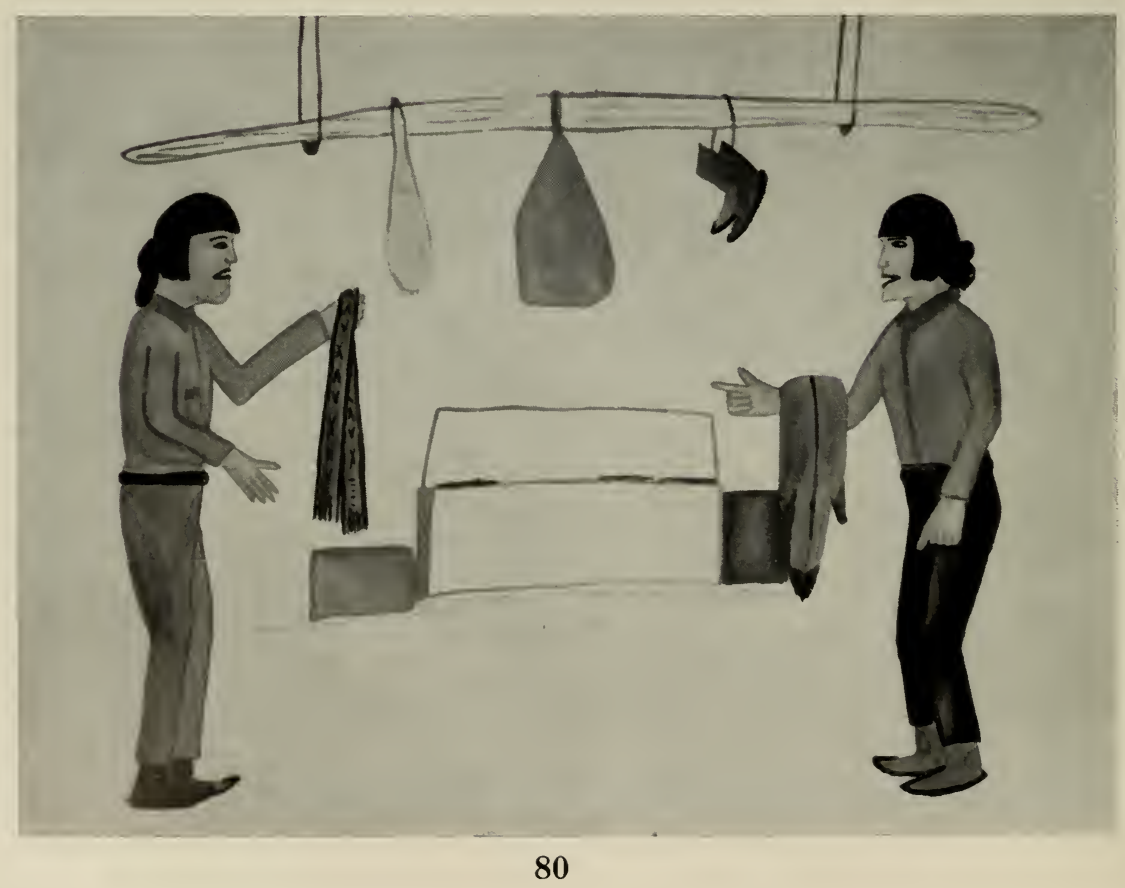


FIGURE 8 I

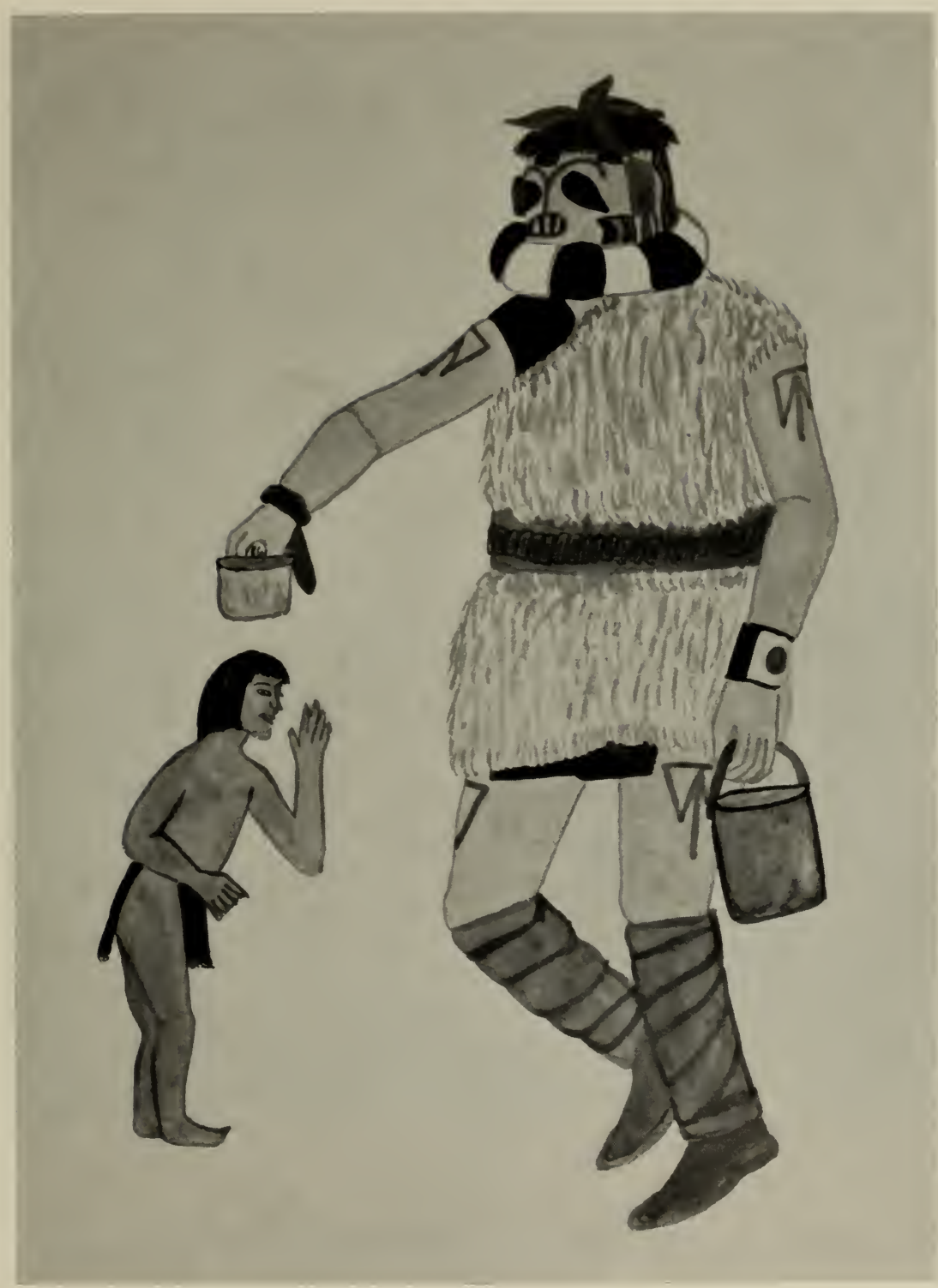


FIGURE 82
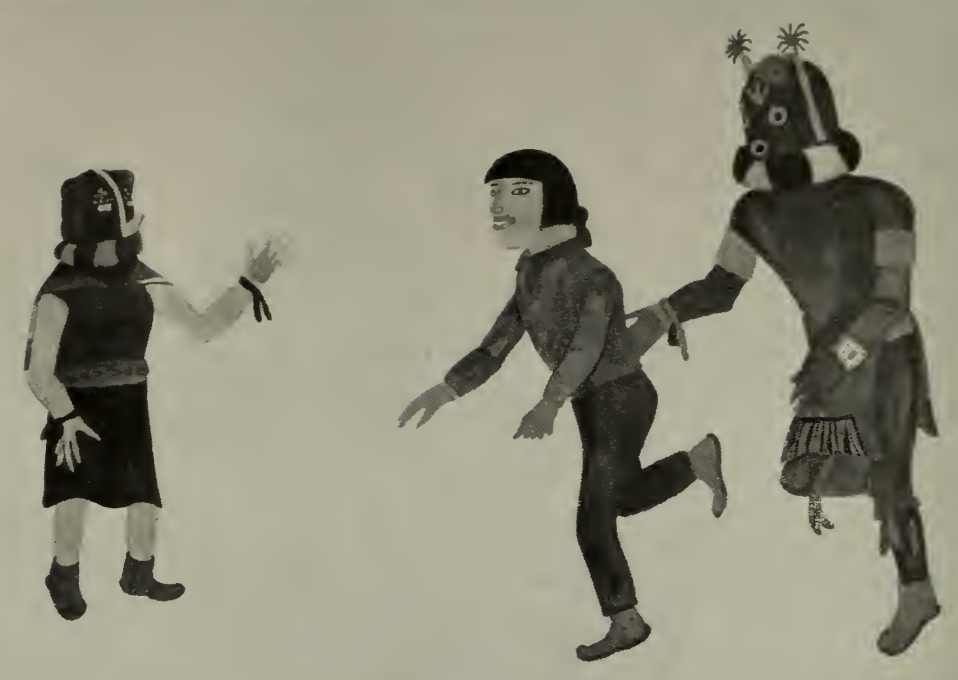
FIGURE 83

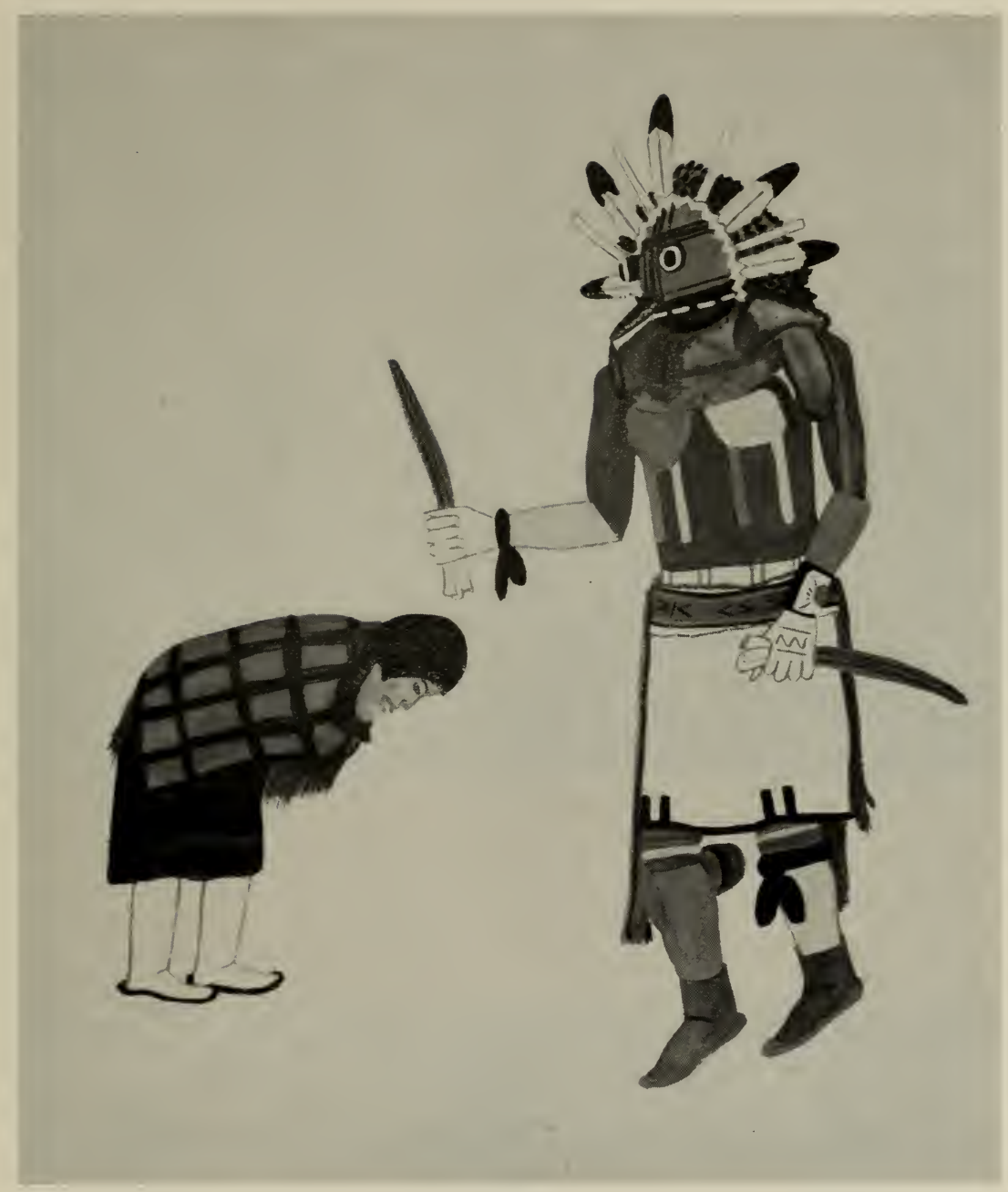


FIGURES 84,85
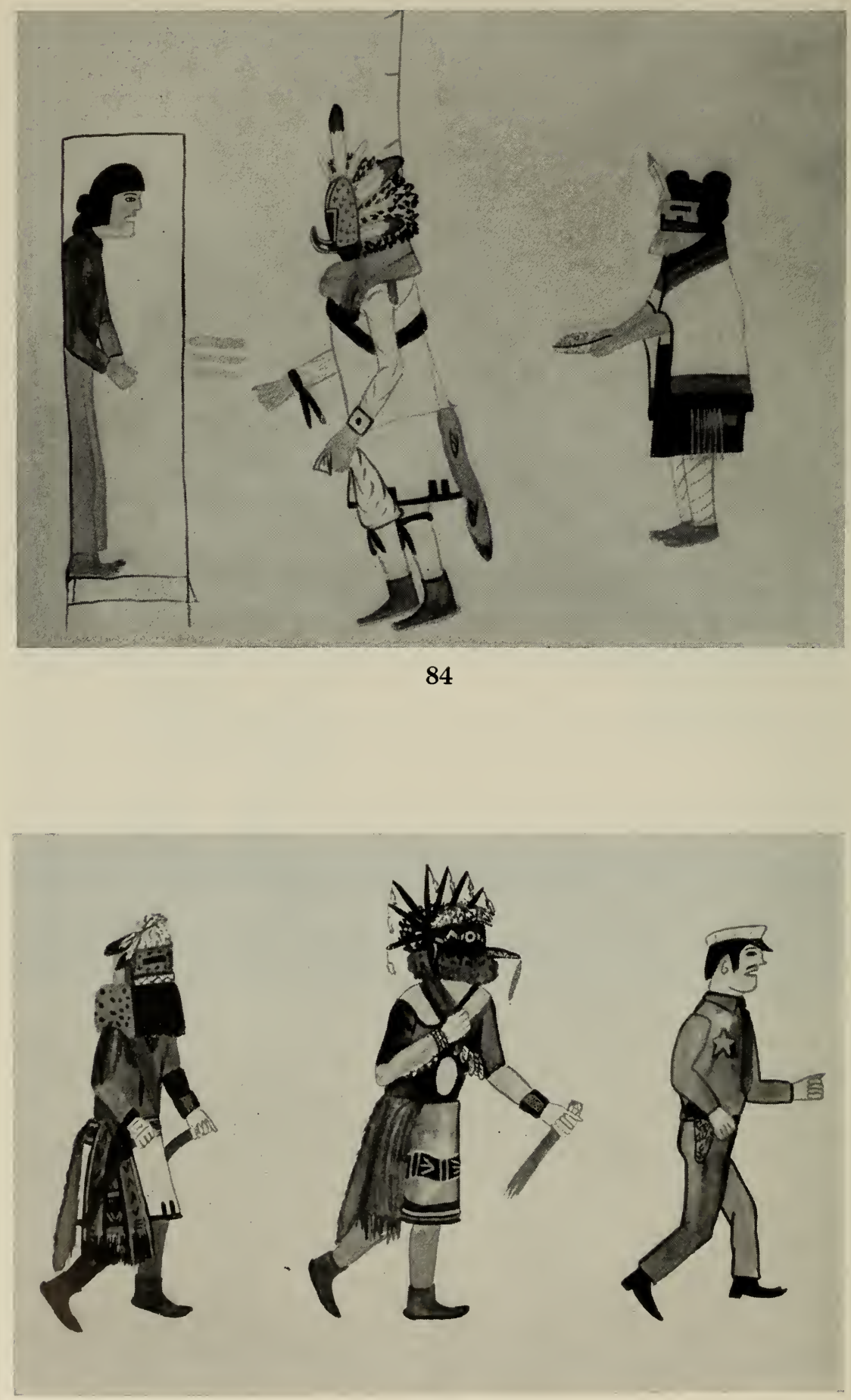
FIG URE 86
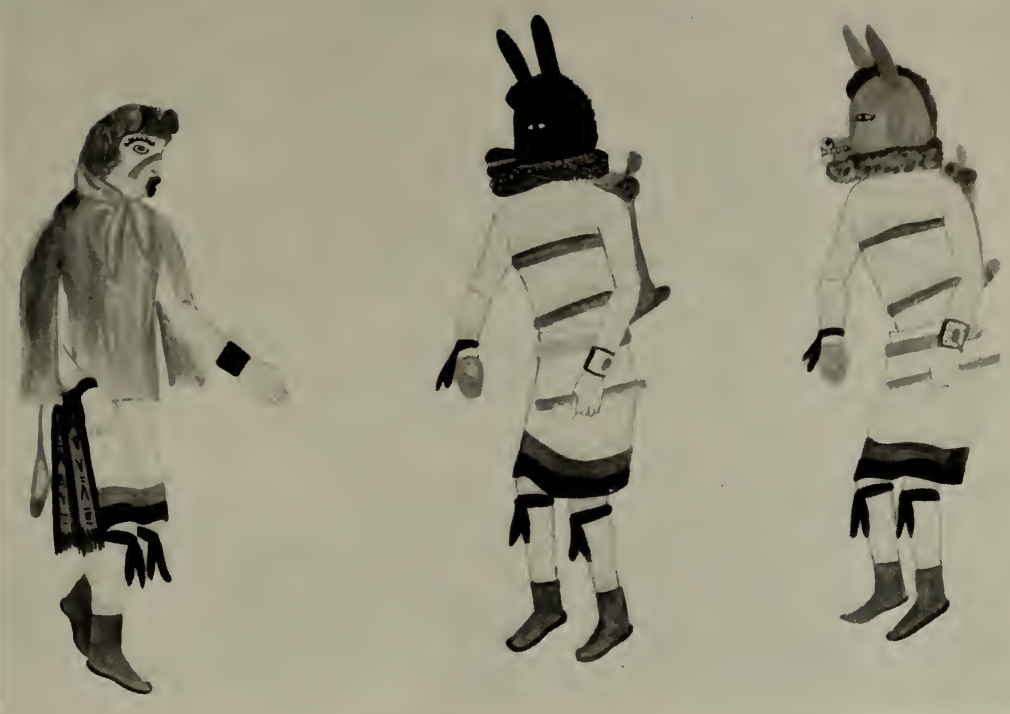
FIGURE 87

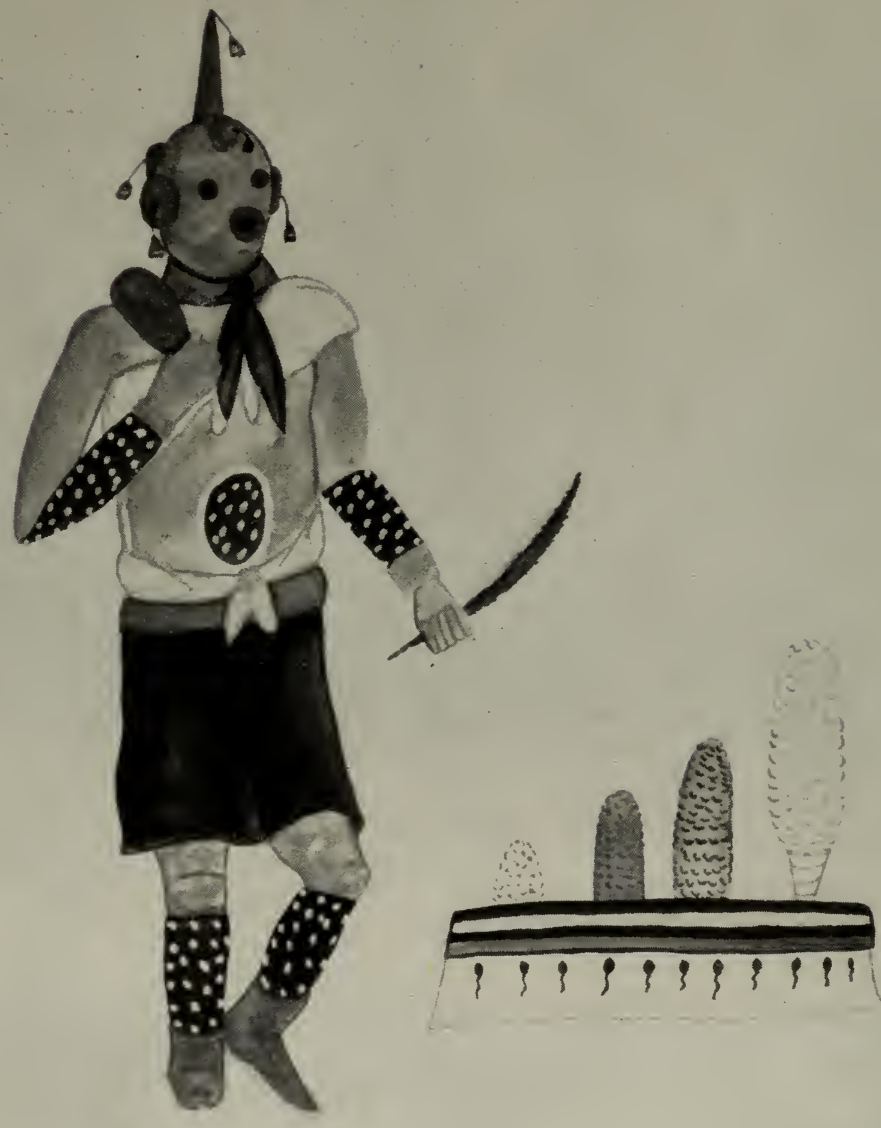


FIGURE 88

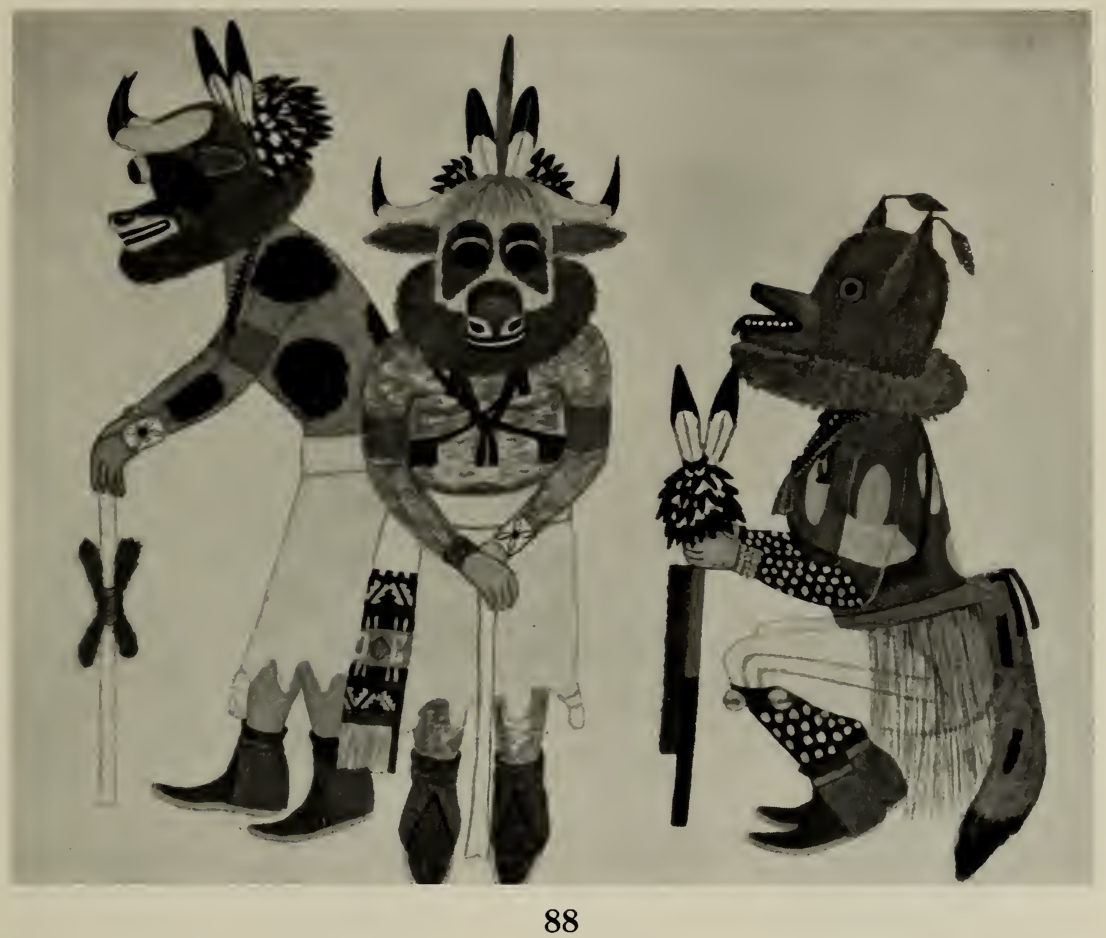


FIGURE 89

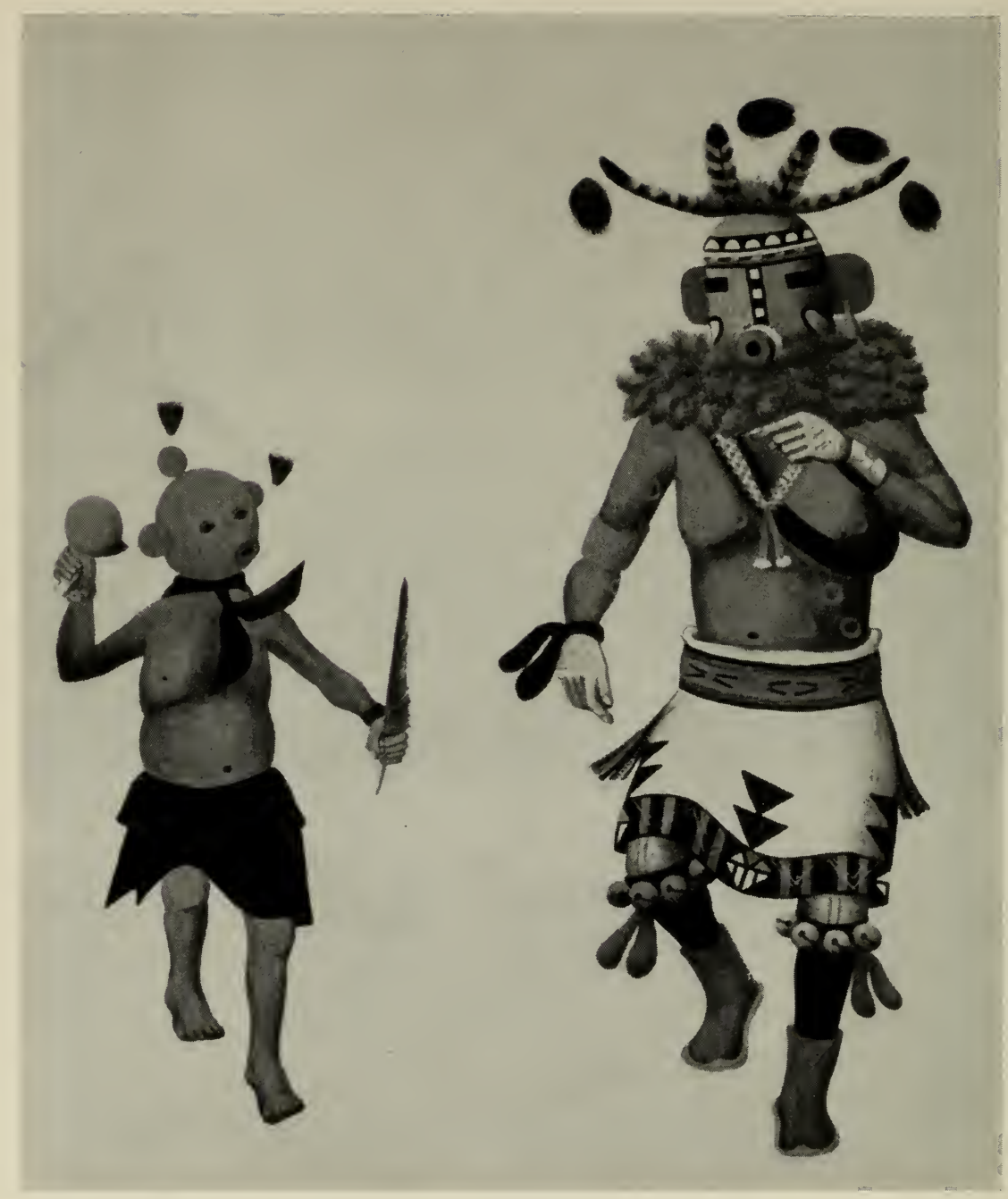


FIGURE 90

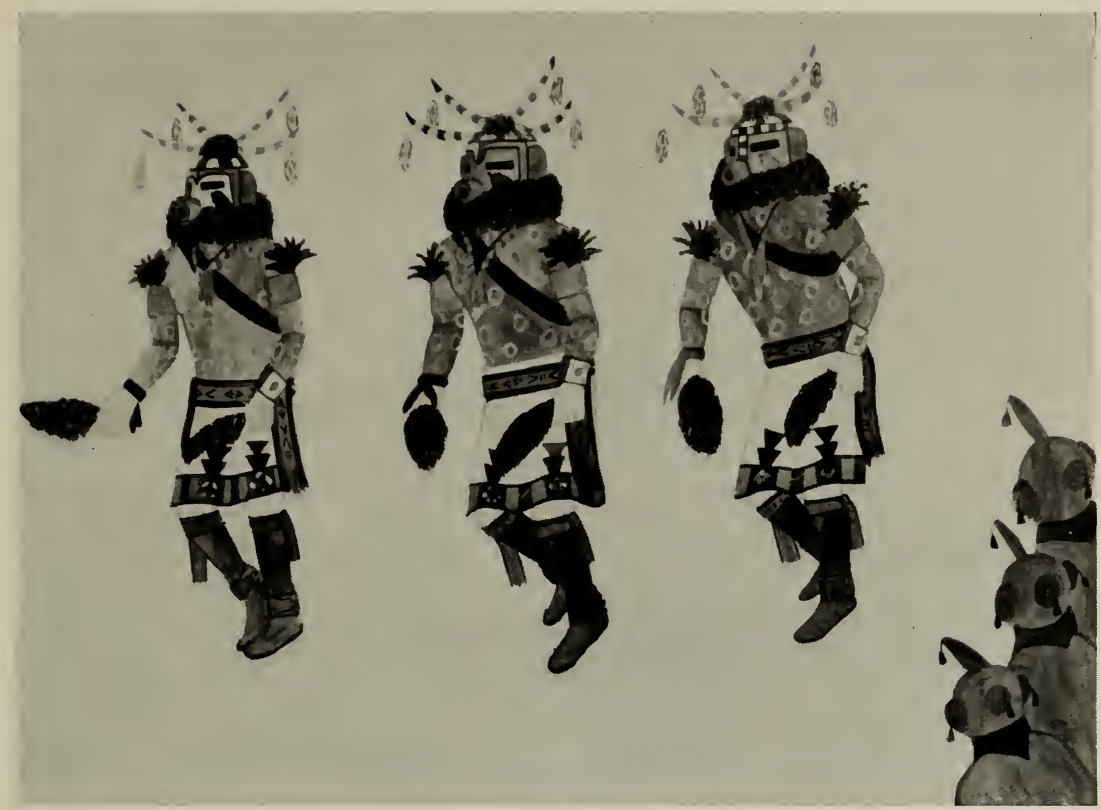




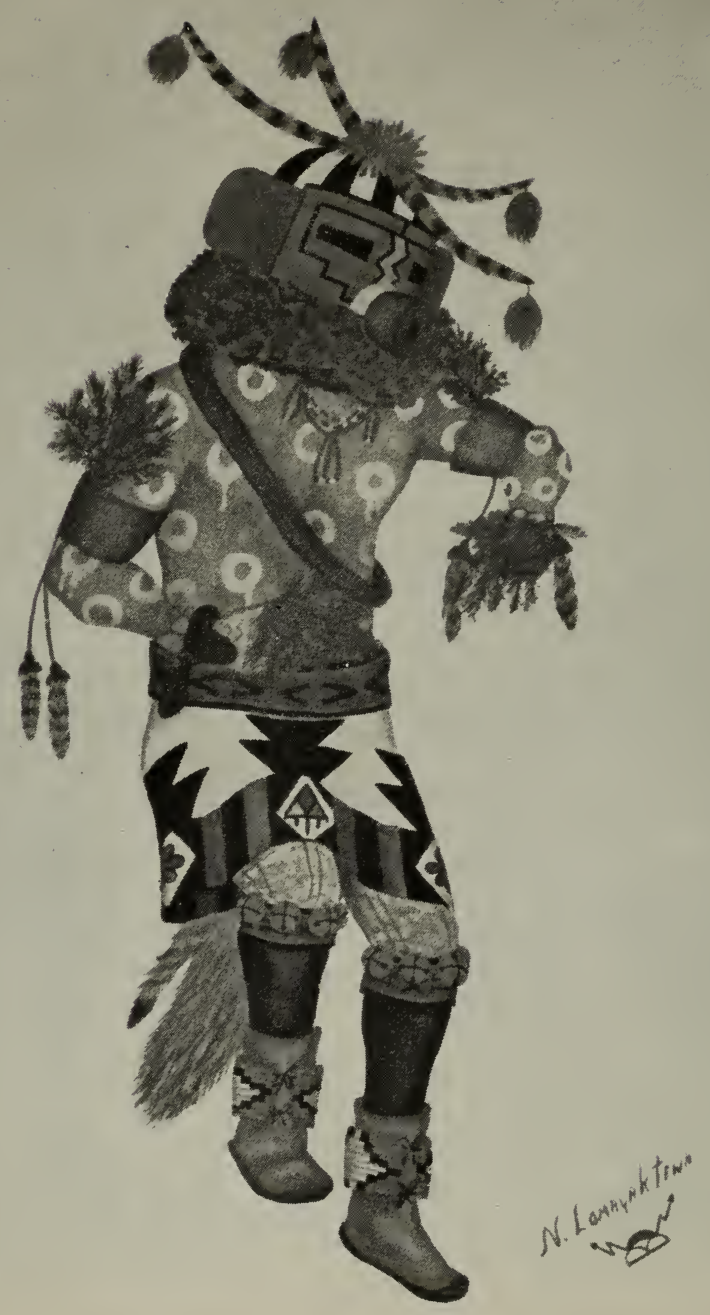




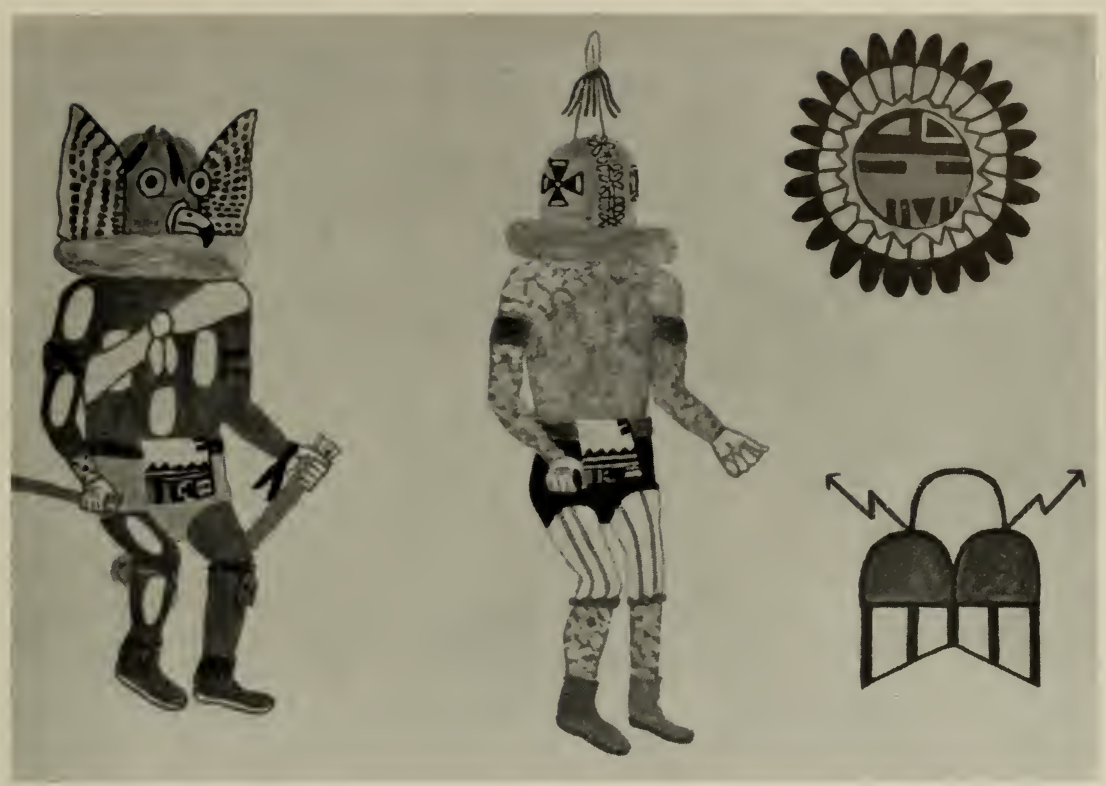

92

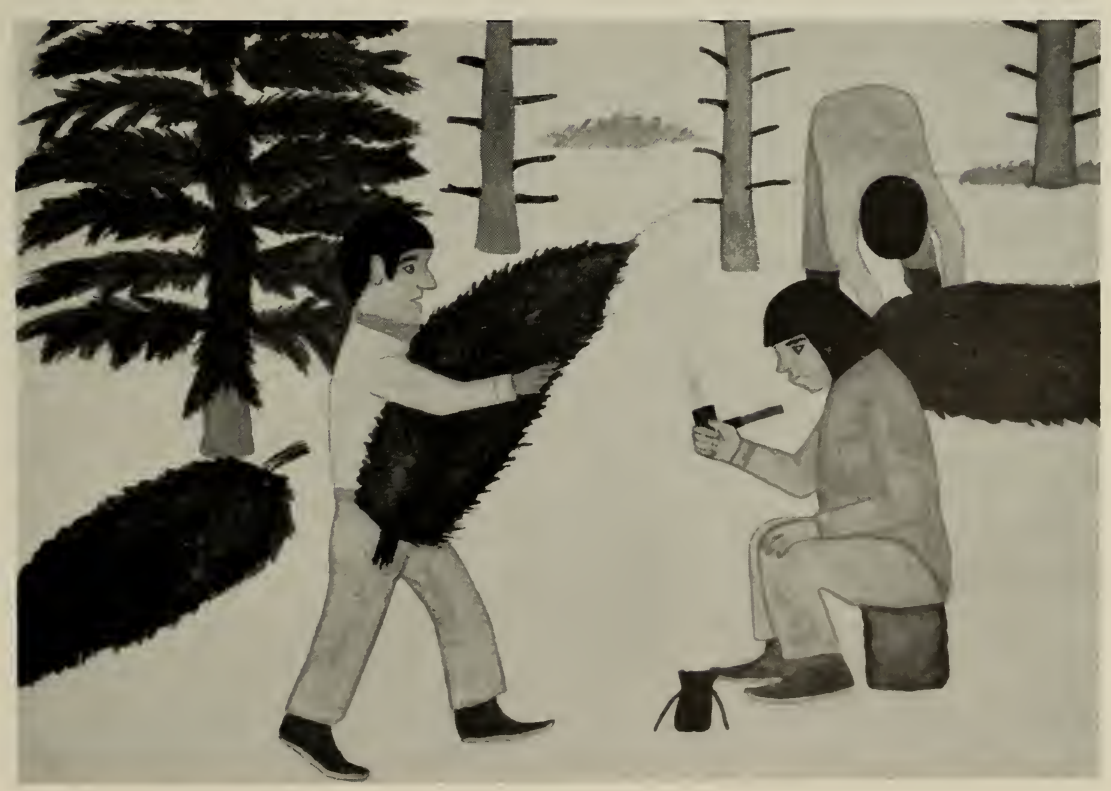


FIGURES 94, 95
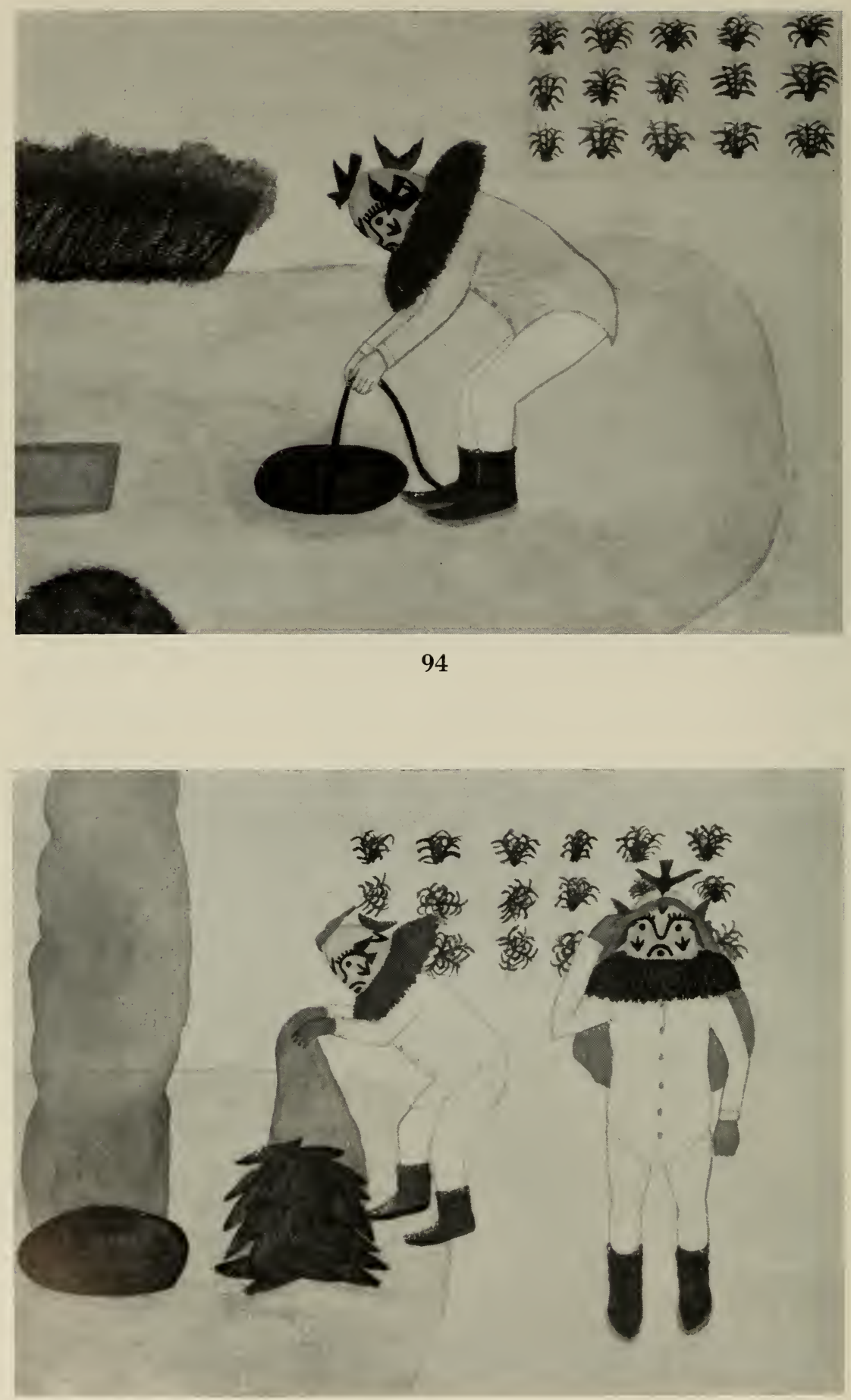

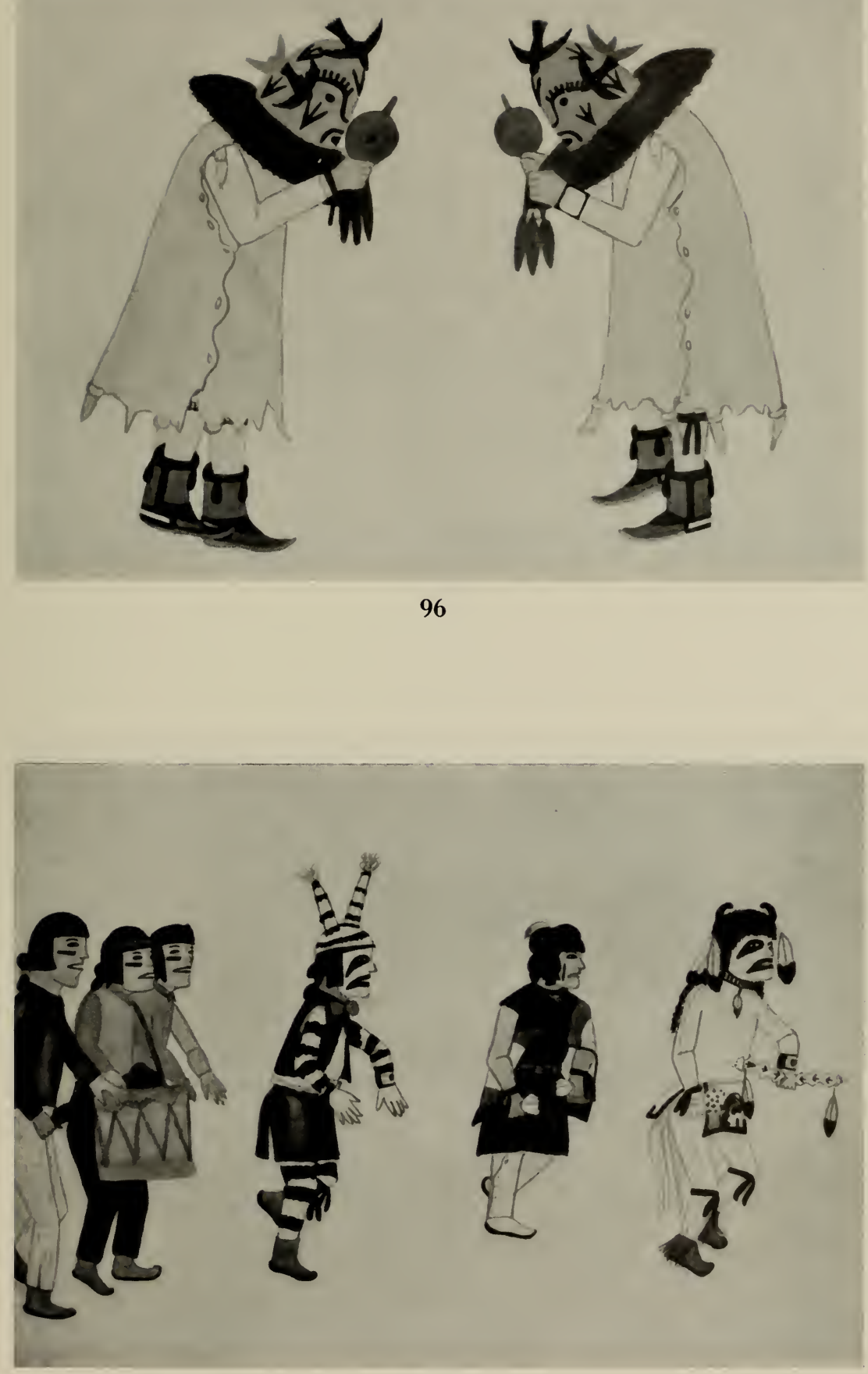
FIGURES 98, 99
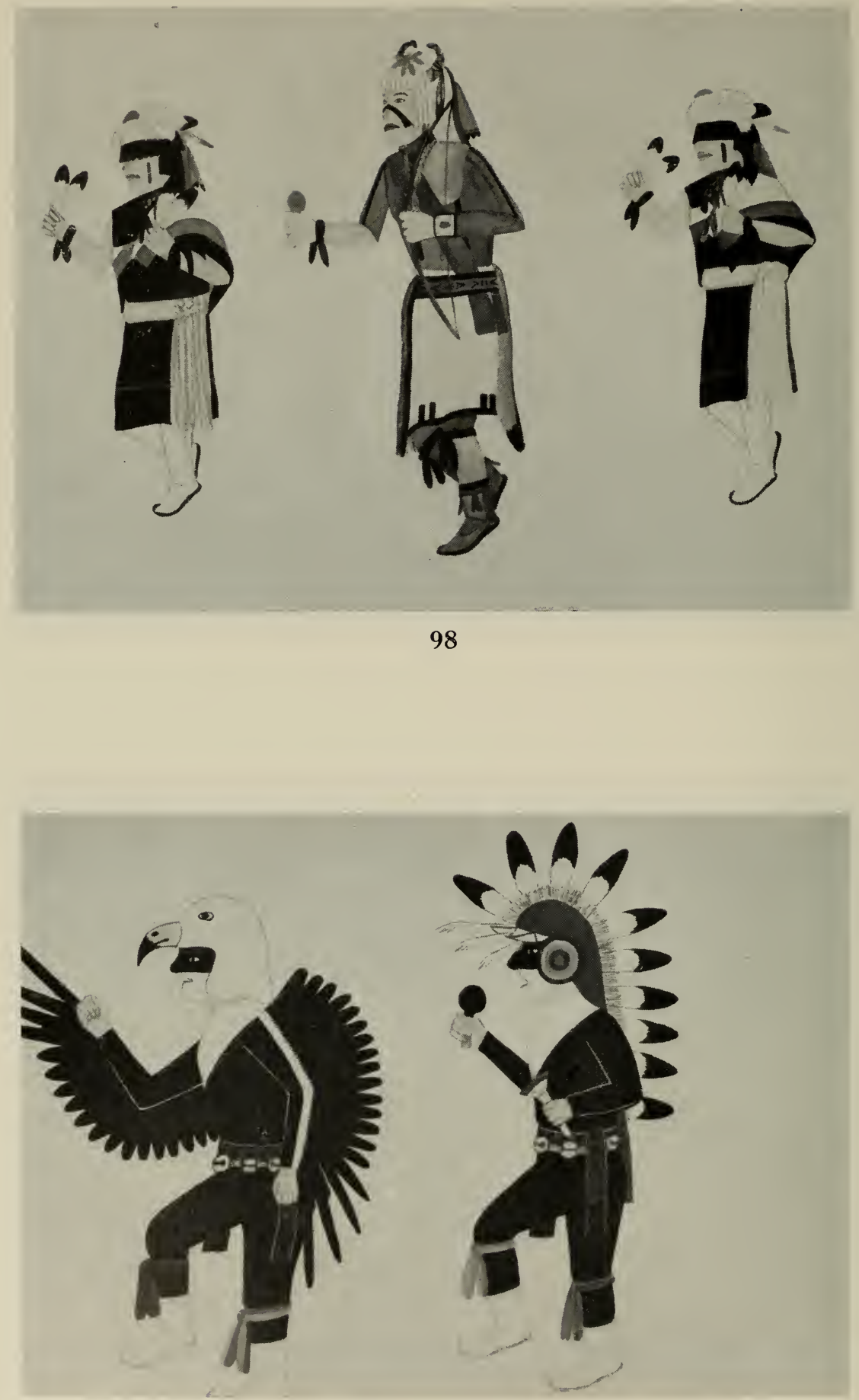
FIGURES IOO, IOI
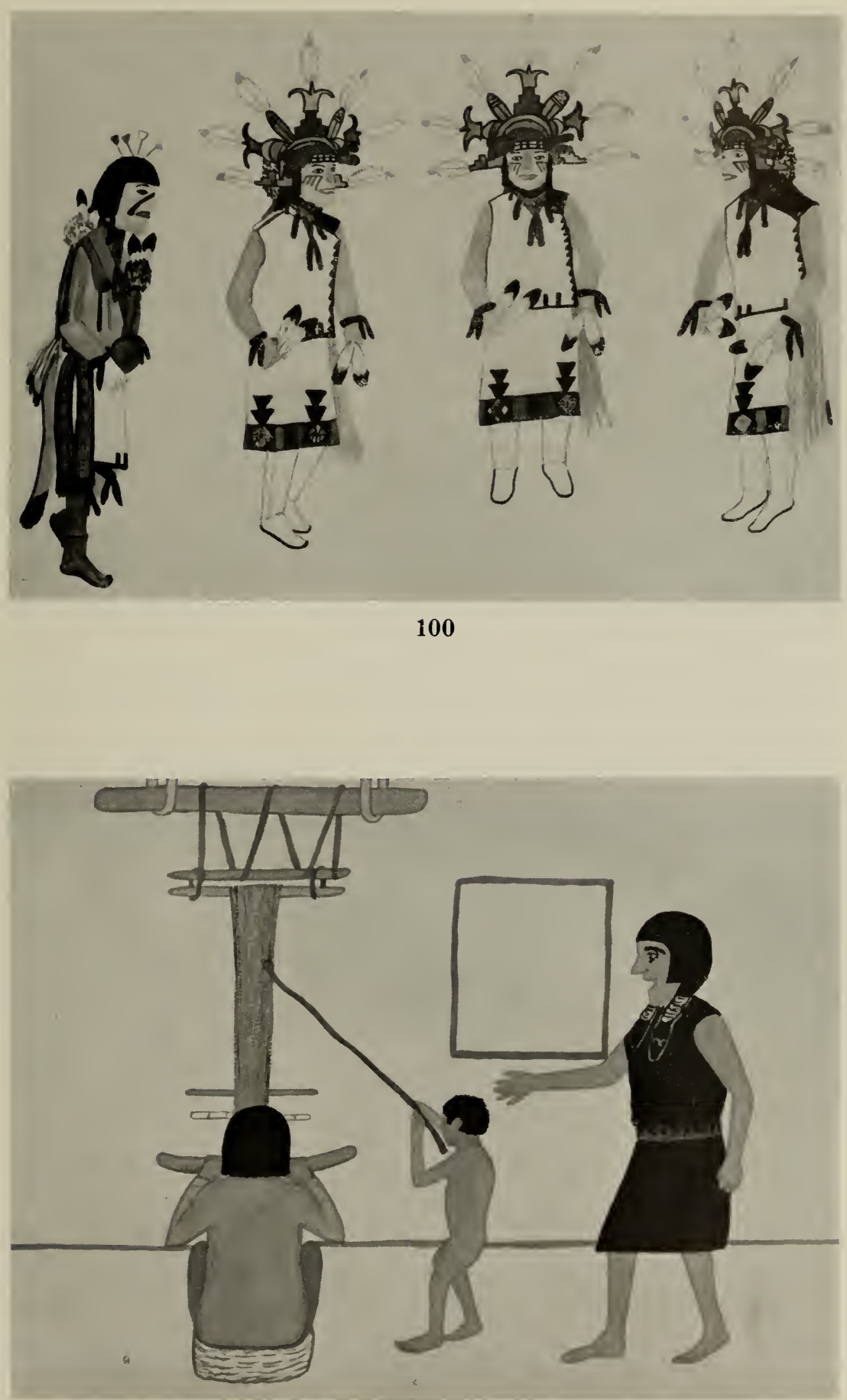


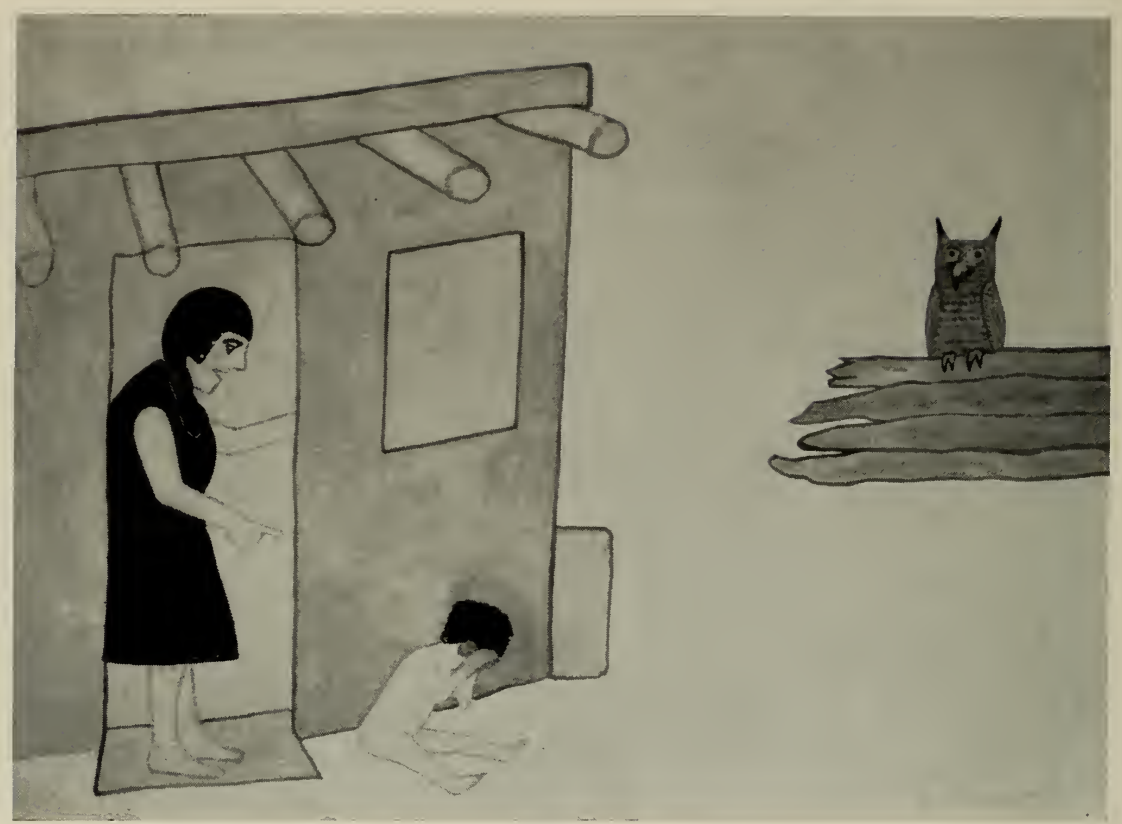

102

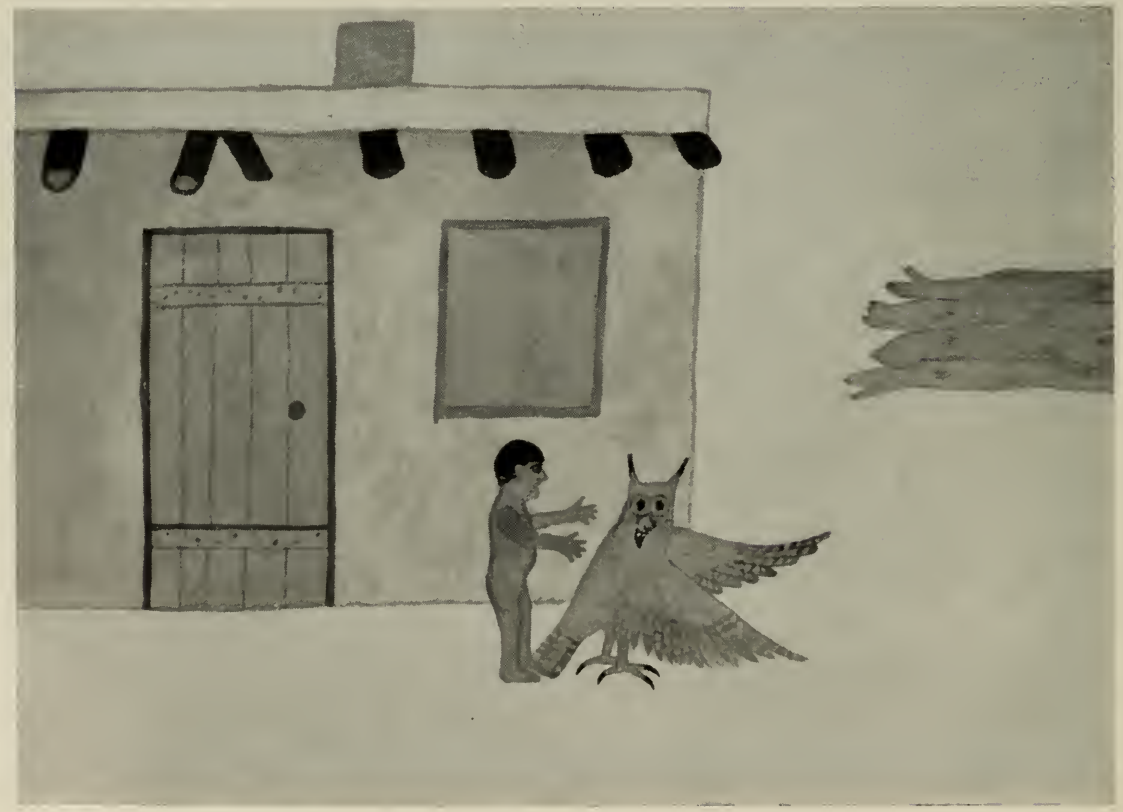


FIGURE $\mathrm{IO}_{4}$

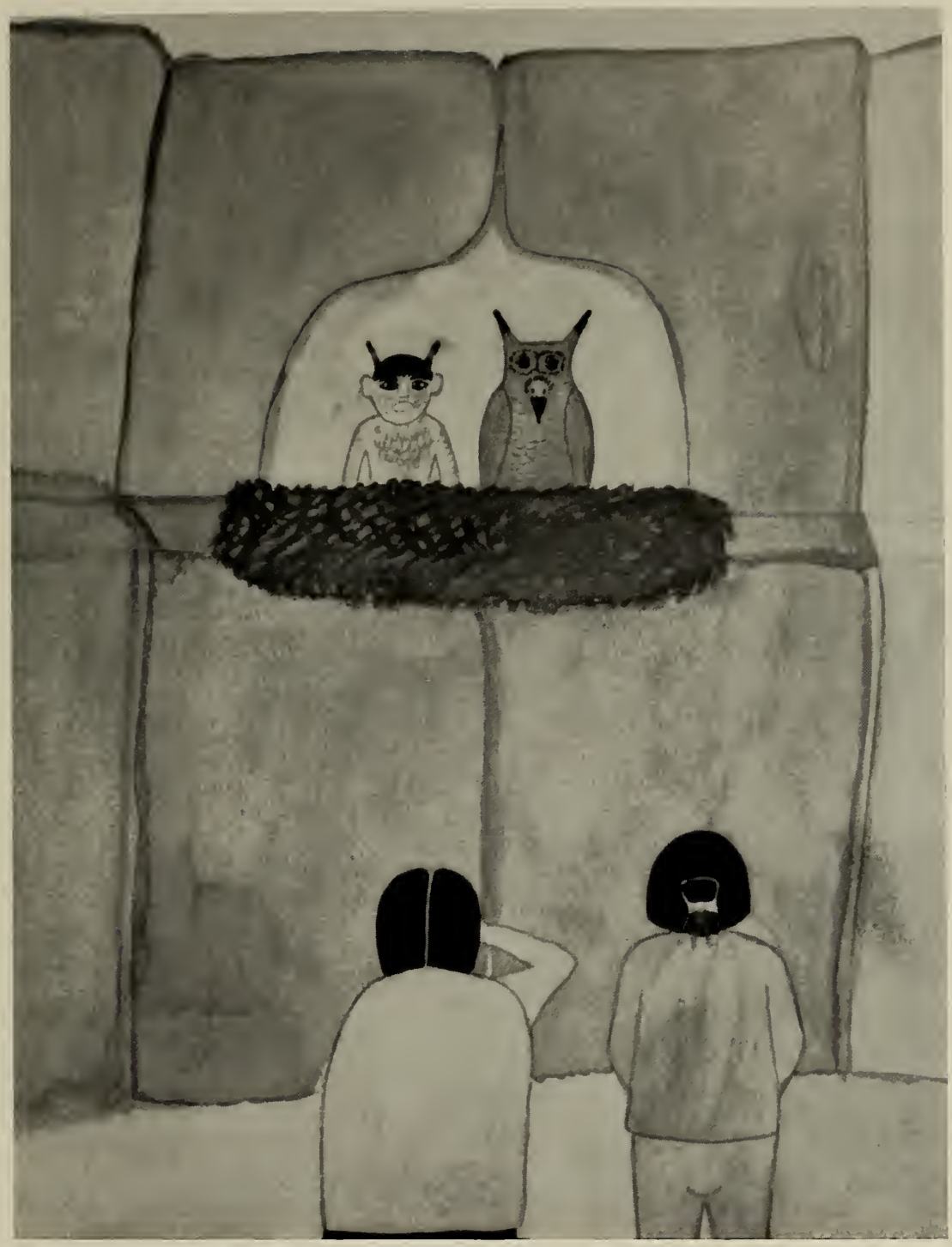

104 
FIGURE IO5

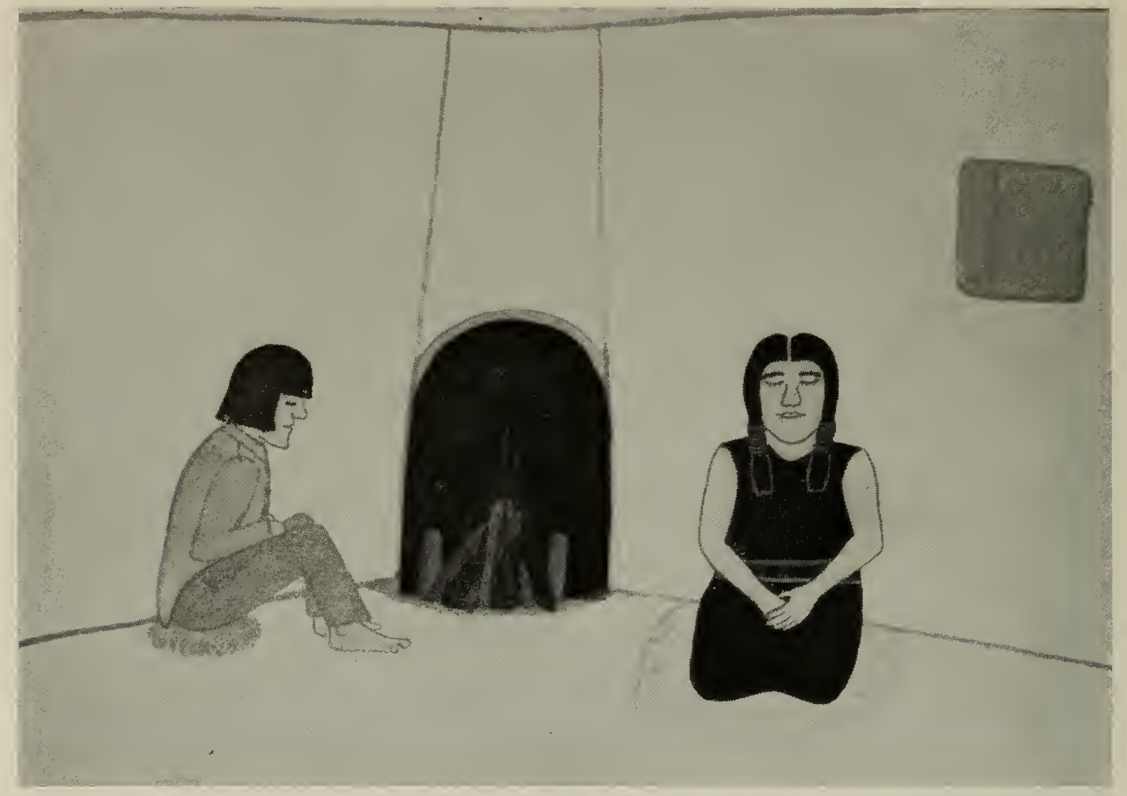

105 
FIGURE IO6

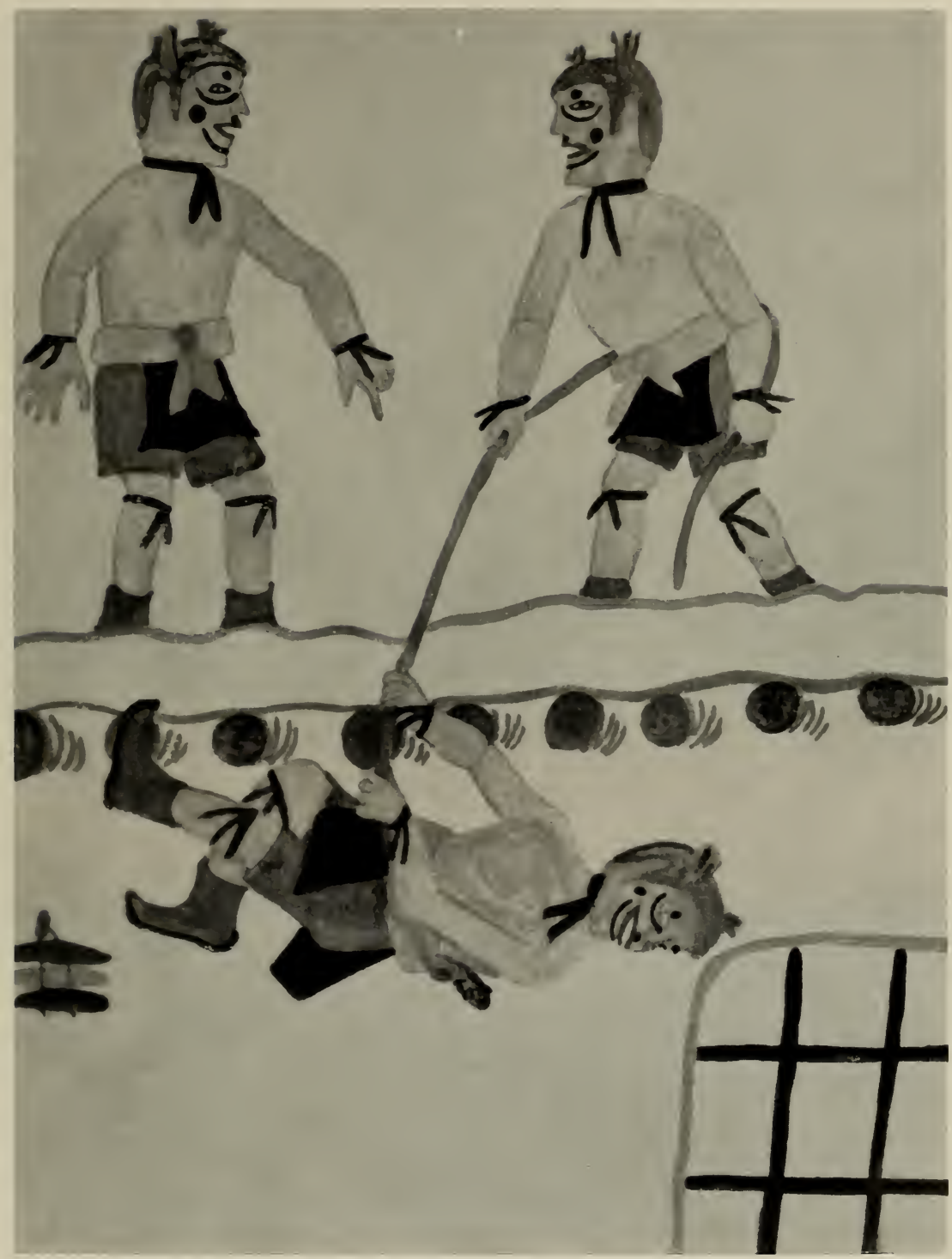


FIGURES 107,108

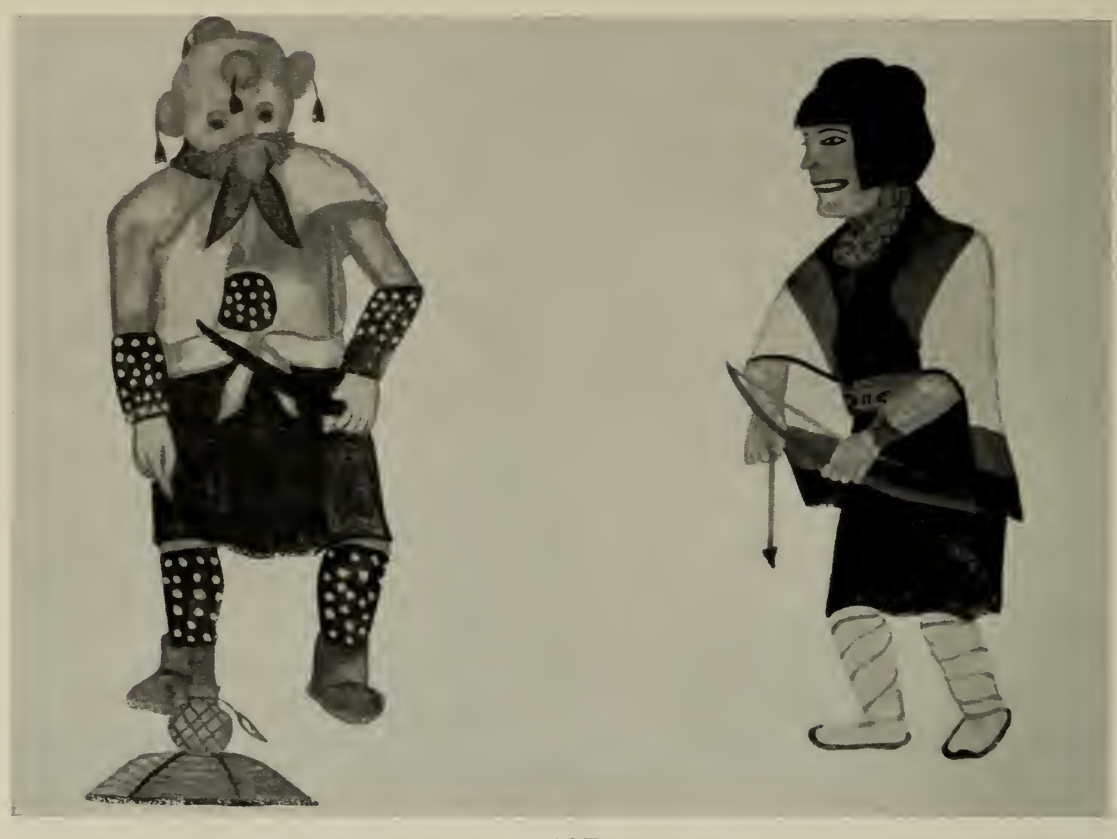

107
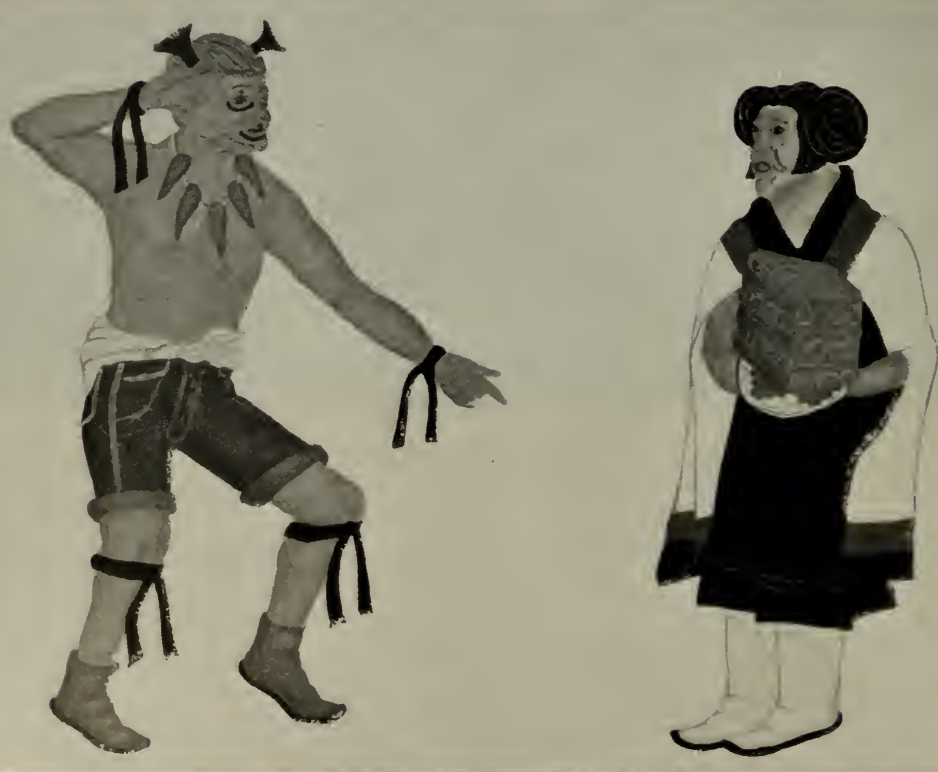

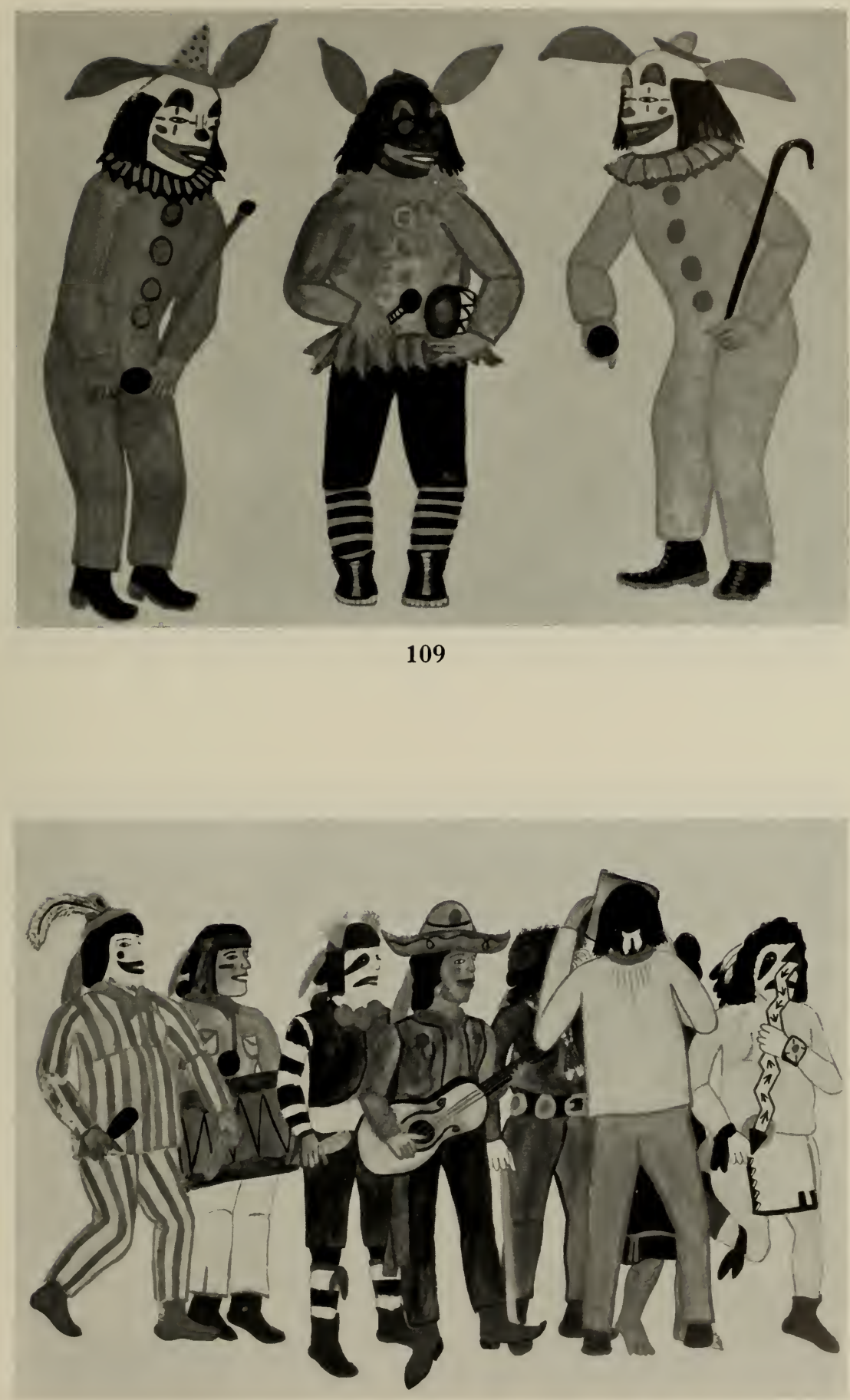


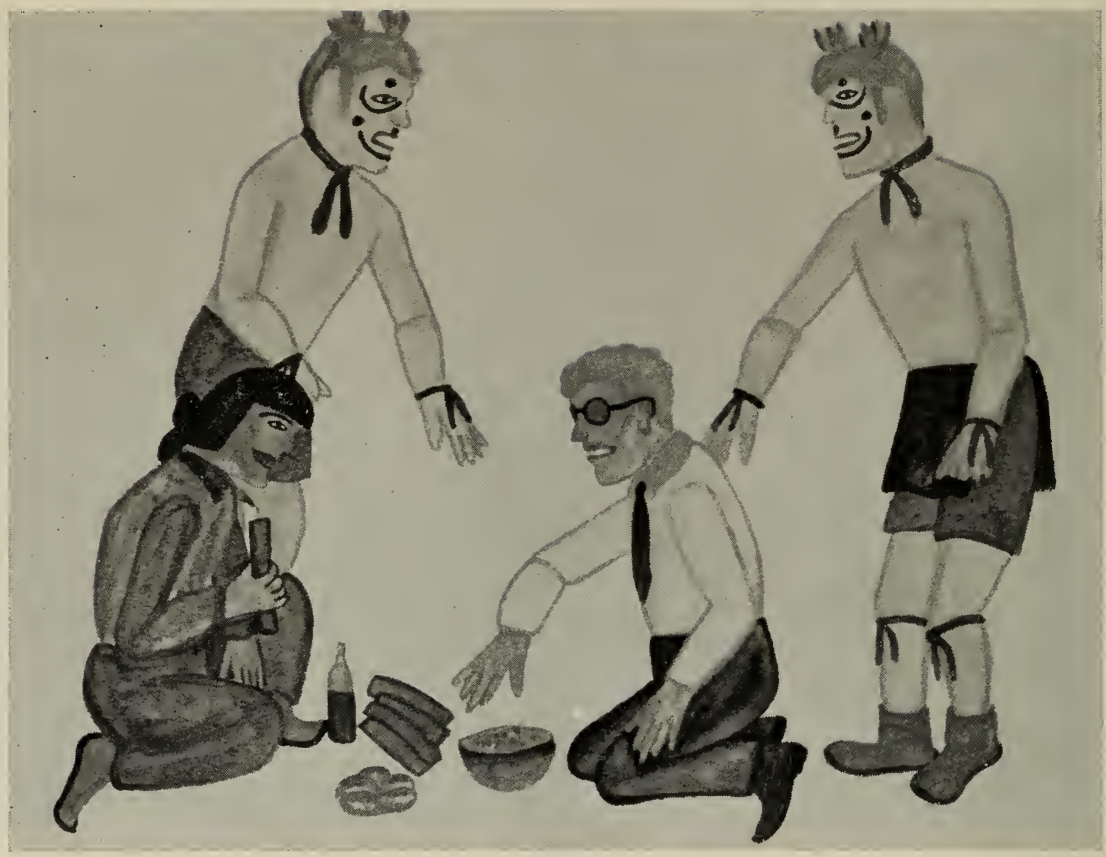

111

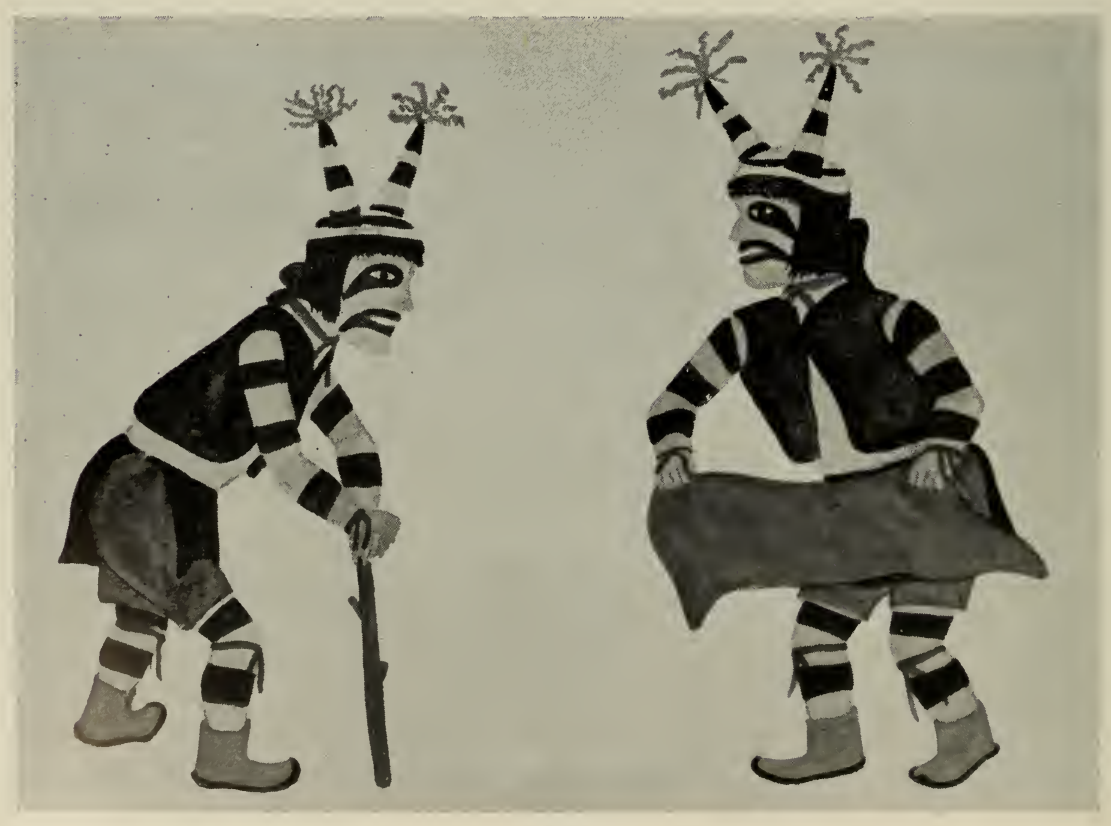



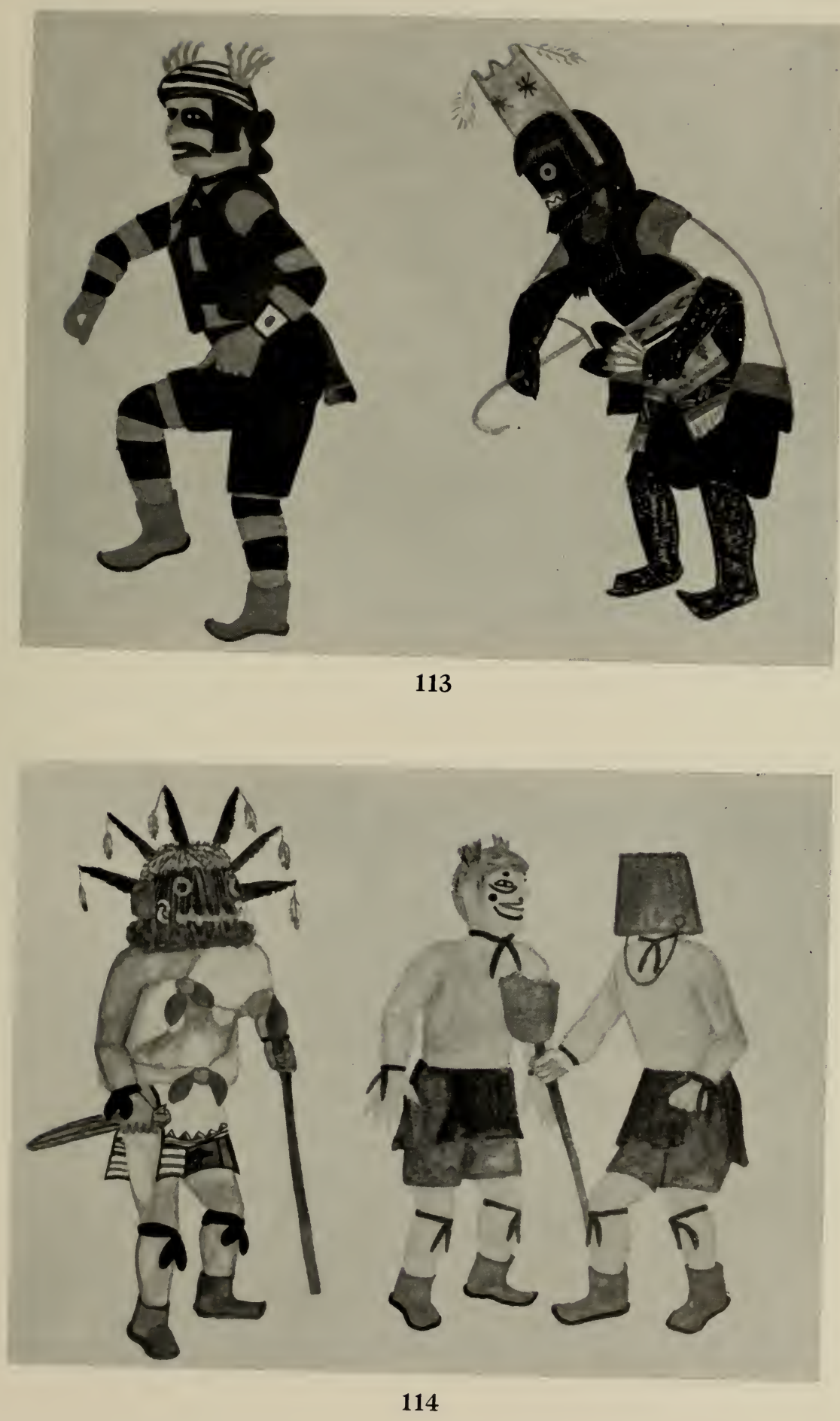
FIGURES I I 5, I I 6
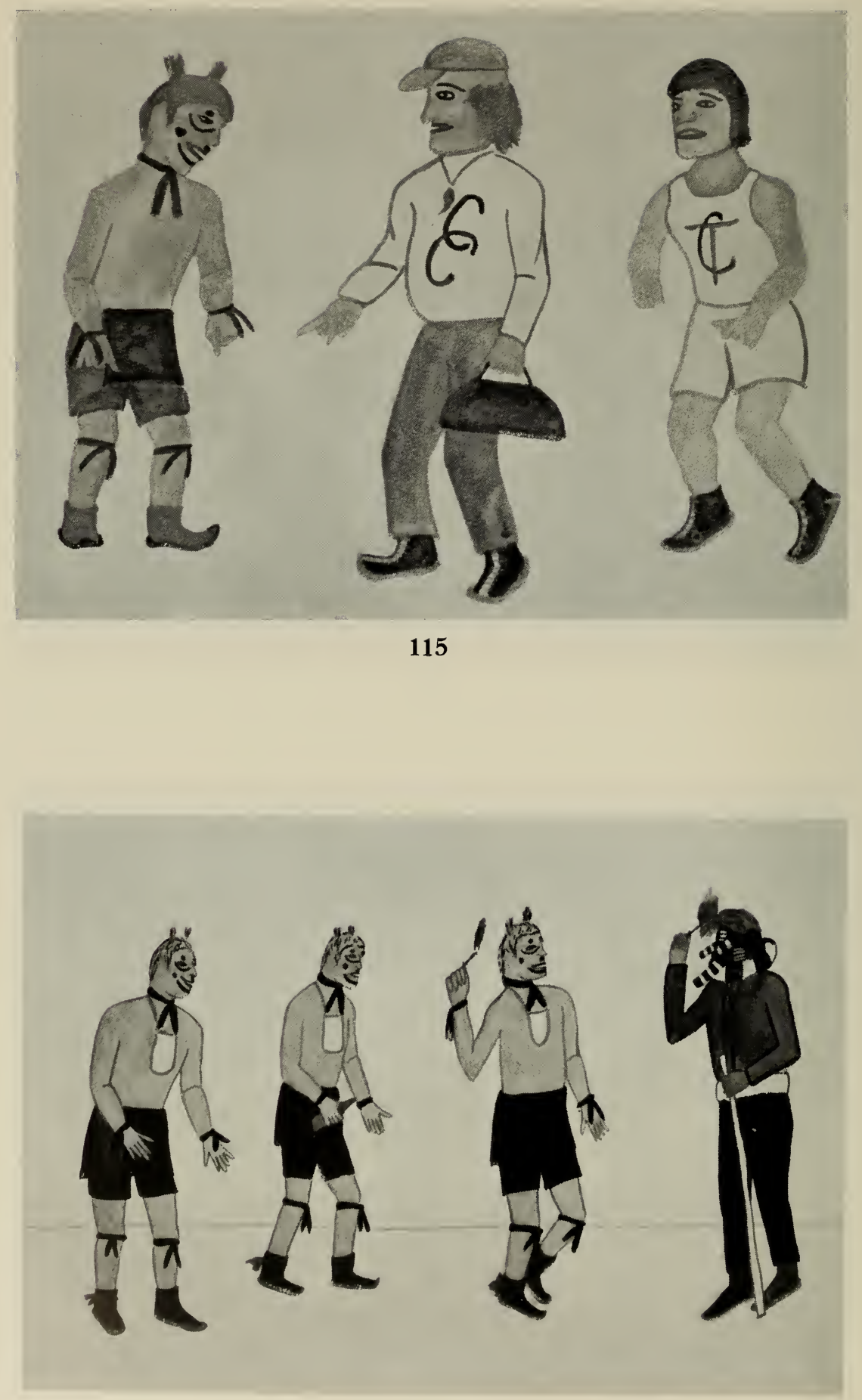

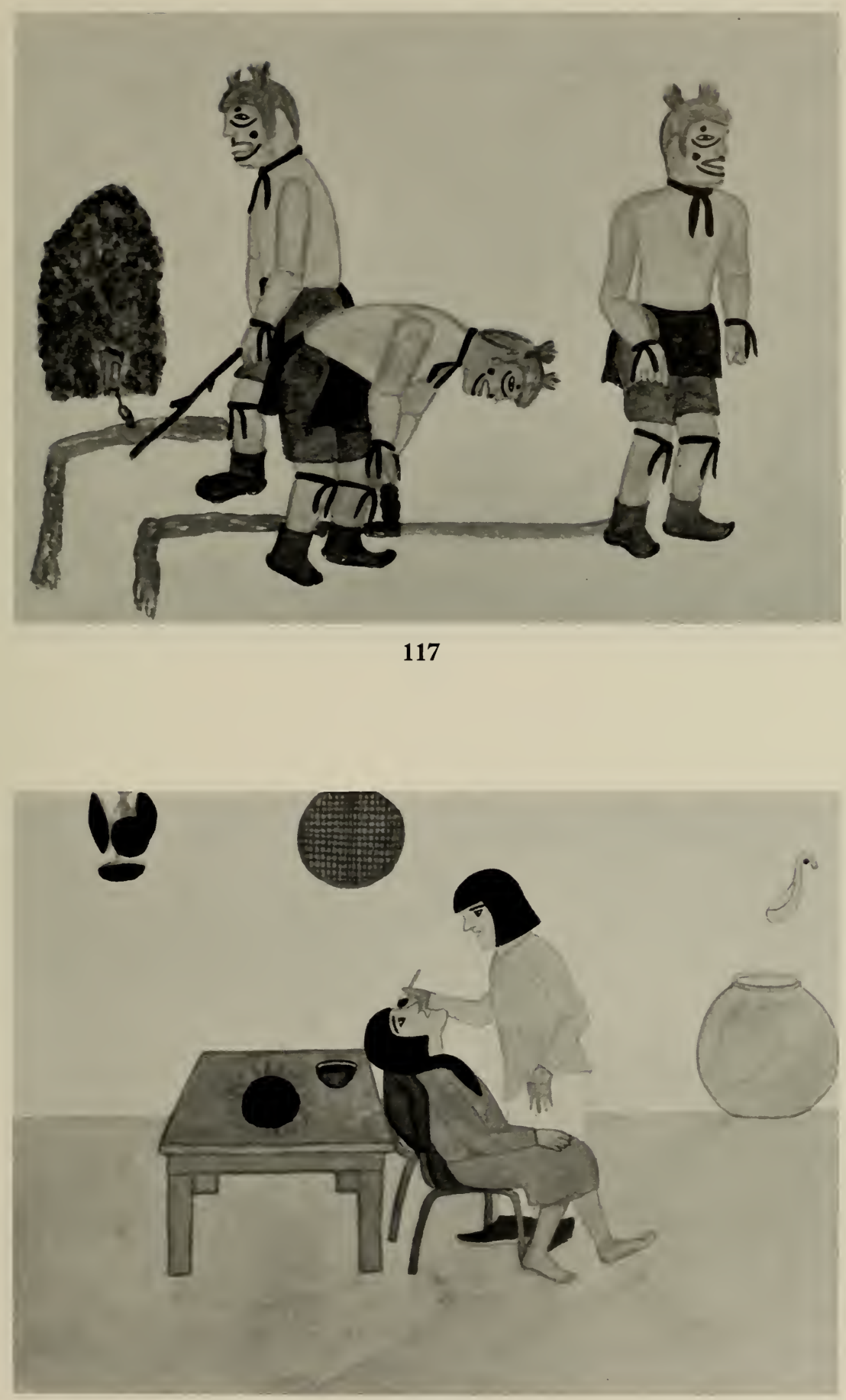


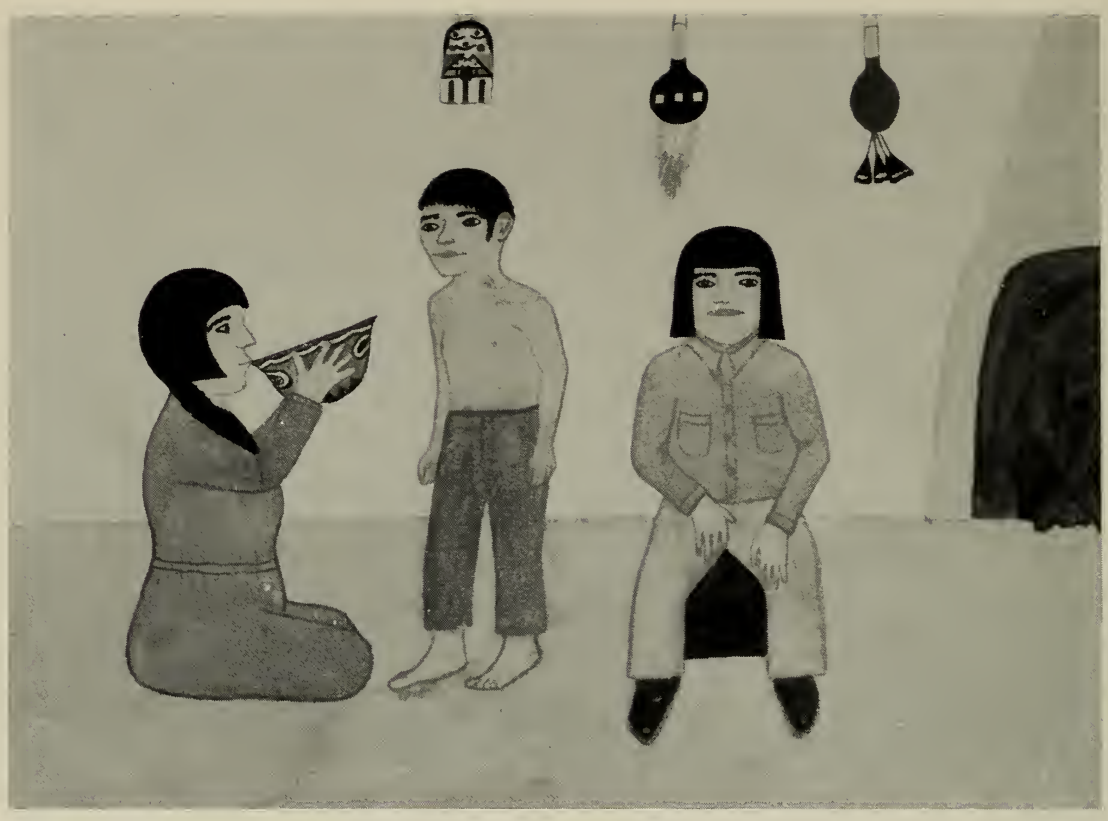

119
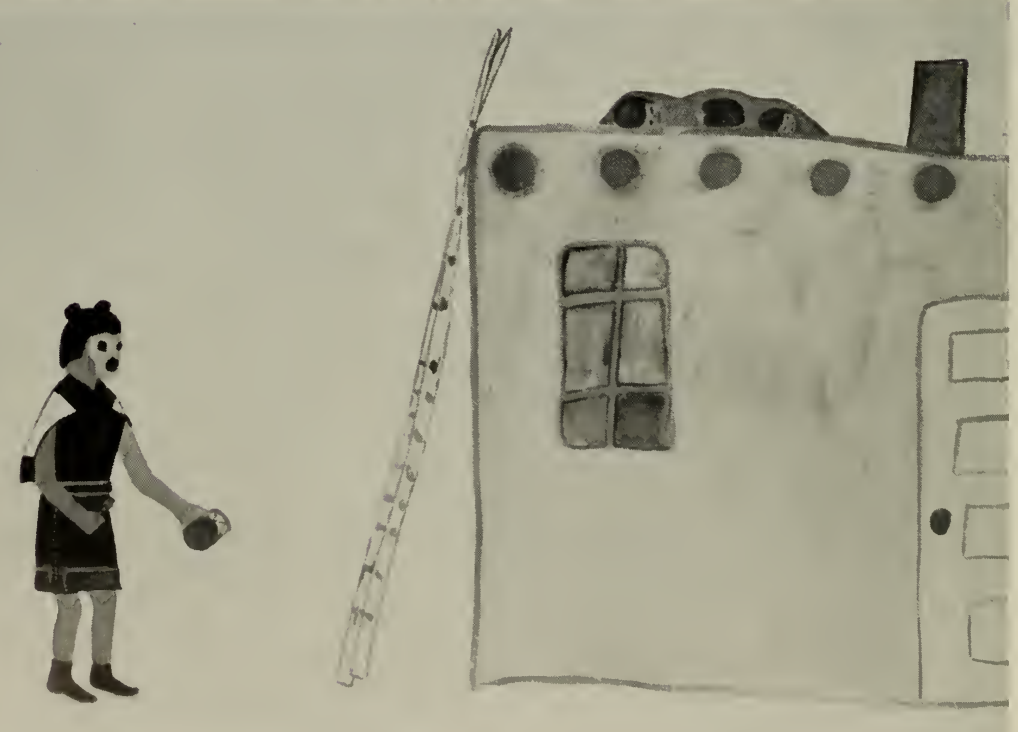
FIGURES I 2 I , I 22

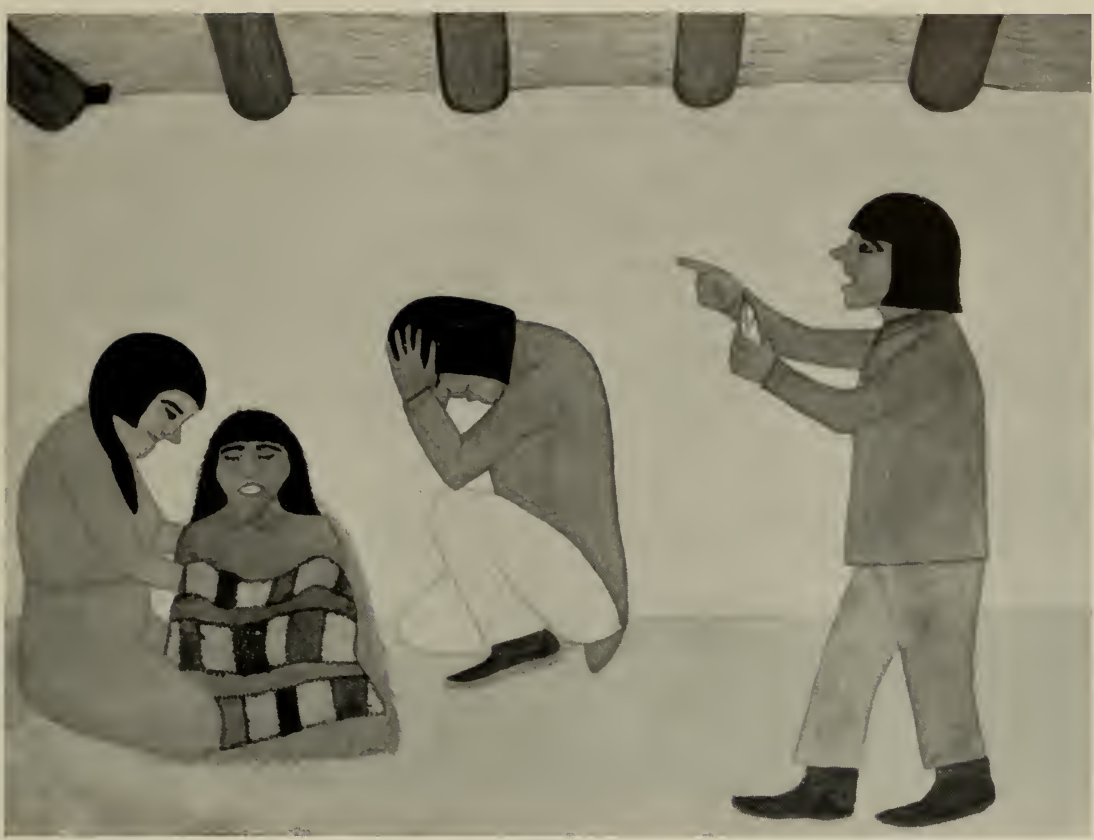

121

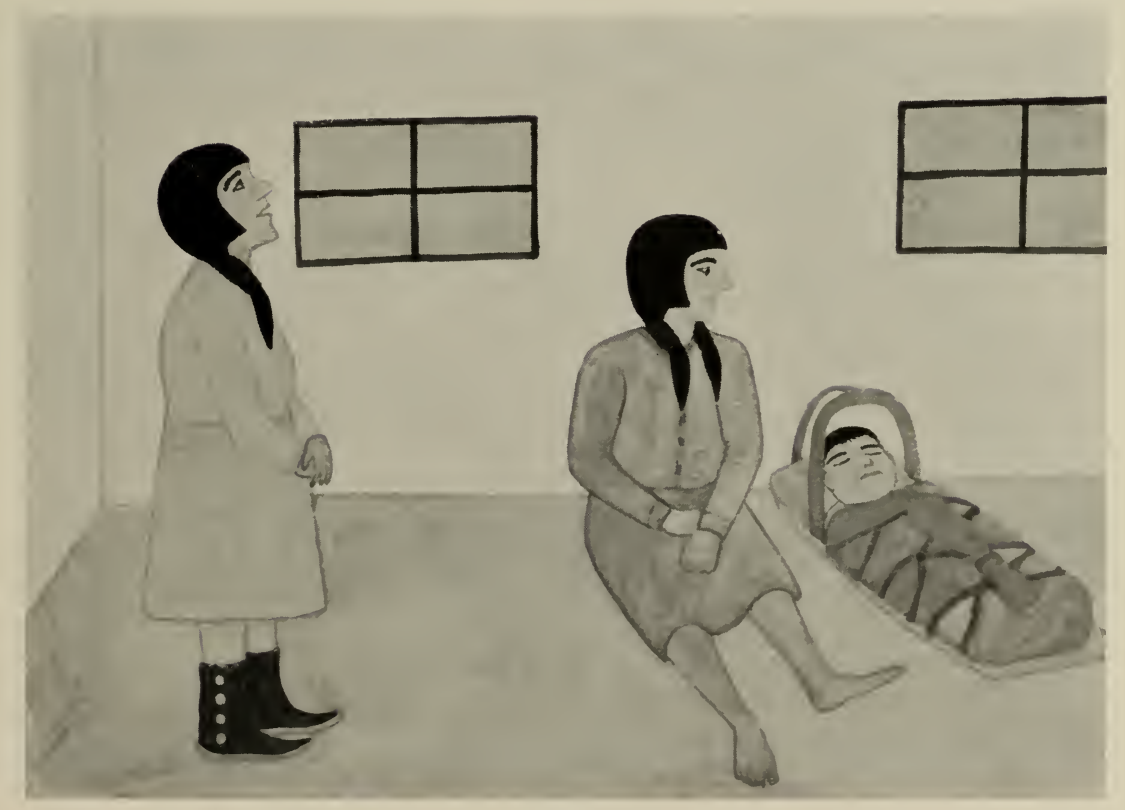

122 
FIGURES I 23, I 24

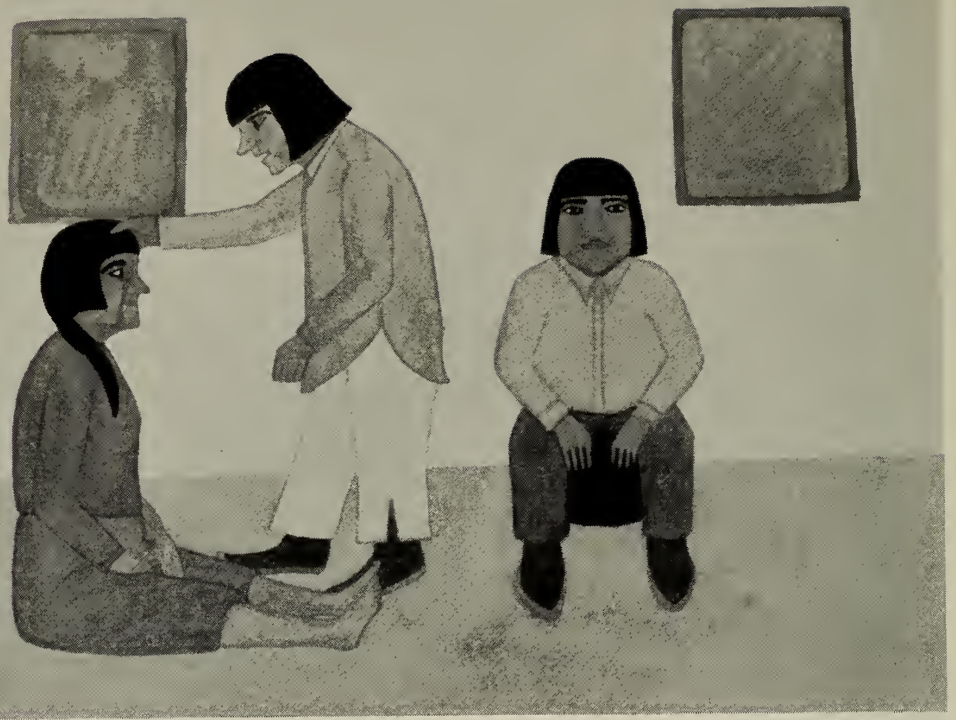

123

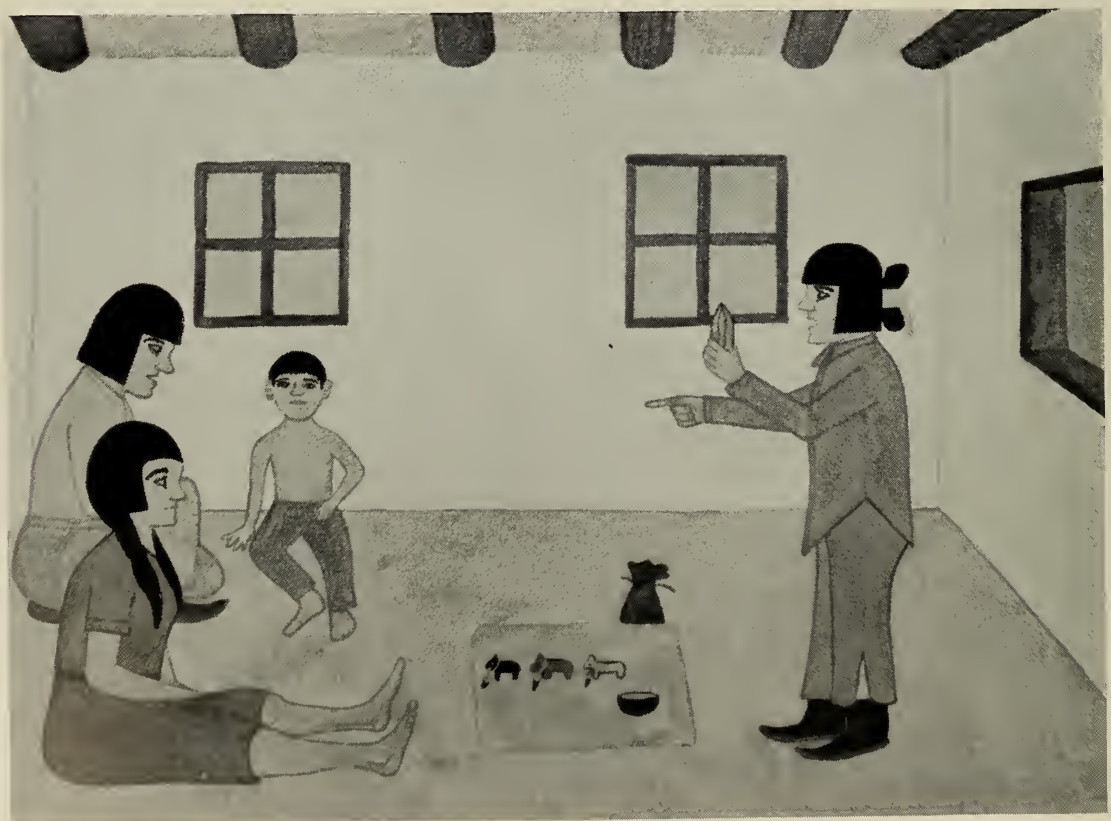




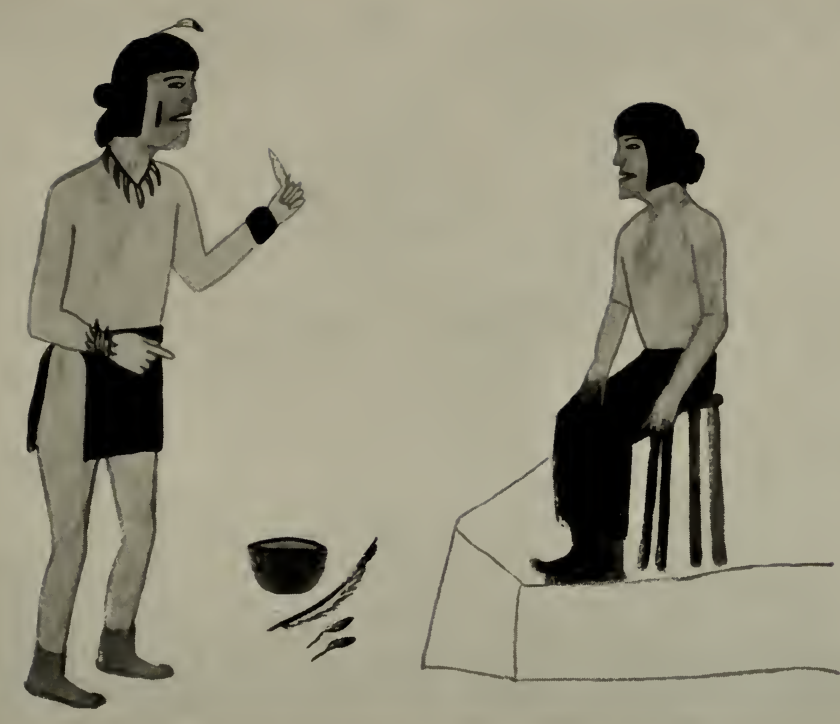


FIGURE I 26

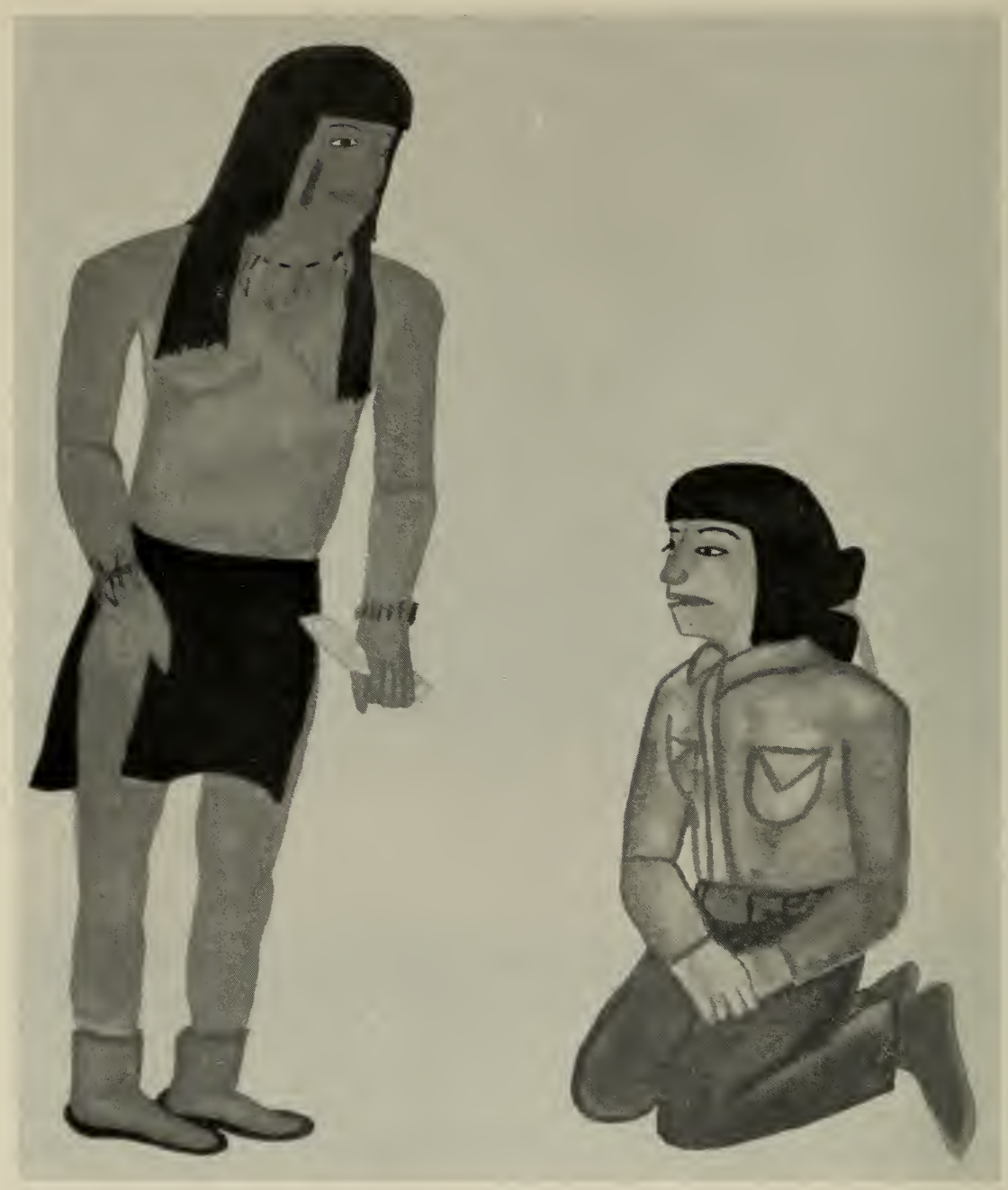

126 
FIGURES 127, I 28

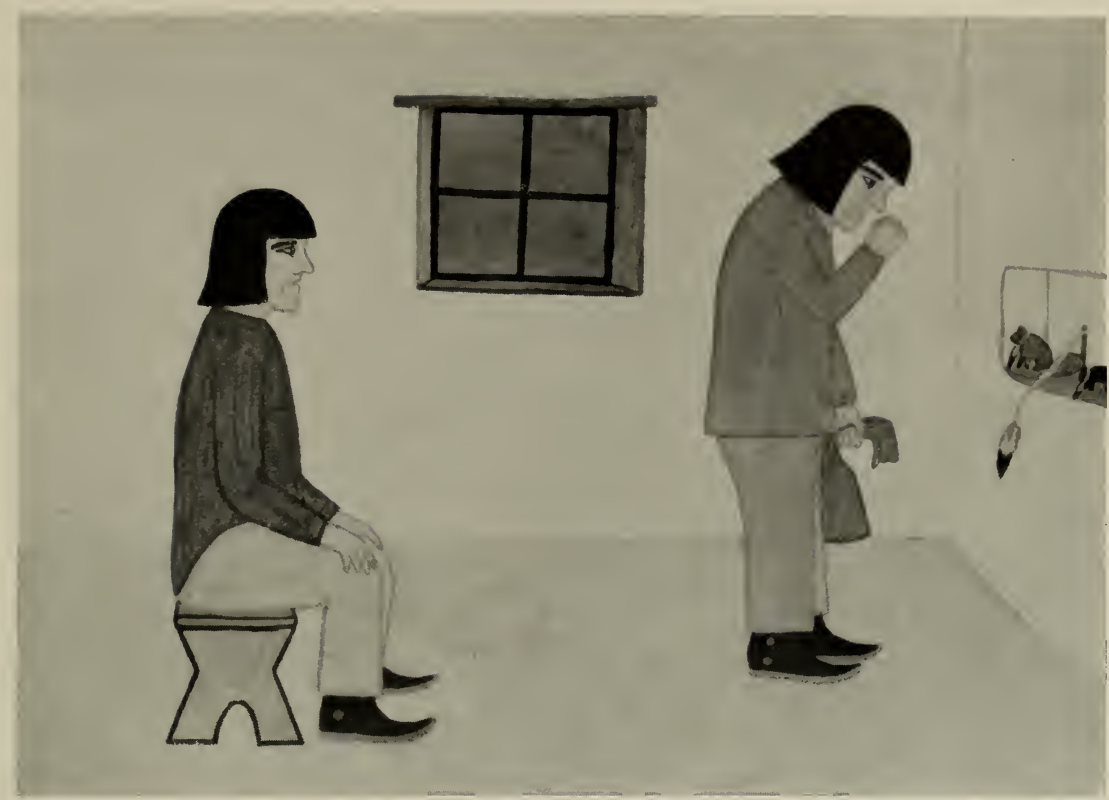

127

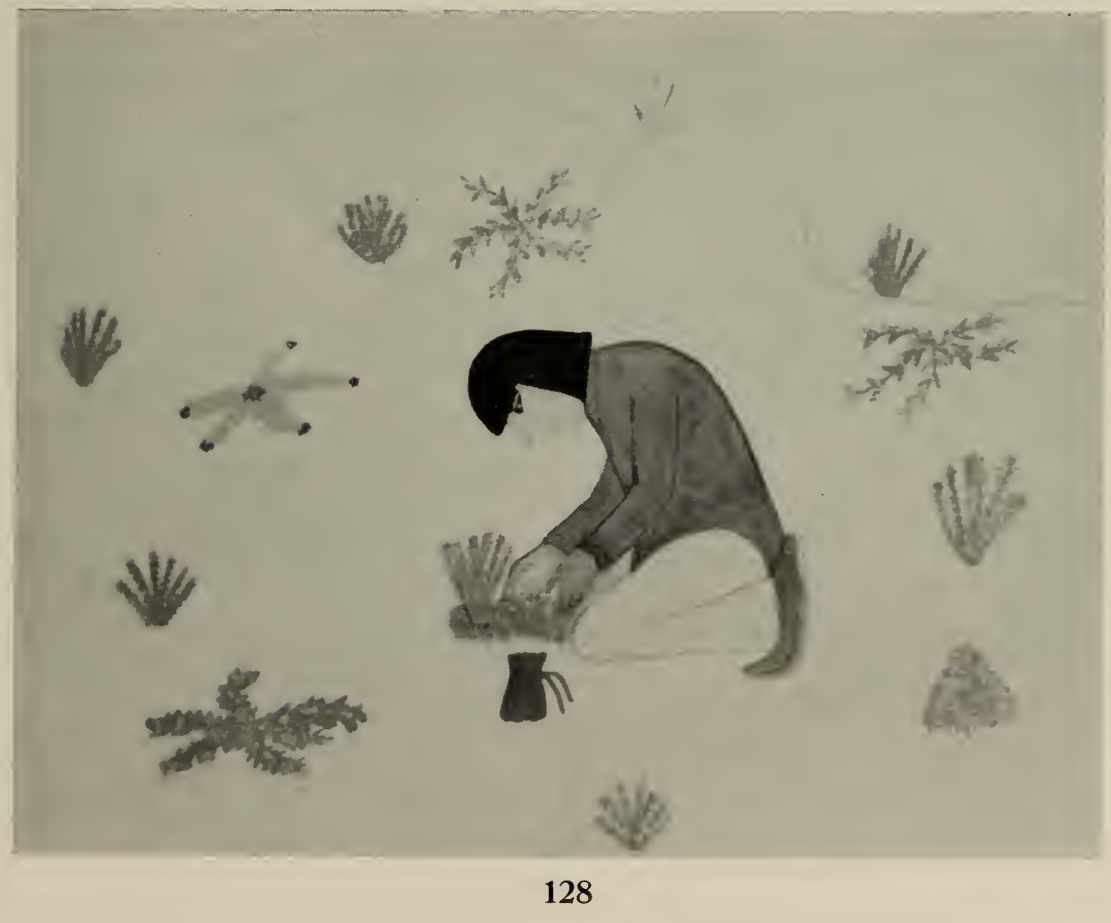


FIGURES I 29, I 30

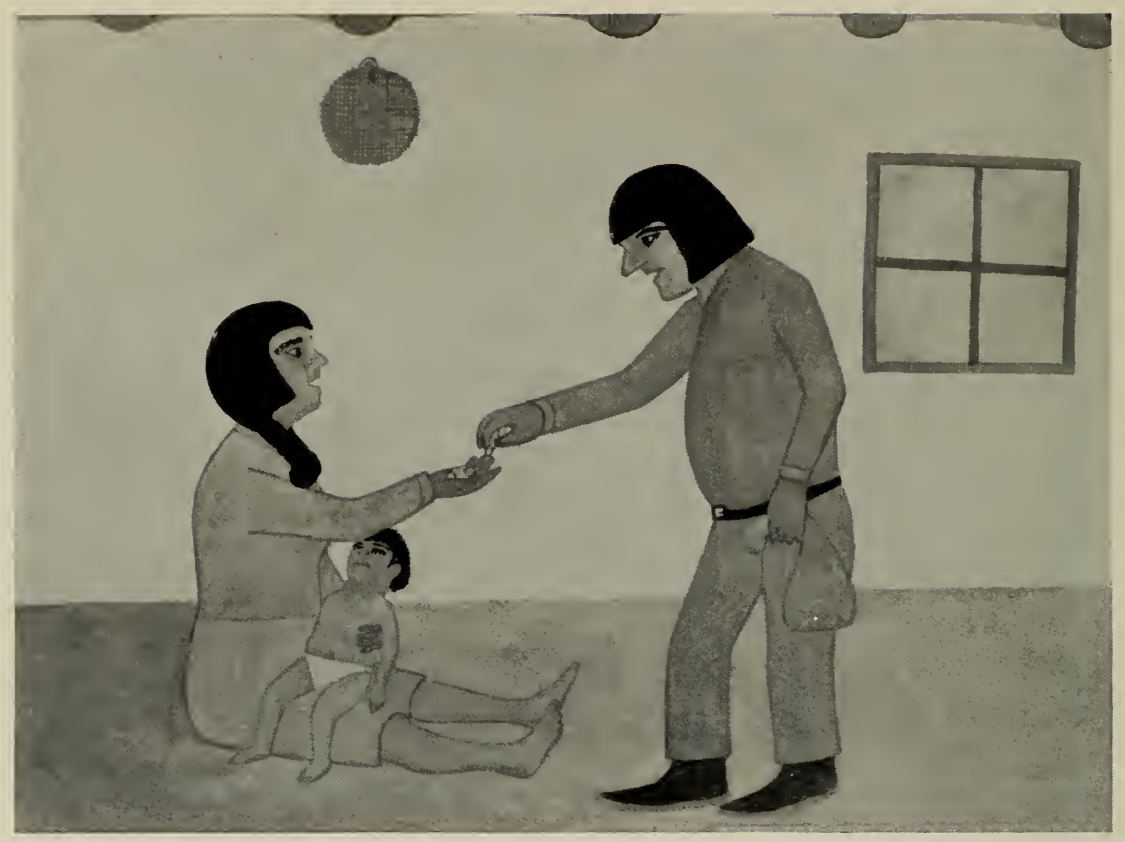

129

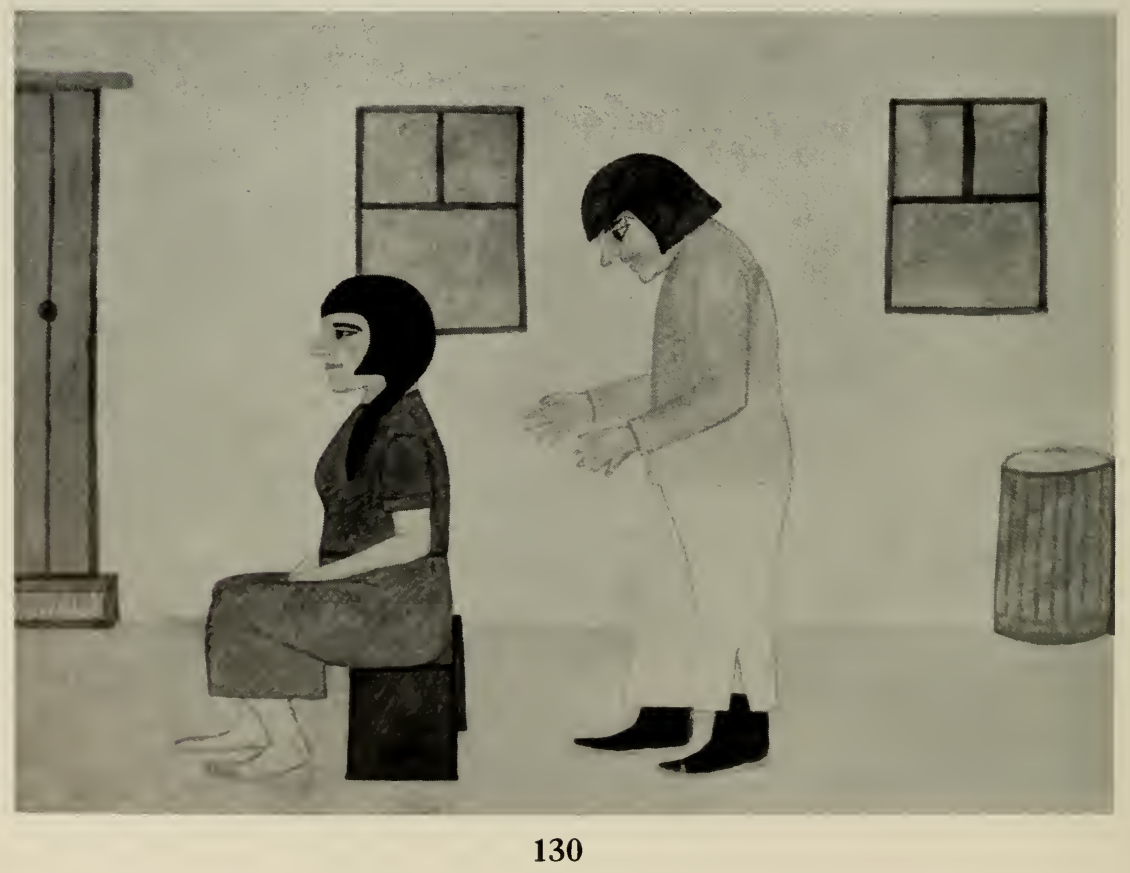


FIGURES I 3 I , I32

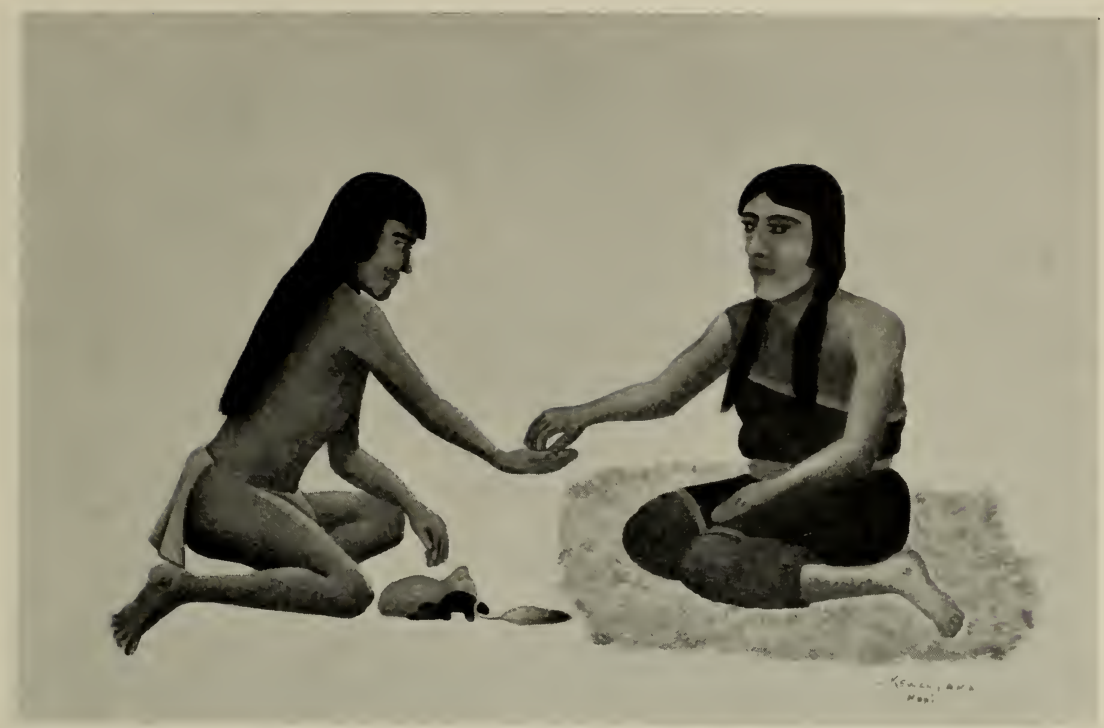

131

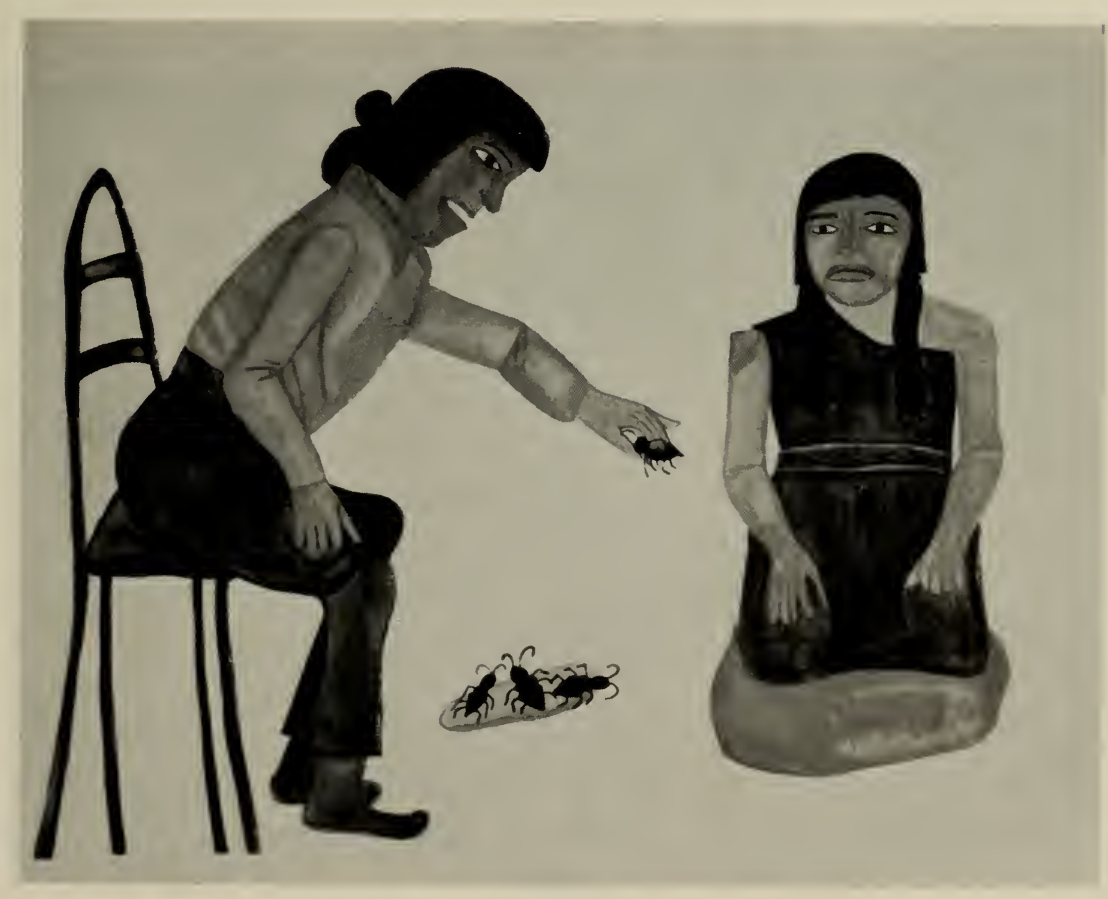

132 
FIGURES I 33, I 34

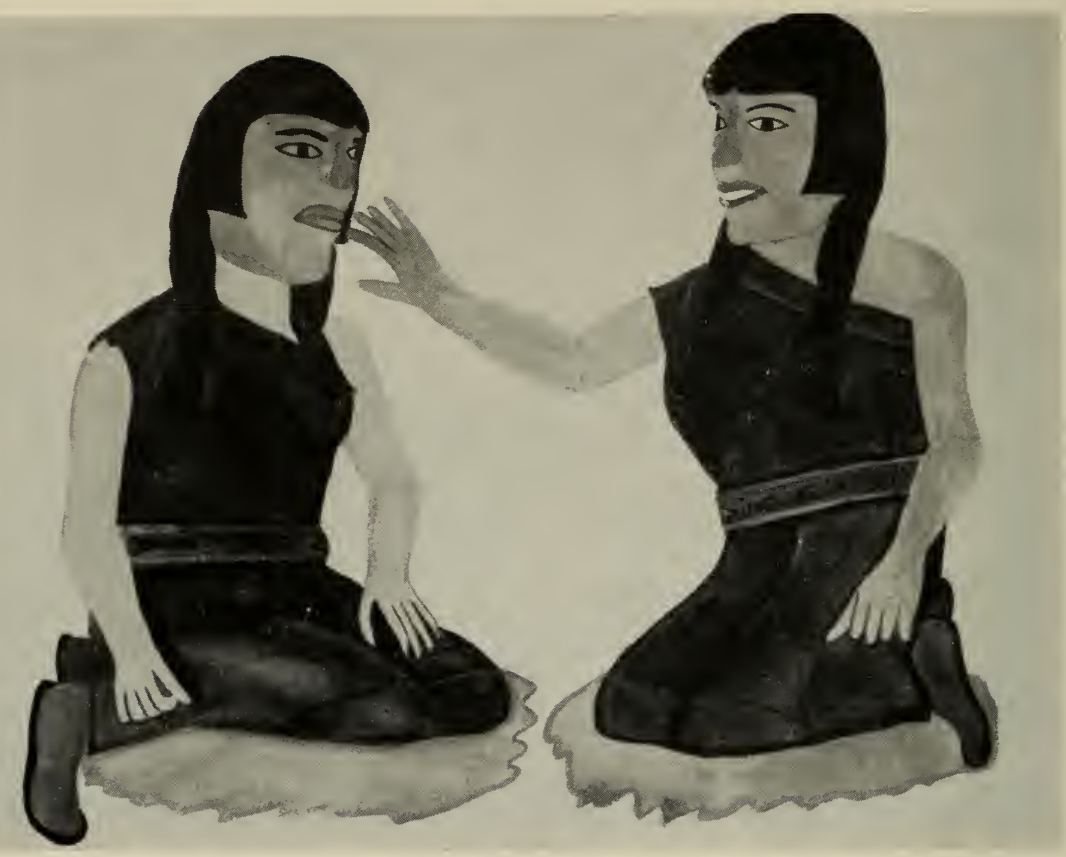

133

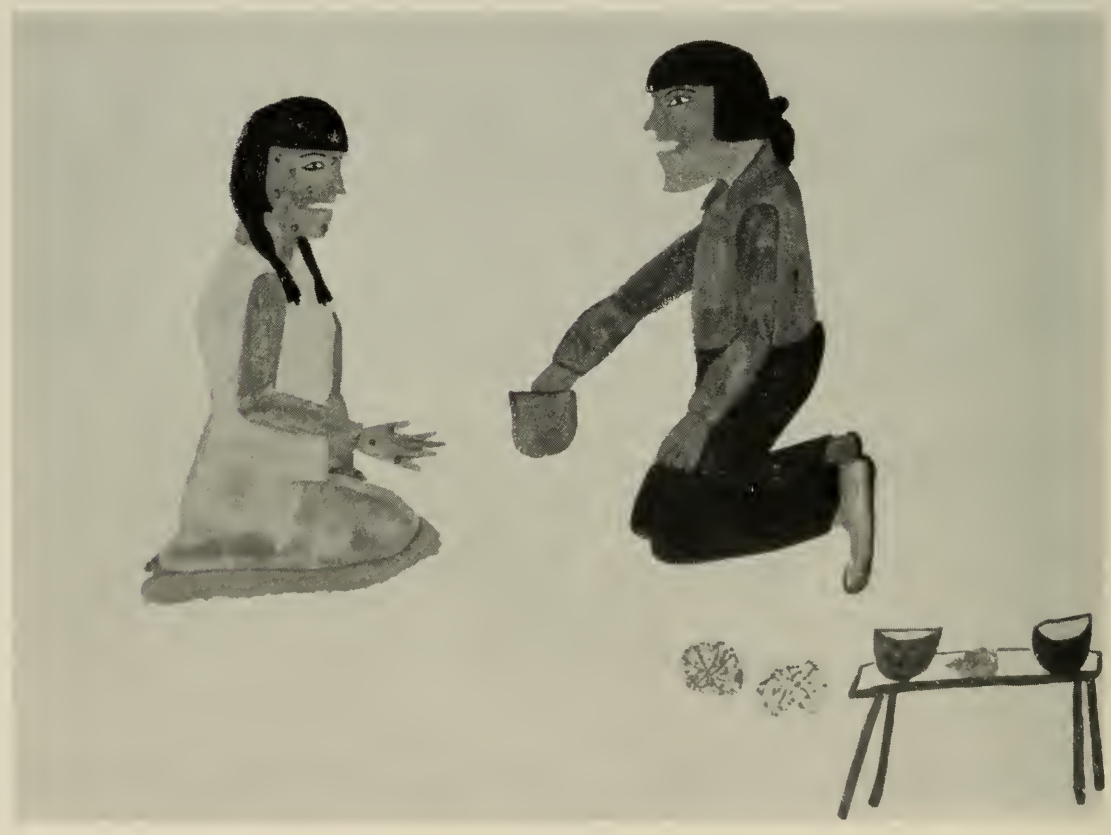


FIGURES I 35, I 36

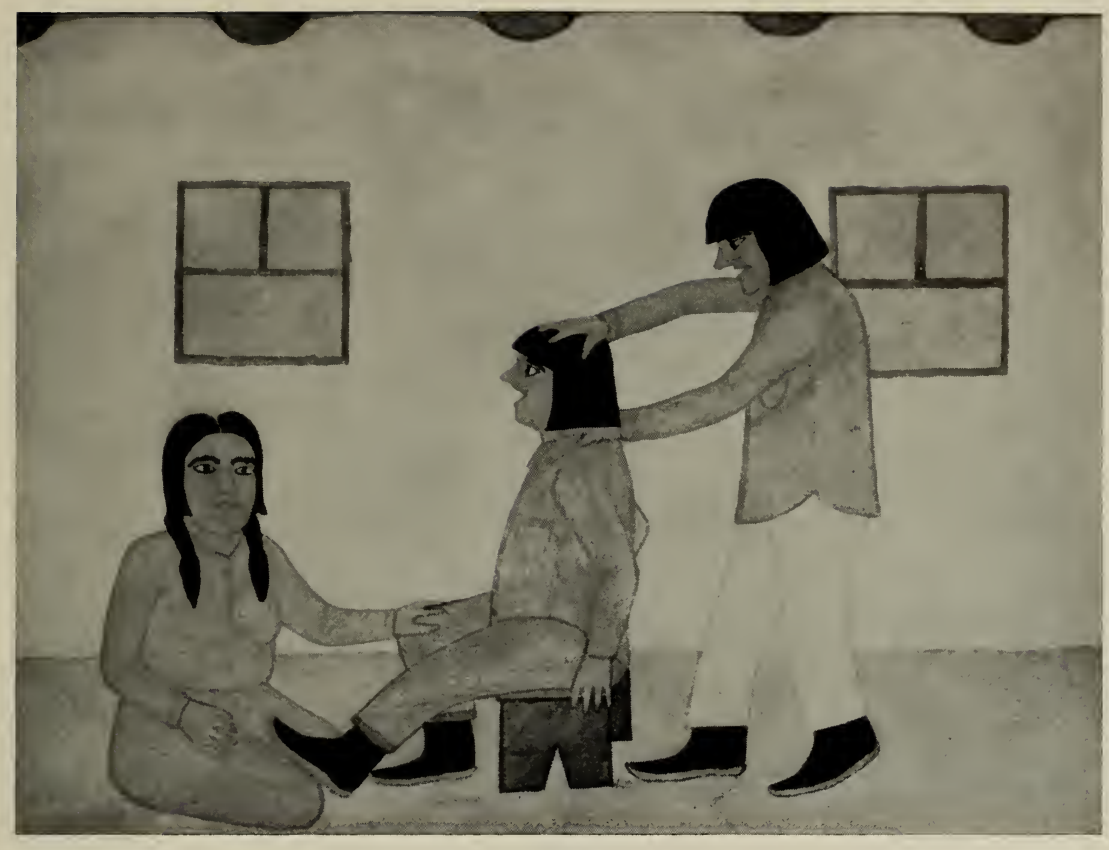

135

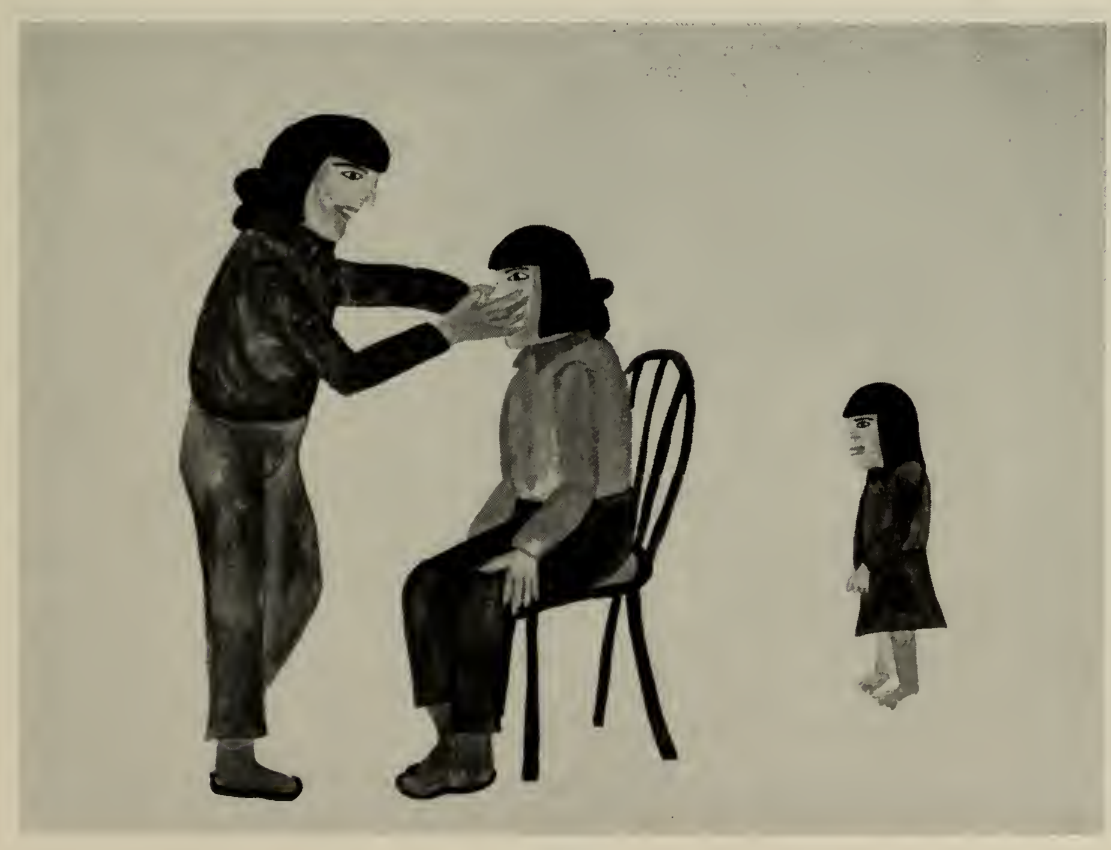



FIGURES I 39, I 40

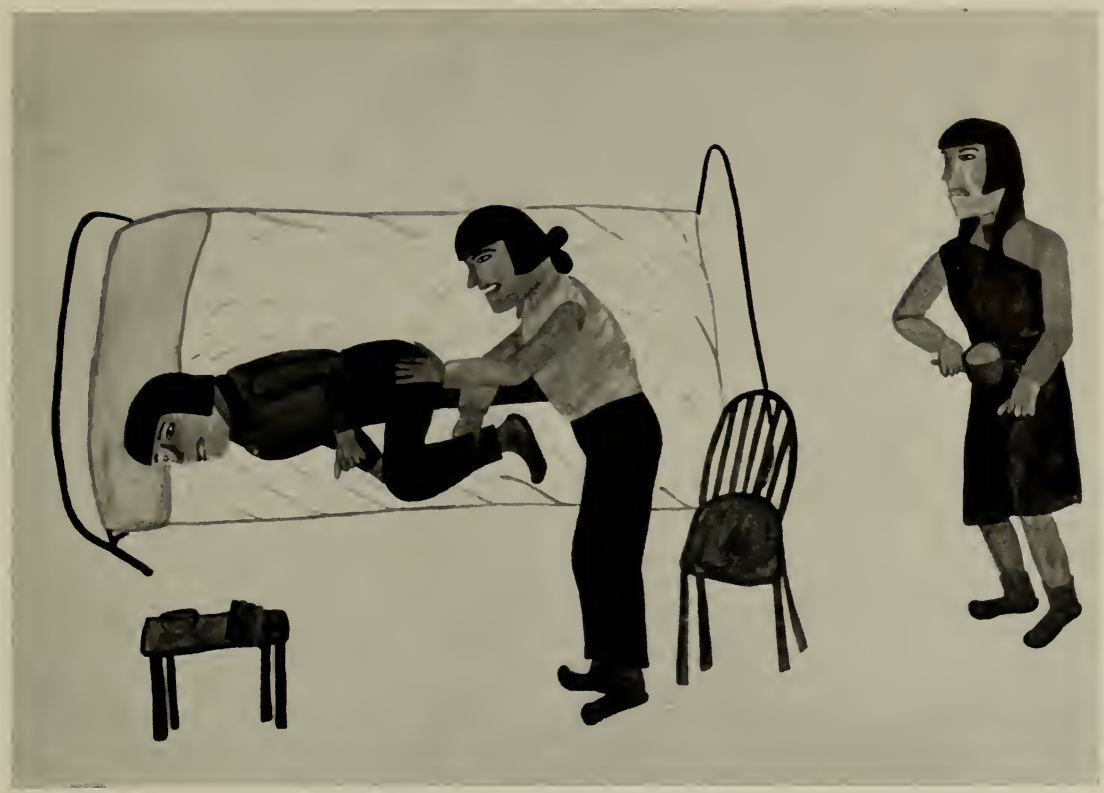

139

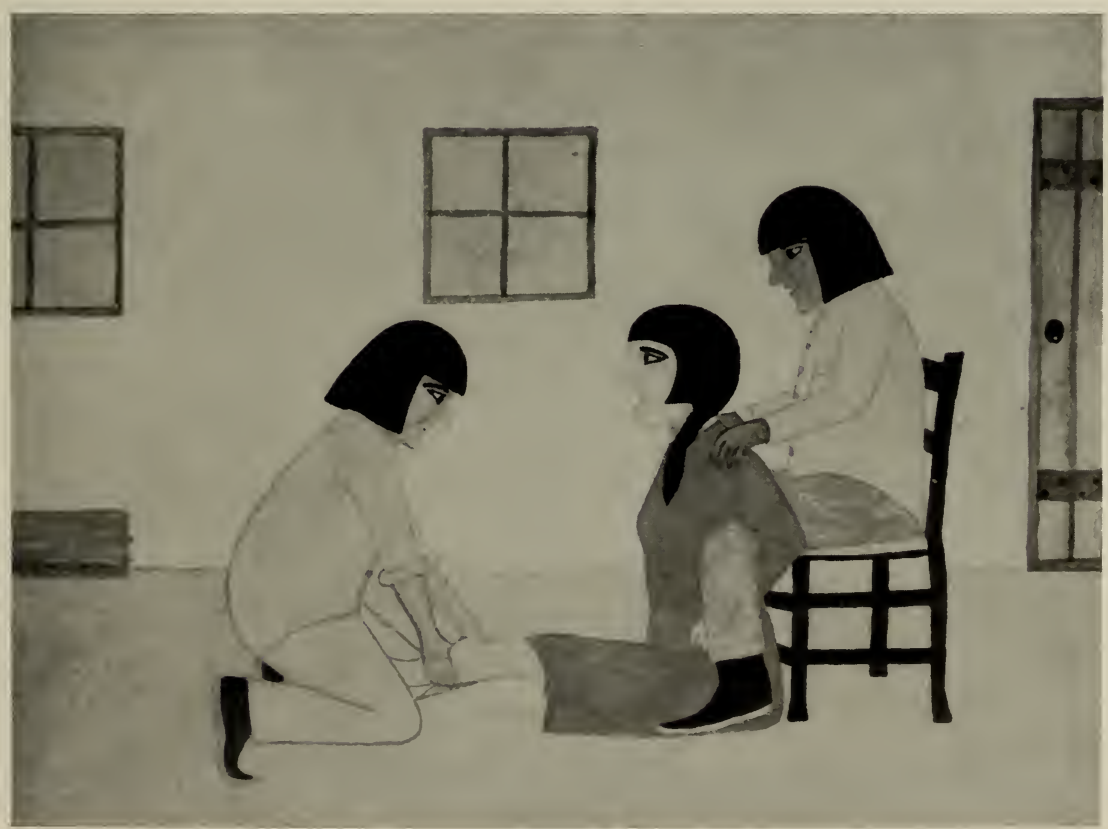


FIGURES I 4I, I 42

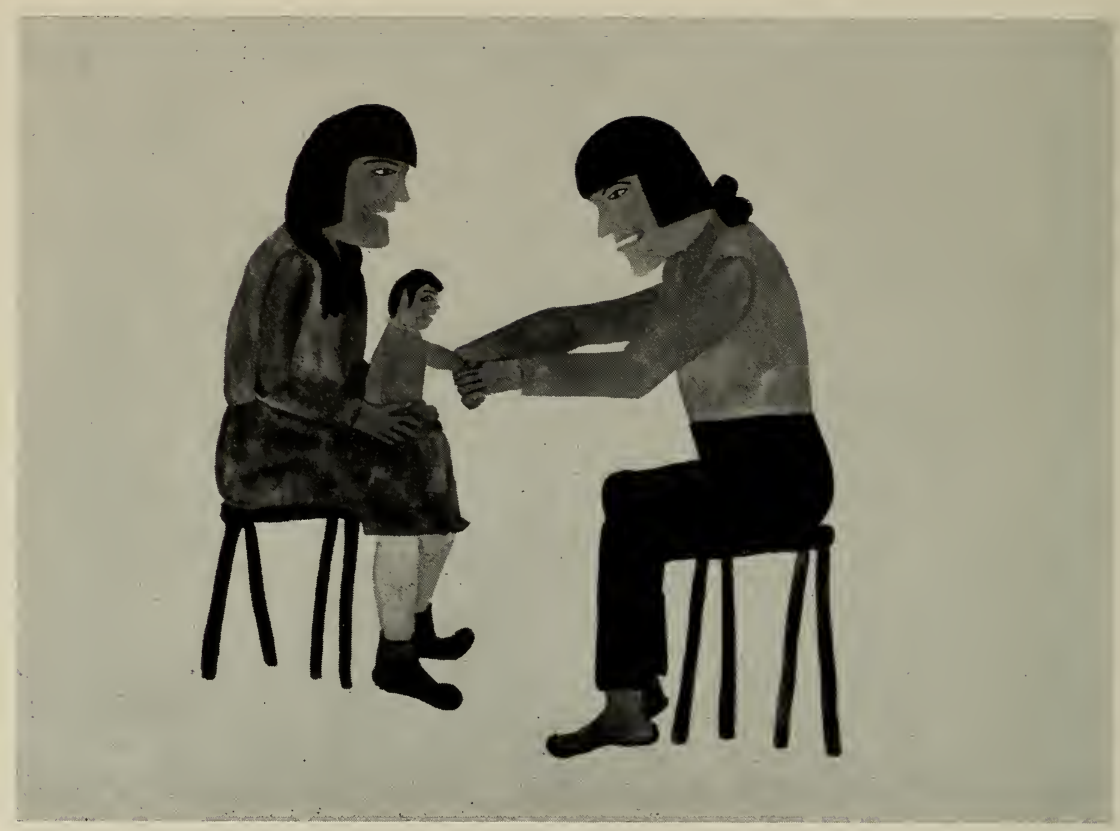

141

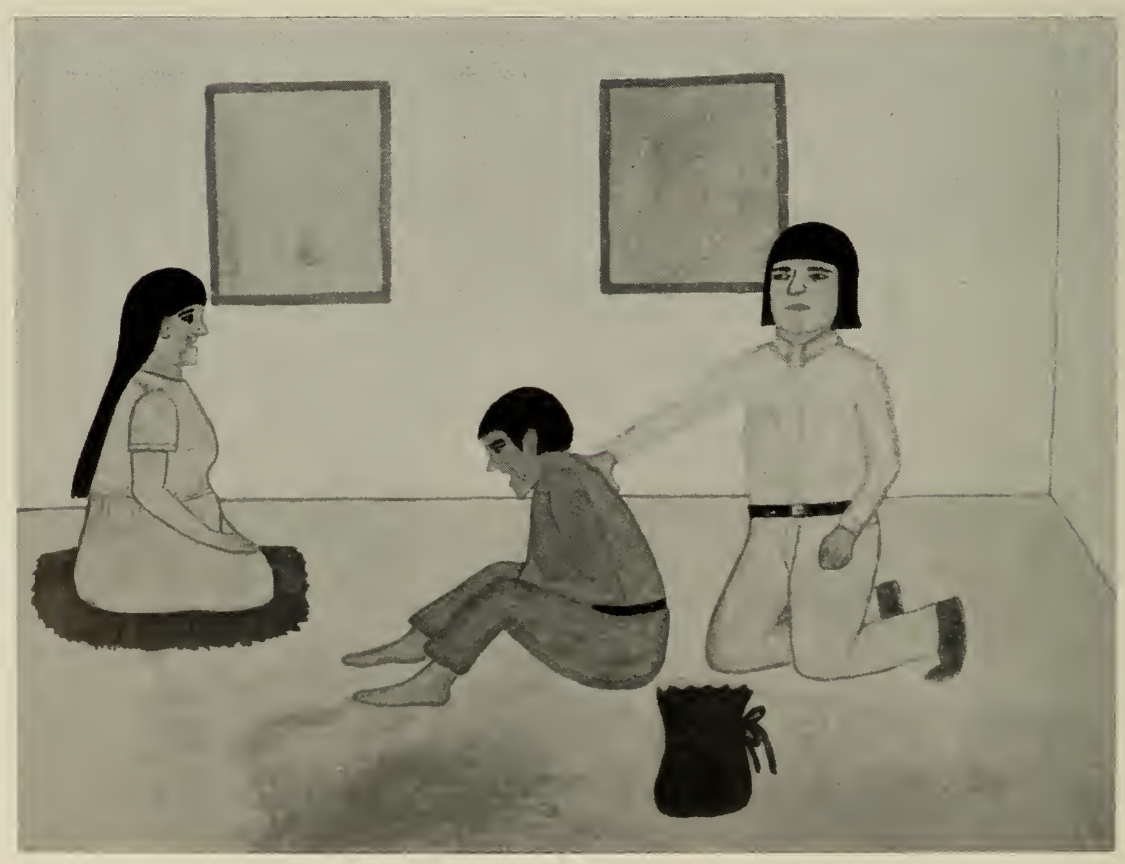


FIGURES I 43，I 44

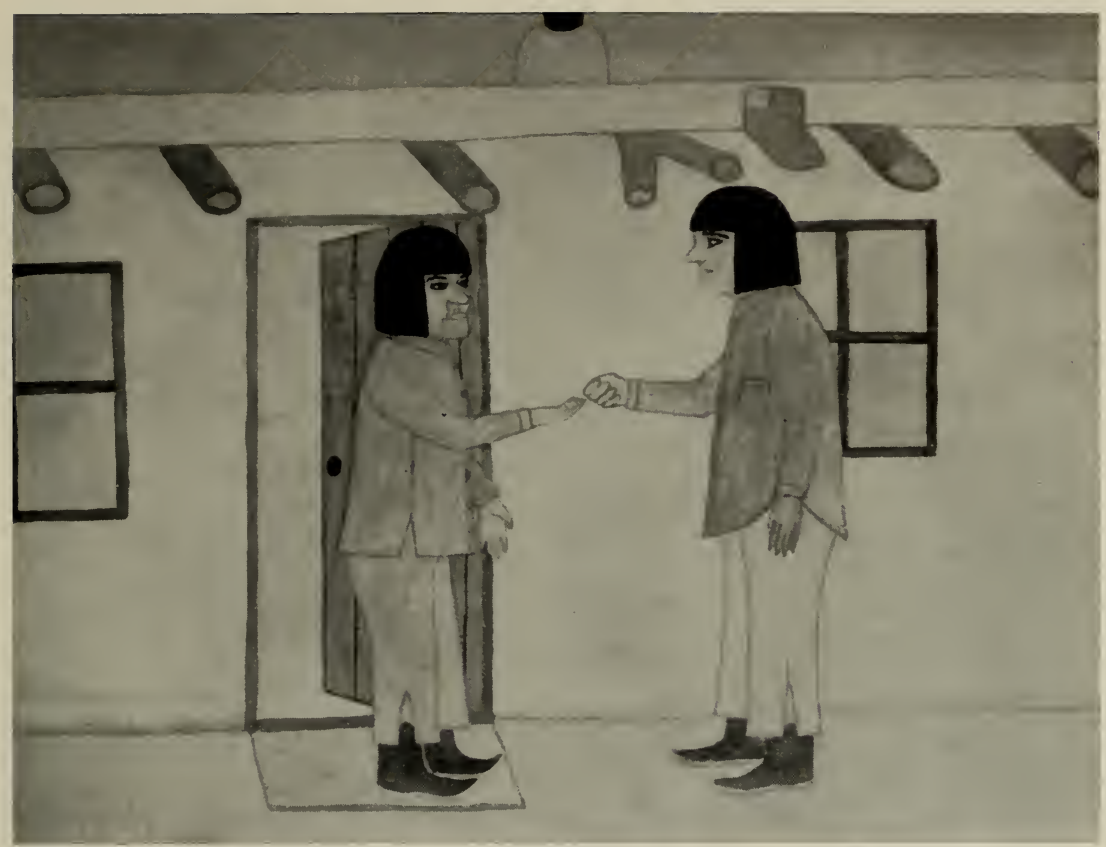

143

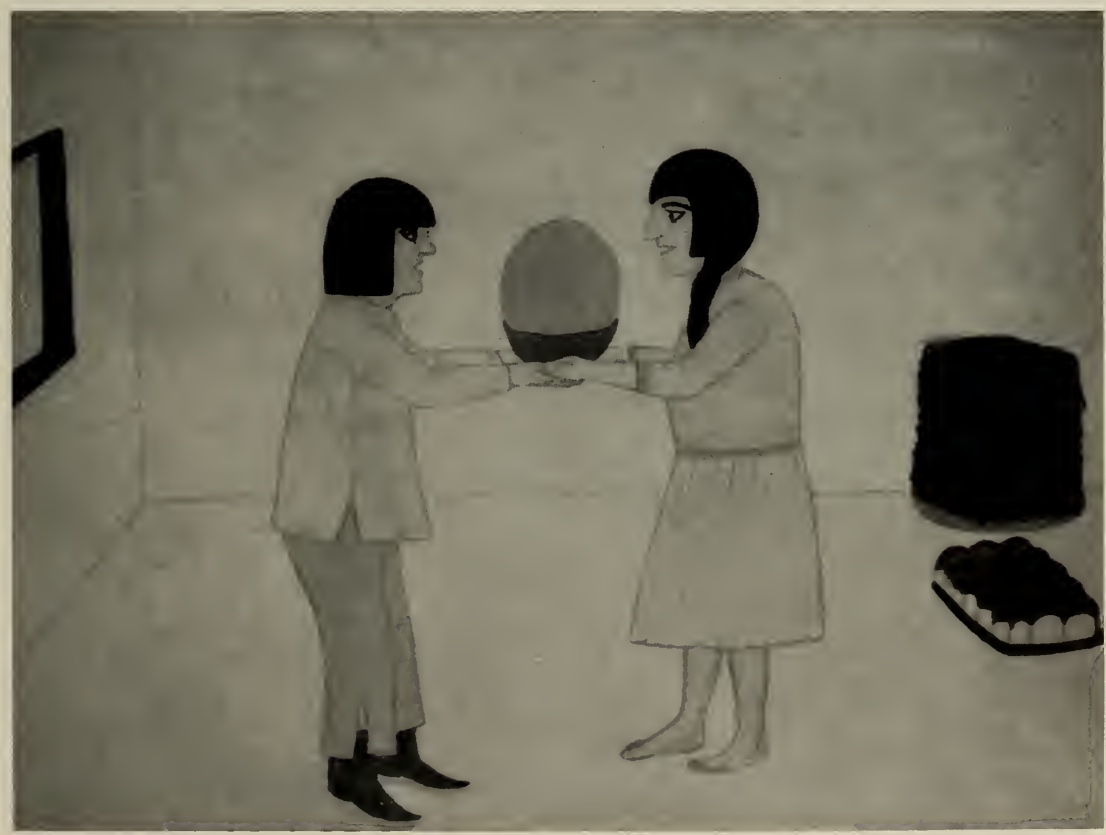




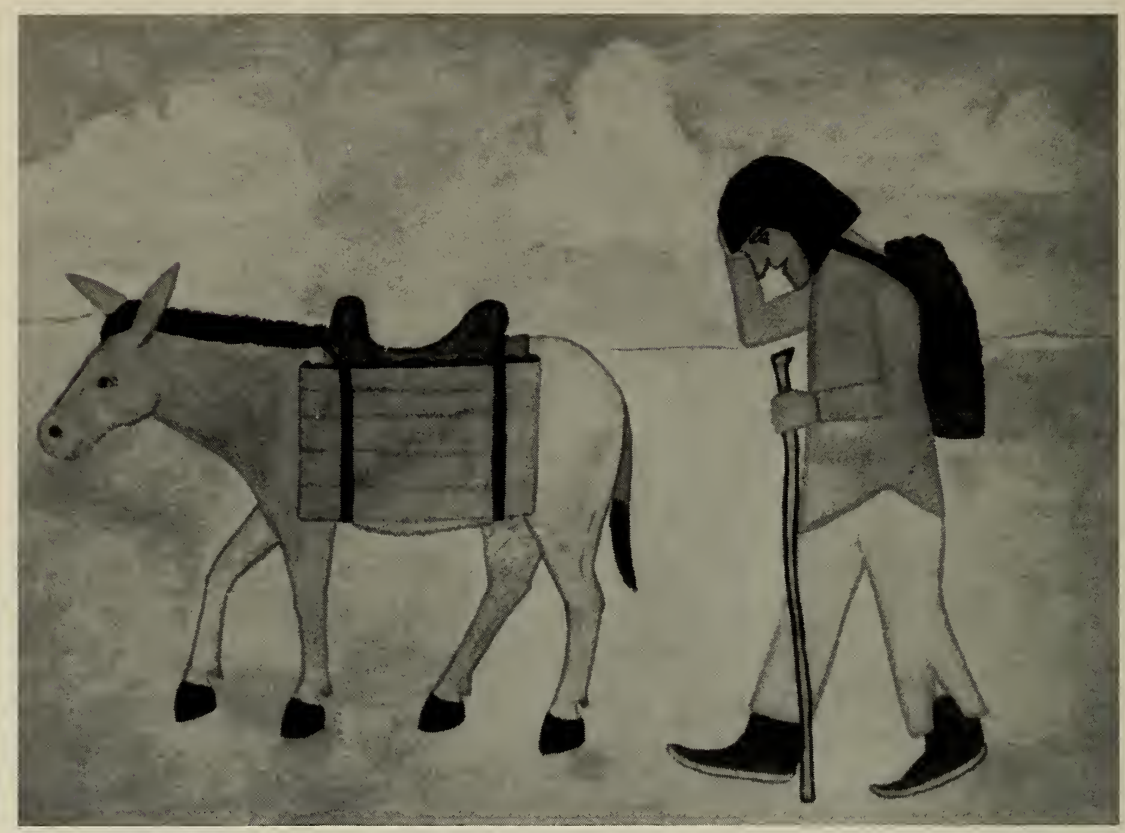

145

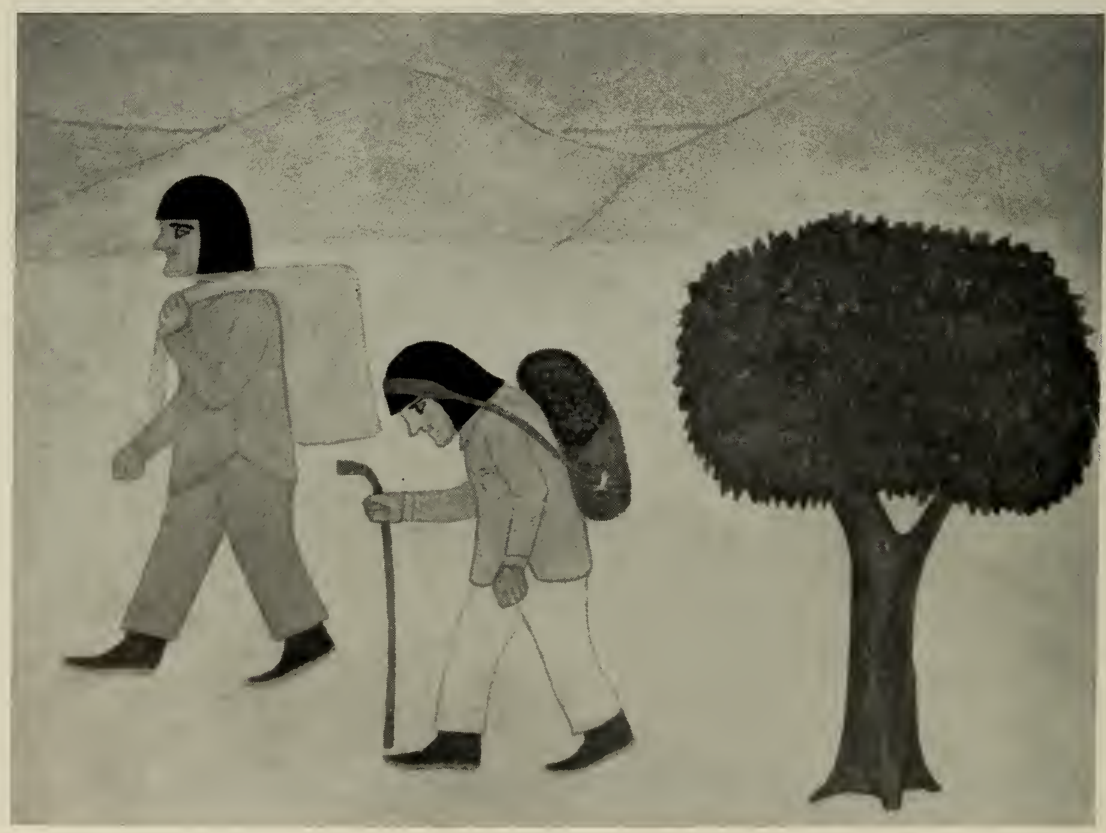

146 
FIGURES I 47, I $_{4} 8$

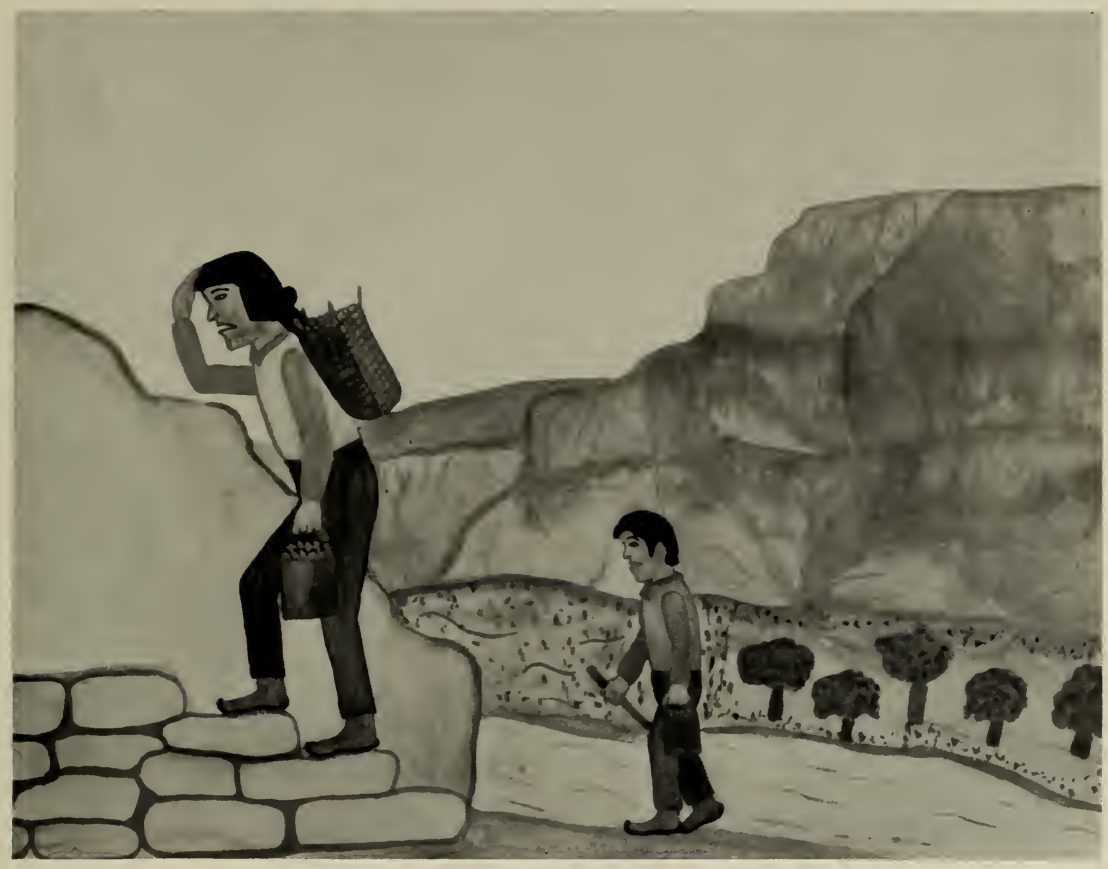

147

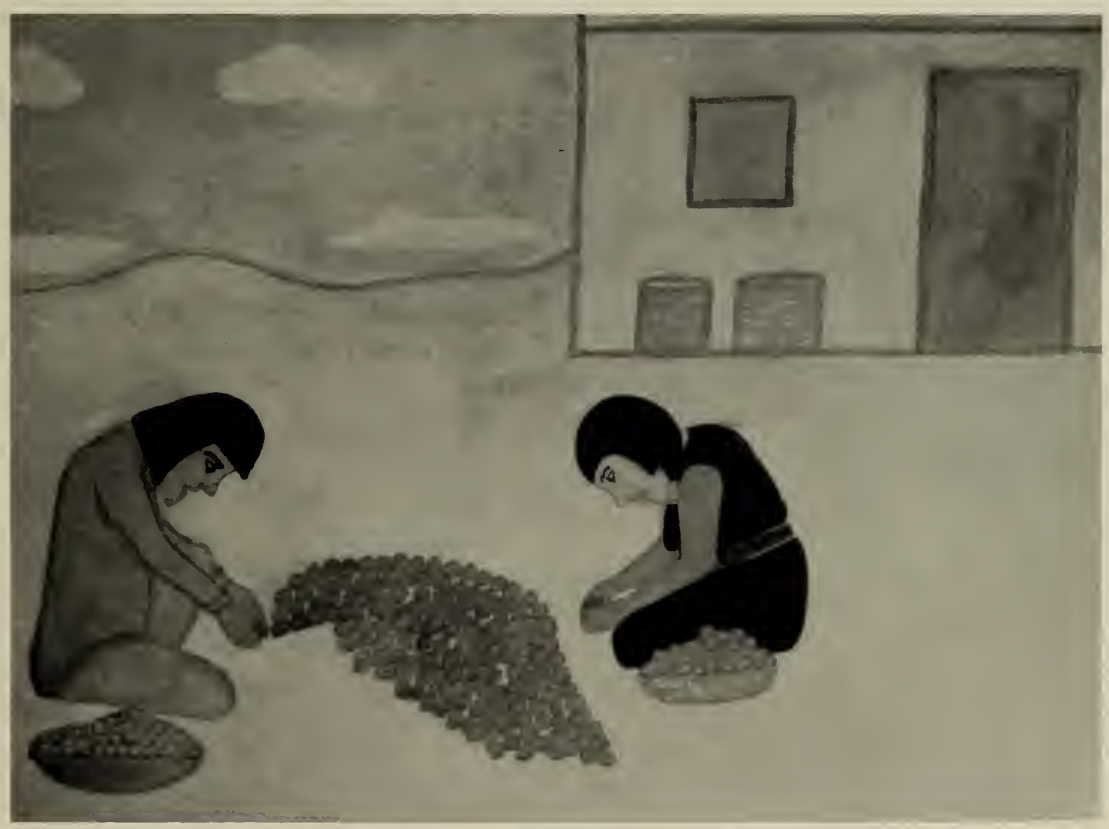


FIGURES I 49, I 50
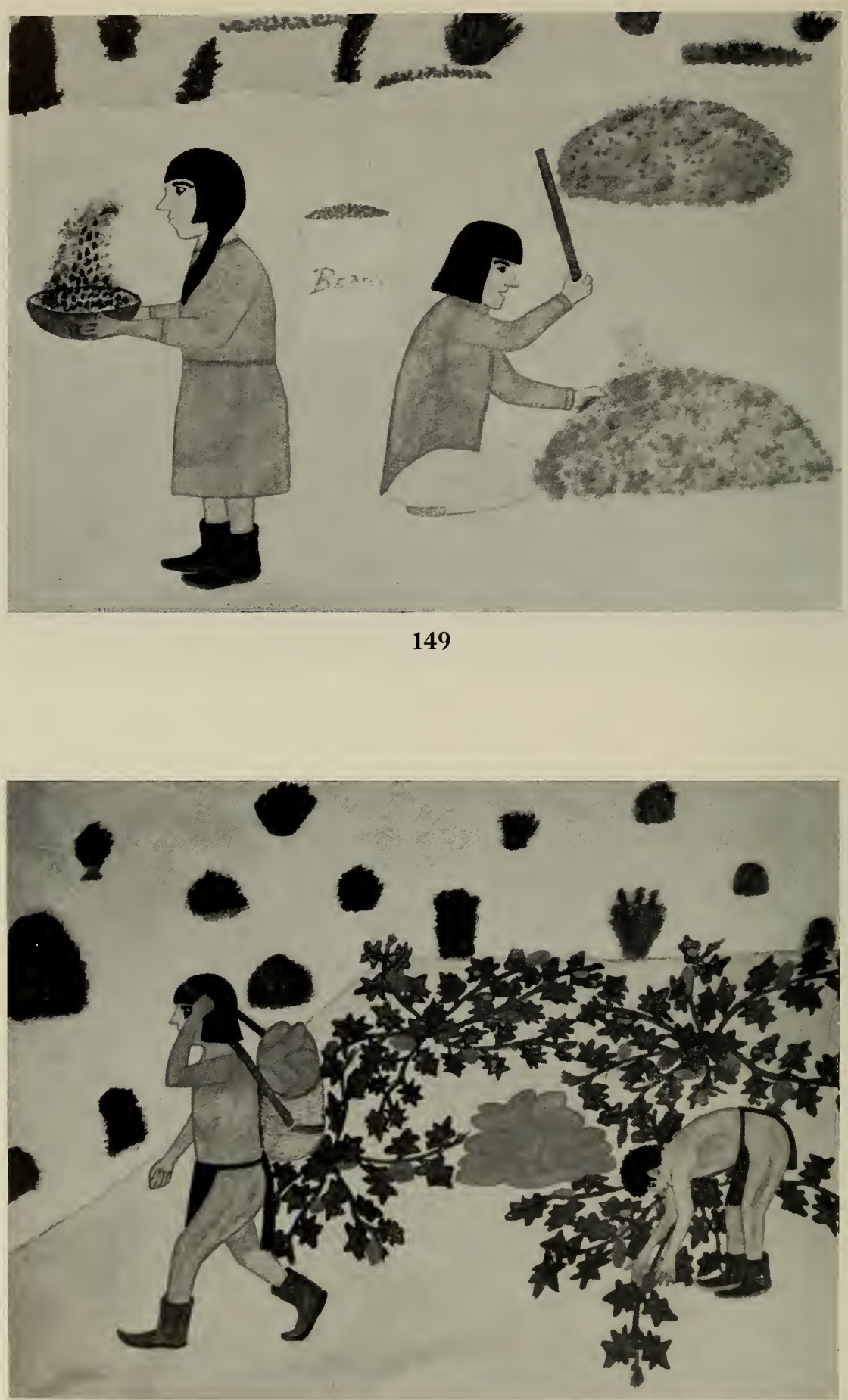

150 


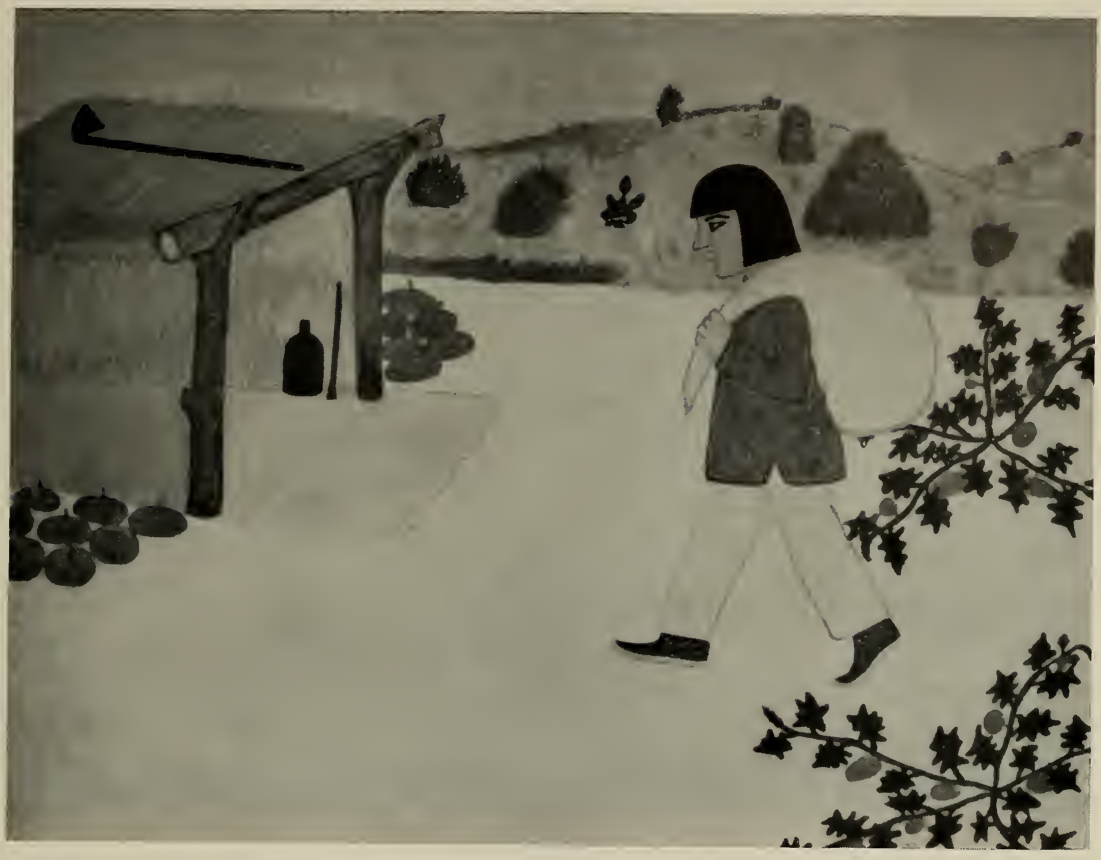

151

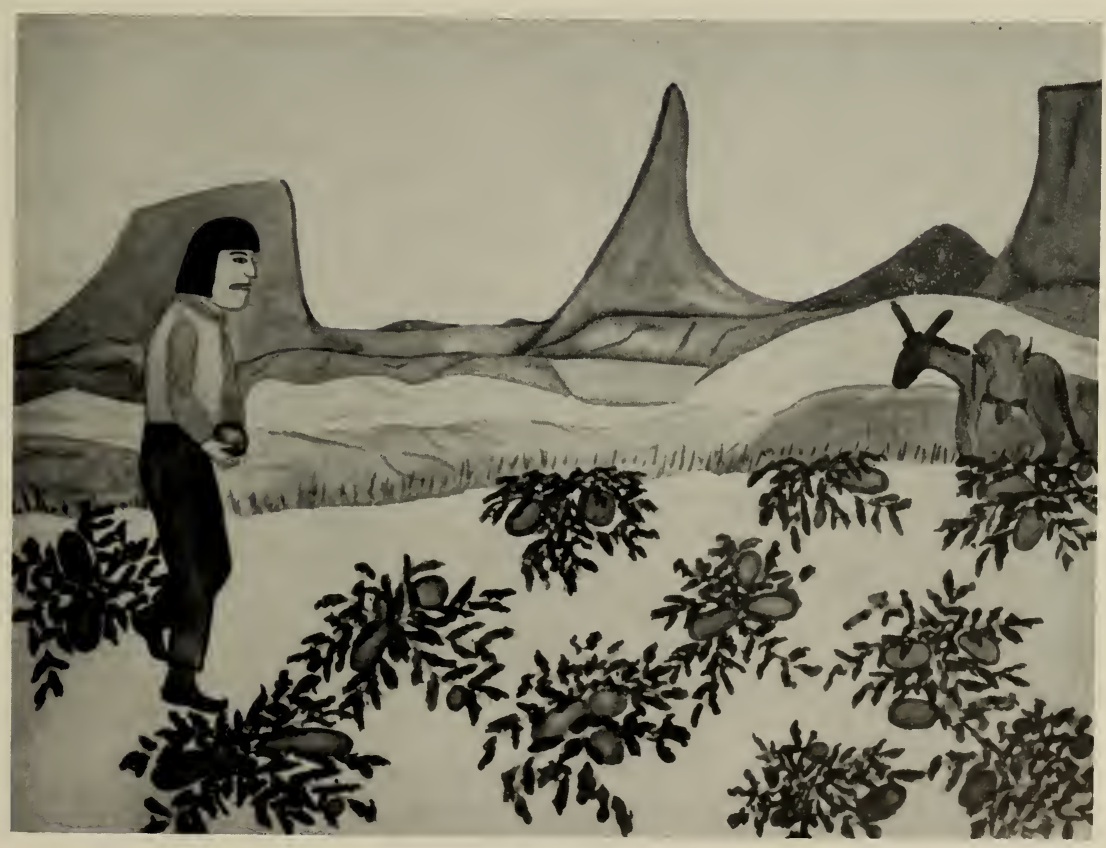




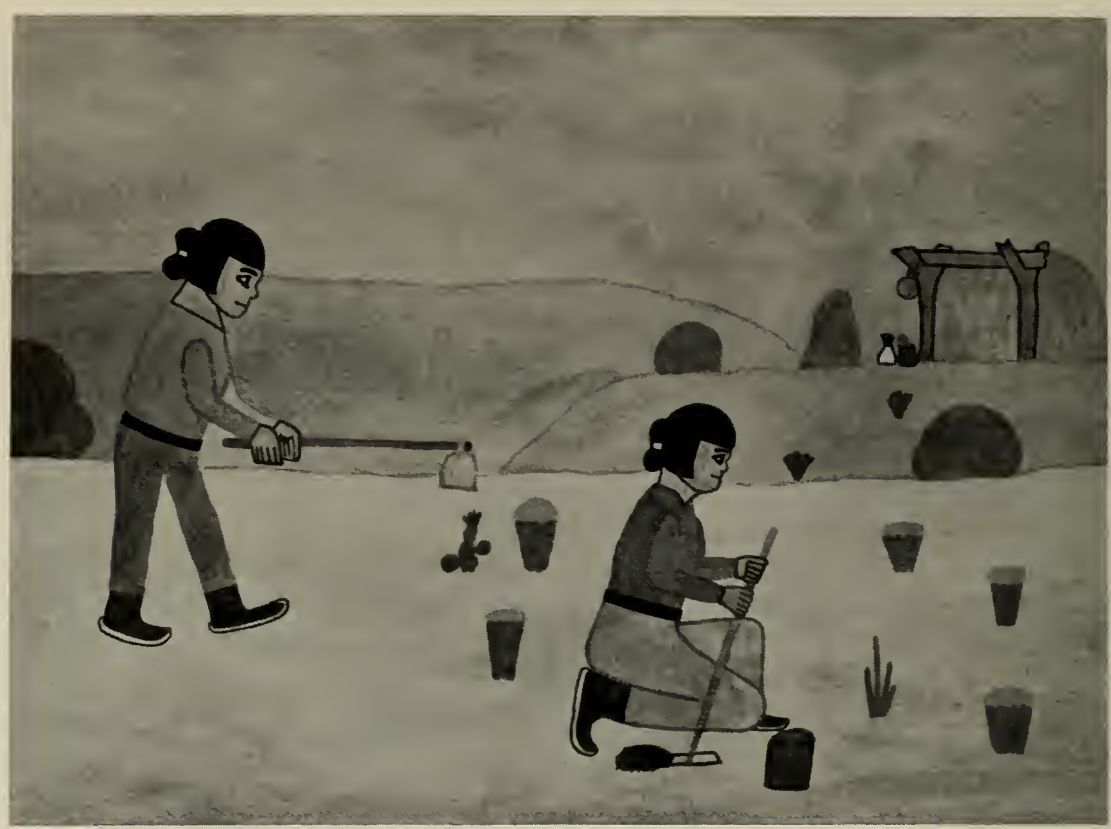

153

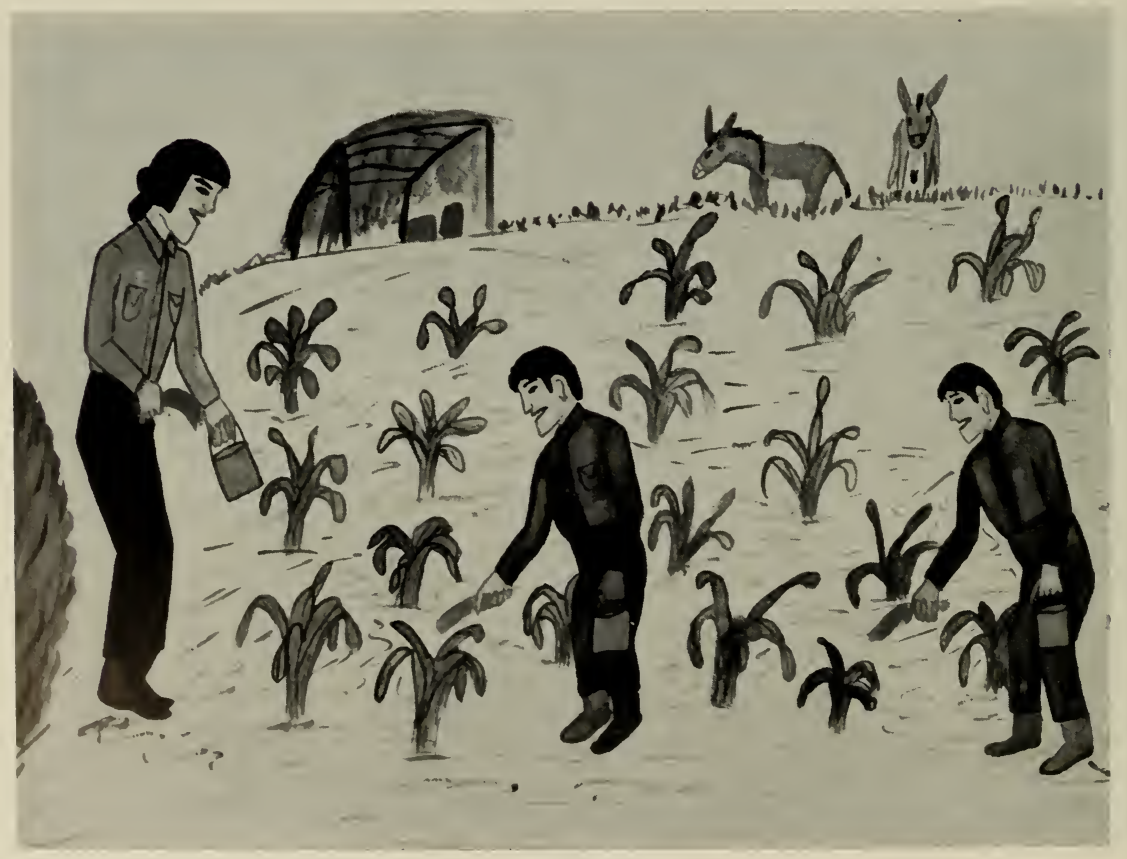


FIGURES I 55, I 56

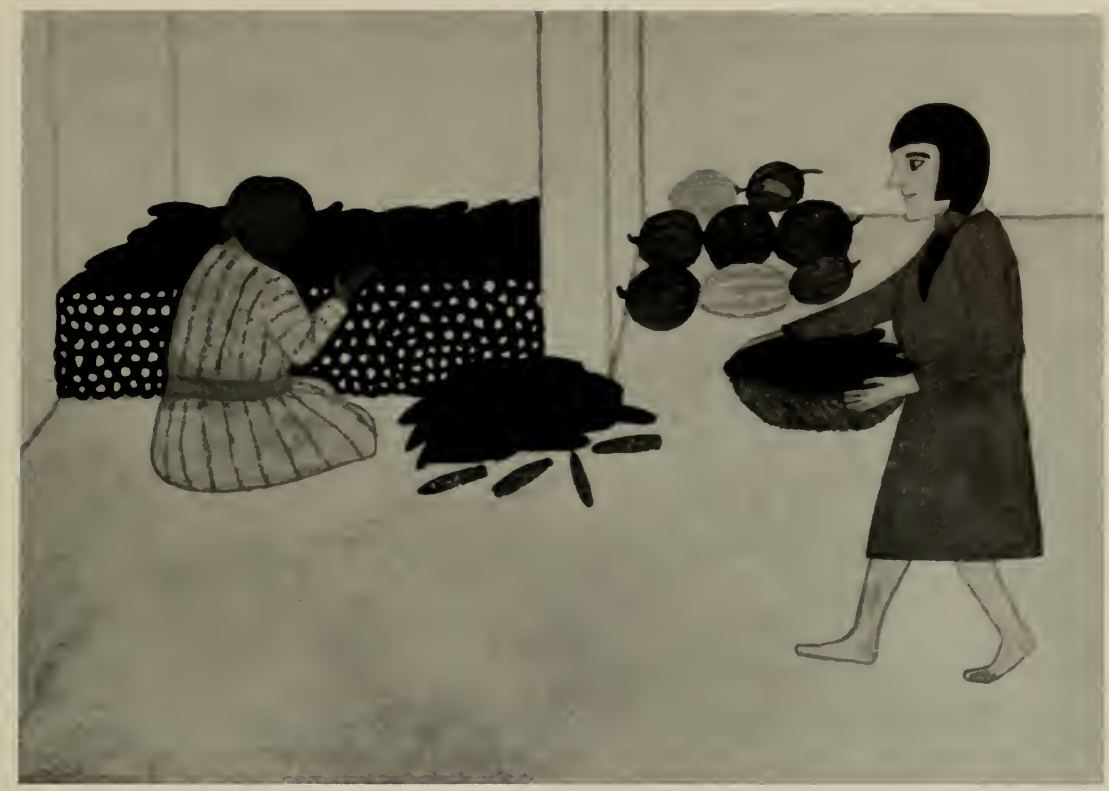

155

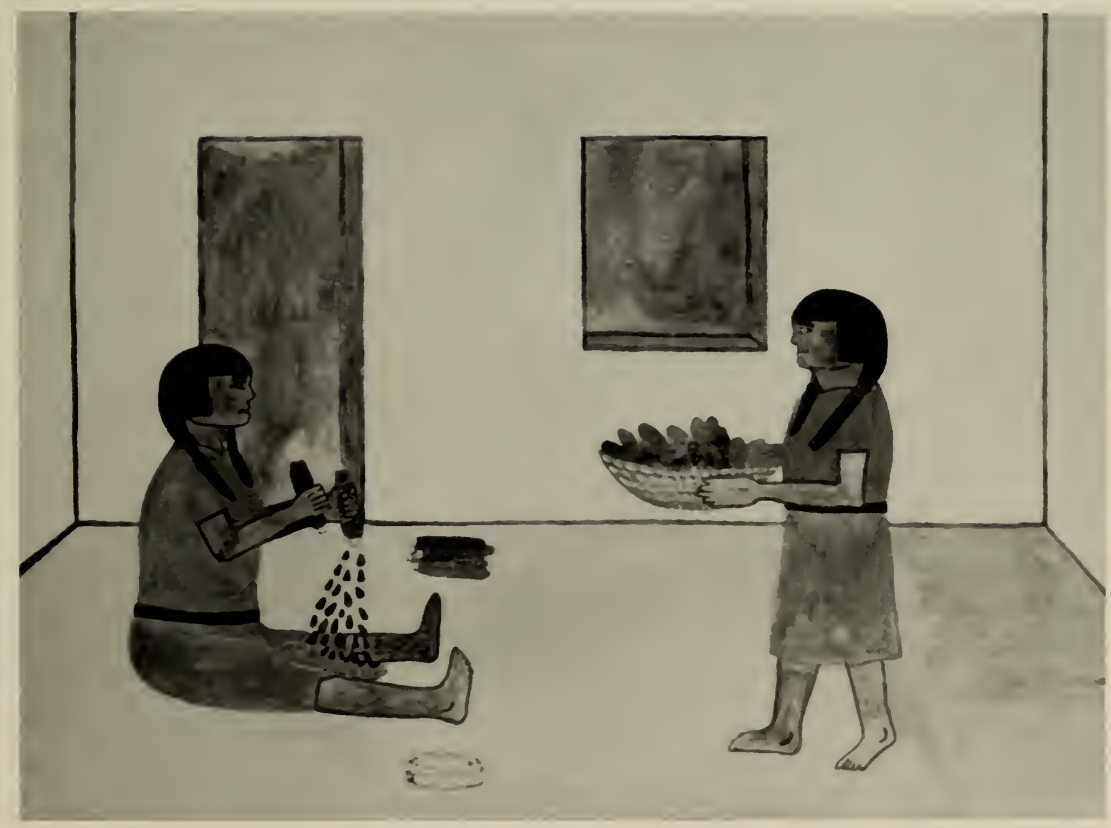


FIGURES I 57, I 58

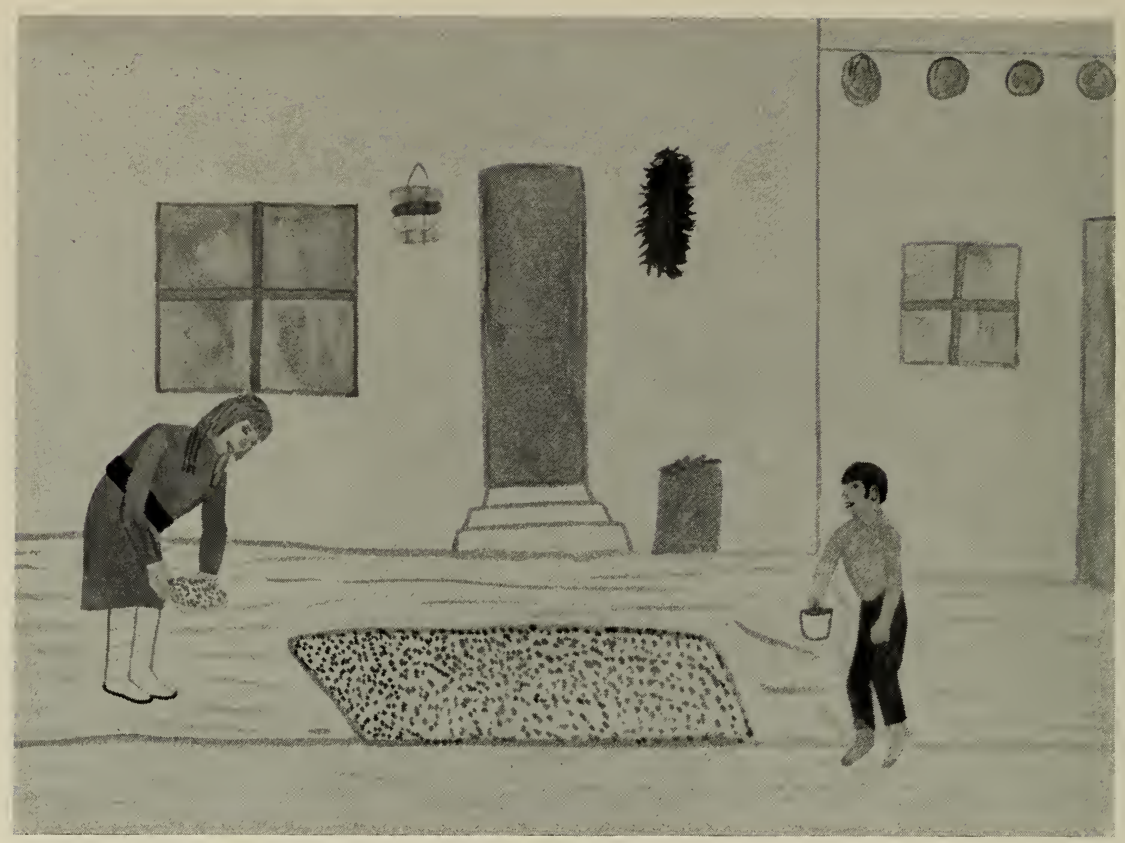

157

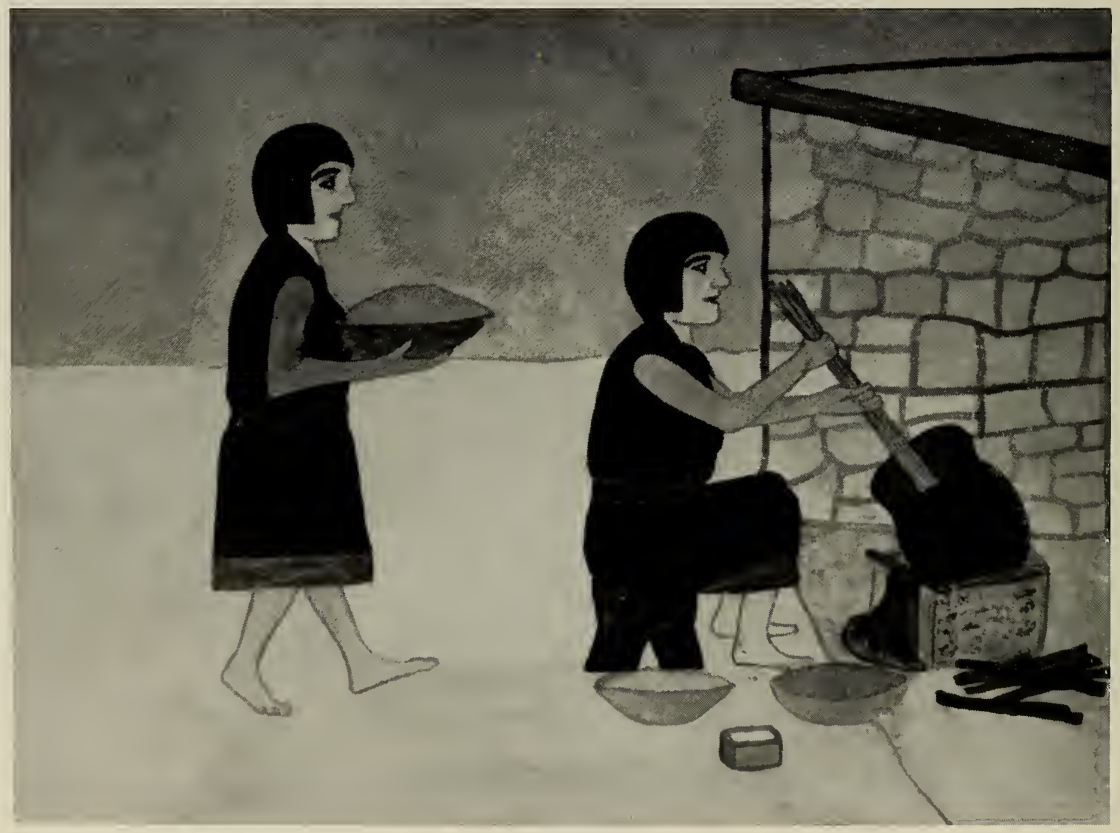


FIGURES I 59, I 60

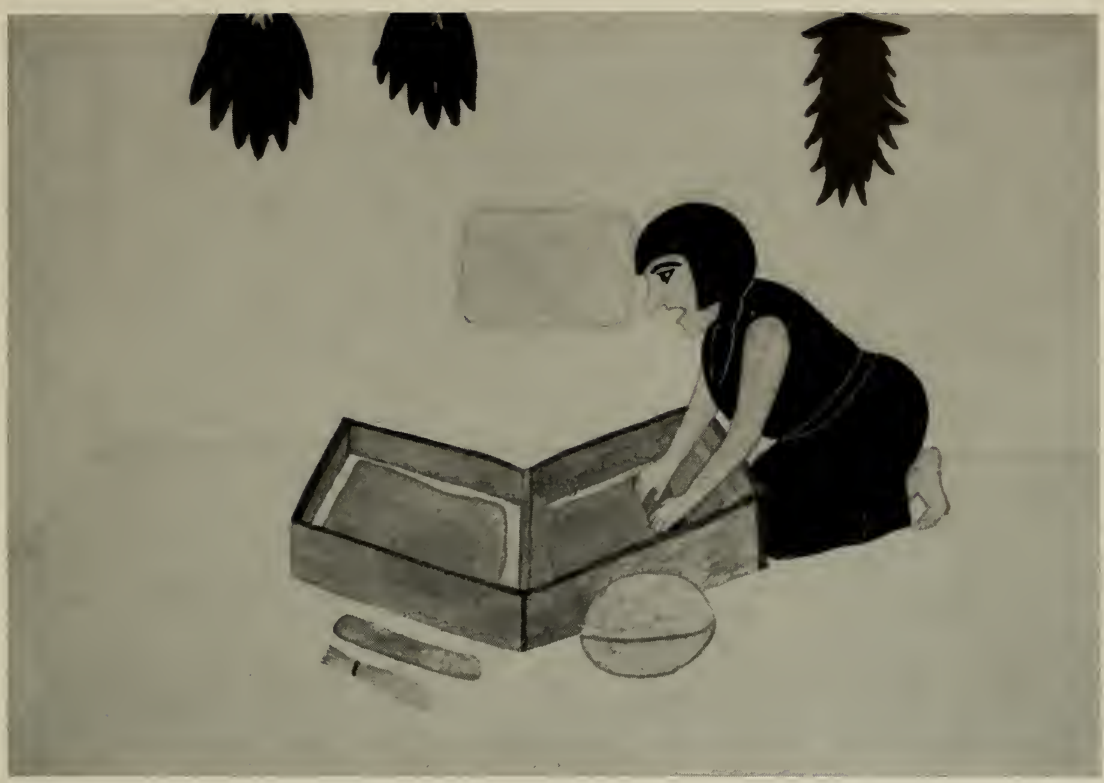

159

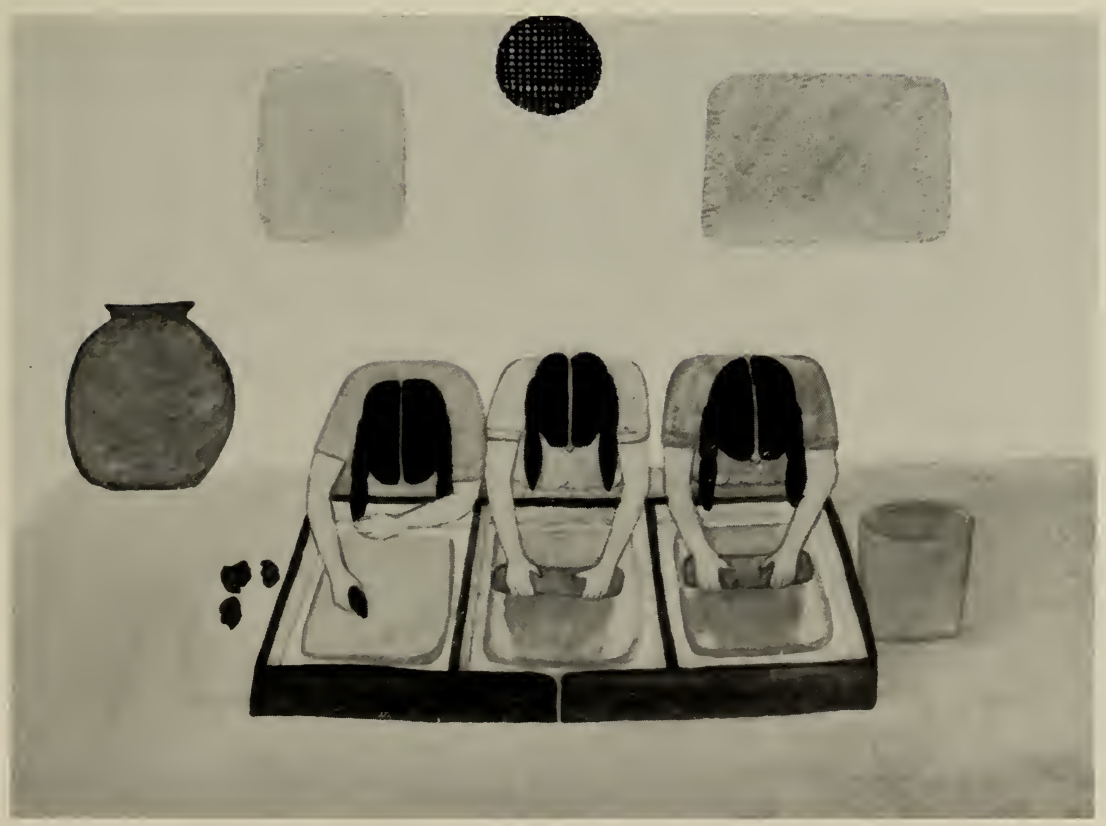


FIGURES I $6 I, I 62$

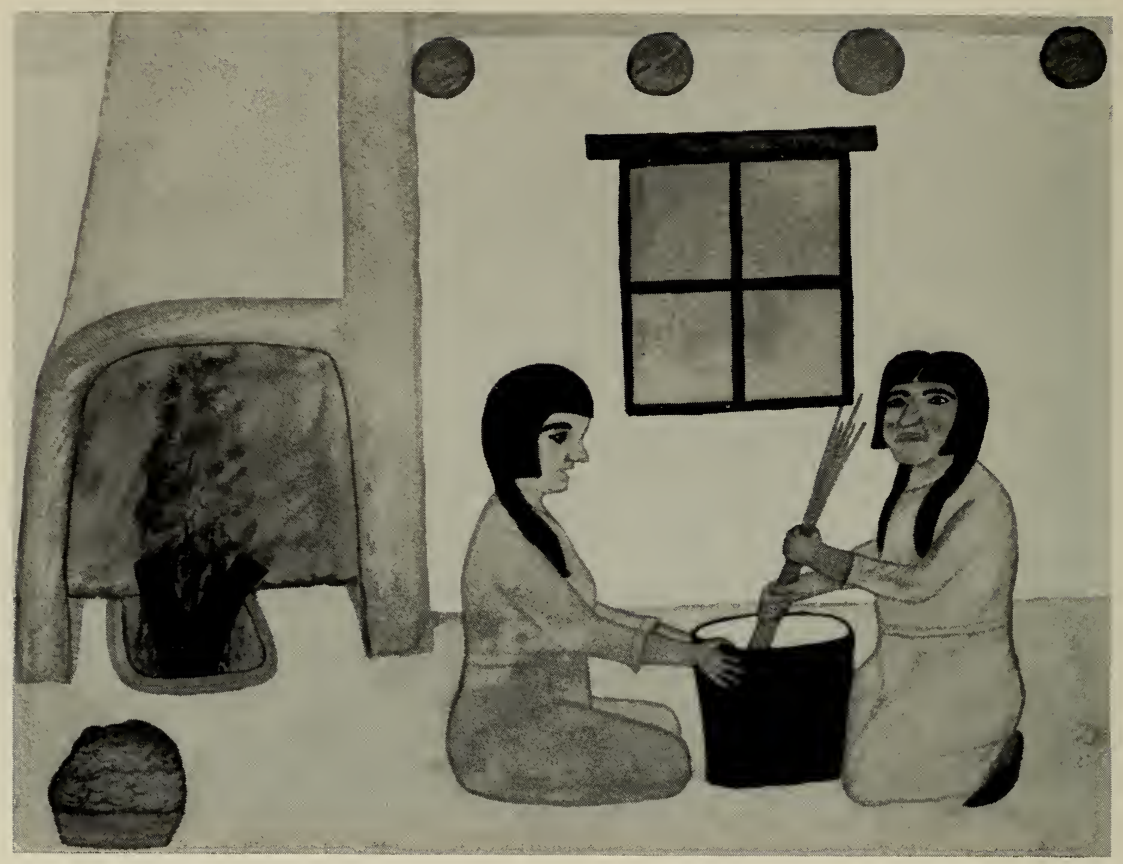

161

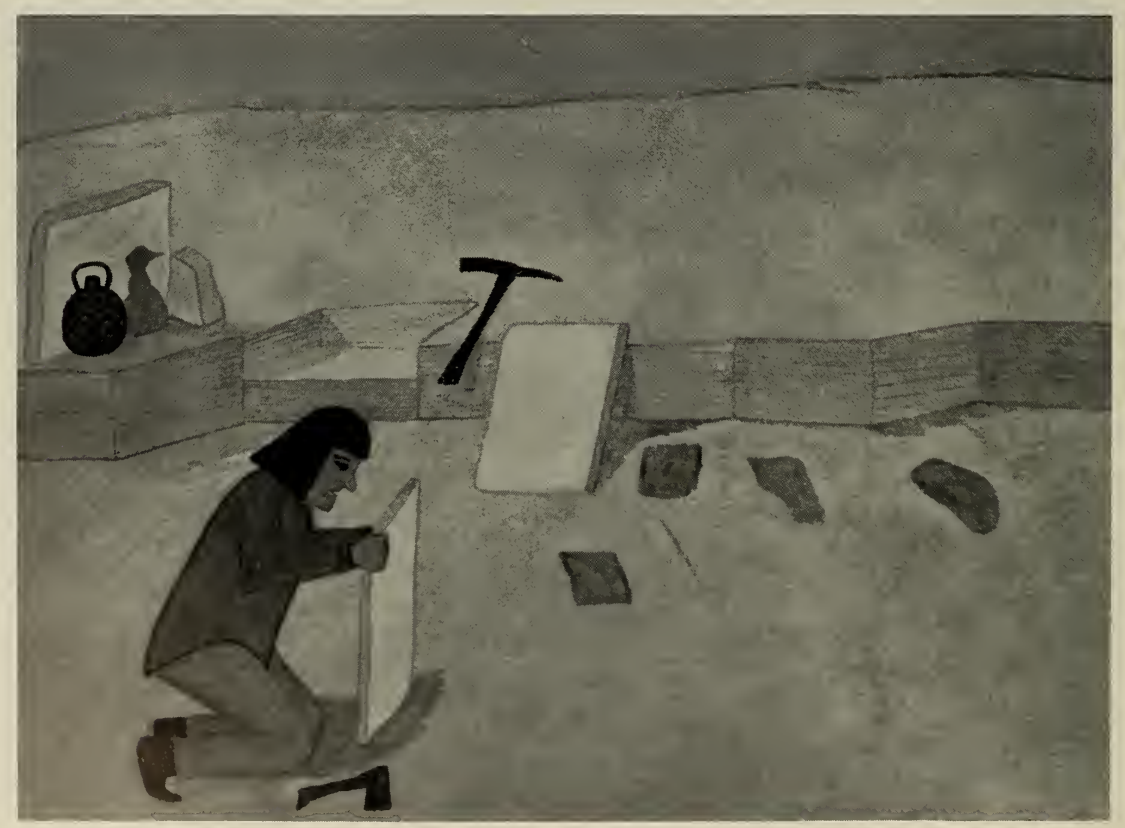

162 
FIGURES I 63,164

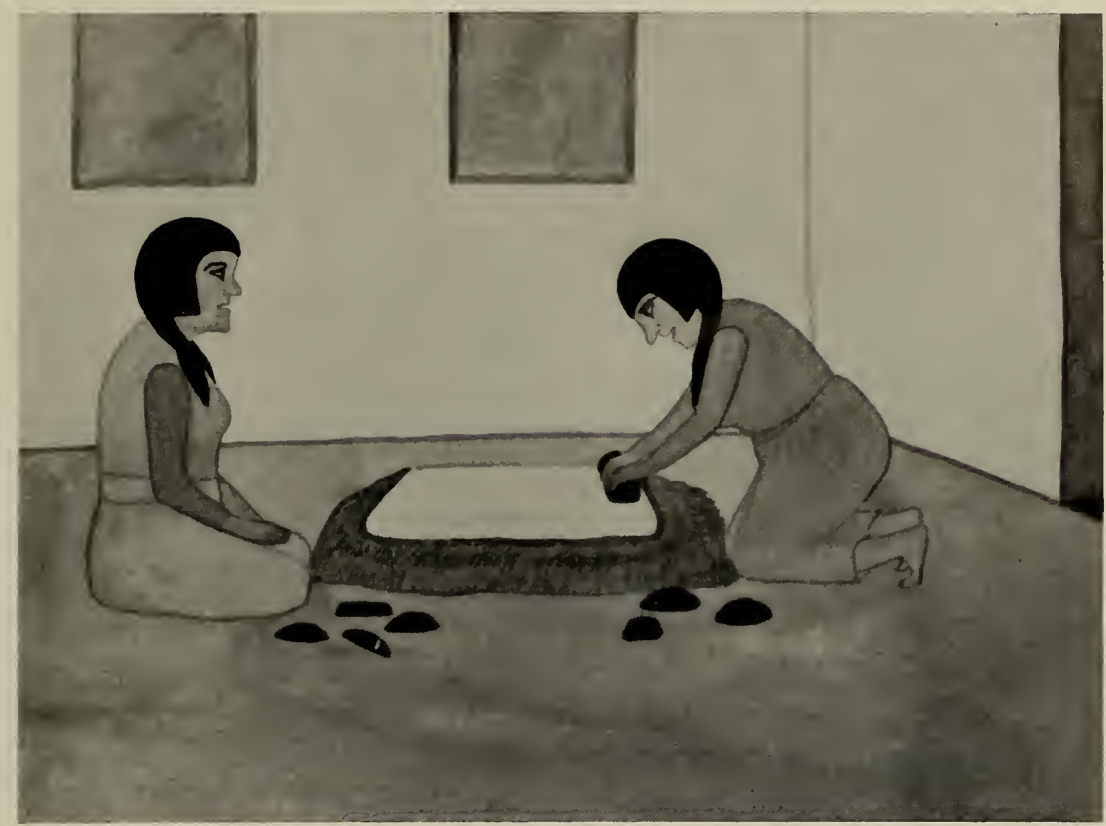

163

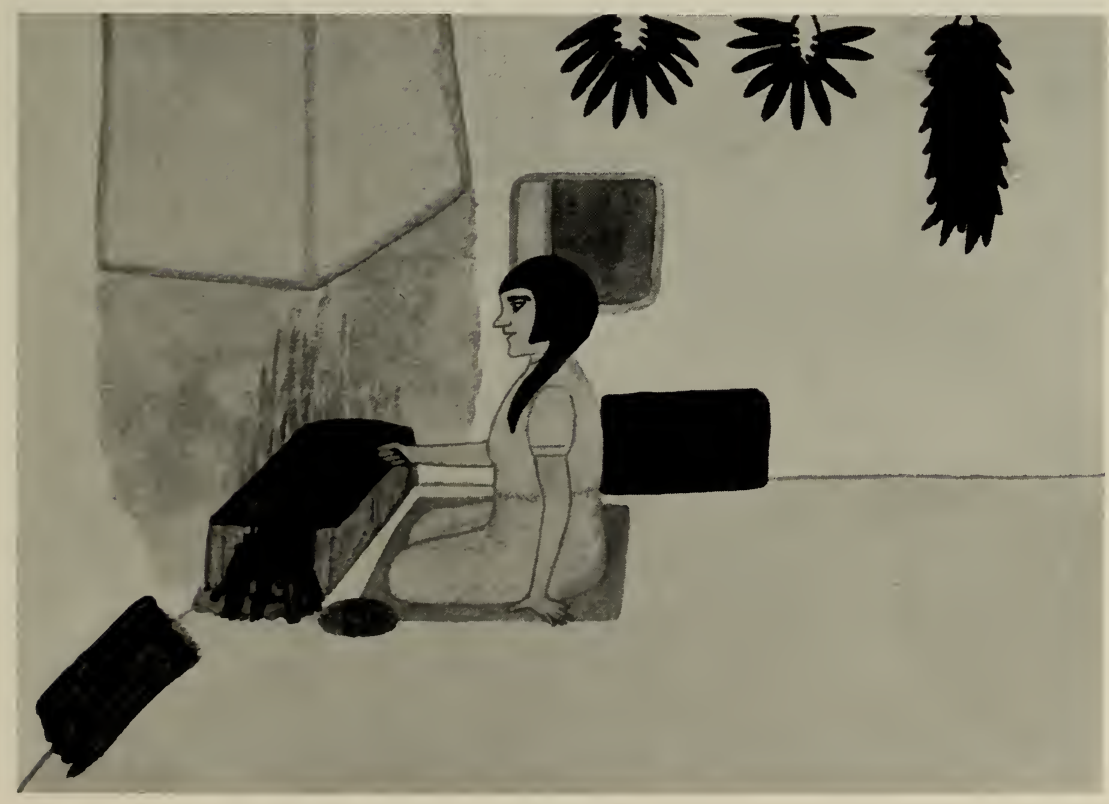


FIGURES I $65, \mathrm{I} 66$

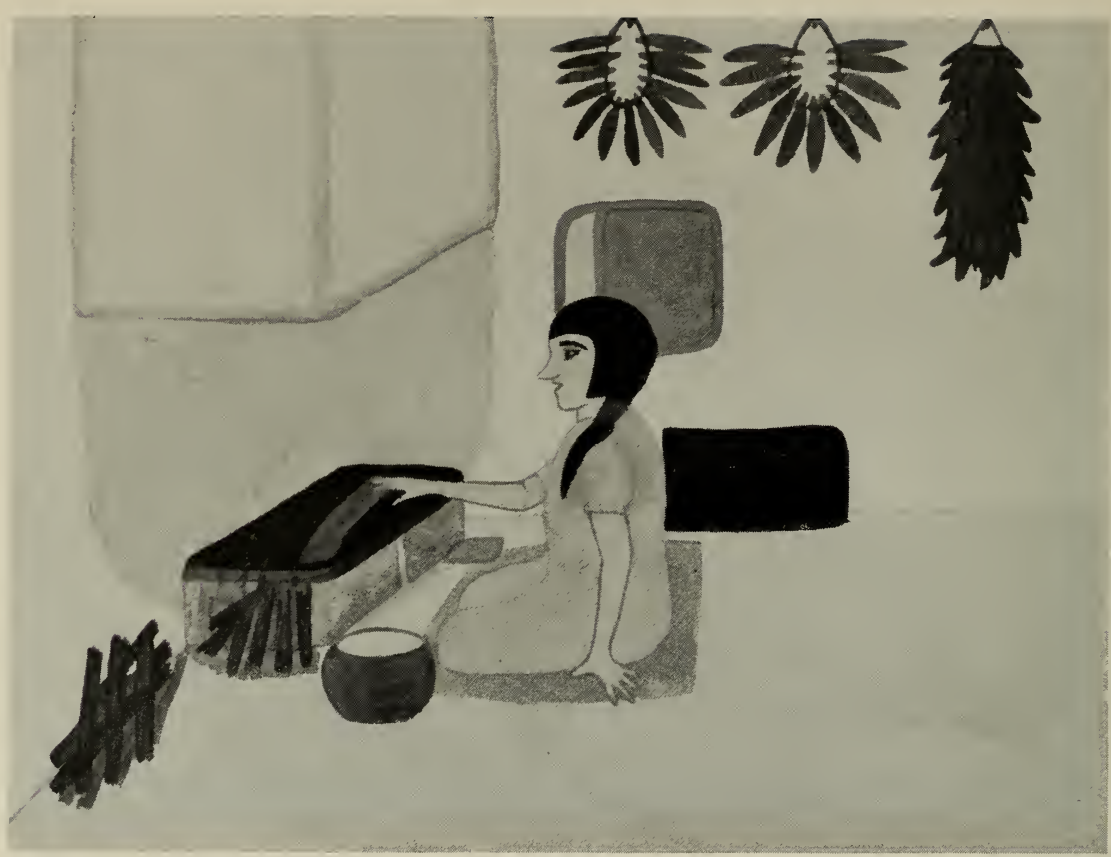

165

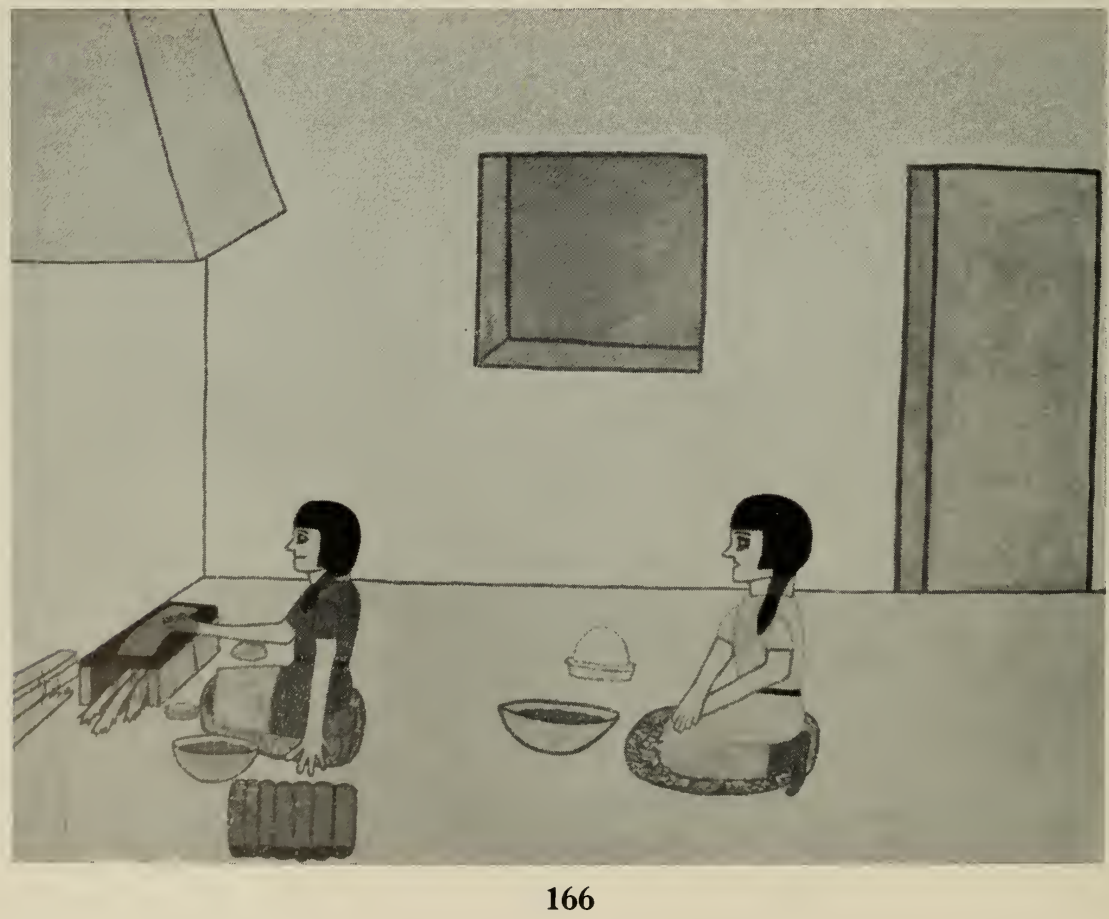


FIGURES 167, I 68
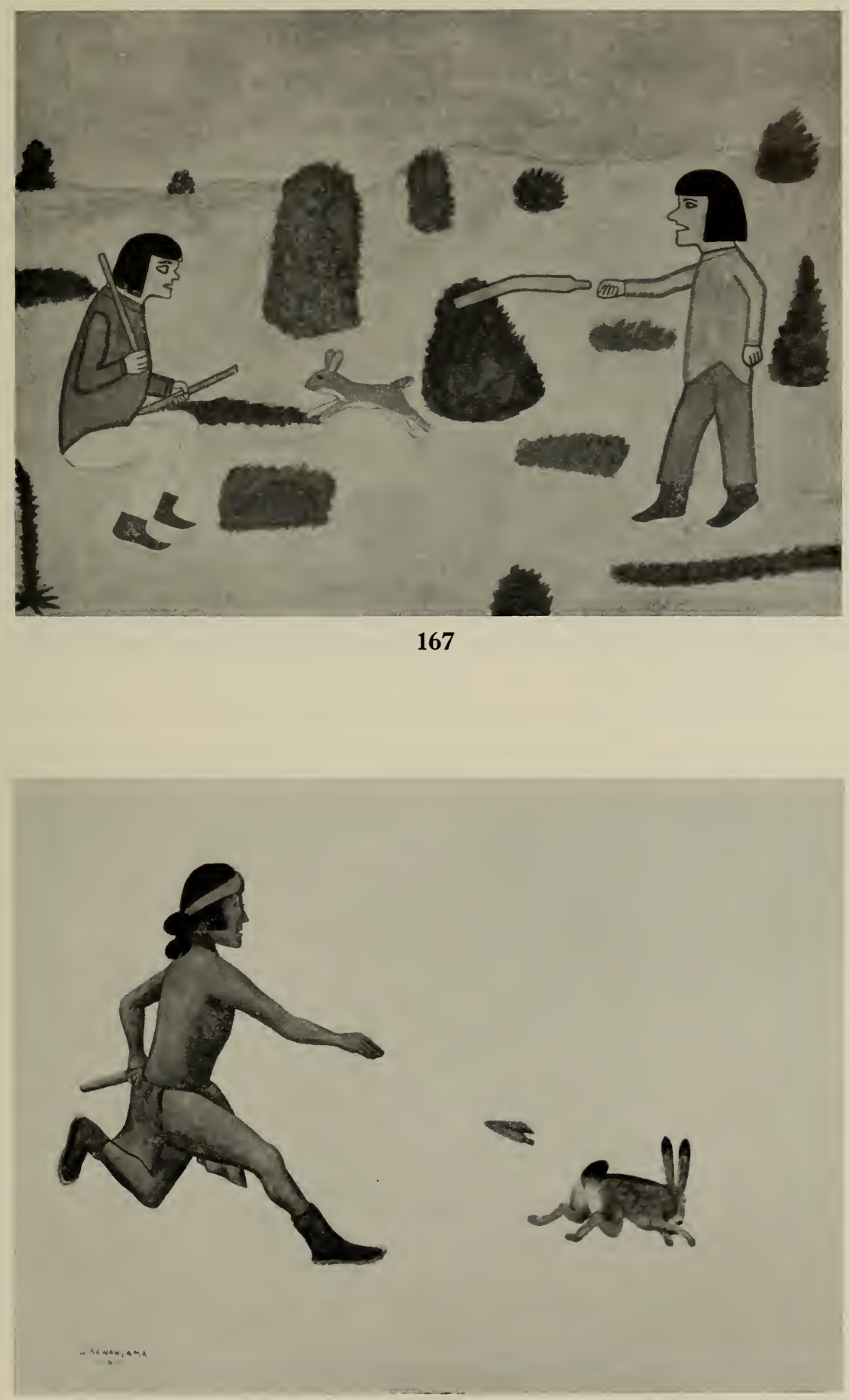

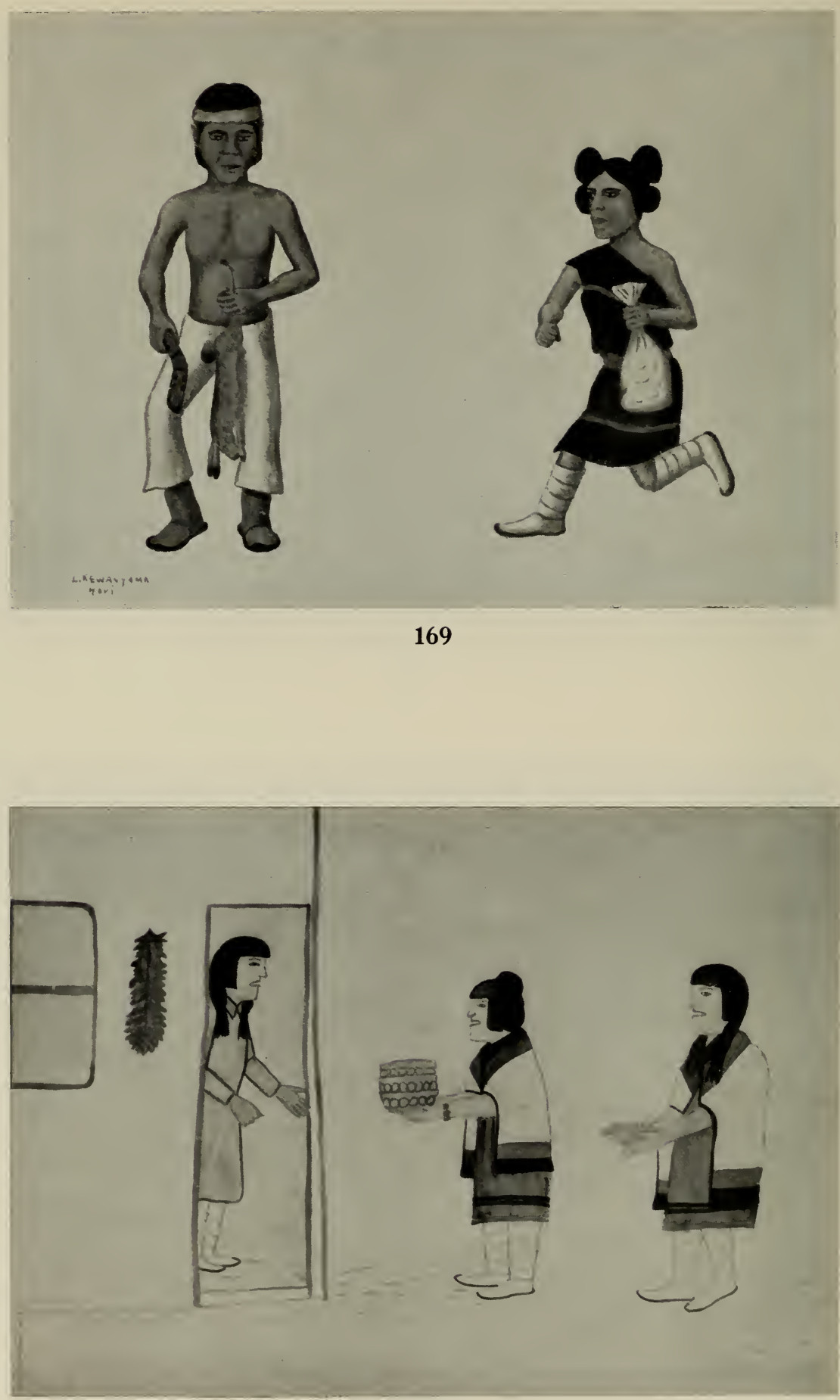
FIGURES I 71,172

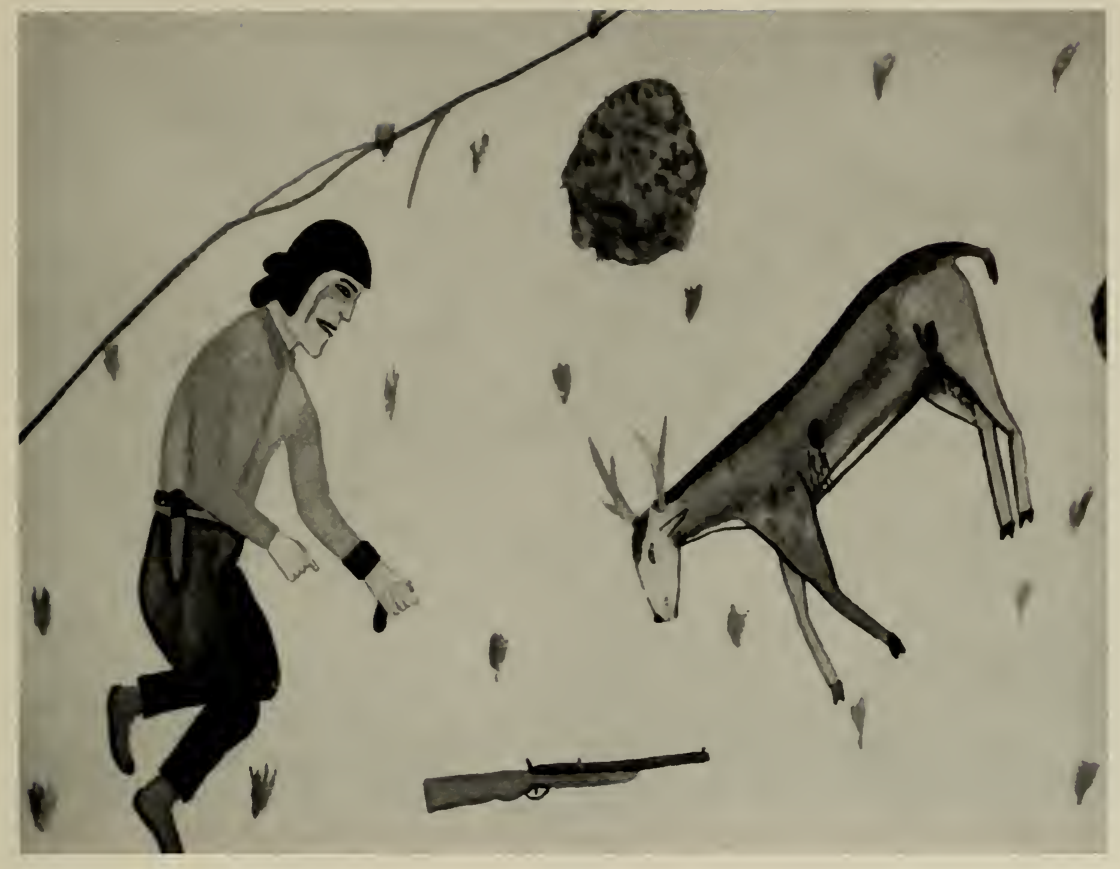

171

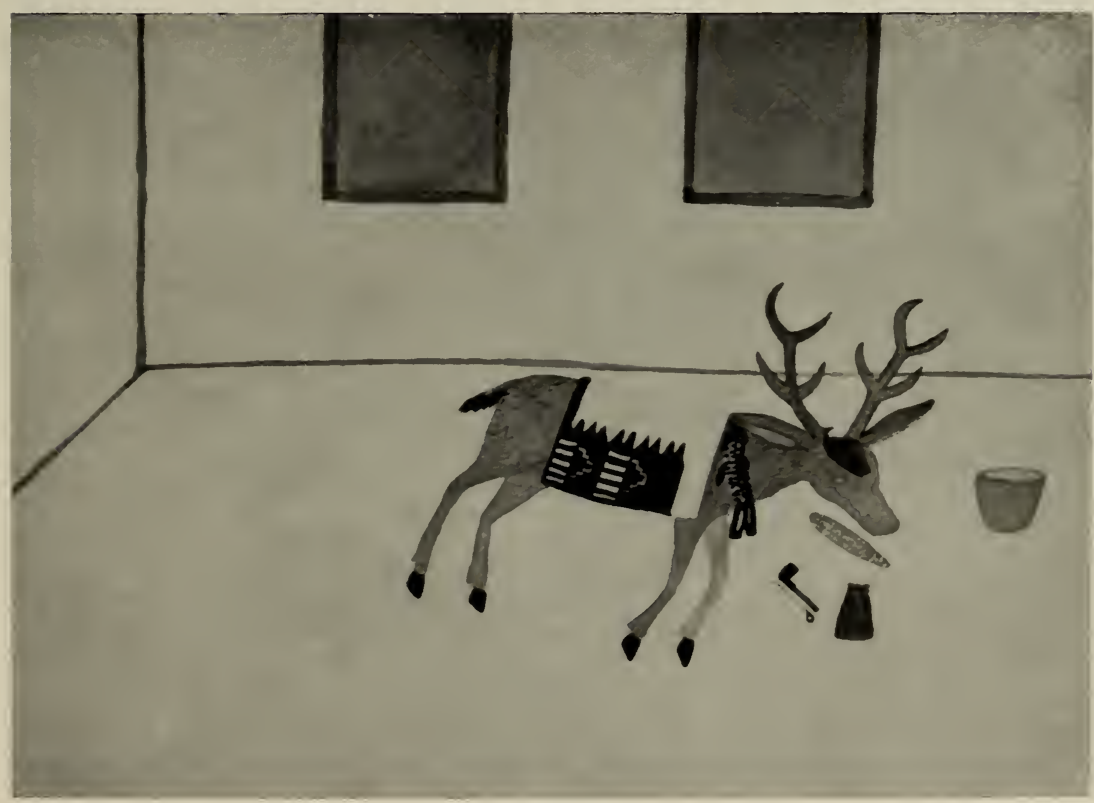



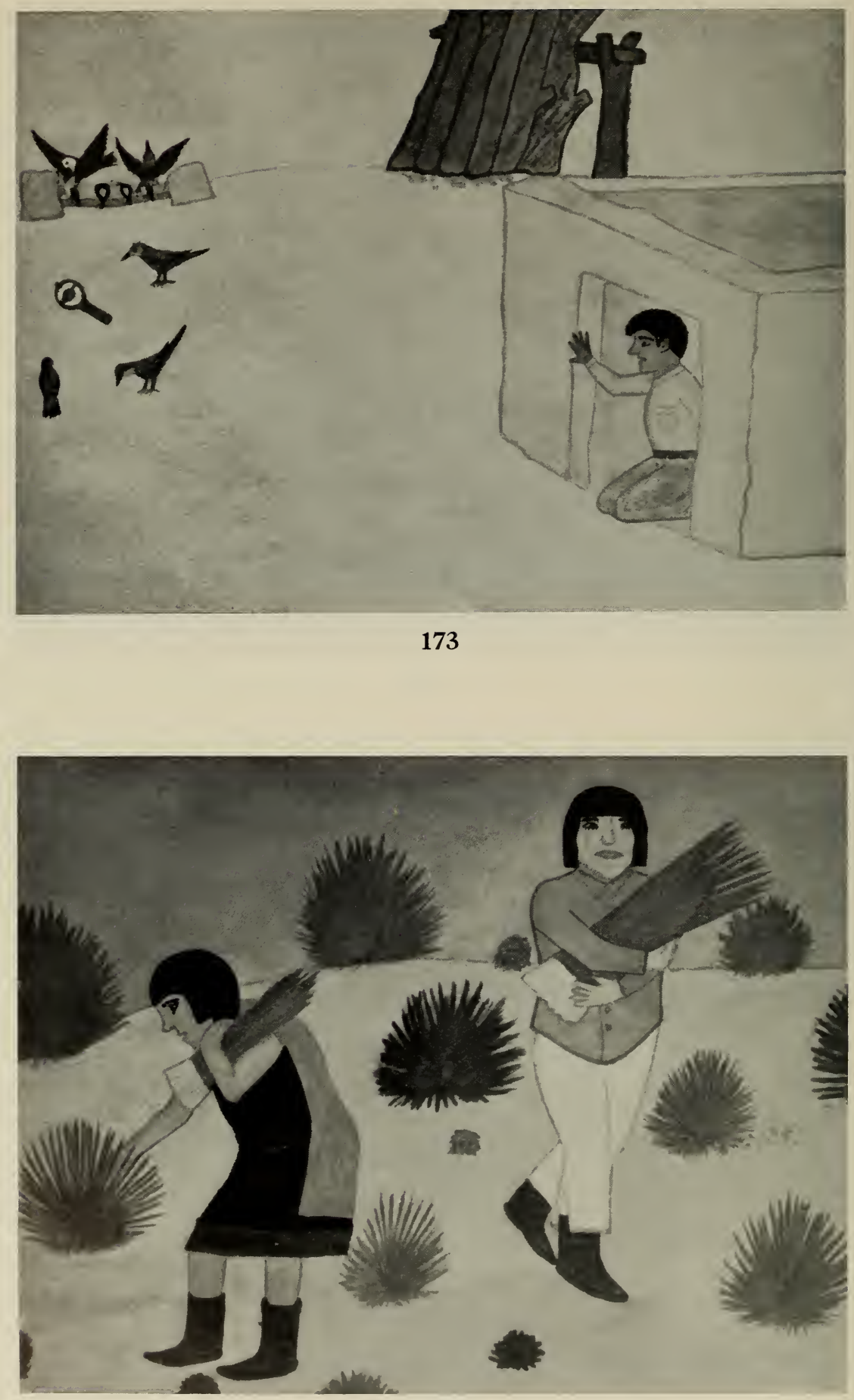
FIGURES I 75,176

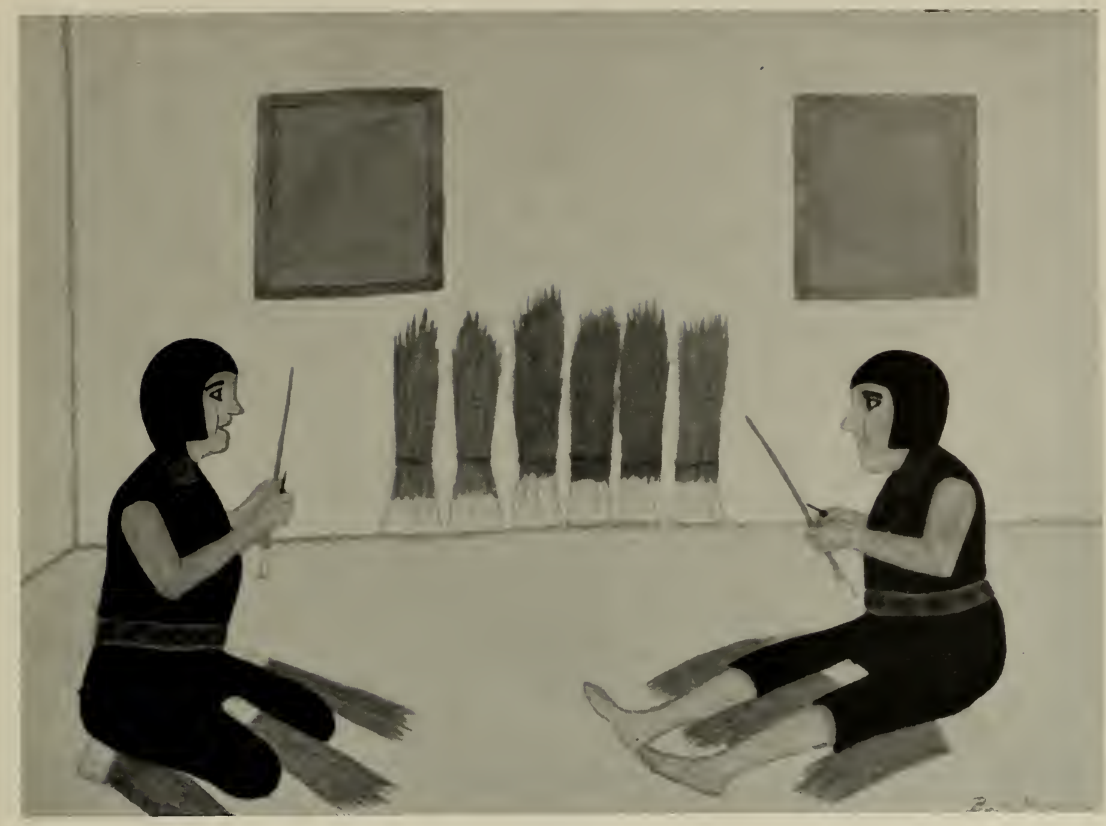

175

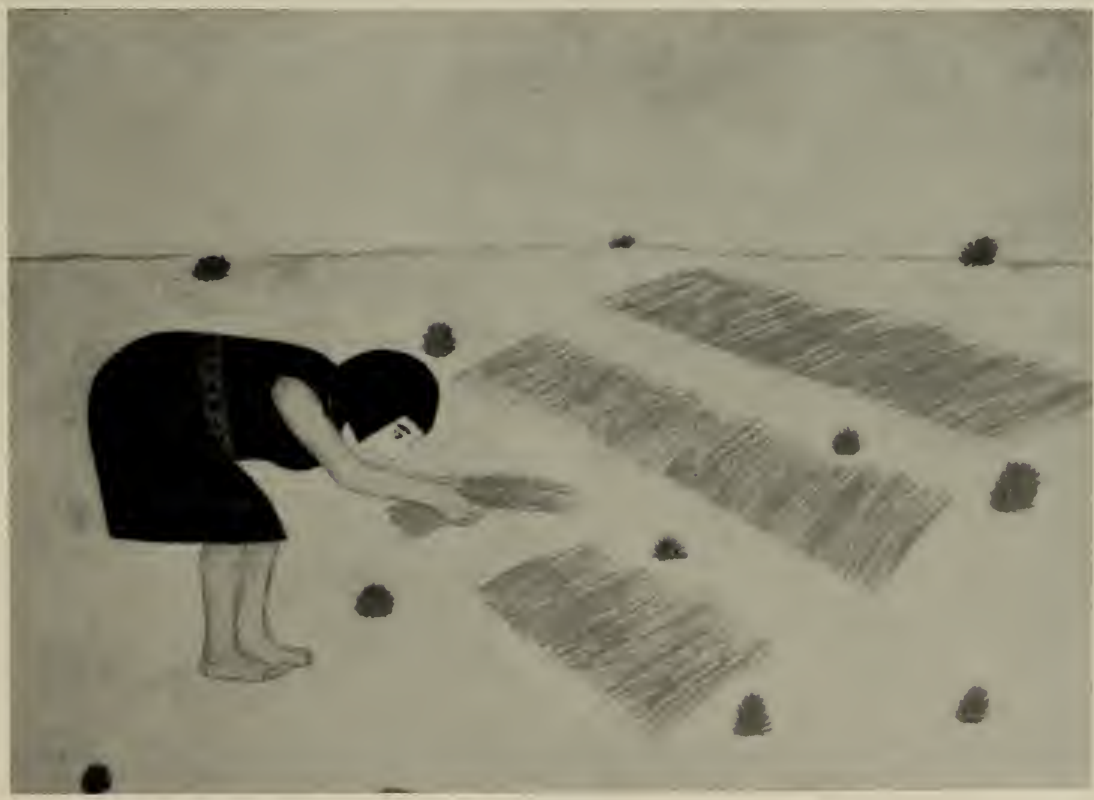

176 
FIGURES I 77, I 78

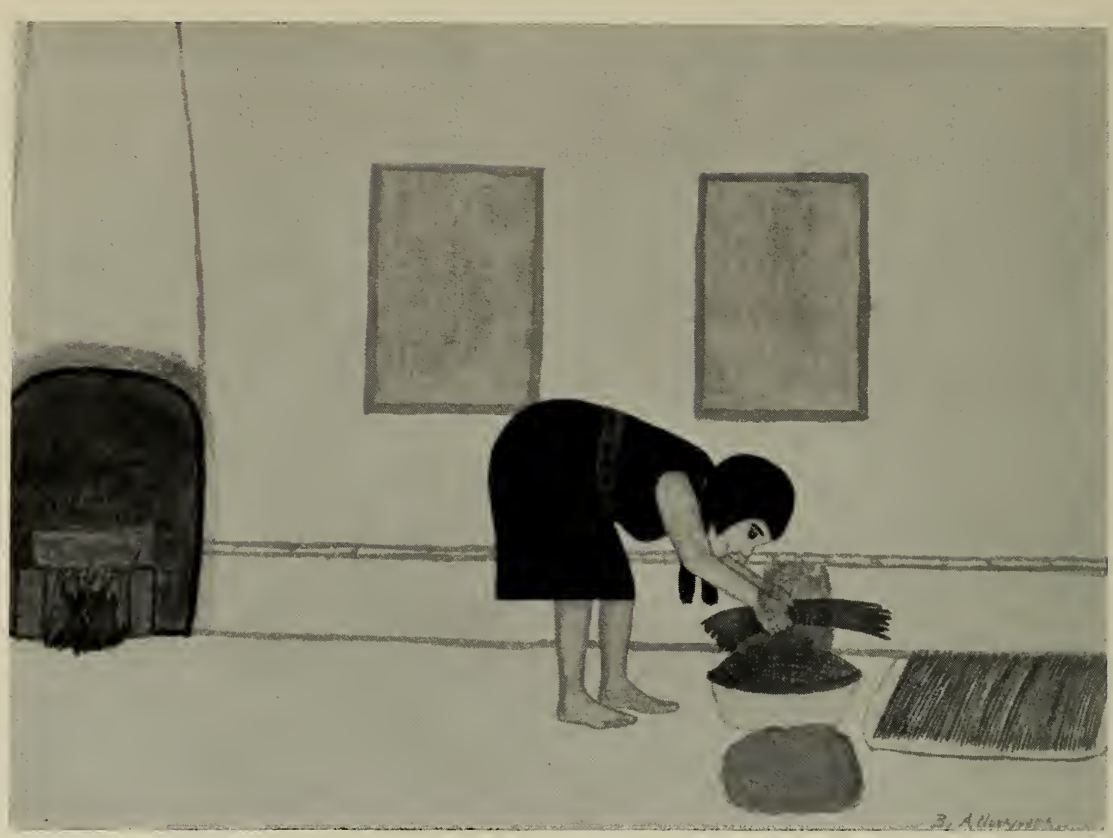

177

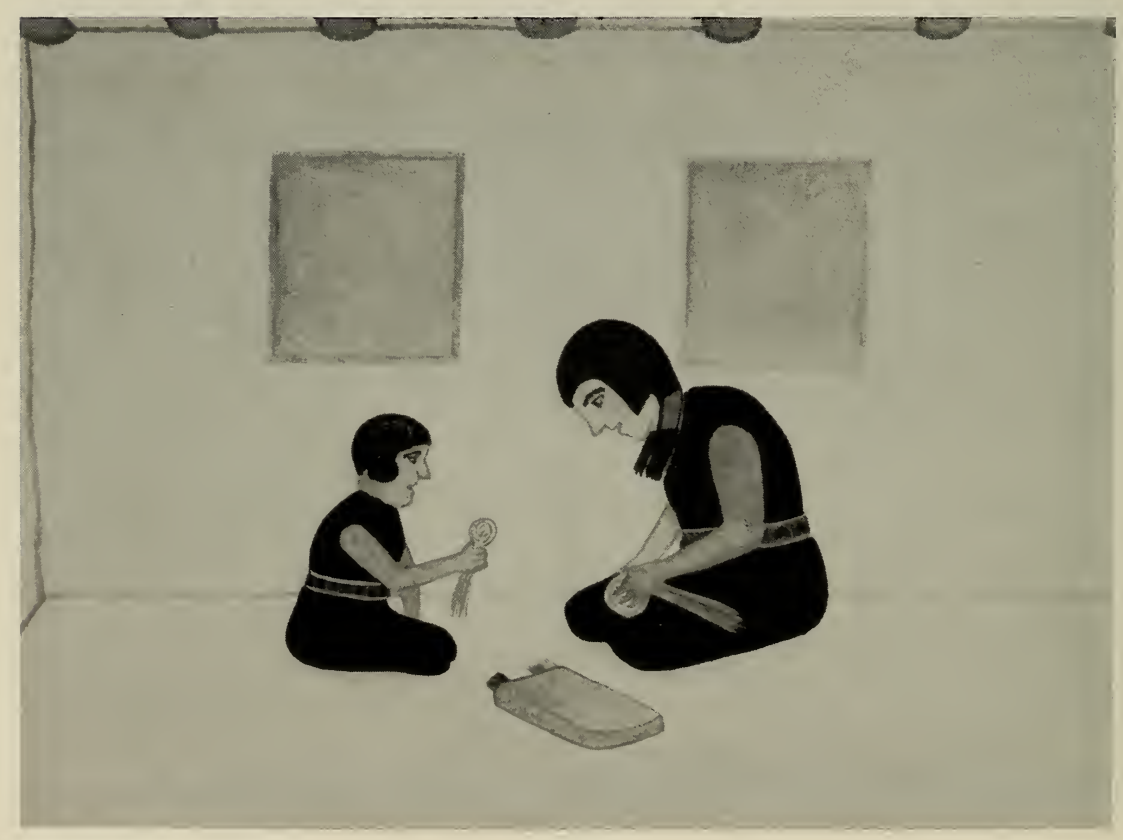


FIGURES I 79, I 80

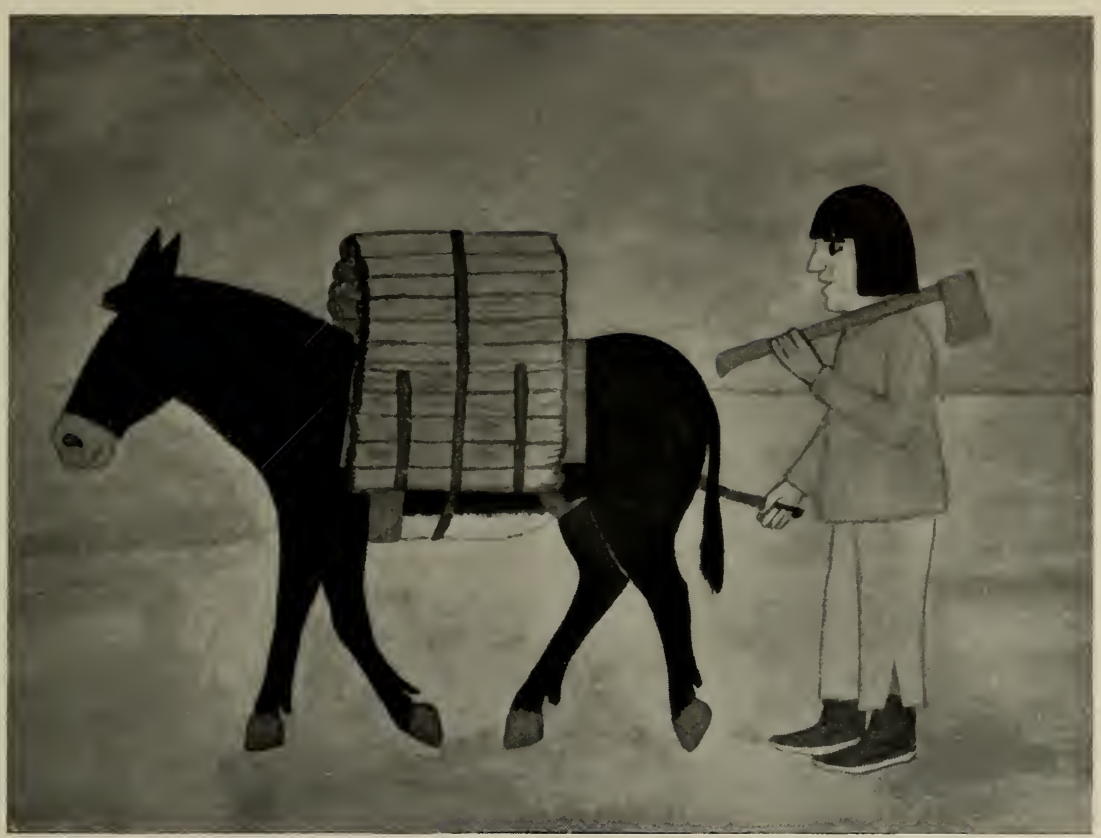

179

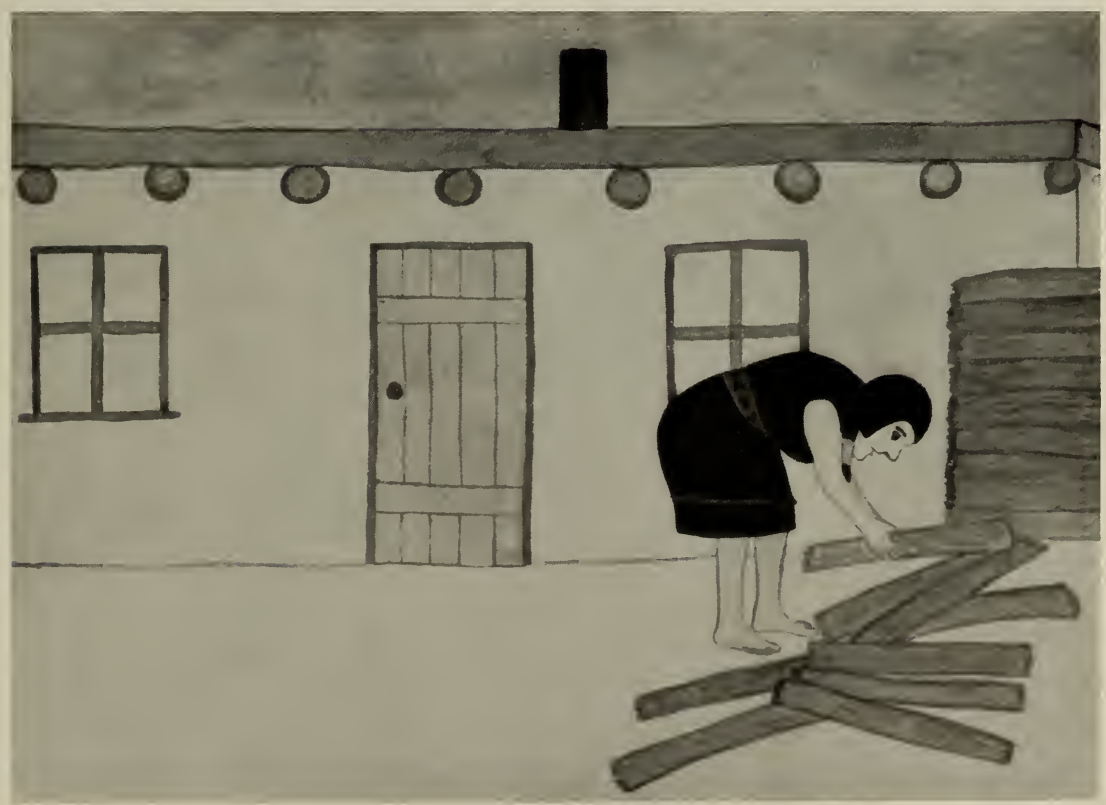


FIGURES I 8 I, I 82

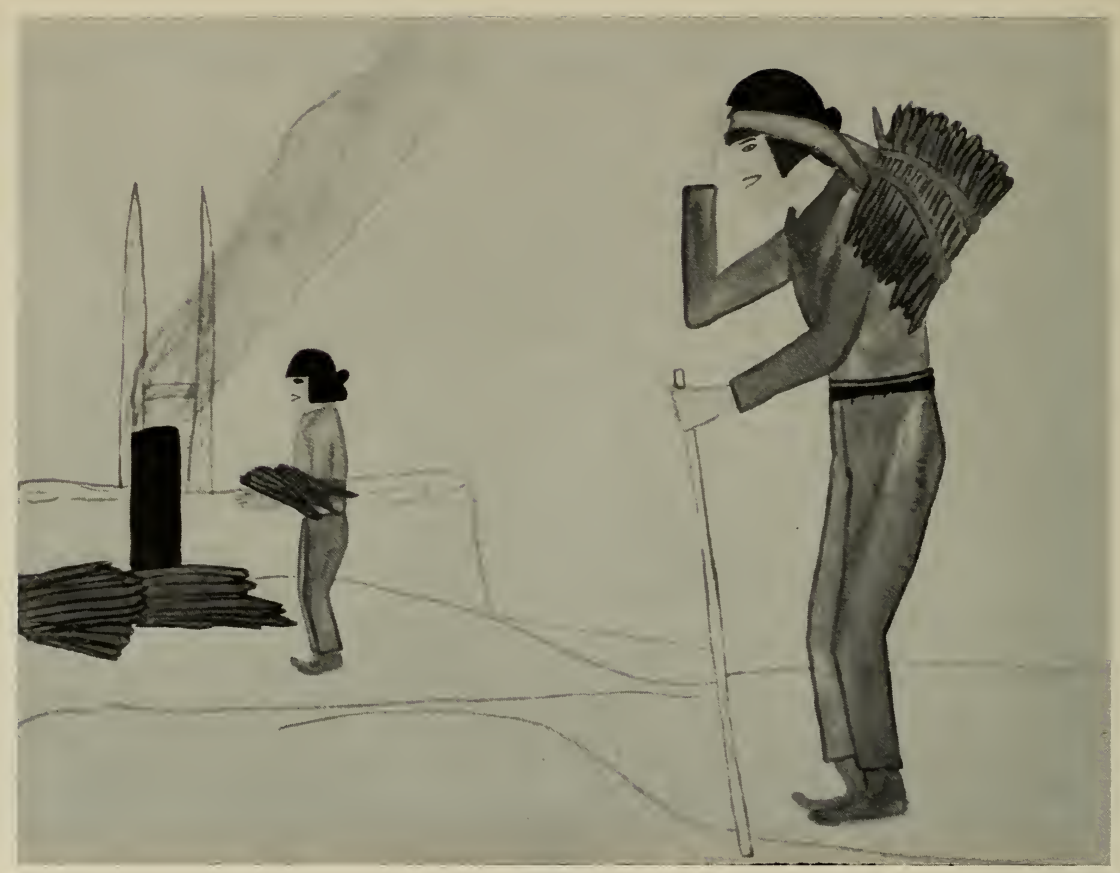

181

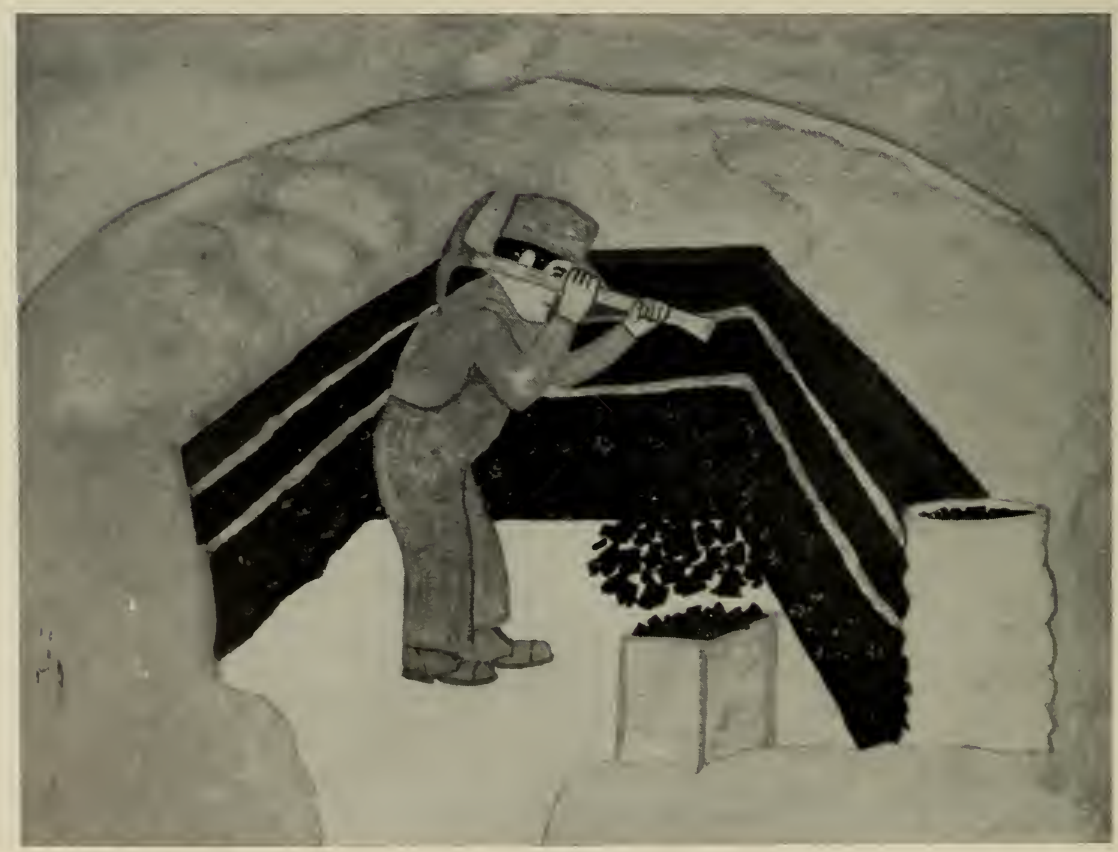




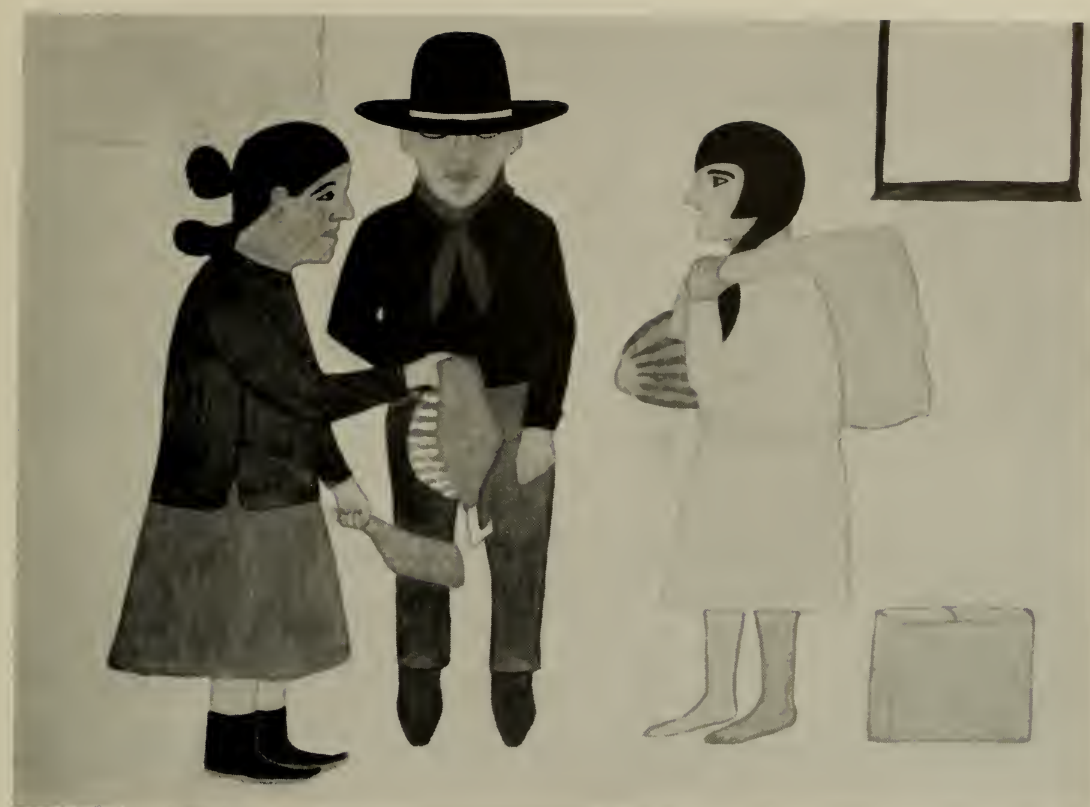

183

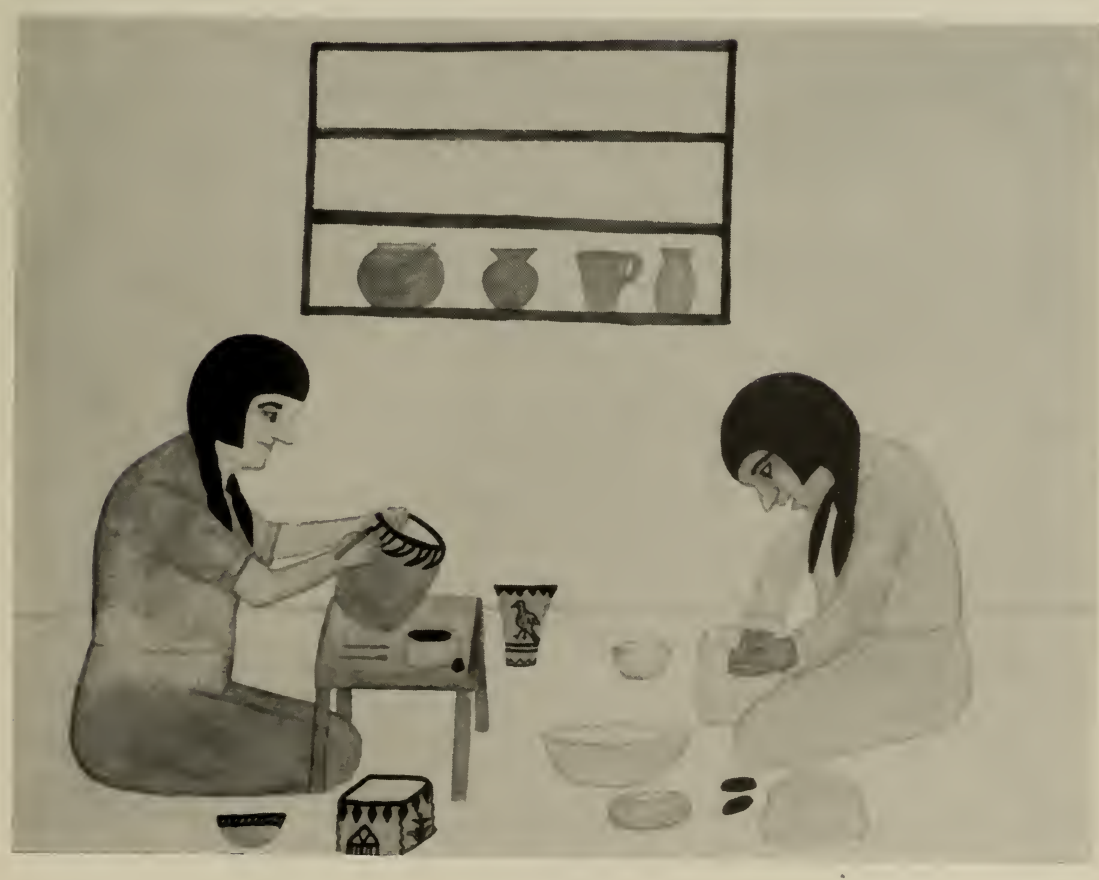

184 


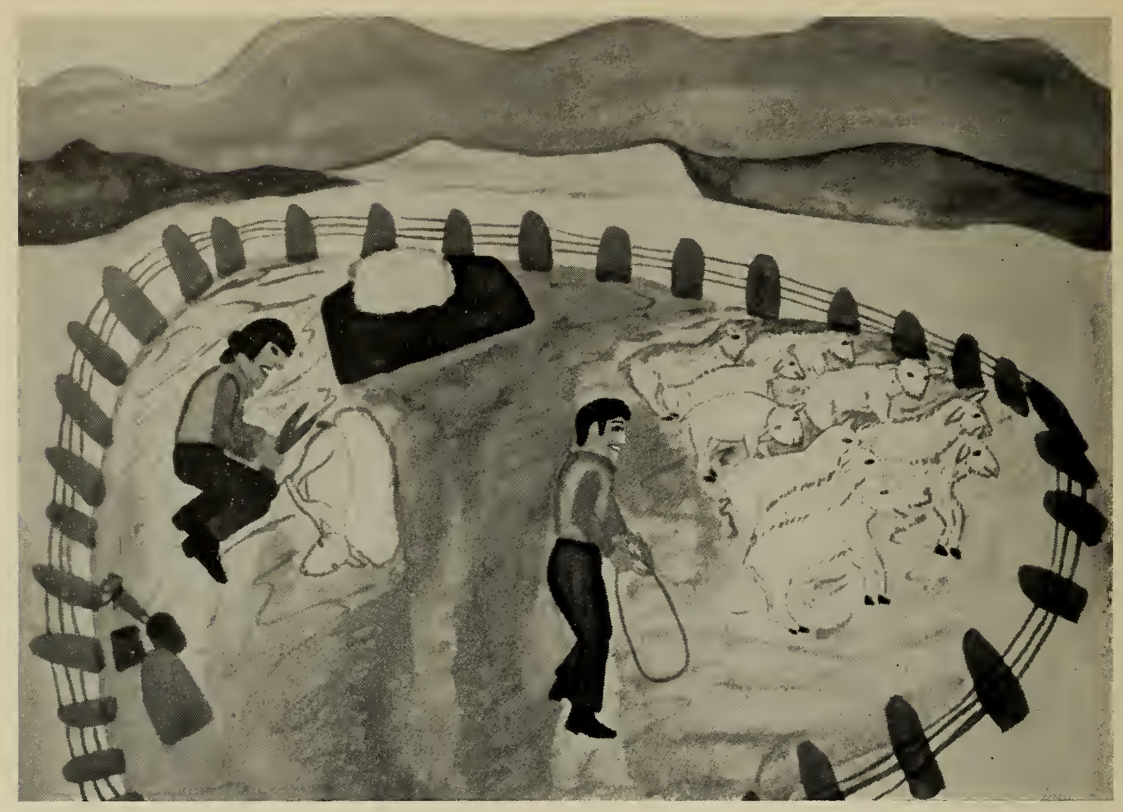

185 

